\title{
DESIGN FIRES FOR COMMERCIAL PREMISES
}

\author{
By
}

Ehab Zalok

M.A.Sc. Engineering

\begin{abstract}
A Thesis Submitted to
the Ottawa-Carleton Institute for Civil Engineering (OCICE),

Department of Civil and Environmental Engineering at Carleton University in partial fulfillment of the requirements for the degree of

Doctor of Philosophy

in
\end{abstract}

Civil Engineering

Carleton University

Ottawa, Ontario

May 2006

(C) Copyright 2006, Ehab Zalok 


$\begin{array}{ll}\begin{array}{l}\text { Library and } \\ \text { Archives Canada }\end{array} & \begin{array}{l}\text { Bibliothèque et } \\ \text { Archives Canada }\end{array} \\ \begin{array}{l}\text { Published Heritage } \\ \text { Branch }\end{array} & \begin{array}{l}\text { Direction du } \\ \text { Patrimoine de l'édition }\end{array} \\ \begin{array}{l}\text { 395 Wellington Street } \\ \text { Ottawa ON K1A ON4 }\end{array} & \begin{array}{l}\text { 395, rue Wellington } \\ \text { Ottawa ON K1A ON4 } \\ \text { Canada }\end{array}\end{array}$

Your file Votre référence ISBN: 978-0-494-16680-2 Our file Notre référence ISBN: 978-0-494-16680-2

NOTICE:

The author has granted a nonexclusive license allowing Library and Archives Canada to reproduce, publish, archive, preserve, conserve, communicate to the public by telecommunication or on the Internet, loan, distribute and sell theses worldwide, for commercial or noncommercial purposes, in microform, paper, electronic and/or any other formats.

The author retains copyright ownership and moral rights in this thesis. Neither the thesis nor substantial extracts from it may be printed or otherwise reproduced without the author's permission.
AVIS:

L'auteur a accordé une licence non exclusive permettant à la Bibliothèque et Archives Canada de reproduire, publier, archiver, sauvegarder, conserver, transmettre au public par télécommunication ou par l'Internet, prêter, distribuer et vendre des thèses partout dans le monde, à des fins commerciales ou autres, sur support microforme, papier, électronique et/ou autres formats.

L'auteur conserve la propriété du droit d'auteur et des droits moraux qui protège cette thèse. $\mathrm{Ni}$ la thèse ni des extraits substantiels de celle-ci ne doivent être imprimés ou autrement reproduits sans son autorisation.
In compliance with the Canadian

Privacy Act some supporting forms may have been removed from this thesis.

While these forms may be included in the document page count, their removal does not represent any loss of content from the thesis.
Conformément à la loi canadienne sur la protection de la vie privée, quelques formulaires secondaires ont été enlevés de cette thèse.

Bien que ces formulaires aient inclus dans la pagination, il n'y aura aucun contenu manquant.

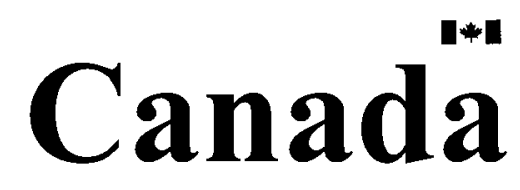




\begin{abstract}
The research explores the potential for identifying design fires for commercial premises. A survey of 168 commercial stores that included clothing stores, fast food outlets, restaurants, shoe stores, bookstores, etc. was conducted in Ottawa and Gatineau to determine fire loads and type of combustibles in commercial premises. Statistical data from the literature were analysed to determine the frequency of fires, ignition sources, and locations relevant to these premises. The data gathered during the survey along with the statistical information were used to develop fuel packages for these premises, to be tested in medium- and full-scale fire tests. The objective of these tests was to determine the fire characteristics for the selected fuel packages, such as heat release rate (HRR) and production rates of toxic gases. Based on the experimental results, input data files for the computational model, Fire Dynamics Simulator (FDS), were developed to simulate the burning characteristics of the fuel packages observed in the experiments. Comparisons between FDS predictions and experimental data of HRR, carbon monoxide, and carbon dioxide indicated that FDS was able to predict the HRR, temperature profile in the burn room, and the total production of $\mathrm{CO}$ and $\mathrm{CO}_{2}$. The outcome of this research includes the following: (1) data on fire loads and relative contributions of different combustibles in commercial premises; (2) definition of seven fuel packages and their burning characteristics representing commercial premises; and (3) representation of seven fuel packages to be used in FDS to simulate fires in commercial premises.
\end{abstract}




\section{Acknowledgments}

I would like to express my heartfelt gratitude to my parents and sisters for the moral, and financial support in good as well as in less good periods of my work. Also for always encouraging me to aim as high as I possibly wanted.

I would like to thank my supervisor, Professor George Hadjisophocleous, whose advice and comments have been invaluable throughout the entire process of this research. I appreciate his patience, and all the time spent to explain things that helped me in my research and also in research-related issues. I also want to say that Professor Hadjisophocleous is a great person and supervisor.

I express sincere appreciation and thanks to Professor Jim Mehaffey for his guidance, valuable advice, insight throughout the research, and editing of my thesis. I also enjoyed his two courses on Fire Dynamics. I would like to thank Dr. Gary Lougheed for his advice and support in conducting the experiments, and Dr. Ahmed Kashef for his valuable suggestions.

I am also grateful for the support of this work from the following: (1) The National Research Council of Canada, and the staff of the Fire Research Program for the extensive technical assistance provided throughout my experimental work; (2) Forintek Canada Corp. and the Natural Sciences and Engineering Research Council, for supporting the Industrial Chair in Fire Safety Engineering at Carleton University; (3) Public Works and Government Services Canada; (4) Friends, colleagues and all others in the Department of Civil and Environmental Engineering, who expressed academic and friendly interest; and (5) The Salvation Army, for donating material for my experimental work. 


\section{Table of Contents}

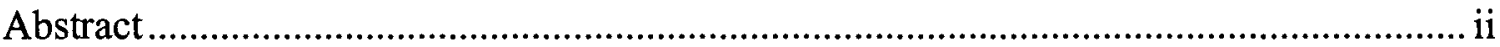

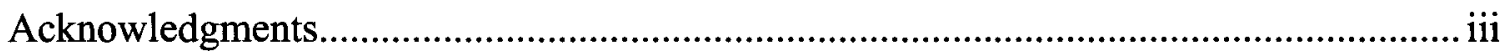

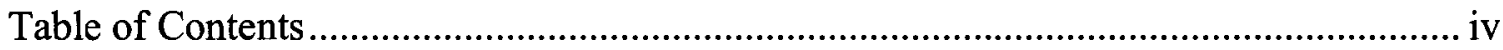

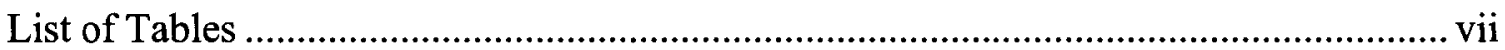

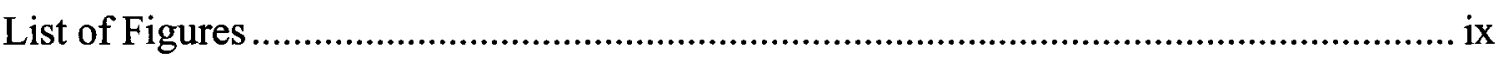

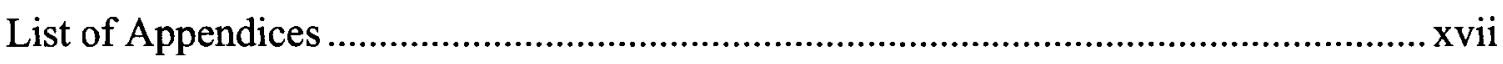

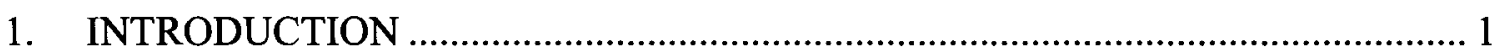

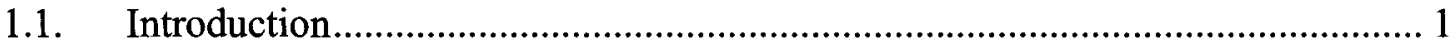

1.2. Problem Definition and Approach ......................................................... 4

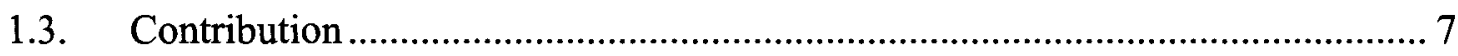

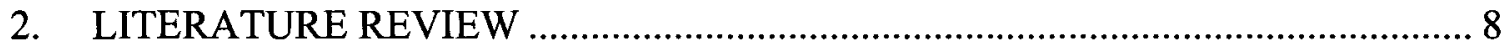

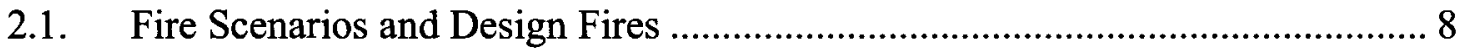

2.1.1. Summary of Design Fires ................................................................ 19

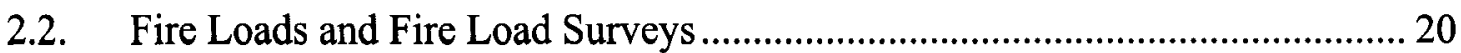

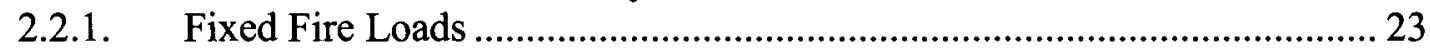

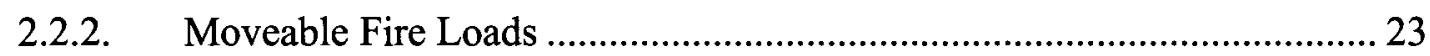

2.2.3. Assumptions Made to Estimate Fire Loads ........................................... 24

2.2.4. Summary of Fire Load Surveys .......................................................... 27

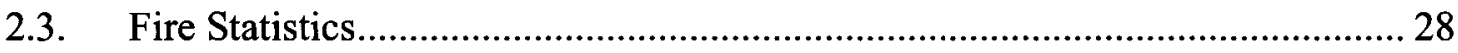

2.3.1. Summary of Fire Statistics........................................................... 40

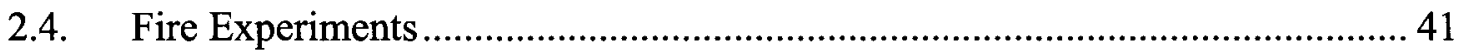

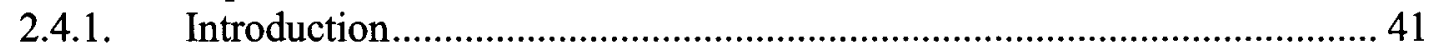

2.4.2. Discussion on Fire Experiments Reported in the Literature .................... 43

2.4.3. Summary of Fire Experiments .......................................................... 49

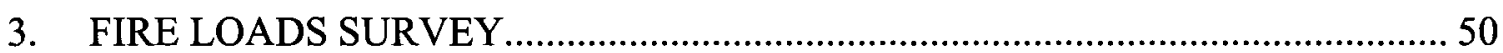

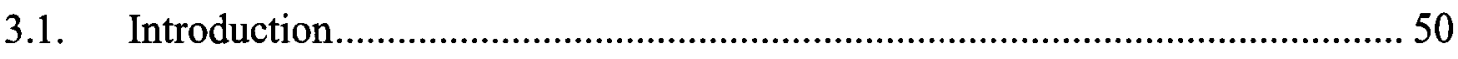

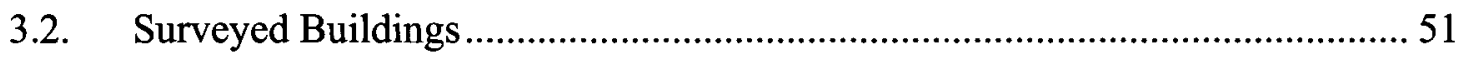

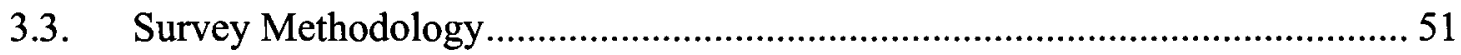

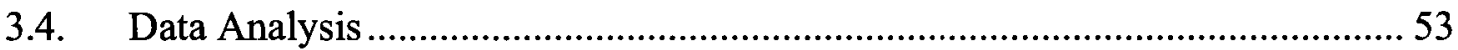

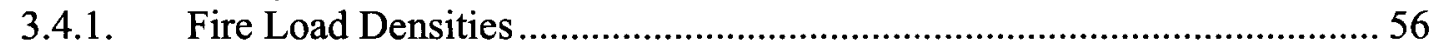

3.4.1.1. Statistical Interpretation of Fire Load Densities .................................. 58

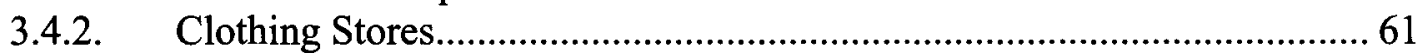

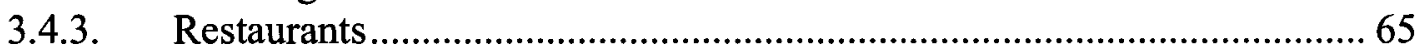

3.4.4. Fast Food Outlets; and Fast Food Outlets and Grocery Stores................... 68

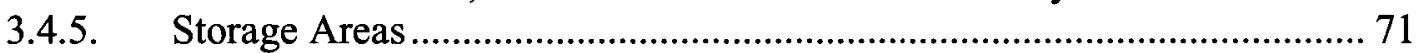

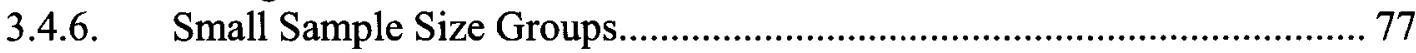

iv 


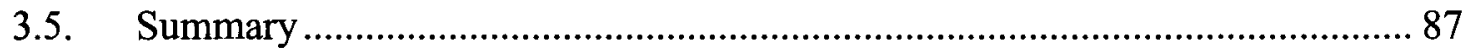

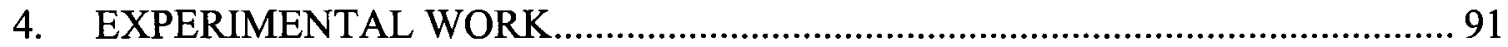

4.1. Introduction............................................................................................ 91

4.2. The Test Facilities ................................................................................... 91

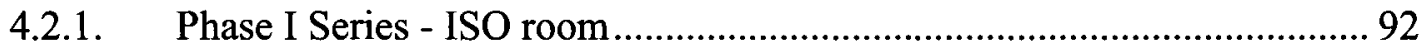

4.2.1.1. Thermocouples......................................................................................... 93

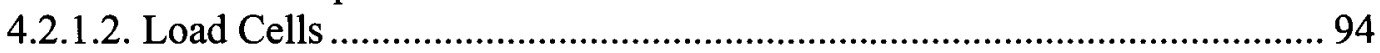

4.2.1.3. Gas Analyzers .................................................................................. 94

4.2.1.4. Other Instrumentation ........................................................................... 95

4.2.2. Phase II Series, Post-Flashover Facility ................................................ 95

4.2.2.1. Thermocouples............................................................................... 96

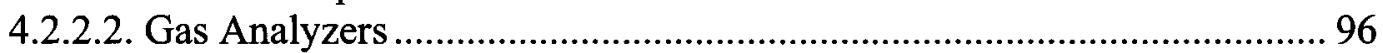

4.2.2.3. Other Instrumentations........................................................................... 96

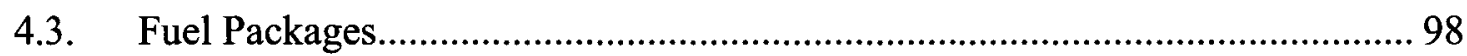

4.3.1. Phase I Fuel Packages..................................................................... 98

4.3.2. Phase II Fuel Packages....................................................................... 99

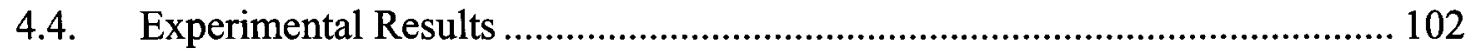

4.4.1. Phase I Experiments-Results And Discussions ..................................... 102

4.4.1.1. Hot Layer Temperature....................................................................... 102

4.4.1.2. Gas Production Rates Measurements................................................ 105

4.4.1.3. Heat Release Rate (HRR) ........................................................... 112

4.4.1.4. Clothing Stores Tests, Tests CLS-I, CLW-I, and CLC-I....................... 116

4.4.2. Phase II Tests-Results and Discussions ............................................. 122

4.4.2.1. Hot Layer Temperature....................................................................... 122

4.4.2.2. Gas Production Rate Measurements .................................................... 127

4.4.2.3. Heat Release Rate (HRR) ............................................................. 133

4.4.3. Comparisons of Phase I and Phase II Tests .......................................... 136

4.4.3.1. Computer Store, Test CMP-I and CMP-II ……………....................... 136

4.4.3.2. Storage Area, Test SA-I and SA-II ........................................................ 141

4.4.3.3. Clothing Stores Tests, Tests CLC-I and CLC-II.................................... 145

4.4.3.4. Toy Store Tests, TOY-I and TOY-II .................................................. 150

4.4.3.5. Shoe Stores and Shoe Storage Areas, SHO-I and SHO-II..................... 155

4.4.3.6. Bookstores and Storage Area of Bookstores, Test BK-I and BK-II ...... 160

4.4.3.7. Fast Food Outlets, Test FF-I and FF-II............................................... 165

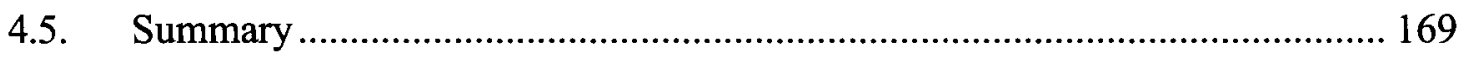

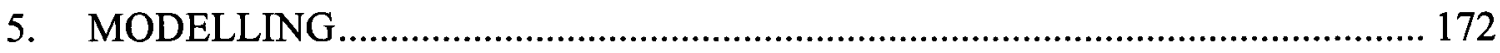

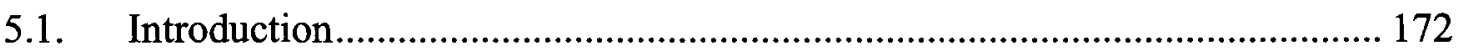

5.1.1. Factors affecting the FDS output results............................................ 177

5.1.1.1. Material Density...................................................................................... 177

5.1.1.2. Heat of Vaporization............................................................................ 178

5.1.1.3. Heat of Combustion ............................................................................... 178

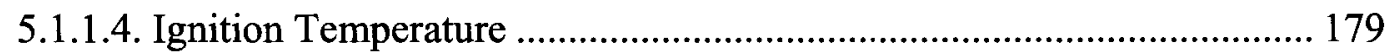


5.2. Modelling Results and Comparisons with Experiments.................................. 181

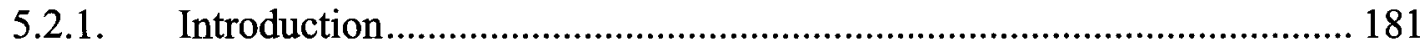

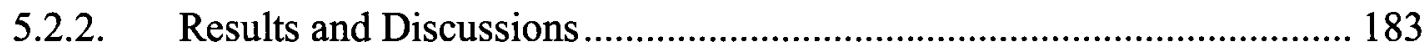

5.2.2.1. Virtual Fuel Packages ........................................................................... 183

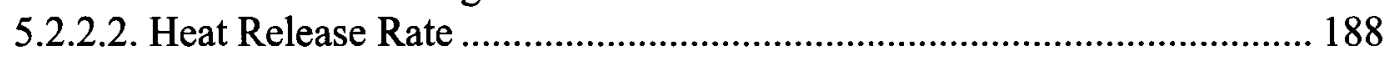

5.2.2.3. Hot Layer Temperature and $\mathrm{CO}$ and $\mathrm{CO}_{2}$ production ........................... 191

5.2.2.4. Simulating Real-Size Stores .................................................................. 195

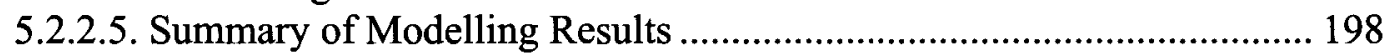

6. SUMMARY AND DEFINING DESIGN FIRES ................................................ 199

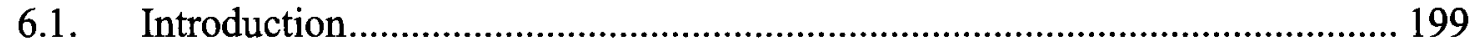

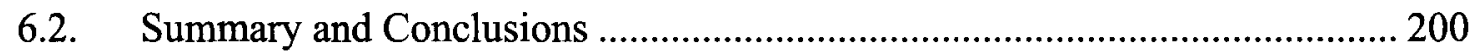

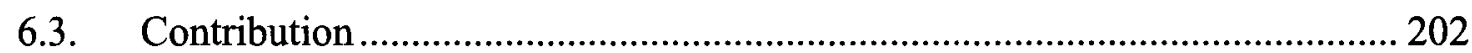

6.4. Recommendations for Future Research...................................................... 202

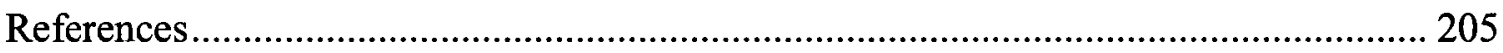




\section{List of Tables}

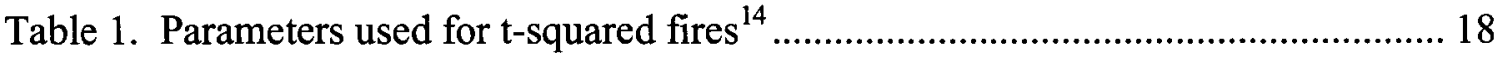

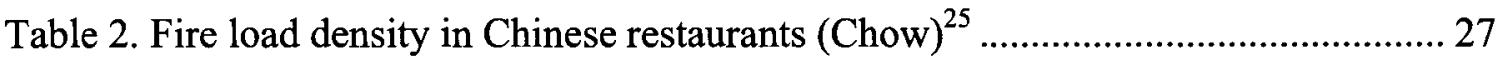

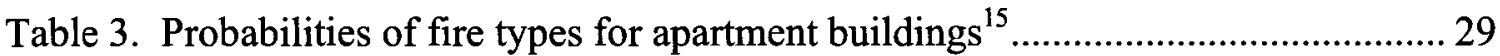

Table 4. Number of fires and casualties for fires in USA office buildings, 1983-1991 ${ }^{9} .30$

Table 5. Number of fires and dollar loss for fires in USA office buildings 1983-1991 ${ }^{9} .30$

Table 6. Percentage of fires with extent of flame damage beyond the room of fire origin in the USA ${ }^{9}$

Table 7. Review of Australian fire statistics (1989 to 1993$)^{27}$.......................................... 35

Table 8. Area of fire origin in retail buildings (summarized from Bennetts et al. $^{27}$ ) f..... 36

Table 9. Cause of fires in retail buildings (summarized from Bennetts et al. ${ }^{27}$ ) .............. 36

Table 10. Area of fire origin in retail buildings, US (summarized from Bennetts et al. ${ }^{27}$ )

Table 11. Cause of fires in retail buildings (summarized from Bennetts et al. ${ }^{27}$ ) …....... 37

Table 12. Identified groups and number of samples of surveyed stores............................ 55

Table 13. Number of samples and fire load densities of the various groups.....................6 60

Table 14. Contribution of different combustibles of the various groups ............................ 61

Table 15. Fire load densities and contribution of combustible materials to fire load

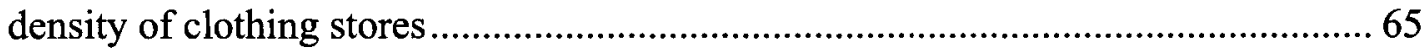

Table 16. Details of Phase I and II fuel packages, fire load densities, and combustible materials 101

Table 17. Peak temperatures and heat flux of Phase I experiments.............................. 103

Table 18. Smoke data and visibility analysis of Phase I experiments ............................ 106

Table 19. Visibility data of Phase I experiments .......................................................... 112

Table 20. Heat released, growth rates, and heat content of Phase I experiments .......... 115

Table 21. Hot layer temperature and heat flux of Phase II experiments........................ 123

Table 22. Smoke data and visibility analysis of Phase II experiments ........................... 127 
Table 23. Average production of carbon monoxide in Phase II experiments

Table 24. Heat released, growth rates, and heat content of Phase II experiments. 135

Table 25. Material properties of the computer store virtual package 185

Table 26. Material properties of the storage area virtual package 185

Table 27. Material properties of the clothing store virtual package 185

Table 28. Material properties of the toy store virtual package 186

Table 29. Material properties of the shoe store virtual package 186

Table 30. Material properties of the bookstore virtual package 186

Table 31. Material properties of the fast food outlet virtual package 187

Table 32. HRR, gas data, and temperatures for FDS and experimental results 194 


\section{List of Figures}

Figure 1. Performance-based design process (modified from the SFPE ${ }^{1}$ )...................... 9

Figure 2. Fire development stages in a room in the absence of an active suppression system

Figure 3. Percentage of floor area of different premises to total floor area of surveyed premises

Figure 4. Frequencies of fire load density of the 168 surveyed stores 56

Figure 5. Total fire load distribution of the 168 surveyed stores 57

Figure 6. Area distribution of the 168 surveyed stores. 57

Figure 7. Fire load frequency and the corresponding lognormal distributions 59

Figure 8. Range of contribution of combustibles to the fire load of the surveyed stores 60

Figure 9. Fire load density of clothing stores 62

Figure 10. Combustible contributions in clothing stores. 63

Figure 11. Effect of floor area on the fire load density of clothing stores. 63

Figure 12. Fire load density of restaurants. 66

Figure 13. Combustible contributions in restaurants 67

Figure 14. Effect of floor area on the fire load density of restaurants 67

Figure 15. Fire load density of fast food outlets.... 68

Figure 16. Fire load density of fast food outlets and grocery stores. 69

Figure 17. Combustible contributions in fast food outlets. 70

Figure 18. Combustible contributions in fast food outlets and grocery stores ............... 70

Figure 19. Effect of floor area on the fire load density of fast food outlets.................... 71

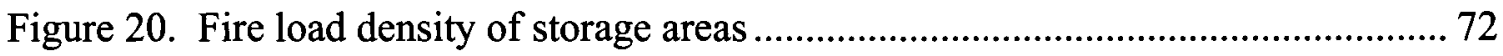

Figure 21. Combustible contributions in storage areas......................................... 73

Figure 22. Fire load density of 8 clothing store storage areas .................................. 74

Figure 23. Combustible contributions in 8 clothing store storage areas....................... 74

ix 
Figure 24. Fire load density of 3 art supply and framing store storage areas 74

Figure 25 . Combustible contributions in 3 art supply and framing store storage areas... 74

Figure 26. Fire load density of 3 fast food outlet storage areas....................................... 75

Figure 27. Combustible contributions in 3 fast food outlet storage areas ....................... 75

Figure 28. Fire load density of 5 restaurant storage areas ............................................... 75

Figure 29. Combustible contributions in 5 restaurant storage areas................................ 75

Figure 30. Fire load density of 3 shoe store storage areas ............................................. 76

Figure 31. Combustible contributions in 3 shoe store storage areas................................ 76

Figure 32. Fire load density of 2 luggage store storage areas......................................... 76

Figure 33. Combustible contributions in 2 luggage shop storage areas ........................... 76

Figure 34. Fire load density of cafés........................................................................... 78

Figure 35. Combustible contributions in cafés ............................................................ 78

Figure 36. Fire load density of tailor shops ……........................................................ 78

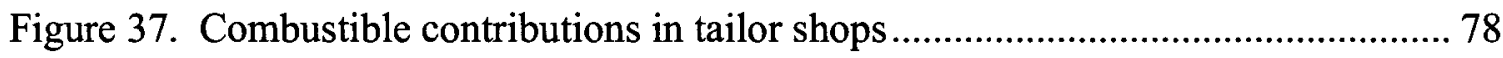

Figure 38. Fire load density of dry-cleaning shops........................................................ 79

Figure 39. Combustible contributions in dry-cleaning shops .......................................... 79

Figure 40. Fire load density of florist shops ................................................................ 79

Figure 41. Combustible contributions in florist shops................................................... 79

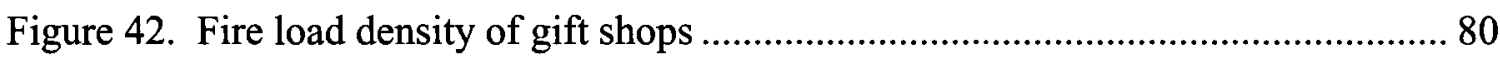

Figure 43. Combustible contributions in gift shops....................................................... 80

Figure 44. Fire load density of grocery stores ……………........................................... 80

Figure 45. Combustible contributions in grocery stores .................................................. 80

Figure 46. Fire load density of hair-stylist salons......................................................... 81

Figure 47. Combustible contributions in hair-stylist salons ............................................. 81

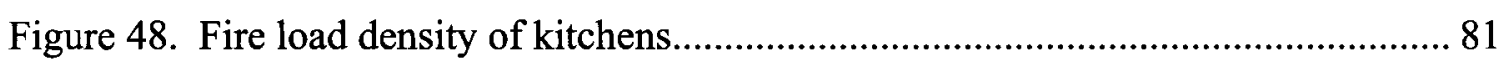

Figure 49. Combustible contributions in kitchens ............................................................ 81 
Figure 50. Fire load density of luggage shops .............................................................. 82

Figure 51. Combustible contributions in luggage shops................................................. 82

Figure 52. Fire load density of photo-finishing ………………................................... 82

Figure 53. Combustible contributions in photo-finishing................................................ 82

Figure 54. Fire load density of printing \& photocopy shops ............................................ 83

Figure 55. Combustible contributions in printing \& photocopy shops.............................. 83

Figure 56. Fire load density of shoe retail shops …………………………....................... 83

Figure 57. Combustible contributions in shoe retail shops .............................................. 83

Figure 58. Fire load density of shoe-repair shops...................................................... 84

Figure 59. Combustible contributions in shoe-repair shops ............................................ 84

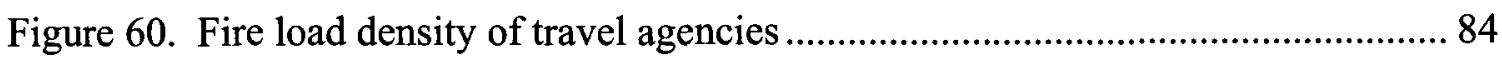

Figure 61. Combustible contributions in travel agencies................................................. 84

Figure 62. Fire load density of computer accessory \& stationary shops .......................... 85

Figure 63. Combustible contributions in computer accessory \& stationary shops........... 85

Figure 64. Fire load density of liquor stores ................................................................. 85

Figure 65. Combustible contributions in liquor stores.................................................... 85

Figure 66. Fire load density of arts \& crafts supply shops ............................................. 86

Figure 67. Combustible contributions in arts \& crafts supply shops................................ 86

Figure 68. Fire load densities range of different groups ................................................ 90

Figure 69. Test setup in the ISO-9705 compatible room................................................. 93

Figure 70. Layout of the Phase II test facility ................................................................. 97

Figure 71. Temperature $2.1 \mathrm{~m}$ from floor, Phase I experiments...................................... 104

Figure 72. Heat flux, Phase I experiments............................................................... 104

Figure 73. Carbon monoxide production rates, Phase I experiments .............................. 106

Figure 74. Carbon dioxide production rates, Phase I experiments ................................... 107

Figure 75. Optical density, Phase I experiments........................................................... 107 
Figure 76. Carbon monoxide production rate, Phase I experiments............................ 109

Figure 77. Carbon dioxide production rate, Phase I experiments ............................... 110

Figure 78. Heat release rates, Phase I experiments............................................. 115

Figure 79. Photographs depicting the test in progress, Test CLS-I ........................... 119

Figure 80. Photographs depicting the test in progress, Test CLW-I............................ 119

Figure 81. Photographs depicting the test in progress, Test CLC-I............................. 119

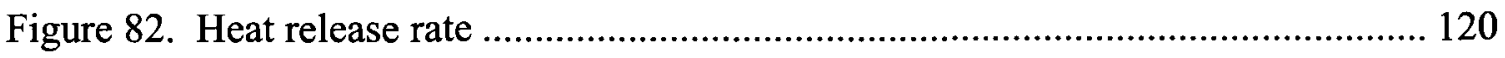

Figure 83. Carbon monoxide production rates .............................................. 120

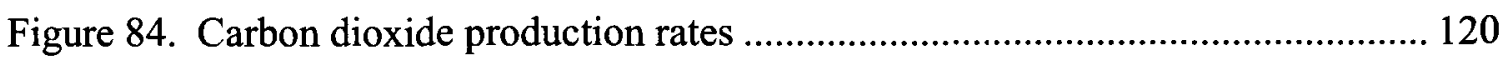

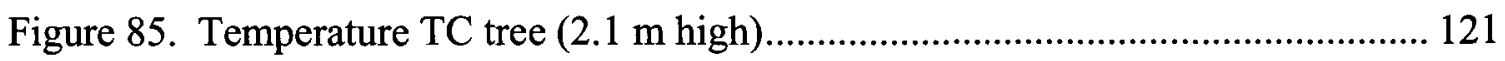

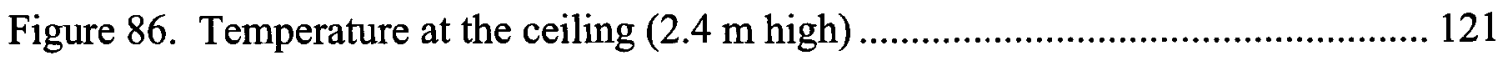

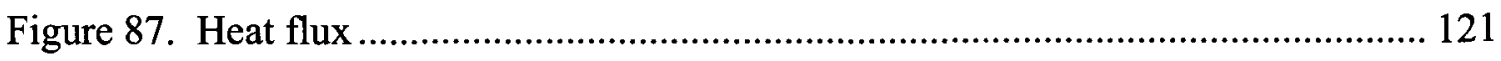

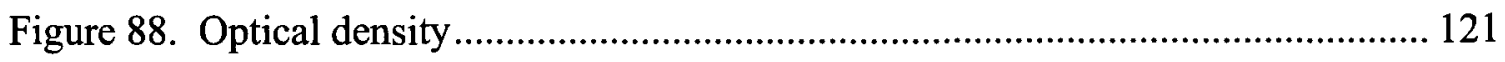

Figure 89. Temperature $2.1 \mathrm{~m}$ high, Phase II experiments ..................................... 124

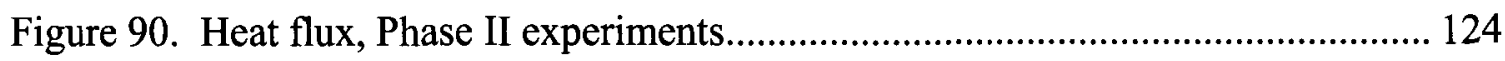

Figure 91. Temperature of test CMP-II, room \& corridor ......................................... 125

Figure 92. Temperature of test SA-II, room \& corridor ......................................... 125

Figure 93. Temperature of test CLC-II, room \& corridor......................................... 125

Figure 94. Temperature of test TOY-II, room \& corridor ....................................... 125

Figure 95. Temperature of test SHO-II, room \& corridor ...................................... 126

Figure 96. Temperature of test BK-II, room \& corridor........................................ 126

Figure 97. Temperature of test FF-II, room \& corridor ........................................... 126

Figure 98. Carbon monoxide concentration, Phase II experiments ........................... 128

Figure 99. Carbon dioxide concentration, Phase II experiments ............................... 128

Figure 100. Carbon monoxide production rates, Phase II experiments ....................... 131

Figure 101. Carbon dioxide production rates, Phase II experiments .......................... 132

$$
\text { xii }
$$


Figure 102. Optical density, Phase II experiments ....................................................... 132

Figure 103. Heat release rates, Phase II experiments …………………...................... 135

Figure 104. Photographs depicting test CMP-I progress .............................................. 138

Figure 105. Photographs depicting test CMP-II progress.......................................... 138

Figure 106. Heat release rate ............................................................................... 139

Figure 107. Carbon monoxide production rate .............................................................. 139

Figure 108. Carbon dioxide production rate ............................................................. 139

Figure 109. Temperature $2.1 \mathrm{~m}$ from floor .......................................................... 140

Figure 110. Temperature at the ceiling level ........................................................... 140

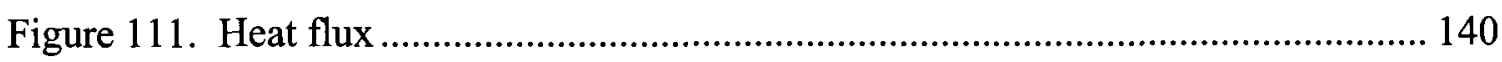

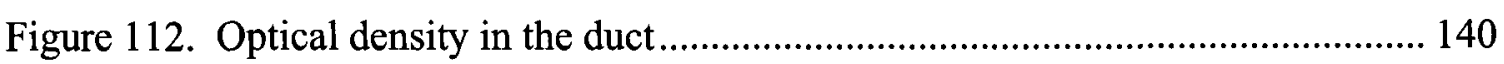

Figure 113. Photographs depicting test SA-I progress ................................................. 142

Figure 114. Photographs depicting test SA-II progress ............................................... 142

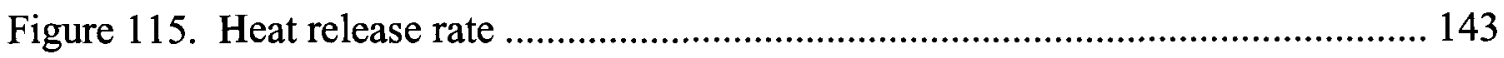

Figure 116. Carbon monoxide production rate ............................................................ 143

Figure 117. Carbon dioxide production rate .............................................................. 143

Figure 118. Temperature $2.1 \mathrm{~m}$ from floor ............................................................... 144

Figure 119. Temperature at the ceiling level .............................................................. 144

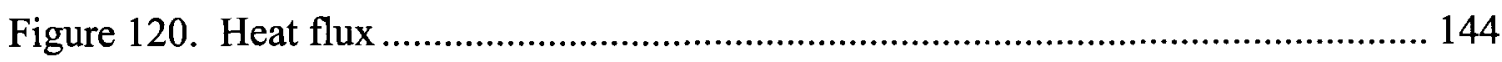

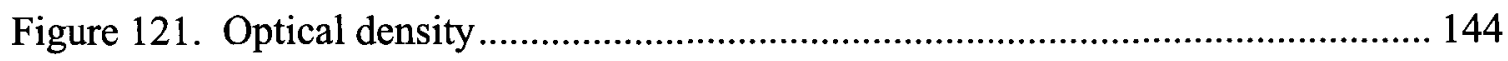

Figure 122. Photographs depicting the test in progress, Test CLC-I.............................. 147

Figure 123. Photographs depicting the test in progress, Test CLC-II ............................ 147

Figure 124. Heat release rate ……………………............................................. 148

Figure 125. Carbon monoxide production rates ..................................................... 148

Figure 126. Carbon dioxide production rates ............................................................ 148

Figure 127. Temperature $2.1 \mathrm{~m}$ from floor ................................................................ 149

xiii 
Figure 128. Temperature at the ceiling level ............................................................... 149

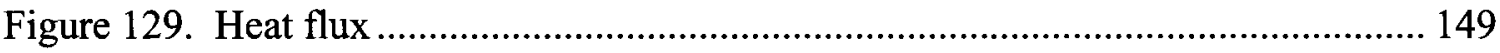

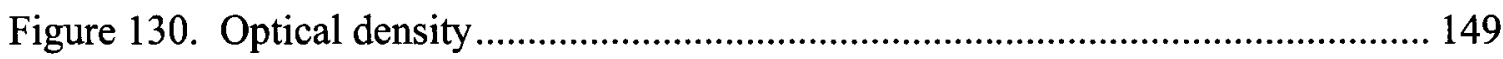

Figure 131. Photographs depicting test TOY-I progress .............................................. 152

Figure 132. Photographs depicting test TOY-II progress ............................................ 152

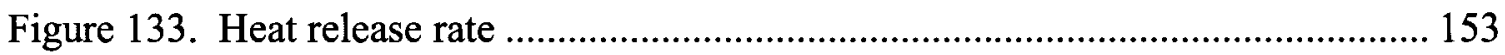

Figure 134. Carbon monoxide production rates ........................................................ 153

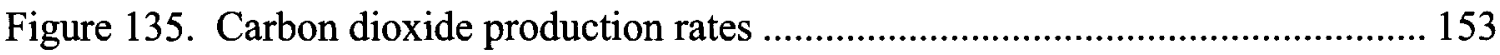

Figure 136. Temperature $2.1 \mathrm{~m}$ from floor ................................................................. 154

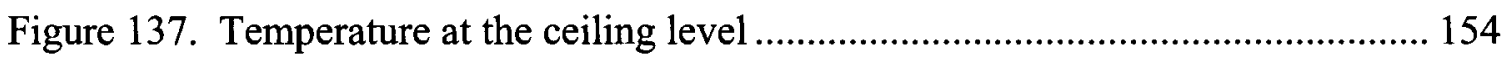

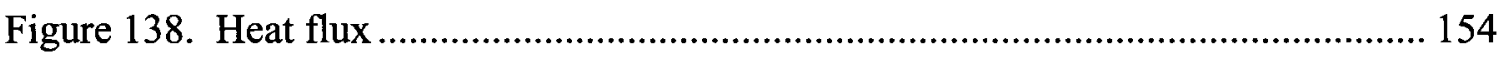

Figure 139. Optical density................................................................................... 154

Figure 140. Photographs depicting test SHO-I progress ............................................... 157

Figure 141. Photographs depicting test SHO-II progress .............................................. 157

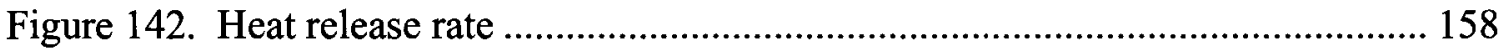

Figure 143. Carbon monoxide production rates ........................................................ 158

Figure 144. Carbon dioxide production rates ............................................................. 158

Figure 145. Temperature $2.1 \mathrm{~m}$ from floor ..................................................................... 159

Figure 146. Temperature at the ceiling level ............................................................. 159

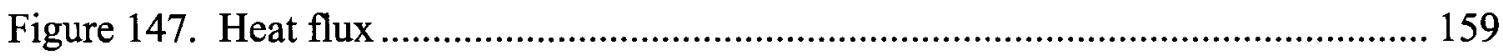

Figure 148. Optical density ....................................................................................... 159

Figure 149. Photographs depicting test BK-I progress .................................................... 162

Figure 150. Photographs depicting test BK-II progress................................................ 162

Figure 151. Heat release rate ………………………………………………….... 163

Figure 152. Carbon monoxide production rates ........................................................... 163

Figure 153. Carbon dioxide production rates .............................................................. 163 xiv 


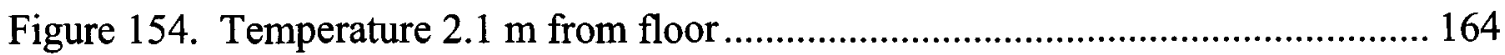

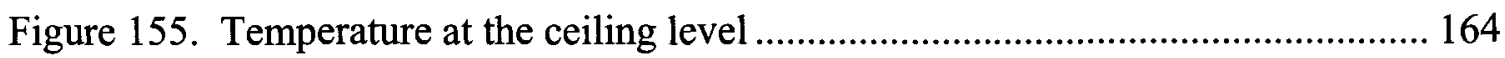

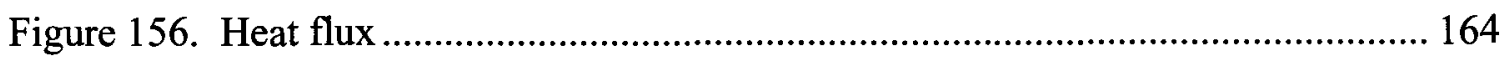

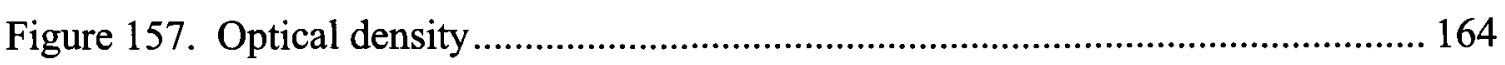

Figure 158. Photographs depicting test FF-I progress ................................................. 166

Figure 159. Photographs depicting test FF-II progress................................................. 166

Figure 160. Heat release rate .............................................................................. 167

Figure 161. Carbon monoxide production rates ............................................................ 167

Figure 162. Carbon dioxide production rates ........................................................... 167

Figure 163. Temperature $2.1 \mathrm{~m}$ from floor .................................................................. 168

Figure 164. Temperature at the ceiling level ............................................................... 168

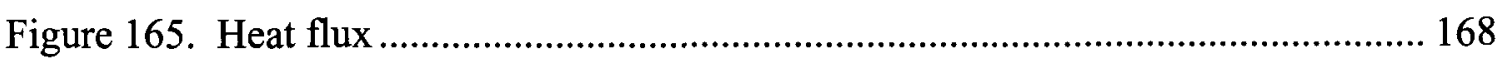

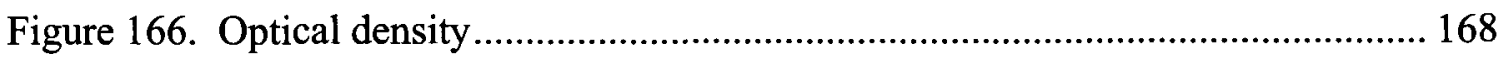

Figure 167. Effect of material density on HRR ……………………….................... 180

Figure 168. Effect of heat of vaporization on HRR................................................... 180

Figure 169. Effect of heat content on HRR ............................................................. 180

Figure 170. Effect of ignition temperature on HRR .................................................. 180

Figure 171. Geometry of the burn room and the fuel package, Phase I experiments.... 182

Figure 172. Geometry of the burn room, corridor, and the fuel packages, Phase II experiments........................................................................................................ 182

Figure 173. Computer store-HRR (FDS vs experiments) .............................................. 189

Figure 174. Storage areas-HRR (FDS vs experiments) ................................................. 189

Figure 175. Clothing store-HRR (FDS vs experiments) ................................................. 189

Figure 176. Toy store-HRR (FDS vs experiments) ..................................................... 189

Figure 177. Shoe store-HRR (FDS vs experiments) ..................................................... 190

Figure 178. Bookstore-HRR (FDS vs experiments) ………….................................. 190 
Figure 179. Fast food outlet-HRR (FDS vs experiments) ............................................... 190

Figure 180. Computer store-Temperature (FDS vs experimental) ……........................ 192

Figure 181. Storage areas-Temperature (FDS vs experimental) …………………….... 192

Figure 182. Clothing store-Temperature (FDS vs experimental) .................................. 192

Figure 183. Toy store-Temperature (FDS vs experimental) ........................................ 192

Figure 184. Shoe store-Temperature (FDS vs experimental) ......................................... 193

Figure 185. Bookstore-Temperature (FDS vs experimental)......................................... 193

Figure 186. Fast food outlet-Temperature (FDS vs experimental) ................................ 193

Figure $18710 \times 10 \mathrm{~m}$ toy store simulation, TOY-III.................................................... 196

Figure 188. Hot layer temperature, simulation of real-size toy store ............................. 196

Figure 189. Heat release rate, simulation of $10 \times 10 \mathrm{~m}$ toy store .................................... 197 


\section{List of Appendices}

Appendix A HEAT CONTENT OF DIFFERENT COMBUSTIBLES 209

Appendix B ASSUMPTIONS MADE IN CALCULATING FIRE LOADS 212

Appendix C FDS INPUT DATA CHARACTERISTICS 213

Appendix D FDS INPUT DATA FILES 222

xvii 


\section{INTRODUCTION}

\subsection{Introduction}

Over the last twenty years, there has been an increasing effort by building-code-writing bodies to move towards performance-based codes. Performance-based codes are being developed and introduced because of their advantages over traditional prescriptive codes. They provide more flexibility in design than prescriptive codes, and facilitate innovation in design, both of which may lead to lower construction costs without lowering the level of safety. In a performance-based code design, computer models may be used to predict the fire growth characteristics in the compartment of fire origin for various fire scenarios, as well as the overall fire safety performance of buildings.

As stated in the Society of Fire Protection Engineering (SFPE) guide to performancebased fire protection ${ }^{1}$, the development of a design fire scenario is a combination of hazard analysis and risk analysis. Hazard analysis identifies potential hazards, such as ignition sources, fuels, and fire development. Risk analysis includes the indicated hazard analysis and the likelihood of occurrence (either quantitatively or qualitatively), and the severity of the outcomes.

A fire risk analysis of a building requires the identification of possible fire scenarios that may occur in the building and the appropriate design fires that should be considered. Fire scenarios describe the conditions in the building that influence the development and outcome of a fire. Each fire scenario is represented by a unique occurrence of events and is the result of a particular set of circumstances that influence the development and spread of fire and smoke. Accordingly, a fire scenario represents a particular combination of outcomes or events associated with parameters such as the type, size and location of the 
ignition source, type of fire, distribution and density of fuel inside the fire compartment, condition of ventilation openings and doors, performance of each of the fire safety measures and air handling system, and whether occupants are in the building or not. These parameters can have a significant impact on the outcome of a fire. A systematic approach for identifying different fire scenarios and selecting the important ones for analysis is desirable in order to provide a consistent approach to be used by different analysts. The selected fire scenarios are called the design fire scenarios.

Design fires represent an idealization of real fires that may occur in the building. These fires are used for evaluating the design fire scenarios. A design fire depends on the use of the building and its contents; therefore, its selection requires a good understanding of the combustibles present. A design fire is the quantitative description of the course of a particular fire with respect to time and space. It depends on the ignition source, the first item ignited, the spread of fire, the interaction of the fire with its environment and its decay and extinction. Design fires are characterized by the heat release rate (HRR) and the production of toxic gases, both of which are affected by the type, amount, and distribution of combustible materials in the compartment of fire origin. Content characteristics such as the type of combustibles and their distribution affect the fire growth characteristics, as well as the production and type of toxic products of combustion of the design fire, while others such as the amount of fuel govern the duration of the fire.

The research discussed in this thesis focuses on developing and recommending design fires to be used in commercial buildings (shopping centres). The research includes the results of medium- and large-scale fire experiments that were conducted to determine the burning characteristics of different fuel packages in commercial premises. 
These experiments were conducted at the National Research Council of Canada (NRCC). The research also includes computer simulations of these experiments using the computational fluid dynamics code, Fire Dynamics Simulator (FDS), developed at the National Institute for Standards and Technology (NIST) ${ }^{2}$.

Shopping centres are large and busy places where many activities happen and where thousands of workers and customers can be found during operational hours. They have many stores with different combinations of goods and often, storage areas that contain large amounts of different combustibles. In order to assess the amount and types of combustibles in these premises; the author, as part of this research, conducted a fire load survey of 168 stores. The survey was conducted in the Canadian cities of Ottawa and Gatineau in 2003. Stores surveyed included fast food outlets, restaurants, clothing stores, toy stores, and shoe stores. The products on display in these stores included textiles, footwear, toys, computer accessories, books, and food items. In the experiments, samples of the aforementioned products were collected and used inside the burn rooms to investigate fire scenarios in these stores.

A series of medium-scale experiments (9 tests) was conducted in a room calorimeter similar to the full-scale room test for surface products described by the International Organization for Standardisation (ISO $9705^{3}$ ). Each fuel package was limited to a $1.0 \mathrm{~m}^{2}$ footprint and represented the fire load density, method of display, and combustible products in the proportions determined in the survey. A series of large-scale tests ( 7 tests) was conducted in a larger facility $(2.7 \times 3.6 \times 2.4 \mathrm{~m})$ that allowed investigation of fire behaviour beyond flashover. The rooms were instrumented to collect data for 
determining the heat release rate, mass loss, smoke production rate, hot layer temperature, and heat flux to the floor.

In the modelling phase of this research, FDS was used to simulate the experimental results. The FDS input data, used to represent the fuel packages, were chosen so that FDS could predict the fire growth rate, time to peak heat release rate, peak HRR, decay profile, and the total amount of carbon monoxide and carbon dioxide produced.

Based on the survey, statistics, experimental results, and modelling outputs, the work presented here recommends design fires for use by building designers and modellers. The description of the recommended design fires include: (1) fire load per floor area $\left(\mathrm{MJ} / \mathrm{m}^{2}\right)$; (2) fire growth rate; (3) peak HRR and expected time to peak HRR; and (4) total amount of carbon monoxide and carbon dioxide produced per kilojoule of fire load.

The results of the medium- and full-scale tests reveal substantial differences in the burning characteristics of the fuel packages simulating the different stores. For each type of store, a fire involving a tailored fuel package with different material properties was simulated using the computational fluid dynamics model. FDS was able to simulate the results of the majority of the medium- and large-scale tests.

\subsection{Problem Definition and Approach}

The characterization of a design fire for a specific occupancy has always been a challenging task. A fire can be represented by a number of stages that include growth, fully-developed burning, and decay. The transition from the growth stage to the fullydeveloped stage is an event known as flashover. Flashover occurs when the fire spreads rapidly from one burning item in the compartment to include all combustibles. 
During these stages, gas temperatures, production rates of toxic gases, and the rate of heat release profiles differ depending on the geometry and ventilation characteristics of the compartment, ignition source, and types of combustibles present.

The production of gases, such as carbon dioxide, carbon monoxide, and hydrogen cyanide can affect occupants and their ability to evacuate a building. Fire duration has a major impact on structural elements and spread of fire to adjacent rooms, floors, or buildings. Many efforts have been made to develop design fires for different uses. These efforts have yielded, for example, simple design fires characterized by standard temperature-time curves used for fire-resistance tests and t-squared fires used to characterize the heat release rate during the fire growth stage (Drysdale ${ }^{4}$ ).

In this research, the procedure used for defining design fires for commercial premises included the following tasks:

1. Building survey: Conduct surveys of buildings to collect data on compartment size, geometry, characteristics of ventilation openings, fire load density, types of combustibles (plastics, wood, etc.), and fuel arrangement within compartments.

2. Statistical analysis: Perform statistical analysis of available data to determine the frequency of fires, ignition sources, and locations relevant to these premises.

3. Fuel package design and Phase I testing: Use the survey data and statistical information to design fuel packages for these premises to be used in mediumscale tests. The goal of these tests was to determine the fire characteristics of the 
fuel packages, such as heat release rate, production rate of toxic gases, and hot layer temperature.

4. Modelling of Phase I experiments: Develop input data for FDS to simulate the burning characteristics of the fuel packages used in Phase I experiments. Perform simulations and compare model predictions with experimental data. Modify fuel package characteristics used in the model to obtain results that compare favourably with the experimental data.

5. Phase II testing: Conduct large-scale tests in a post-flashover facility to determine the burning characteristics of selected fuel packages in the post-flashover fire stage.

6. Modelling of Phase II experiments: Use the input data for the fuel packages determined in Task 4 to verify that the model predicts the Phase II experiments and to demonstrate the capability and limitations of the model for simulating similar fuel packages in different compartments.

7. Design fire selection: Based on the results from the above tasks, select appropriate design fires representing potential fires in commercial buildings. Each of the design fires will be characterized by a fuel package, the experimental data, and the fuel package data used in the FDS model. 


\subsection{Contribution}

The product of this research has three main elements that are beneficial to the fire safety communities:

1. Fire loads and fuel packages representing the types of combustibles found in commercial buildings.

2. Experimental data showing the burning characteristics of the fuel packages.

3. Input data files to be used in fire models to represent the fuel packages in commercial premises.

The acceptance of the recommended design fires by fire safety designers and authorities having jurisdiction will bring consistency in the engineering design of fire protection systems in commercial buildings. 


\section{LITERATURE REVIEW}

The literature review focused on the following topics: (1) fire scenarios and design fires;

(2) fire loads and fire load surveys; (3) fire experiments; and (4) fire statistics. Detailed discussions of each of these topics are provided in the following sections.

\subsection{Fire Scenarios and Design Fires}

In a performance-based code design, computer models can be used to predict the fire growth characteristics in the compartment of fire origin, as well as the overall fire safety performance of buildings. The SFPE engineering guide to performance-based fire protection ${ }^{1}$ concluded that design fire scenarios are an important part of the performancebased design process, as illustrated in Figure 1. 


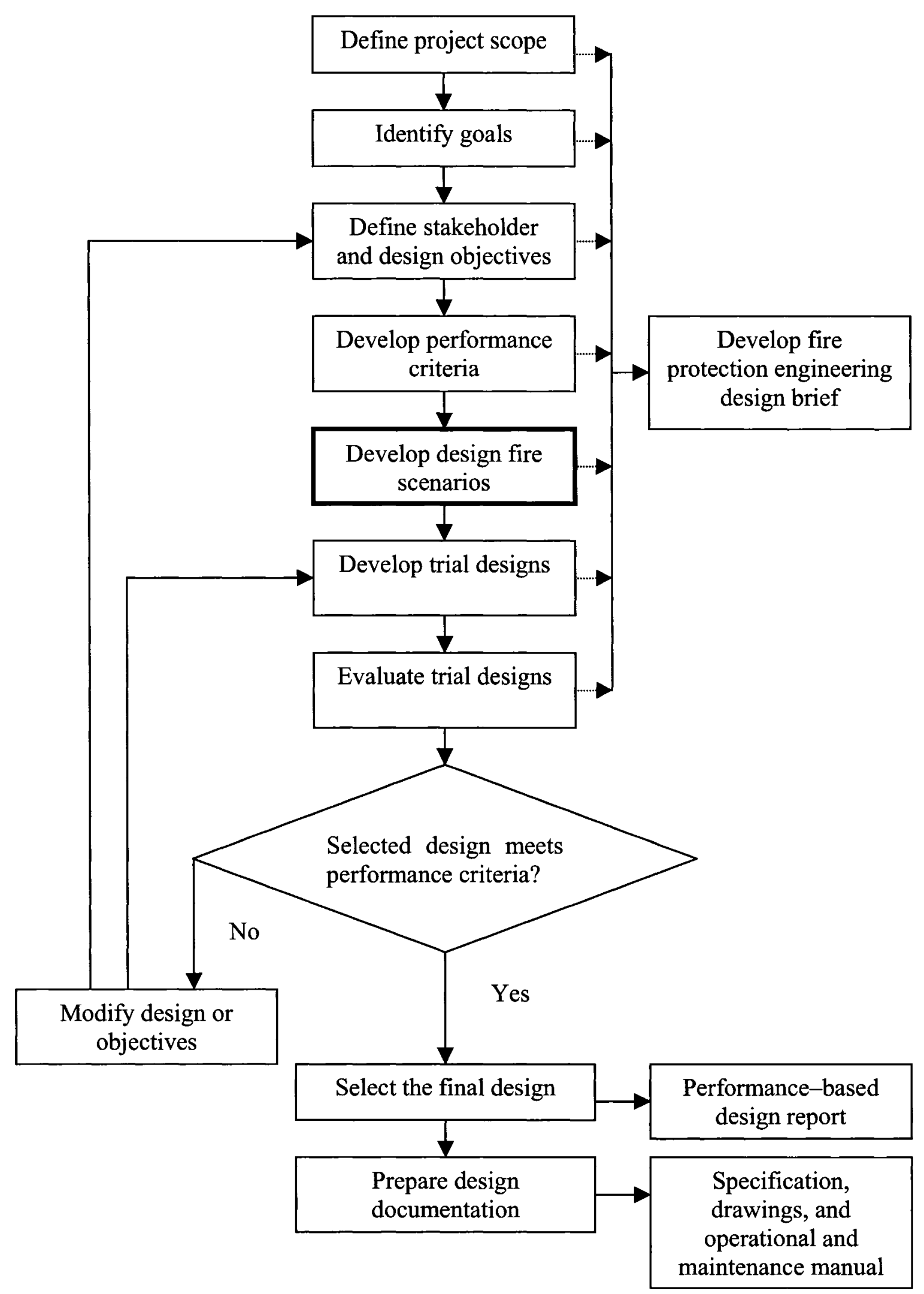

Figure 1. Performance-based design process (modified from the SFPE ${ }^{1}$ ) 
A fire risk analysis of a building requires the identification of possible fire scenarios that may occur in the building and the appropriate design fires that should be considered. Fire scenarios describe the conditions in the building that influence the development and outcome of a fire. During the qualitative design review stage of a performance-based design, it is important to identify important design fire scenarios, and to eliminate scenarios that are of low consequence or have a very low probability of occurrence from further consideration (ISO/TR $13387-2^{5}$ ).

Generally, several design fire scenarios must be considered for the building under consideration to address different fire-safety objectives. The design fire scenario is one of the primary uncertainties in fire safety engineering (Chow et al. ${ }^{6}$ ). The fire scenario is defined in the Australian fire engineering guidelines ${ }^{7}$ as “... prescribed conditions associated with the ignition, growth, spread, decay, and burnout of a fire in a building as modified by the fire safety system of the building. A fire scenario is described by the times of occurrence of the events that compromise the fire scenario".

At least one fire scenario should be considered for structural hazards and one for life safety hazards. A risk ranking process is recommended as the most appropriate basis for the selection of design fire scenarios. Such a process takes into account both the consequence and likelihood of the scenario. Key aspects of the risk ranking process recommended by ISO/TR $13387-2^{5}$ are: (1) identification of a comprehensive set of possible fire scenarios; (2) estimation of the probability of occurrence of each scenario using available data and engineering judgment; (3) estimation of the consequence of each scenario using engineering judgment; (4) estimation of the relative risk of the scenarios 
(product of consequence and probability of occurrence); and (5) ranking of the fire scenarios according to the relative risk.

The fires used for quantifying conditions that develop in alternative fire-protection design scenarios are called 'design fires'. A design fire depends on the use of a building and the material used and stored; therefore, it cannot be selected without understanding the combustibles present. The definition for design fire is stated in ISO/TR $13387-2^{5}$ as follows:

" $A$ design fire is the description of the course of a particular fire with respect to time and space. It includes the impact of the fire on building features, occupants, fire safety systems, and all other factors. It would typically define the ignition source and process, the growth of fire on the first item ignited, the spread of fire, the interaction of the fire with its environment, and its decay and extinction. It also includes the interaction of this fire with the building occupants and the interaction with the features and fire safety system within the building. Design fire is an idealization of real fires that may occur in the building".

In the SFPE engineering guide to performance-based fire protection ${ }^{1}$, a design fire scenario is described as "a set of conditions that defines or describes the critical factors for determining outcomes of a trial design". Design fire scenarios are often characterized by quantifying building and occupant characteristics, and design fire curves. Parameters that affect design fire characteristics include ignition sources, fire growth, initial fuels, secondary fuels, extension potentials, and target locations. 
Fuel packages that describe the initial fuel can be characterized as follows:

1. Fuel state: Solid, liquid, or gas.

2. Type and quantity of fuel: Cellulosic materials and plastic-based materials have different calorific values, and produce different heat release rates. The quantity of the fuel will determine the fire duration.

3. Fuel configuration: Different geometrical arrangements of fuel will have different fire growth and heat release rates because of the differences in surface area, ventilation, and radiation feedback.

4. Fuel location: A fuel package in the room or near a wall will have a growth rate that is faster than at the centre of the room.

5. Heat release rate: The rate at which heat is released is governed by the heat of combustion (calorific value) of the fuel, the efficiency of combustion, the mass loss rate, and the incident heat flux.

6. Rate of fire growth: Fires grow at rates that are dependent on the type and configuration of the fuel, and the available ventilation.

7. Production rate of combustion products (smoke, $\mathrm{CO}, \mathrm{CO}_{2}$ ): Different compositions of fuel packages and burning environments govern the products generated during combustion. The rate of smoke production, toxic gases, and other combustion products are also related to the mass loss rate. 
In the National Fire Protection Association (NFPA) uniform fire $\operatorname{code}^{8}$, characterizing design fire scenarios includes the following building and occupant characteristics.

\section{Building Characteristics}

(1) architectural features; (2) structural components; (3) fire loads; (4) egress components; (5) fire protection systems; (6) building services/processes; (7) operational characteristics; (8) fire department response characteristics; and (9) environmental factors.

\section{Occupant Characteristics}

(1) human behaviour; (2) response characteristics; and (3) evacuation times.

Eight design fire scenarios are suggested in the NFPA uniform fire code $^{8}$, as follows:

NFPA design fire scenario 1: An occupancy-specific fire that is representative of a typical fire in the occupancy. It explicitly accounts for the following: (1) occupant activities; (2) number and location of occupants; (3) room size (4) furnishings and contents; (5) fuel properties and ignition sources; (6) ventilation conditions; and (7) identification of the first item ignited and its location.

NFPA design fire scenario 2: An ultra-fast developing fire in the primary means of egress, with interior doors open at the start of the fire. It addresses the concern regarding a reduction in the number of available means of egress.

NFPA design fire scenario 3: A fire that starts in a normally unoccupied room, potentially endangering a large number of occupants in a large room or other areas. 
It addresses the concern regarding a fire starting in a normally unoccupied room and migrating into the space that potentially holds the greatest number of occupants in the building.

NFPA design fire scenario 4: A fire that originates in a concealed wall or ceiling space adjacent to a large occupied room. It addresses the concern regarding a fire originating in a concealed space that does not have either a detection system or a suppression system, which then spreads into the room within the building that potentially holds the greatest number of occupants.

NFPA design fire scenario 5: A slowly-developing fire, shielded from fire protection systems, in close proximity to a high occupancy area. It addresses the concern regarding a relatively small ignition source causing a significant fire.

NFPA design fire scenario 6: The most severe fire resulting from the largest possible fuel load (or fire load) characteristic of the normal operation of the building. It addresses the concern regarding a rapidly-developing fire with occupants present.

NFPA design fire scenario 7: An outside exposure fire. It addresses the concern regarding a fire starting at a location, remote from the area of concern and either spreading into the area, blocking escape from the area or developing untenable conditions in the area.

NFPA design fire scenario 8: A fire that originates in ordinary combustibles in a room or area with passive or active fire protection systems independently rendered ineffective. It addresses the concern regarding the unreliability or unavailability of each fire protection 
system or fire protection feature, considered individually. It is not required to be applied to fire protection systems for which both the level of reliability and the design performance in the absence of the system are acceptable to the authority having jurisdiction.

In the Australian fire safety engineering guidelines ${ }^{7}$, a design fire is defined as a mathematical representation of a fire that is characterized by the variation of heat output with time and is used as a basis for assessing fire safety systems. The complete specification of design fires requires knowledge of all aspects of the fire (incipient, growth, fully-developed, and decay). Figure 2 depicts the heat release rate (HRR) of the main four stages of a fire as a function of time. The figure also highlights flashover, which is the phenomenon when fire spreads from the first ignited object to all other combustibles in the room.

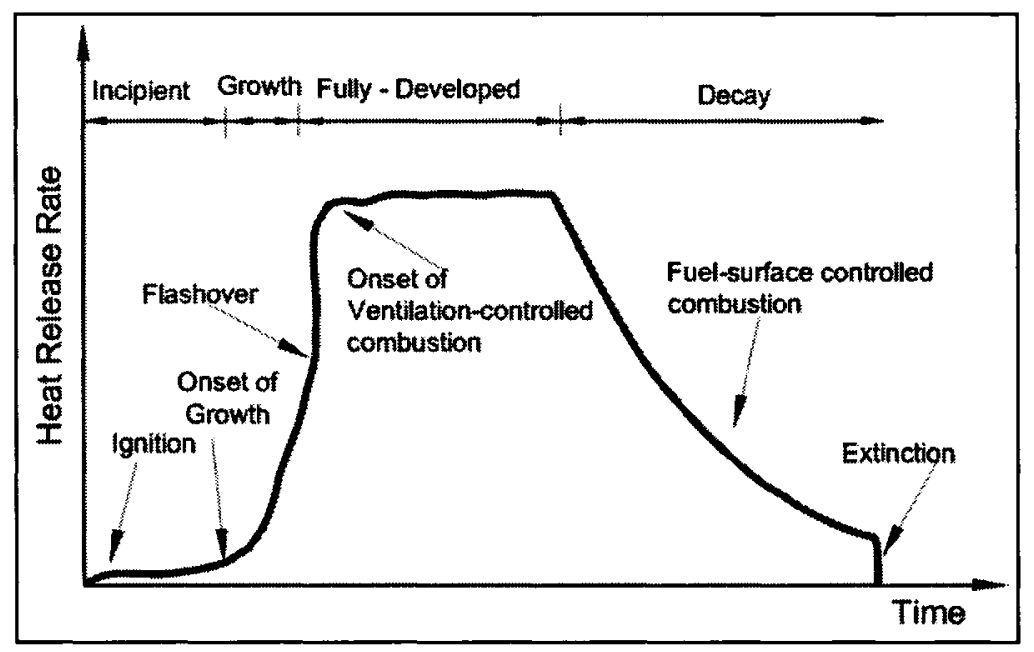

Figure 2. Fire development stages in a room in the absence of an active suppression system 
The growth characteristics of the design fire influence the time of detection, as well as the time when conditions in the compartment of fire origin become untenable. The faster the fire is detected the earlier occupants will be notified of the fire and begin to evacuate the building; however, the time available for the occupants to evacuate safely will depend on the time when untenable conditions are reached in the compartments and the exit routes. The ability of the compartment barriers to withstand the fire attack and contain the fire, preventing it from spreading to other compartments in the building, depends on the intensity and duration of the fire.

A description of the design fire and its components and the impact of each on the fire safety system is given by Thomas and Bennetts ${ }^{9}$. They discussed the different parts of the design fire (growth, fully-developed, and decay) that govern the behaviour and response of different components of the fire safety system. The rate of fire growth governs the time for the fire to be noticeable, for detectors to trigger alarms, and other fire safety components to be engaged (sprinklers to activate, etc.). The strength of the ignition source, and the form and type of the fuel initially ignited are the main factors that govern fire growth. The maximum HRR and the duration of the fire, particularly the duration of the fully-developed fire, govern the response and the possible failure of different structural elements.

Fire engineering designs are often based on a standard temperature-time exposure or on tsquared fires. Standard fire exposures (temperature-time relationships) are used for determining the fire resistance rating of building components. These curves are described by the American Society for Testing and Materials (ASTM E119-05) ${ }^{10}$, Underwriters' Laboratories of Canada (CAN/ULC S101) ${ }^{11}$, and ISO 834-1 ${ }^{12}$. 
In ASTM E119-05 and CAN/ULC S101, the temperature at any time during the course of a fire can be approximated as:

$$
T_{f}=20+750[1-\exp (-3.79553 \sqrt{t})]+170.41 \sqrt{t}
$$

Equation 1

Where, $T_{f}=$ fire temperature $\left({ }^{\circ} \mathrm{C}\right)$ at time $t$, and $t=$ time (hours).

In ISO 834 , the temperature course during the fire is prescribed as :

$T_{f}=T_{\circ}+345 \log _{10}(480 t+1)$

Where, $T_{f}=$ fire temperature $\left({ }^{\circ} \mathrm{C}\right)$ at time $t, T_{\circ}=$ ambient temperature $\left({ }^{\circ} \mathrm{C}\right)$, and $t=$ duration of fire exposure (hours).

The t-squared fires are widely used to characterize the growth rate of design fires. In tsquared fires, the heat release rate is calculated as a function of the square of time after ignition. Equation 3 shows the HRR as a function of a parameter $\alpha$, and time $t$. The parameter $\alpha$ expresses different fire growth rates for different fires, while $t-t_{i}$ is the elapsed time after ignition $\left(\right.$ Heskestad $\left.^{13}\right)$.

$H R R=\alpha\left(t-t_{i}\right)^{2}$ Equation 3

Where, $\mathrm{HRR}=$ heat release rate $(\mathrm{kW}), t=$ time of concern(s), $t_{i}=$ time of ignition, and $\alpha=$ parameter to express ultra-fast-, fast-, medium-, and slow-growth fires. Table 1 shows examples of different fire growth rates and their related $\alpha$. 
Table 1. Parameters used for $t$-squared fires ${ }^{14}$

\begin{tabular}{llc}
\hline Description & \multicolumn{1}{c}{ Typical fuels } & $\alpha\left(\mathrm{kW} / \mathrm{s}^{2}\right)$ \\
\hline Slow & Densely-packed paper products & 0.00293 \\
Medium & $\begin{array}{l}\text { Traditional mattress/boxspring } \\
\text { Traditional armchair }\end{array}$ & 0.01172 \\
Fast & $\begin{array}{l}\text { PU mattress (horizontal) } \\
\text { Ultra-fast }\end{array}$ & $\begin{array}{l}\text { PE pallets, stacked 1-m high } \\
\text { High rack storage }\end{array}$ \\
& PE rigid foam stacked 5-m high & 0.0469 \\
\hline
\end{tabular}

In a project at the University of Canterbury aimed at developing design fires for apartment buildings and to standardize design fires for use in a performance-based fire engineering design, Yung et al. ${ }^{15}$ mentioned that $\mathrm{t}$-squared fires, with an $\alpha$ coefficient that varies with the burning material, are the simplest and most widely used type of design fires. However, t-squared fires do not take into account environmental conditions such as fuel load, ventilation conditions, radiative feedback, and compartment size. Also, t-squared fires do not give an idea about the fire risk impact on occupants away from the fire, such as temperatures and outflow of toxic gases within the building and to the outside. The paper also discusses how deterministic and random parameters can be included in design fires. Deterministic parameters are parameters determined during the design process, such as ventilation conditions, radiative feedback, and compartment size. Random parameters include ignition source, ignition location, and arrangement of fuel load.

The aim of the University of Canterbury project was to generate a set of inputs for design fires for apartment buildings. Those inputs include: (1) proper fire scenario; 
(2) probability of the fire to occur; (3) fire load density $\left(\mathrm{MJ} / \mathrm{m}^{2}\right)$; (4) fire growth rate (ultra-fast, fast, medium, and slow); (5) HRR; and (6) species yields ( $\mathrm{CO}, \mathrm{CO}_{2}$, etc).

Thomas and Bennetts ${ }^{9}$ discussed statistics for office fires in the USA. The statistics suggested that there was a significant proportion of casualties that happened in fires where flames do not spread widely, and such circumstances should be accounted for when considering design fires. USA office fire statistics records for personnel casualties and fire costs suggested that a design fire should also include spread beyond the area of fire origin, beyond the room of fire origin, and even beyond the structure of origin. Spread throughout the building should be considered even with sprinklers installed in the building. Sprinklers, detectors, and protected structures show high effectiveness in confining the fire within the room or building of origin, but do not completely eliminate all fires.

\subsubsection{Summary of Design Fires}

From the previous discussions of efforts towards characterizing fire scenarios and design fires, the following can be concluded:

A risk ranking process is recommended as the most appropriate basis for the selection of design fire scenarios. It is important to identify important design fire scenarios and to eliminate scenarios that are of low consequence or have a very low probability of occurrence from further consideration. At least one fire scenario should be considered for structural hazards and one for life safety hazards.

It is important to develop design fires for different occupancies to be used in a performance-based fire engineering design to ensure that fire safety engineers use 
accepted fire characteristics for their fire safety analysis. A design fire should describe the course of a particular fire with respect to time and space. It also must include the interaction of this fire with the building occupants and the interaction with the features and fire safety systems within the building. Design fires are usually characterized in terms of the following variables with respect to time: heat release rate, production rates of toxic species, and time to key events such as flashover.

Although t-squared fires do not take into account environmental conditions, such as fuel load, ventilation conditions, radiative feedback, and compartment size, and they do not give an idea about the risk impact on occupants away from fire, t-squared design fires provide a simplified method to input fire growth for a fuel package into a numerical model and they are used extensively in the design of fire safety systems. The other factors noted above are consistent using computer modelling.

The first step in the process of defining and characterizing design fires for a building is the characterization of the combustibles in that building. This can be done through statistical data from literature and from surveys of buildings to collect data that includes fire load, type and arrangement of combustibles, size of compartments, and ventilation characteristics.

\subsection{Fire Loads and Fire Load Surveys}

Fire load density is defined as the heat energy that could be released per square meter of floor area of a compartment by the complete combustion of the contents of the compartment and any combustible part of the building itself (Kumar and Rao) ${ }^{16}$. The higher the value of the fire load density, the greater the potential fire severity and 
damage, as the duration of the burning period of the fire is considered proportional to the fire load (Yung et al. $)^{15}$.

Fire load includes both fixed and moveable combustible items within the compartment of fire origin, and it is usually distributed randomly around the fire compartment (Buchanan) ${ }^{17}$. The types of combustibles contributing to the fire load determine ignition characteristics (smouldering or flaming) and the development of the fire (slow or fast). The total fire load in a compartment together with ventilation conditions determines the fire duration. The design fire load for an enclosure is often a value chosen between the 80th and 95th percentile of the fire load, which is not likely to be exceeded during the life of a building.

At the design stage, fire load is the starting point for estimating the potential size and severity of a fire, and thus the endurance required for walls, columns, doors, floor-ceiling assemblies, and other parts of the enclosing compartment (Yung et al. $)^{15}$.

The total fire load in a compartment can be computed using the following equation:

$$
Q=\sum k_{i} m_{i} h_{c_{i}}
$$

Equation 4

Where, $Q=$ total fire load in a compartment $(\mathrm{MJ}), k_{i}=$ proportion of content or building component $i$ that can burn, $m_{i}=$ mass of item $i(\mathrm{~kg})$, and $h_{c_{i}}=$ calorific value of item $i$ $(\mathrm{MJ} / \mathrm{kg})$. 
The fire load in a compartment is most often expressed as fire load energy density (FLED) or fire load density (FLD), that is, the total fire load per square meter of the floor area, $Q^{\prime \prime}\left(\mathrm{MJ} / \mathrm{m}^{2}\right)$, given by:

$$
Q^{\prime \prime}=Q / A_{f}
$$

Equation 5

Where, $A_{f}=$ floor area of the fire compartment $\left(\mathrm{m}^{2}\right)$.

Many European references express fire load as the energy density per square meter of the internal surface boundaries of a compartment. Petterson ${ }^{18}$ defined fire load per unit area of the total internal surface area of the fire compartment $\left(q^{\prime \prime}\right)$ in terms of the relationship:

$$
q^{\prime \prime}=\frac{\sum m_{i} h_{c_{i}}}{A_{t}}
$$

Equation 6

Where, $m_{i}=$ total weight of each single combustible item in the fire compartment $(\mathrm{kg})$, $h_{c_{i}}=$ calorific value of each combustible item $(\mathrm{MJ} / \mathrm{kg})$, and $A_{t}=$ total internal surface area of the fire compartment $\left(\mathrm{m}^{2}\right)$.

The total internal surface area and the floor area can be converted from one to the other by using the following equation:

$$
\begin{array}{ll}
A_{t}=2\left[A_{f}+H(L+W)\right] & \text { Equation 7 }
\end{array}
$$

Where, $A_{t}=$ total internal surface area $\left(\mathrm{m}^{2}\right), A_{f}=$ floor area $\left(\mathrm{m}^{2}\right), H=$ height of the fire compartment (m), $L=$ length of the fire compartment (m), and $W=$ width of the fire compartment (m). 
To be consistent with the definition of the fire load density used in North America, in the current work, the fire load density is expressed in terms of the floor area of the compartment. Calorific values for some of the combustibles that are usually present in stores can be found in references (e.g., Yii ${ }^{19}$; Thomas $^{20}$ ).

\subsubsection{Fixed Fire Loads}

This category consists of items such as built-in structural elements, floor coverings, cupboards, bookshelves, doors and frames, and windowsills. Other fixed items such as skirting boards and wall switches are ignored because they provide a small contribution to the total heat release rate.

\subsubsection{Moveable Fire Loads}

This category covers much more diverse items, and includes items such as furniture, computers, televisions, books and papers, pictures, telephones, rubbish bins and personal effects. This category involves all the items that can easily be taken out or put into the fire compartment.

In practice, the fire load will vary with the occupancy, with the location in the building, and with time, however, it is possible to determine by means of fire load surveys the fire load density in various occupancies such as stores, hotels, offices, schools, and hospitals.

Inventory and weighing are two types of techniques that have been used in fire load surveys. In the inventory technique, the mass of an object is related to its physical characteristics. In this technique, dimensions of items are measured and their volume calculated. The mass of an item is calculated by multiplying the volume and density. The inventory technique is best for fixed fire loads when items are fixed to the 
compartment or too heavy to be lifted and weighed. Fire load of moveable items that are easy to be lifted and weighed, such as furniture, computers, televisions, books and papers can be accounted for using the weighing technique.

\subsubsection{Assumptions Made to Estimate Fire Loads}

To simplify the fire loads estimation; surveys conducted in the past have made the following assumptions (Narayanan ${ }^{21}$ ): (1) combustible materials are uniformly distributed throughout the building; (2) all combustible material in the compartment would be involved in a fire; and (3) all combustible material in the fire compartment would undergo total combustion during a fire. These assumptions were also used for the survey performed in this work.

In surveys conducted by Barnett ${ }^{22}$, the fire load densities were first calculated as energy density in $\mathrm{MJ} / \mathrm{m}^{2}$, and then converted to mass density in $\mathrm{kg} / \mathrm{m}^{2}$ as wood equivalents, using the gross calorific value of wood as $20 \mathrm{MJ} / \mathrm{kg}$. As the author states, this calorific value might be too high, as it relates to "oven dry" wood. A more appropriate value might be $15 \mathrm{MJ} / \mathrm{kg}$, related to wood as normally found in buildings. Therefore, in order to be fully consistent, when one weighs wood at normal moisture content in a fire load survey, it should be converted to a weight of "oven dry" wood equivalents by multiplying by $15 / 20$, or 0.75 .

Bush et al. ${ }^{23}$ stated that in the US cities, fuel load estimations have been developed and presented for three primary urban land-use classes: residential, commercial/service, and industrial, where the latter two classes were categorized as non-residential. Residential building fuel load densities vary regionally from 123 to $150 \mathrm{~kg} / \mathrm{m}^{2}$, whereas for non- 
residential building classes, fuel load densities vary from 39 to $273 \mathrm{~kg} / \mathrm{m}^{2}$. Values of fuel loads reported from their study are very high compared to other studies; however, for residential areas this may be expected because wood is the main structural element and the fuel load from wood is included in the total fuel load.

Kumar and Rao ${ }^{24}$ conducted a survey in Kanpur, India, 1991-1992. 66 housing units (413 rooms) in 35 residential buildings with total floor area of $4256.6 \mathrm{~m}^{2}$ were surveyed. The houses had $1,2,3,4$, or more bedrooms. The survey data were collected using the inventory technique. Findings from the survey showed that, the larger the house occupied by one family, the smaller the mean and standard deviation of fire load density. Store rooms had the greatest fire load, with minimum, maximum, mean, and standard deviation values of $235,2175,852,622 \mathrm{MJ} / \mathrm{m}^{2}$, respectively. Kitchens had minimum, maximum, mean, and standard deviation values of $164,1557,673,207 \mathrm{MJ} / \mathrm{m}^{2}$, respectively. Bathrooms and balconies had the lowest fire loads. The frequency of distribution is positively skewed, indicating that, on the whole, high values of fire load were less prevalent.

An increase in the number of rooms occupied by one family caused the mean fire loads of living rooms, bedrooms, and kitchens to decrease and the fire loads of store rooms to increase. The mean fire load density of dining rooms did not show any significant variation with the size of the house. With variation in house size, the standard deviations of fire load density in bedrooms, kitchens, and storerooms increased while those of drawing rooms and dining rooms showed no particular trend. 
A study conducted in Kanpur, India to examine the effect of room use and room floor area in office buildings by Kumar and $\mathrm{Rao}^{16}$ showed that the average fire load density and standard deviation for all rooms were 348 and $262 \mathrm{MJ} / \mathrm{m}^{2}$, respectively. The maximum fire load density and mean fire load density $\left(\mathrm{MJ} / \mathrm{m}^{2}\right)$ for different occupancies were as follows: (1) storage and filing 1860,601 ; (2) clerical 1760,432 ; (3) reception 1540,537 ; (4) technical 1240, 434; and (4) conference $317,189\left(\mathrm{MJ} / \mathrm{m}^{2}\right)$. Surprisingly, lavatories were high in fire load density; the maximum and mean fire load densities were 762 and $146 \mathrm{MJ} / \mathrm{m}^{2}$, respectively.

The analysis showed that the maximum fire load density and the standard deviation decreased with an increase in floor area of the room. This observation was made for different types of usages, such as reception areas, storage and filing areas, technical areas, conference areas, and lavatories. Clerical areas, general areas, and corridors did not follow the same trend. The authors concluded that there was no correlation between fire load and floor level. This was applicable for ground, first, and second floor; however, the maximum fire load for the third floor was half that of the other floors. Wood and paper contributed up to $98.7 \%$ of fire loads in office buildings. In office buildings, fixed combustibles contributed $11.7 \%$ of the total fire load, while the remaining $88.3 \%$ was from moveable contents.

In a fire load survey by $\mathrm{Chow}^{25}$ for fifteen Chinese "Yam Cha" restaurants of different sizes, it was found that fire loads are quite high, as large amounts of combustible materials such as furniture, partitions, carpets, and tablecloths were present, and most furnishing materials used in dining halls consisted of synthetic materials. The fire load density in these restaurants, excluding toilets and storage, varied from 75 to $867 \mathrm{MJ} / \mathrm{m}^{2}$. 26 
In the dining hall itself, it varied from 69 to $1055 \mathrm{MJ} / \mathrm{m}^{2}$, whereas in the kitchen, the fire load density varied from 111 to $303 \mathrm{MJ} / \mathrm{m}^{2}$. The mean fire load density of Yam Cha Chinese restaurants in Hong Kong was $284 \mathrm{MJ} / \mathrm{m}^{2}$ for the entire restaurant, $312 \mathrm{MJ} / \mathrm{m}^{2}$ in the dining hall, and $216 \mathrm{MJ} / \mathrm{m}^{2}$ in the kitchen, Table 2.

The data from the survey also showed that the smallest restaurant had the largest fire load density; however, the largest restaurant did not have the smallest fire load density. An overall trend for the fire load density was to decrease with the increase of restaurant floor area. The percentage of moveable fire load to the total load was less for larger restaurants, and this was found to be applicable for both the entire restaurant and the dining hall. The percentage of moveable to total fire load for the kitchen was almost constant at $95 \%$.

Table 2. Fire load density in Chinese restaurants (Chow $)^{25}$

\begin{tabular}{ccc}
\hline & \multicolumn{2}{c}{ Fire load density $\left(\mathrm{MJ} / \mathrm{m}^{2}\right)$} \\
\cline { 2 - 3 } & Range & Mean \\
\cline { 2 - 3 } Yam Cha Restaurants & $75-867$ & 284 \\
Dining hall & $69-1055$ & 312 \\
Kitchen & $111-303$ & 216 \\
\hline
\end{tabular}

\subsubsection{Summary of Fire Load Surveys}

When conducting a fire load survey, different techniques can be used. The direct weighing technique can be used for items that are easy to weigh, such as toys and light furniture, while the inventory technique can be used for items that are difficult to weigh, such as heavy furniture and built-in shelves. In this method, dimensions are required to calculate the volume and then knowing the density, mass can be calculated. 
Fire load distribution is random in nature, time dependent and often depends on use of the building, living standards, cultural, and social aspects. To get accurate and realistic data for experiments, surveys and statistical analyses should be conducted in different countries. This is due to the increased awareness that a great variation in fire loads exists between various regions of the world, due to different cultures, climatic conditions, standards of living, and the nature of construction materials. Surveys should be conducted periodically as fire loads in buildings may vary from season to season and year to year. This is especially the case in commercial buildings where the fire loads during the holidays is much higher than the normal fire loads.

Surveys have shown that fire loads are dependent on occupancy and that the same occupancies show a tendency to have a lower fire load density with an increase in floor area of the compartment.

\subsection{Fire Statistics}

Data of fire incidents are collected and analyzed in many countries. These data provide valuable information to assist in the development and implementation of fire prevention and fire protection strategies. Fire statistics vary depending on the source. Factors that play an important role when looking into statistical data from different sources are: (1) statistics collection: developed vs developing communities; (2) cities vs suburbs; (3) methodology of collection; and (4) building age at the time of data collection (old vs new).

For apartment buildings, Table 3, from Yung et al. ${ }^{15}$ shows the probabilities of three fire types after ignition in three different countries. In the table, fire types are based upon the 
condition at the time when the fire fighters arrive at the scene, and observe and record the fire. The table suggests that fire scenarios used for engineering analysis should consider not only flashover fires, which have a low probability of occurrence following ignition has occurred, but also non-flashover fires, which have a high probability, even though they may individually have less impact on occupants, building and environment.

Table 3. Probabilities of fire types for apartment buildings ${ }^{15}$

\begin{tabular}{lccc}
\hline & Canada (\%) & USA (\%) & Australia (\%) \\
\hline Smouldering fire & 19.1 & 18.7 & 24.5 \\
Non-flashover fire & 62.6 & 63.0 & 60.0 \\
Flashover fire & 18.3 & 18.3 & 15.5 \\
\hline
\end{tabular}

As reported by Thomas and Bennetts ${ }^{9}$, in the USA, statistics have been collected for about 25,244 office fires that occurred between 1983 and 1991 as summarized in Table 4 and Table 5. Table 4 shows that the wider the spread of flame damage, the greater the rate of fire fighter injuries and civilian fatalities. The average dollar loss per fire rises rapidly as the extent of flame damage increases, which can be seen from Table 5. The categories for the extent of flame damage as per the National Fire Incident Reporting System (NFIRS) database are as follows:

EFD 1 Confined to the object of origin

EFD 2 Confined to the part of the room or area of origin

EFD 3 Confined to the room of origin

EFD 4 Confined to the fire-rated compartment of origin

EFD 5 Confined to the floor of origin

EFD 6 Confined to the structure (building) of origin

EFD 7 Extended beyond structure of origin 
Table 4. Number of fires and casualties for fires in USA office buildings, 1983-1991 ${ }^{9}$

\begin{tabular}{|c|c|c|c|c|c|c|c|c|c|c|}
\hline 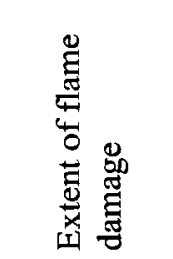 & 总 & 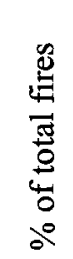 & 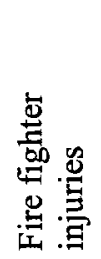 & 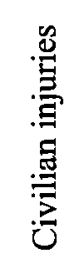 & 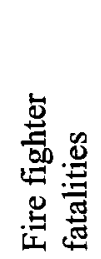 & 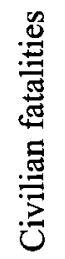 & 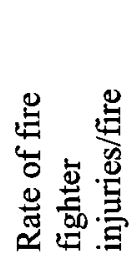 & 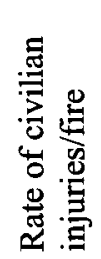 & 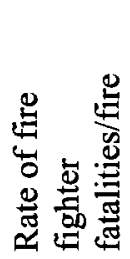 & 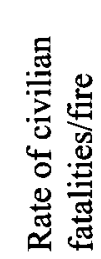 \\
\hline EFD 1 & 12,895 & 51 & 79 & 170 & 0 & 1 & 0.006 & 0.013 & 0.0000 & 0.0001 \\
\hline EFD 2 & 3,900 & 15 & 118 & 105 & 0 & 5 & 0.030 & 0.027 & 0.0000 & 0.0013 \\
\hline EFD 3 & 3,939 & 16 & 124 & 99 & 0 & 4 & 0.032 & 0.025 & 0.0000 & 0.0010 \\
\hline EFD 4 & 203 & 1 & 21 & 10 & 0 & 0 & 0.103 & 0.049 & 0.0000 & 0.0000 \\
\hline EFD 5 & 870 & 3 & 164 & 39 & 0 & 3 & 0.189 & 0.045 & 0.0000 & 0.0034 \\
\hline EFD 6 & 2,871 & 11 & 693 & 75 & 1 & 14 & 0.241 & 0.026 & 0.0003 & 0.0049 \\
\hline EFD 7 & 566 & 2 & 154 & 14 & 0 & 3 & 0.272 & 0.025 & 0.0000 & 0.0053 \\
\hline Unknown $^{1}$ & 2,435 & - & 64 & 27 & 0 & 1 & 0.026 & 0.011 & 0.0000 & 0.0004 \\
\hline Total & 25,244 & --- & 1417 & 539 & 1 & 31 & --- & --- & -- & --- \\
\hline
\end{tabular}

Table 5. Number of fires and dollar loss for fires in USA office buildings 1983-1991 ${ }^{9}$

\begin{tabular}{lccc}
\hline $\begin{array}{c}\text { Extent of flame } \\
\text { damage }\end{array}$ & Fires & $\begin{array}{c}\text { Total estimated } \\
\text { loss (\$US) }\end{array}$ & $\begin{array}{c}\text { Average estimated } \\
\text { loss per fire (\$US) }\end{array}$ \\
\hline EFD 1 & 12,895 & $23,368,908$ & 1,868 \\
EFD 2 & 3,900 & $22,607,274$ & 5,941 \\
EFD 3 & 3,939 & $56,331,521$ & 14,429 \\
EFD 4 & 203 & $9,086,469$ & 47,080 \\
EFD 5 & 870 & $82,888,804$ & 97,402 \\
EFD 6 & 2,871 & $401,702,383$ & 143,979 \\
EFD 7 & 566 & $62,095,312$ & 114,356 \\
Unknown & 2,435 & $18,739,819$ & 7,696 \\
\hline
\end{tabular}

Sprinklers, detectors, and protected structures are three effective elements that can reduce fire spread in a wide range of occupancies. Table 6 (Thomas and Bennetts ${ }^{9}$ ) shows the effect of each or the combination of two or three of the elements on the extent of flame damage beyond the room of fire origin. NNN means none of these elements existed in the building, YYY means all of them existed in the building. For example, YNN means sprinklers are installed but detectors and protected structures were not present. 
Table 6 shows that sprinklers have a major effect in containing fires. The presence of any fire protection element reduces the extent of flame spread.

Table 6. Percentage of fires with extent of flame damage beyond the room of fire origin in the USA ${ }^{9}$

\begin{tabular}{lllllllll}
\hline & \multicolumn{6}{c}{ Sprinklers, detectors, and protected structures (in order) } \\
\cline { 2 - 8 } Occupancy & NNN & NNY & NYN & NYY & YNN & YNY & YYN & YYY \\
\hline Apartments & 24.7 & 18.4 & 15.1 & 11.4 & 5.9 & 6.2 & 6.2 & 4.1 \\
Hotels/motels & 26.2 & 16.3 & 14.7 & 9.7 & 7.7 & 2.9 & 4.4 & 2.6 \\
Rooming/boarding & 35.9 & 27.6 & 17.8 & 16.9 & 10.0 & 12.5 & 4.8 & 5.2 \\
Offices & 31.2 & 19.7 & 17.1 & 9.6 & 9.9 & 5.3 & 7.5 & 3.5 \\
Retail & 29.8 & 21.4 & 19.8 & 12.0 & 6.9 & 5.4 & 6.6 & 4.1 \\
Education & 18.7 & 8.3 & 7.6 & 3.8 & 5.9 & 3.0 & 4.1 & 2.2 \\
Institutional & 16.0 & 5.5 & 7.3 & 2.8 & 2.8 & 2.0 & 1.5 & 1.5 \\
Public assembly & 28.6 & 19.7 & 16.2 & 9.8 & 8.0 & 6.2 & 6.1 & 3.9 \\
Factories & 27.4 & 18.8 & 16.0 & 9.6 & 10.0 & 8.4 & 8.2 & 6.6 \\
Warehouses & 61.5 & 45.8 & 39.0 & 28.4 & 17.6 & 16.8 & 12.3 & 10.4 \\
\hline
\end{tabular}

Fire incidents in retail premises were examined in a study on fire safety in shopping centres undertaken by Bennetts et al. ${ }^{26}$. The approach adopted in that project was to first determine the various fire scenarios that can occur in shopping centres and their probability of occurrence. The study tried to understand the behaviour of occupants in the buildings with respect to fire fighting and evacuation, and the role and impact of the fire service on each fire scenario. In addition, the project studied the impact of smoke, associated with the range of fire scenarios, on the occupants of the buildings taking into account smoke exhaust and venting, building geometry, occupant behaviour, and types and location of exits. Results from the project report are summarized in the following sections.

In the majority of situations, fires only developed to a significant size if the fire was initiated in an unpopulated area (e.g.,, storage area or ceiling space), or when the building 
was unoccupied. It appears that very few fires resulted in extensive fire spread in areas that were directly observable by the occupants.

A major mechanism for fire spread to other parts of a building appears to have been through the ceiling space, irrespective of whether there were combustibles in the ceiling space. There were many situations where the ceiling space was not sprinklered. In a few situations, combustible-ceiling tiles led to rapid fire spread across the enclosure leading to a serious fire safety scenario.

In some shopping centres, the decision to install sprinklers in a particular shop appeared to have been made by the owner of the shop or store. Thus, there were some shopping centres where certain shops were sprinklered but others were not. Although it was noted that in some circumstances fire was prevented from spreading into the sprinklered parts by the action of the sprinklers, in many cases, the shopping centre was totally destroyed. Significant water damage was experienced due to activation of the sprinklers.

Other cases were noted where the building was essentially sprinklered throughout but where combustibles or combustible construction within parts of the building (e.g., ceiling space construction or combustibles associated with verandas and awnings) allowed a significant fire to develop such that the sprinklers were overwhelmed and not able to adequately control the fire. Unfortunately, no information was given on the design delivery rate of sprinkler systems where this occurred.

In two cases, the sprinkler system had been shut off overnight and fire (which occurred at night) resulted in almost complete destruction of the buildings. One of these buildings incorporated a smoke detection system but this had also been shut off. 
It appears that fires that could be extinguished rapidly by the fire service tended to be small. For this to be the case, the fire service had to arrive and locate the fire in a short period of time, or the fire had to have been kept small due to the action of the occupants or the sprinkler system. In other cases where there were walls providing fire separation or partial sprinklering, the fire fighters were able to confine the fire to an area such as the shop of fire origin. Otherwise, for the cases reviewed, the extent of flame spread was very large and significant parts of the shopping centre were destroyed. Generally, the fires reported in the literature were larger fires, as these are more "newsworthy" than smaller fires that have been easily extinguished.

The report also covers a study of situations where deaths occurred (Bennetts et $a .^{26}$ ). The incidence of fire deaths in retail premises in Australia is very small, and it was assumed that the broad conclusions drawn from an analysis of the much larger USA database would be valid for Australian shopping centres. The following remarks relate to all fatal fires in retail premises recorded in the NFIRS database. There were 86 deaths in 77,996 retail fires over 10 years in the USA, giving a death rate of about 1.1 per thousand fires. This may be contrasted with a rate of deaths in residential buildings in Australia of 7.08 per thousand fires. The nature of these deaths in retail fires was assessed and about ten of the victims were asleep at the time of alarm, about twenty were likely to have been asleep, and about six more could have been asleep at that time.

Of the remainder, about seven victims appear likely to have been involved in incendiary fires, another seven in suspicious fires and in some cases possibly involved in starting the fires or possibly subjected to the attack themselves. Fires in or from cars might have resulted in a further two of the fatalities and that a further twelve of the victims were 
bedridden, too young, or too old to act. Sixteen of the victims might have been intimately involved in the ignition (but not in an incendiary or suspicious manner). Thus, in these retail buildings, well over one third of the fatalities might have been asleep at the time of ignition, a further one sixth "impaired" in some way (bedridden, too young, too old) resulting in over half of the victims likely to have been unable to respond to the fire. A further one third might have died as a result of having been intimately involved in the ignition (not necessarily in an incendiary or suspicious manner). Thus, over two thirds of the fatalities might have resulted from circumstances and involvement such that the behaviour, age, or condition of the person was a significant contributing factor in their death in the fire.

Bennetts et al. ${ }^{27}$ as part of the work by the Fire Code Reform Centre (FCRC) undertook a research project to investigate the fire safety of low-rise, sprinklered shopping centres. Outcomes from the project showed that all deaths appeared to result from smoke inhalation. The possible exception to this was in the case of several fire fighters who may have died due to exposure to radiation and flames. There was no case where structural failure of the building resulted in death.

A review of Australian fire statistics by Bennetts et al. ${ }^{27}$ show that the estimated property losses are about four times higher per fire for commercial buildings than for residential buildings. The losses estimated by the fire fighters were approximately AUD $\$ 13,700$ per fire for residential buildings and $\$ 54,100$ for commercial buildings. Also, it can be seen from these numbers that there are major differences in the rates of human casualties and property damage resulting from fires in the two categories, Table 7. 
Nearly six times as many civilians were killed per thousand fires in residential buildings than in commercial buildings, while the comparable rate for fire fighters was just less than three times. The figures are far closer for civilian injuries with about twice as many civilians injured per thousand fires in residential compared with commercial buildings, however, for fire fighters the ratio was reversed. About twice as many fire fighters were injured per thousand fires in commercial than in residential buildings.

Table 7. Review of Australian fire statistics (1989 to 1993) ${ }^{27}$

\begin{tabular}{|c|c|c|c|c|c|c|c|c|c|c|}
\hline Building & 总 & 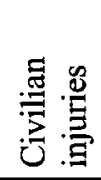 & 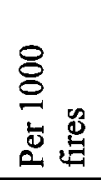 & 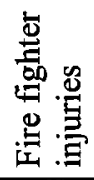 & 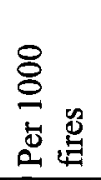 & 胥莺 & 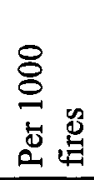 & 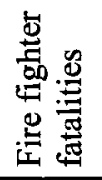 & 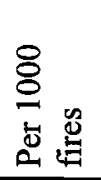 & $\frac{\infty}{\stackrel{\infty}{0}}$ \\
\hline Commercial & 24491 & 745 & 30.4 & 461 & 18.8 & 30 & 1.22 & 1 & 0.04 & 1325.3 \\
\hline Residential & 35303 & 2192 & 62.09 & 382 & 10.82 & 250 & 7.08 & 4 & 0.11 & 483.46 \\
\hline Unknown & 570 & 11 & 19.29 & 1 & 1.75 & 1 & 1.75 & 0 & 0.00 & 6.2327 \\
\hline
\end{tabular}

Bennetts $e t a l{ }^{27}$ also reported detailed information about 97 fires that occurred in retail buildings in the United States, Canada, Europe, Pakistan, Australia, and South Africa between 1967 and 1996. Storage areas, ceiling spaces, department stores, clothing racks, and restaurants were the high-frequency areas where fires started in retail buildings, Table 8 . 
Table 8. Area of fire origin in retail buildings (summarized from Bennetts et al. ${ }^{27}$ )

\begin{tabular}{lclc}
\hline Area of fire origin & Frequency & Area of fire origin & Frequency \\
\hline Storage area & 16 & Structural area & 2 \\
Area within building & 15 & Appliance store & 1 \\
Ceiling space & 11 & Cabinet in store & 1 \\
Department store & 6 & Chemist shop & 1 \\
Fast food outlet & 6 & Display area & 1 \\
Clothing racks & 4 & Electrical storeroom & 1 \\
Restaurant & 4 & Escalator & 1 \\
Unknown & 4 & Exhaust duct & 1 \\
Carpet area & 3 & Furniture store & 1 \\
Electrical sign & 3 & Greengrocer store & 1 \\
Beauty salon & 2 & Leather shop & 1 \\
External walkway & 2 & Loading area & 1 \\
Market area & 2 & Sports department & 1 \\
Picture framing area & 2 & Supermarket & 1 \\
Toy store & 2 & & 97 \\
\hline
\end{tabular}

Electrical and heating sources contributed to about $32 \%$ of the causes of fires in retail buildings, which is even higher than fires caused by arson, Table 9.

Table 9. Cause of fires in retail buildings (summarized from Bennetts et al. ${ }^{27}$ )

\begin{tabular}{lc}
\hline \multicolumn{1}{c}{ Cause of fire } & Percentage of the 97 fires (\%) \\
\hline Arson & 29 \\
Unknown & 29 \\
Electrical source & 27 \\
Heating source & 5 \\
Others & 4 \\
Spontaneous & 3 \\
Welding operations & 3 \\
\hline Total & 100 \\
\hline
\end{tabular}

Bennetts et $a l .^{27}$ described another 73 fires where fatalities occurred in retail buildings in the United States. Service and equipment areas, storage areas, sales and assembly areas, residential areas, and, "surprisingly", means of egress were the high frequency areas 
where fires started in retail buildings, Table 10. Incendiary, unknown, misuse of heat, mechanical and electrical faults were the highest causes of fire in retail buildings, Table 11.

Table 10. Area of fire origin in retail buildings, US (summarized from Bennetts $e t$ al. $^{27}$ )

\begin{tabular}{lc}
\hline \multicolumn{1}{c}{ Area of fire origin } & Frequency \\
\hline Service and equipment area & 19 \\
Storage area & 15 \\
Sales and assembly area & 14 \\
Means of egress & 8 \\
Residential area & 8 \\
Unknown & 4 \\
Ceiling space & 2 \\
Structural area & 2 \\
Vehicle, transport area & 1 \\
\hline Total & 73 \\
\hline
\end{tabular}

Table 11. Cause of fires in retail buildings (summarized from Bennetts $e t a l .{ }^{27}$ )

\begin{tabular}{lc}
\hline \multicolumn{1}{c}{ Cause of fire } & $\begin{array}{c}\text { Percentage of the } \\
73 \text { fires }(\%)\end{array}$ \\
\hline Incendiary & 22 \\
Unknown & 22 \\
Misuse of heat & 16 \\
Misuse of material & 14 \\
Mechanical failure/electric fault & 8 \\
Suspicious & 8 \\
Operational deficiency & 5 \\
Design/construction/installation deficiency & 3 \\
Mechanical failure & 1 \\
\hline Total & 100 \\
\hline
\end{tabular}

The study conducted by Bennetts et al. ${ }^{26}$ on fire safety in shopping centres included an extensive investigation of several major shopping centres in New South Wales and Victoria, particularly in regard to construction layouts, distribution of specialty shops, retail fire loads, operating, maintenance and management practices, statistics and fire incident experience. Construction of shopping centres provided a prime opportunity for 37 
investigation of cost-effective designs, as they are normally relatively-low-rise premises spread over large ground areas, as distinct from the traditional regulatory assumption that buildings are high-rise over limited ground areas.

An extensive program of full-scale, real-fire experimental tests was undertaken to examine fire behaviour patterns and sprinkler performances in typical retail environments. The following are some of the project findings:

Available statistical evidence verifies that shopping centres are not an unduly significant risk to life for occupants, and that if shopping centre occupants remain awake they are very unlikely to perish as a result of fire. Recorded USA data indicates that the death rate for shopping centre premises is one tenth of that of residential buildings, even without taking into account the beneficial effect of sprinklers. Sprinklers can play a vital role in restricting the spread of fire. Based on the available USA statistics, it is indicated that if sprinklers were present the recorded death rate for (the unsprinklered) shopping centre premises would be reduced by a factor of three. By virtue of their observations and reactions, occupants in shopping centres (visitors, tenants and staff) play a major role in controlling any outbreak and spread of fires. Improvements in the design of valving and monitoring of sprinkler systems would provide better protection during the frequent system "shut-down" periods that seem to be necessary in shopping centres.

The reliabilities (activated vs not activated) of a sprinkler system in these buildings are dependent on how it is managed. The system must be soundly managed in order to minimize the times during which the sprinkler zones are isolated. If this is the case, and the sprinklers are designed to be commensurate with the hazard, then the average 
effectiveness can be taken as $98.5 \%$ for sprinkler zones associated with specialty shops and $99.5 \%$ for sprinkler zones associated with major stores. This compares with an average effectiveness of $86 \%$ associated with retail buildings in the USA. Thus, buildings in Australia with well-managed sprinkler systems would be expected to offer a higher level of fire safety.

The presence of a soundly managed sprinkler system means that the probability of having a fire that goes beyond the area of fire origin, and is not controlled by the sprinklers, is extremely small. In considering the impact of fires in these buildings, it was concluded that the primary design fires for these buildings should be sprinklered fires.

Observations made during past emergencies in shopping centres indicate that the tunnels and passages provided for egress of occupants (at very significant cost) are not favoured and tend to be avoided. A much better alternative is to design the premises so that the normal entrances and exits can be used for emergency evacuation.

More fires occur during normal operating hours due to the greater demand for electricity, heating systems, cooking equipment, and the use of appliances. Nevertheless, the majority of these fires are detected by the occupants and extinguished before they extend beyond the area of fire origin. These are small fires to which the fire service may or may not be called. The occupants, therefore, have a major impact on controlling fires in these buildings.

In the L'Innovation fire in Brussels, Belgium (1967) as reported by Bennetts et al. ${ }^{26}, 400$ civilian deaths and many injuries occurred mostly from smoke inhalation. The fire appeared to have started in a clothing area on the second storey, and spread very rapidly. 
Many people died from smoke inhalation during the evacuation process, or during the search for the exits while the exit signs were blocked by smoke.

In the Dusseldorf Airport fire in Dusseldorf, Germany (1996) as reported by Bennetts et $a l^{26}, 8$ people died in a VIP lounge when the single exit from the lounge was blocked by smoke. Other people died when an elevator arrived at an area that was saturated with smoke and the elevator doors would not close due to the interference of smoke with the infrared door sensors. All 16 people in the elevator died from smoke inhalation.

\subsubsection{Summary of Fire Statistics}

Available statistical evidence verifies that shopping centres do not pose an unduly significant risk to life for occupants. Recorded USA data indicates that the death rate for shopping centre premises is one tenth of that of residential buildings, even without taking into account the beneficial effect of sprinklers.

Statistics suggest that it is important to take into account not only flashover fires, which have low probability of occurrence, but also non-flashover fires, which have high probability of occurrence, even though they have less impact on occupants, building and environment.

Sprinklers, detectors, and protected structures (in that order) are the effective systems to confine the fire within the room of fire origin. It is not an effective practice to install partial sprinklers in a shopping centre, as this system can be overcome by a fire that starts in the non-sprinklered areas. 
Storage areas, ceiling spaces, department stores, clothing racks, and restaurants were the high-frequency areas where fires started in retail buildings. Electrical and heating sources contributed to about $32 \%$ of the causes of fires in retail buildings, which is even higher than fires caused by arson.

\subsection{Fire Experiments}

\subsubsection{Introduction}

The following sections explain some of the common terms used in the literature addressing fire experiments undertaken to identify various fire characteristics.

Mass loss rate is defined as the mass of fuel consumed per unit time. At flashover, the mass loss rate increases dramatically due to the ignition of all the combustible materials. The mass loss rate becomes constant after flashover until parts of the material have burned away $\left(\mathrm{Yin}^{19}\right)$.

When a fire burns in an enclosure, one of two scenarios can arise. The first scenario occurs when there is limited fuel inside the compartment, which constrains the fully developed fire stage to what is called a fuel-controlled fire. The second scenario happens when there is enough fuel to keep up the combustion process, but not enough oxygen enters the fire compartment to support combustion of the entire fire load; in this scenario, the fire becomes ventilation-controlled.

Mass loss rate for wood materials in ventilation-controlled burning in an enclosure depends on the size of the openings of that enclosure. A good estimation of the mass loss rate can be identified using the formula based on Kawagoe and Sekine ${ }^{28}$, Kawagoe ${ }^{29}$ (Equation 8), and Thomas ${ }^{30}$ (Equation 9). 
$R=0.092 A_{v} \sqrt{H_{v}}(\mathrm{~kg} / \mathrm{s}), R=5.5 A_{v} \sqrt{H_{v}}(\mathrm{~kg} / \mathrm{min})$

Equation 8

$R=6 A_{v} \sqrt{H_{v}} \quad(\mathrm{~kg} / \mathrm{min})$

Equation 9

Where, $H_{v}=$ height of the opening $(\mathrm{m})$, and $A_{v}=$ area of the opening $\left(\mathrm{m}^{2}\right)$.

According to Kawagoe and Sekine ${ }^{28}$, and Thomas ${ }^{30}$, the mass loss rate is proportional to the product of the square root of opening height, $\sqrt{H_{v}}$, and area of opening, $A_{v}$. However, present studies show that these assumptions for deriving the mass loss rate are not satisfactory. By calculating the mass loss rate of wood materials in proportion to the product of $\sqrt{H_{v}}$ and $A_{v}$, it is found that this method is a gross approximation, and even under closely-controlled experimental conditions, the value of the mass loss rate could vary by $\pm 10 \%\left(\mathrm{Yii}^{19}\right)$.

Heat release rate can also be calculated knowing the burning rate of the fuel and its heat of combustion, $H_{c}$, which is also known as the calorific value or the amount of energy released during complete burning of unit mass of fuel. The typical range of net calorific value of cellulosic materials is found to be 17 to $20 \mathrm{MJ} / \mathrm{kg}\left(\right.$ Barnett $\left.^{22}\right)$. The net calorific value for some materials that contain some moisture under ambient conditions, especially wood, can be calculated by the following formula (Buchanan ${ }^{31}$ ):

$\Delta H_{c}=\Delta H_{c, d}\left(1-0.001 m_{c}\right)-0.025 m_{c}$ Equation 10

Where, $\Delta H_{c, d}=$ heat of combustion of oven dry wood $(\mathrm{MJ} / \mathrm{kg})$, and $m_{c}=$ moisture content as a percentage by weight given by: 
$m_{c}=\left(100 \times m_{d}\right) /\left(100+m_{d}\right)$

Equation 11

Where, $m_{d}=$ moisture content as a percentage of the dry weight, as usually used for wood products

The rate at which a burning item releases heat is a critical parameter in fire protection engineering. Heat release rate can provide information on fire size and fire growth rate and hence can be used in the characterization of the hazard represented by a given fuel package. When used as input to a computer fire model, the heat release rate can be used to estimate the conditions in the compartment and the available egress time and to determine detection or suppression system activation time.

Heat release rate is the product of mass loss rate and heat of combustion, and since mass loss rate could be ventilation-controlled, the corresponding ventilation-controlled heat release rate, $Q_{\text {vent }}(\mathrm{MW})$ (ventilation limit), can be calculated by Equation 12 $\left(\right.$ Buchanan $\left.^{32}\right)$.

$Q_{\text {vent }}=R h_{c_{i}}$ Equation 12

Where, $h_{c_{i}}=$ calorific value of the fuel $(\mathrm{MJ} / \mathrm{kg})$, and $R=$ mass loss rate of the fuel $(\mathrm{kg} / \mathrm{s})$ (Kawagoe and Sekine ${ }^{28}$, Kawagoe ${ }^{29}$ (Equation 8), and Thomas ${ }^{30}$ (Equation 9))

\subsubsection{Discussion on Fire Experiments Reported in the Literature}

Three fire tests were conducted by Stroup et al. ${ }^{33}$ to characterize the potential hazards from ignition of men suits hanging on racks. Suits on a suit rack 1.8-m long were placed in the open under a large calorimeter. The rack was loaded with plastic hangers with metal hooks, and twenty-four suits (polyester and wool blend). The HRR was 
determined as a function of time after ignition using the oxygen depletion principle as described by Janssens ${ }^{34}$. In addition, the total heat flux from the burning suits and the mass loss were measured. The main hood had a 4 × 5-m area and sloped upward to a $1.2 \mathrm{~m}^{2}$ duct; heat flux gauges were placed $0.9 \mathrm{~m}$ above the floor and $0.9 \mathrm{~m}$ from the outer edges of the suits, and readings were taken every second. Temperatures were measured at the entrance to the exhaust hood immediately above the centre of the burning clothes (5.5 m high). Background data were recorded for $60 \mathrm{~s}$ before a propane torch was applied to the sleeve of a suit. The flow of propane was adjusted to provide a $25 \mathrm{~mm}$ long flame that was held in contact with the suit for $10 \mathrm{~s}$. The three tests were identical, except that in the first and second tests the propane torch was applied to the sleeve of a suit located in the centre of the rack facing the heat flux gauge, and in the third test the ignition location was at the end of the rack facing the heat flux gauge.

In all three tests, a heat release rate of approximately $1 \mathrm{MW}$ was sustained for about 5 minutes. The peak heat release rate for the first and third tests was about $1 \mathrm{MW}$, while the second test peaked briefly at $2 \mathrm{MW}$. During most of the tests, the temperature above the burning clothes was $150^{\circ} \mathrm{C}$. The temperature spiked briefly to $200^{\circ} \mathrm{C}$ during the early portion of the second test. The initial mass of suits and racks was $55.8,57.1$, and $57.6 \mathrm{~kg}$, for the first, second, and third tests, respectively. The final mass at the end was 46.7, 48.0 , and 49.0 , respectively.

Bennetts et al..$^{35}$ reported the results of 11 fire tests designed to study the efficiency of the requirements of the Building Code of Australia (BCA), which apply to low-rise sprinklered shopping centres, and identified the characteristics of the design fires that are likely or appropriate. The study provided data on the quantity and rate of smoke 44 
production, and on the impact of sprinklers on the air temperature close to the fire and within the hot smoke layer. However, their experiments were conducted in a large burn hall and HRR was not measured. The test program consisted of eleven full-scale fire tests as follows: (1) two tests, simulating fire in a toyshop were performed: one sprinklered and the other unsprinklered; (2) two tests, simulating fire in a storage area of a shoe retail shop, were also conducted: one sprinklered and the other unsprinklered. The above four tests were chosen to represent the worst scenarios, since they involved substantially non-cellulosic material stored in a shelved arrangement. Non-cellulosic fires grow more rapidly than fires with cellulosic fuels and the application of water to the seat of the fire may be difficult. Another five tests were conducted to simulate sprinklered clothing stores. These are challenging scenarios in terms of smoke generation and smoke production rate. Clothing and the like (textiles) constitute a high proportion of the floor area of modern shopping centres. Two tests, simulating a sprinklered bookshop fire, were done to study the amount of smoke developed in fires of predominantly cellulosic combustibles. The observations from the tests are summarized below:

Two toy store tests, sprinklered and unsprinklered, were conducted. The sprinklered test was described as a severe fire in terms of smoke produced from burning plastics arranged in high shelving, and sprinklers were not able to suppress the fire or to get to the seat of the fire. The unsprinklered test was described as a severe fire in terms of the heat release rate and rate of smoke production, that resulted in higher smoke temperature than the sprinklered test. 
In the sprinklered and unsprinklered shoe retail shop storage test, it took considerable time for the fire to develop due to the relatively compact nature of the combustibles. It is not reported clearly in this test if the sprinklers were able to control the fire; however, the paper (Bennetts et al. ${ }^{35}$ ) stated that the sprinklers' best position would be between the racks.

In five sprinklered clothing stores tests, fires burned vigorously, but once the sprinklers activated, the fires were rapidly controlled and reduced in intensity; however, fire redeveloped after the sprinklers were turned off.

In two sprinklered bookstore tests, it took considerable time for the fire to develop. Once the sprinklers activated, the fire was rapidly controlled and it did not re-ignite after the sprinklers were turned off. Smoke was whiter than in the clothing store tests.

The combination of non-cellulosic combustibles in racks with active sprinkler heads remote from the ignition locations was found to give rise to substantial volumes of black smoke, but still less smoke than that of unsprinklered fires. The volume of smoke generated by a sprinklered fire is more dependent on the level of shielding against the sprinklers' spray pattern, more than the type of sprinkler head.

A study of the effect of surface area and thickness of combustibles on fire dynamics was carried out by Yii ${ }^{19}$. The study investigated the impact of the exposed surface area of the fuel items on the rate and duration of burning, especially during post-flashover fires. 
The study showed that the larger the exposure of the fuel surface area to the fire, the higher the heat release rate, unless the area is so large that the fire becomes ventilationcontrolled, and the thicker the fuel the longer the duration of burning.

Another set of experiments was undertaken to test bookshelves by Law and Arnault ${ }^{36}$, where books and papers on shelves were assumed to have the same burning characteristics as wood. It was found that the peak heat release rate increased as the percentage of contents of the bookshelf decreased. This was because more surface area of books and shelves was exposed to the fire. It was found that the burning duration depends upon the combustible contents, $100 \%$ full shelves were always the last to burn out. It was also found that there is a large drop in the heat release rate after approximately 18 minutes of exposure when the bookshelves were $75 \%, 50 \%$, and $25 \%$ full. This is due to the thinner part of shelves exposed to fire burning out more quickly. The lower heat release rate after the drop represented the burning of the thicker parts of the shelves, which takes more time to burn out. The tests showed that, as the contents of the bookshelves decreased, the duration of burning decreased as well.

Chow et al. ${ }^{6}$ discussed the necessity of carrying out full-scale tests for post-flashover retail shop fires. They stated that for assessing the consequences of a fire, the expected heat release rate should be studied experimentally, even though this is expensive.

Janssens ${ }^{34}$ described the theory of how to measure the rate at which heat is released by measuring the oxygen consumption. In 1917, the theory was developed by Thornton ${ }^{37}$ who showed that for a large number of organic liquids and gases, a more or less constant net amount of heat is released per unit mass of oxygen consumed for complete 
combustion. Huggett ${ }^{38}$ found this to be true also for organic solids, and obtained an average value of $13.1 \mathrm{MJ} / \mathrm{kg}$ of $\mathrm{O}_{2}$ for this constant. This value may be used for practical applications and is accurate with very few exceptions to within $\pm 5 \%\left(\right.$ Janssens $\left.^{34}\right)$.

For measuring the HRR, combustion products are collected and passed through an exhaust duct. At a distance downstream sufficient for adequate mixing, both flow rate and composition of gases are measured. As a minimum, $\mathrm{O}_{2}$ concentration must be measured. However, the accuracy can be improved by adding instrumentation for measuring the production rates of $\mathrm{CO}, \mathrm{CO}_{2}$, and $\mathrm{H}_{2} \mathrm{O}$. It should be emphasized that the analysis is approximate and the following list describes the main simplifying assumptions made by Janssens ${ }^{34}$ :

The amount of energy released by complete combustion per unit mass of oxygen consumed is taken as constant, and a generic average value of $13.1 \mathrm{MJ} / \mathrm{kg}$ of $\mathrm{O}_{2}$ was suggested by Huggett ${ }^{38}$. If the fuel composition is known, a more precise value may be assumed. All gases are considered to behave as ideal gases.

Incoming air consists of $\mathrm{O}_{2}, \mathrm{CO}_{2}, \mathrm{H}_{2} \mathrm{O}$, and $\mathrm{N}_{2}$. All "inert" gases, which do not take part in the combustion reactions, are lumped into the nitrogen component. $\mathrm{O}_{2}, \mathrm{CO}_{2}$, and $\mathrm{CO}$ are measured on a dry basis, i.e., water vapour is removed from the effluent before gas analysis measurements are made. Typical commercial analyzers for these gases cannot handle wet mixtures. Water vapour is removed by using a cooling unit and moisture sorbent; no other chemical sorbent should be used.

Janssens ${ }^{34}$ stated that in oxygen consumption-based calculations the mass flow rate, not the volumetric flow rate, should be used because volumetric flow rate requires 48 
specification of temperature and pressure that result in a great deal of confusion. In fires where considerable soot production is expected, pitot-static tubes cannot be used for velocity measurements because of clogging of the holes.

\subsubsection{Summary of Fire Experiments}

Fire severity is a function of the amount of combustibles in the room, size and geometry of the room, dimensions of the ventilation available, the emissivity of the flames in the room, and the thermal properties of the room surfaces. In fire experiments, heat release rate, gas temperatures and production rates, and heat fluxes should be measured, and every effort should be made to have the tests' set-up simulating the realistic cases.

Clothing stores burn vigorously and fire can redevelop after sprinklers are turned off. Shoe storage areas and toy stores that are not sprinklered can experience severe fires in terms of the quantity of smoke and rate of smoke production. Fires in bookstores take a considerable time to develop. Books and papers on shelves are assumed to have the same burning characteristics as wood.

For a fuel-controlled fire, the larger the exposure of the fuel surface area to the fire, the higher the heat release rate, and the thicker the fuel the longer the duration of burning. In other words, the value of the heat release rate is a function of the surface area, while the duration of burning is a function of the thickness of the fuel.

Non-cellulosic combustibles in racks with active sprinklers remote from the ignition location give rise to substantial volumes of black smoke; but, less than unsprinklered fires. 


\section{FIRE LOADS SURVEY}

\subsection{Introduction}

This section presents the procedures and results of the survey performed to determine fire loads, types of combustibles, and fuel arrangements in commercial premises. Fire load, types of combustibles, and fuel arrangement in buildings are important elements needed to characterize design fires that can be used in evaluating fire-protection designs for buildings. They affect fire growth, fire severity and duration, as well as the production rate and type of toxic products of combustion. The buildings surveyed were multi-storey office buildings with the first two floors used for services and shopping facilities, and the upper floors used for offices, as well as stores in smaller buildings along one of the main streets in the city of Ottawa.

Data were collected from all stores in the surveyed buildings. The establishments surveyed were retail stores providing various goods and services such as cloths, shoes, food, toys, books, as well as restaurants, travel agencies, pharmacies, computer showrooms, and storage areas.

Besides the fire load, compartment geometry is an important factor since it affects the development and temperature of the hot layer, as well as the radiative feedback to the fire. Lining materials can also contribute to the fire load and to fire spread. Openings, and ventilation play an important role in a fire, particularly during the fully-developed phase. 


\subsection{Surveyed Buildings}

Three multi-storey buildings were selected for the survey. They were all federal government office buildings with the first two storeys used for shopping facilities. The three buildings surveyed in the Phase I survey were: (1) L'Esplanade Laurier (140 O'Connor Street, Ottawa); (2) CD Howe (240 Sparks Street, Ottawa); and (3) Place du Portage Complex, Building Numbers I, II, III, and IV (140 Promenade du Portage, Gatineau). In the Phase II survey, stand-alone stores (some were two and three storeys in height), were surveyed (Glebe area, 553-925 Bank Street, Ottawa). In total, 168 commercial premises located in these buildings were surveyed with a total floor area of $17,127 \mathrm{~m}^{2}$

\subsection{Survey Methodology}

Determining fire loads in a building is a tedious task. It involves determining the mass of all the different types of combustibles and their calorific values. The mass of an item in a compartment can be determined by weighing it (weighing technique), or by determining its volume and identifying its density (inventory technique). The direct-weighing method was used for items that could easily be weighed, such as toys and books. The inventory method was used for items such as heavy furniture and built-in shelves. In this method, dimensions of items were measured and their volume was calculated. The weight was then computed by multiplying the volume by the density of the material. To facilitate the survey process, a combination of the weighing and inventory methods was used, in which some common items were pre-weighed, and then the surveyor noted their inventory. To ensure a high quality of the survey data and to avoid inconsistencies that might occur 
when individuals such as storeowners or managers had to complete questionnaires, the author conducted the survey himself.

A survey form was developed to facilitate the survey process and to ensure that data were collected in a systematic and consistent fashion for all buildings and stores. The survey form was divided into the following five sections: (1) building and store identification, and date of investigation; (2) type of establishment; (3) store dimensions; (4) fixed fire loads: this section contained information regarding building construction, weight, and type of lining materials; and (5) moveable fire loads: this section dealt with the building contents. For each item, the type of materials and their mass were recorded.

To determine the relative distribution of different establishments located on commercial floors of office buildings, all stores on these floors were included in the survey. In addition, if stores had storage areas associated with them, the storage areas were also surveyed and data for these storage areas were kept separate.

For each survey, the surveyor followed a similar procedure. First, the building name and address, as well as the type of establishment and date of the investigation were recorded. Second, the dimensions of the store were measured and the types of wall, floor, and ceiling lining materials were determined and noted in the fixed fire load section of the survey form. The third step was to identify and classify all contents in the store. Items that could be weighed were weighed, to determine their mass; the materials that the item was made of were determined and recorded. For items consisting of more than one material type, the percentage of each type was determined and quantified. The mass of items that could not be weighed, such as heavy furniture and built-in shelving units, was 
determined by measuring their volume and using the density of the material to calculate their mass. The fire load of carpets and lining materials was determined in a similar fashion.

Pictures were valuable during the analysis process and were used to assist in reproducing store arrangements and fuel packages, which were used for the tests performed to characterize and quantify design fires. During the process of data collection and analysis, it was assumed that combustibles within the compartment were uniformly distributed, and that in case of fire, all combustibles would be involved in the fire and would experience complete combustion (Kumar and $\mathrm{Rao}^{39,16}$ ). Values of the heat content for different combustibles and assumptions made in calculating the fire loads are shown in Appendix A and Appendix B, respectively.

\subsection{Data Analysis}

The data collected were analyzed to determine the total fire load in each store, the fire load densities $\left(\mathrm{MJ} / \mathrm{m}^{2}\right)$, and the contribution of different materials (wood, plastics, textiles, food, etc.) to the total fire load and to the fire load densities. As shown in Figure 3 , the area of clothing stores has the largest contribution to the total area of the buildings surveyed, followed by restaurants, storage areas, arts \& crafts supply shops, and fast food outlets. Bennetts et al. ${ }^{35}$ reported the same finding about clothing stores. The total floor area of clothing stores in the Ottawa survey was about $30 \%$ of the total area of surveyed stores, restaurants $13 \%$, storage areas $9 \%$, arts \& crafts supply shops $5 \%$, and fast food outlets $4 \%$. 


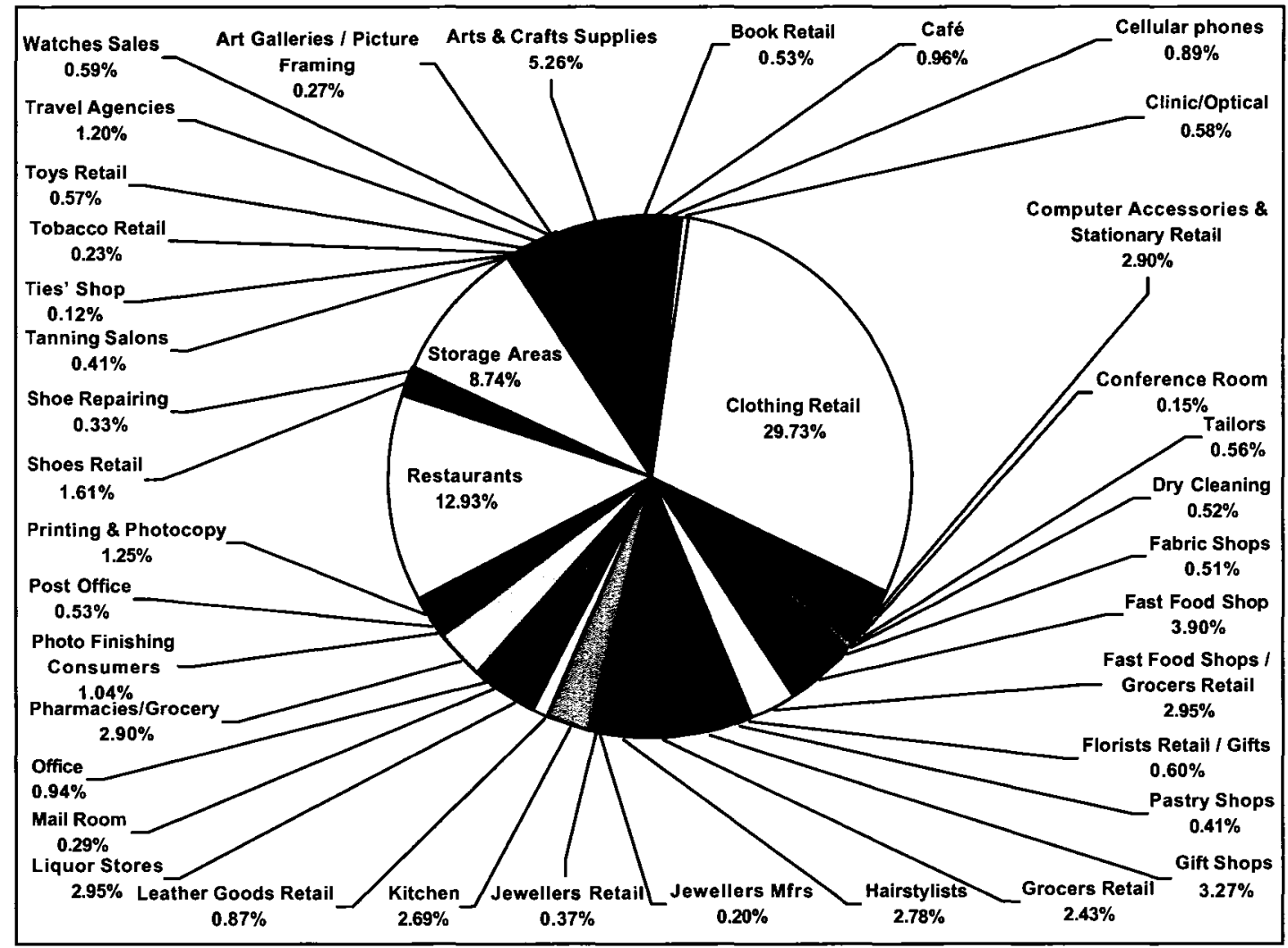

Figure 3. Percentage of floor area of different premises to total floor area of surveyed premises

To further analyze the 168 surveyed stores, stores were categorized into 66 different groups as shown in Table 12. Some groups have sufficient samples for further analysis, while other groups do not have sufficient samples for accurate analysis. Groups like clothing stores, fast food outlets, and restaurants have samples with 14, 22, and 11 stores, respectively, while groups like café shops, computer accessories \& stationary shops, and jewellers retail have samples of 5, 3 and 1 stores, respectively. 
Table 12. Identified groups and number of samples of surveyed stores

\begin{tabular}{|c|c|c|c|c|c|}
\hline 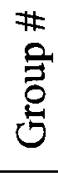 & Category & $\frac{\mathscr{0}}{\frac{\mathscr{U}}{2}}$ & 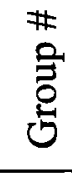 & Category & $\frac{\mathscr{E}}{\tilde{E}}$ \\
\hline 1 & Art Galleries/picture framing & 1 & 34 & Pharmacy/grocery & 1 \\
\hline 2 & Arts \& Crafts supply shop & 3 & 35 & Photo-finishing consumer & 2 \\
\hline 3 & Bank & 1 & 36 & Post office & 1 \\
\hline 4 & Book dealers retail & 1 & 37 & Printing/photocopy shop & 2 \\
\hline 5 & Café shop & 5 & 38 & Restaurant (seating area) & 11 \\
\hline 6 & Cellular phones & 1 & 39 & Shoe-repair shop & 2 \\
\hline 7 & Smoke shop & 1 & 40 & Shoe retail shop & 3 \\
\hline 8 & Clinic/dental & 2 & 41 & Storage (bookstore) & 1 \\
\hline 9 & Clinic/optical & 1 & 42 & Storage (café shop) & 2 \\
\hline 10 & Clothing retail & 14 & 43 & Storage (cards/gifts) & 2 \\
\hline 11 & Computer accessories/stationary shop & 3 & 44 & Storage (cell phones) & 1 \\
\hline 12 & Stationary/printing & 1 & 45 & Storage (clothing) & 8 \\
\hline 13 & Conference room & 1 & 46 & Storage (computer supplies) & 1 \\
\hline 14 & Dry-cleaning & 2 & 47 & Storage (fast food outlet) & 3 \\
\hline 15 & Fabric shop & 1 & 48 & Storage (gifts (sliver/steel)) & 1 \\
\hline 16 & Fast food outlet & 22 & 49 & Storage (grocery store) & 3 \\
\hline 17 & Fast food/grocery & 4 & 50 & Storage (leather goods) & 1 \\
\hline 18 & Florist shop & 1 & 51 & Storage (liquor store) & 2 \\
\hline 19 & Florist/gift shop & 1 & 52 & Storage (mail room) & 2 \\
\hline 20 & Gift shop & 2 & 53 & Storage (optical) & 1 \\
\hline 21 & Gift shop/cards & 2 & 54 & Storage (pharmacy) & 1 \\
\hline 22 & Gift shop/CDs/books & 2 & 55 & Storage (printing) & 1 \\
\hline 23 & Gift shop (silver/steel) & 1 & 56 & Storage (restaurant) & 5 \\
\hline 24 & Grocery store & 4 & 57 & Storage (shoe store) & 3 \\
\hline 25 & Hair-stylist salon & 6 & 58 & Storage (travel agency) & 1 \\
\hline 26 & Jewellers manufacturer & 1 & 59 & Storage (luggage shop) & 1 \\
\hline 27 & Jewellers retail & 1 & 60 & Storage (art/framing) & 3 \\
\hline 28 & Kitchen (restaurant/fast food outlet) & 8 & 61 & Tailor shop & 2 \\
\hline 29 & Luggage shop & 2 & 62 & Tanning salon & 1 \\
\hline 30 & Liquor store & 2 & 63 & Ties shop & 1 \\
\hline 31 & Mail room & 1 & 64 & Toys store/puzzles & 1 \\
\hline 32 & Office & 2 & 65 & Travel agency & 5 \\
\hline 33 & Pastry shop & 1 & 66 & Watch sales & 1 \\
\hline
\end{tabular}




\subsubsection{Fire Load Densities}

Figure 4 shows the fire load densities of the 168 surveyed stores. The fire load densities have a lognormal distribution with a mean value of $747 \mathrm{MJ} / \mathrm{m}^{2}$, a maximum of $5,305 \mathrm{MJ} / \mathrm{m}^{2}$, a minimum of $56 \mathrm{MJ} / \mathrm{m}^{2}$, and a standard deviation of $833 \mathrm{MJ} / \mathrm{m}^{2}$. The four fire load densities at the extreme right-hand side of the figure are for a bookstore, storage areas for the bookstore, a shoe store, and a greeting card shop.

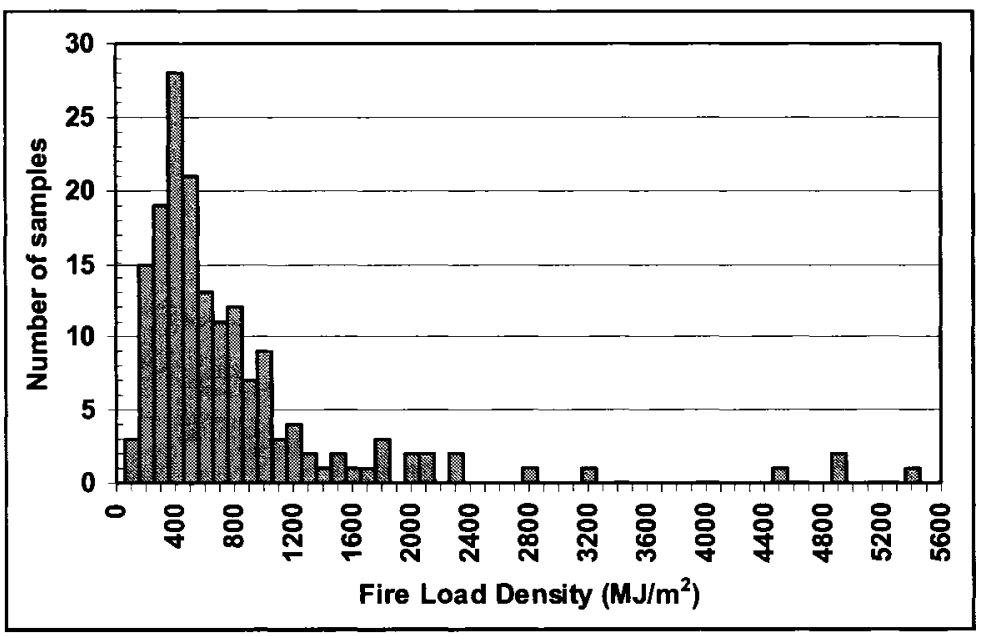

Figure 4. Frequencies of fire load density of the 168 surveyed stores

To analyse the fire load density frequencies, the 95 th percentile was calculated using the Excel software from Microsoft Corporation ${ }^{40}$. Excel uses the following equation to return the $p$-th percentile of values in a range (Borghers and Wessa) ${ }^{41}$ :

$$
(n+1) p=i+f
$$

Where, $n=$ number of observations, $p=$ percentile value divided by $100, i=$ integer part of $(n+1) p, f=$ the fractional part of $(n+1) p$ 
The distribution of the total fire load in the surveyed stores is shown in Figure 5. The total fire load has a maximum value of $511,413 \mathrm{MJ}$, a minimum of $1,126 \mathrm{MJ}$, a mean of $52,339 \mathrm{MJ}$, a 95 th percentile of $167,383 \mathrm{MJ}$, and a standard deviation of $77,166 \mathrm{MJ}$. As the figure shows, there are three stores with a fire load over $260,000 \mathrm{MJ}$. Those were for a bookstore and two clothing stores with floor areas of 1,175 and $1,707 \mathrm{~m}^{2}$. Wood was the main type of combustible for the three stores. The area of the surveyed stores ranges from 3.25 to $1,707 \mathrm{~m}^{2}$, and the distribution of floor areas is shown in Figure 6 .

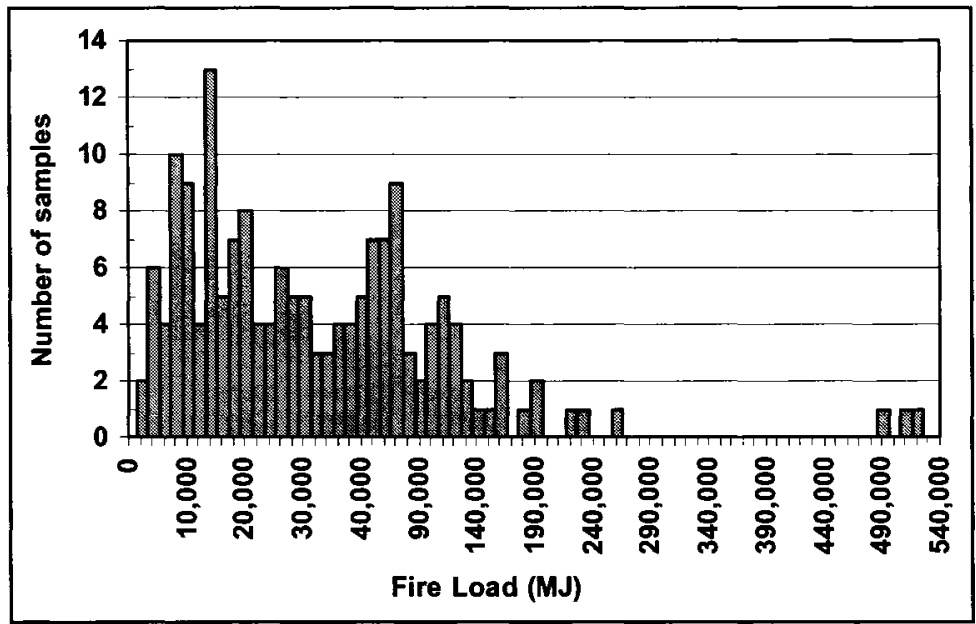

Figure 5. Total fire load distribution of the 168 surveyed stores

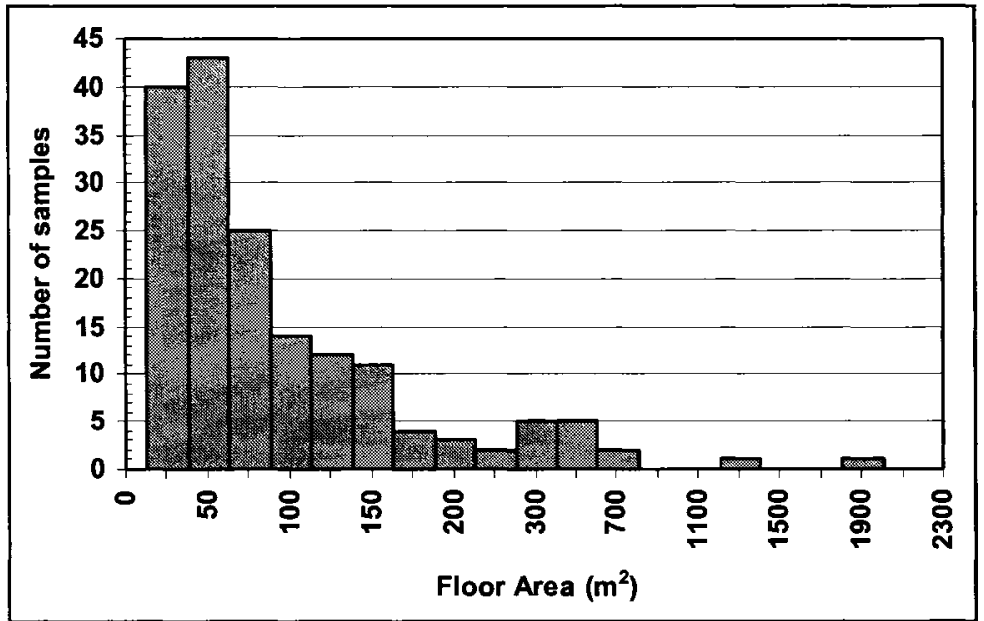

Figure 6. Area distribution of the 168 surveyed stores 


\subsubsection{Statistical Interpretation of Fire Load Densities}

It was decided to carry out a formal statistical test of the hypothesis that the original fire load density sample $\left(x_{0}, x_{1}, \ldots \ldots ., x_{n}\right)$ could be represented by a lognormal distribution. The standard lognormal probability density function is as follows:

$f(x)=\frac{1}{x \sigma \sqrt{2 \pi}} e^{-\frac{1}{2}\left(\frac{\ln x-\mu}{\sigma}\right)^{2}}$

Equation 14

Where, $\mu=$ population mean, $\sigma=$ standard deviation, for the domain $0 \leq x<+\infty$, the parameters $\sigma>0, \mu>0$.

Using the popular Kolmogorov-Smirnov test $\left(\mathrm{Weisstein}^{42}\right.$ ), the hypothesis that the underlining distribution is a lognormal distribution could not be rejected. The Probability Density Function (PDF) of the lognormal distribution showed the best fitting with a population mean $\mu=6.2497$ and standard deviation $\sigma=0.8187$. The probability value (P-value) of a statistical hypothesis test is the probability of getting a value of the test statistic as extreme as or more extreme than that observed by chance alone. The P-value is equal to the significance level of the test for which we would only just reject the null hypothesis. The P-value is compared with the desired significance level of our test and, if it is smaller, the result is significant. That is, if the null hypothesis were to be rejected at the $5 \%$ significance level, this would be reported as "P $<0.05$ ". Accordingly, the Pvalue of the test was recorded as 0.79 , which is extremely large. The distribution fitting program, EasyFit $C^{43}$ was used to test the best-fit distribution for the fire load density of survey stores, and "R" software to calculate the P-value (Venables ${ }^{44,45}$ ). As depicted in Figure 7, the test results clearly confirm that the fire load frequencies have a lognormal distribution. 


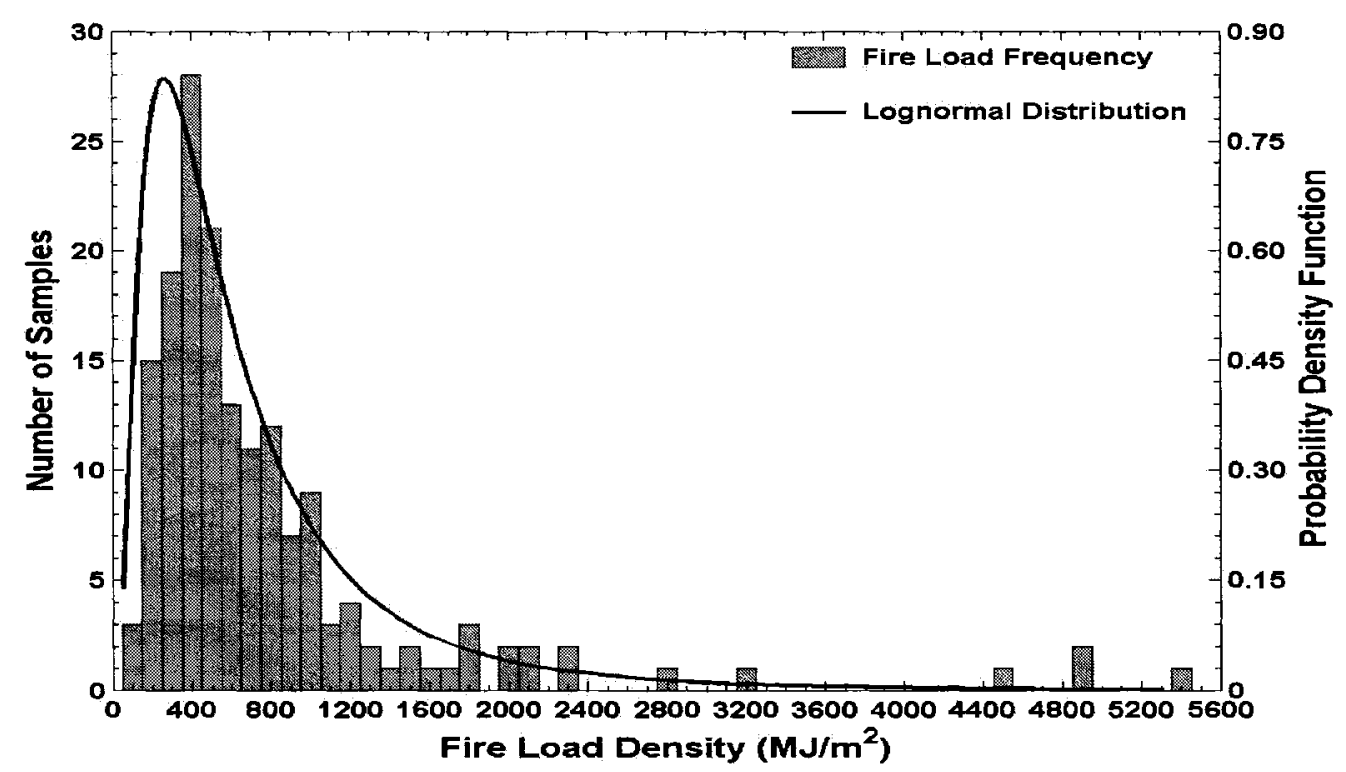

Figure 7. Fire load frequency and the corresponding lognormal distributions $(\mu=6.2497, \sigma=0.8187)$

Figure 8 shows the range of contributions for different types of combustibles to the total fire load. The five groups of combustibles selected were textiles, plastics, wood/paper, food, and miscellaneous (misc.). Miscellaneous items included all combustibles not included in the first four groups, for example, alcohol and tobacco products, etc. It is obvious that the contribution of combustibles from the five different groups has a wide range and hence there is a need for further analysis of the data focusing on the different groups of establishments individually. For example, Figure 8 shows that there might be a store with $0 \%$ textiles content (e.g., fast food outlet) and another that has $85 \%$ textiles content (e.g., clothing store). In all figures that show the combustible contributions, the range is depicted as straight vertical lines connecting the minimum and maximum values; the 95th percentile is denoted with the symbol (-), and mean with the symbol ( $\bullet)$. 


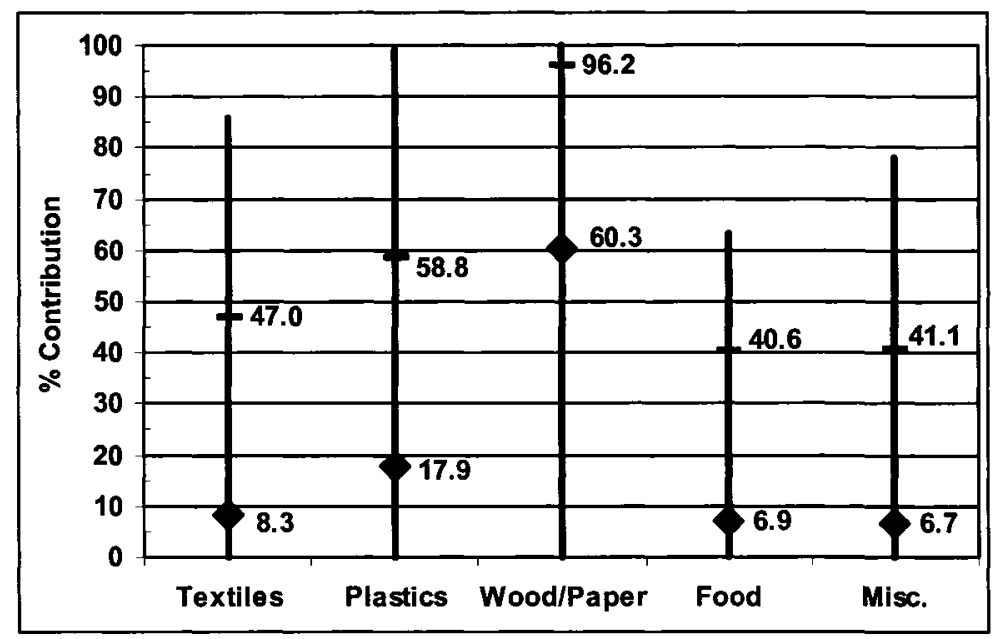

Figure 8. Range of contribution of combustibles to the fire load of the surveyed stores

To facilitate the fire load analysis, the surveyed stores were categorized into a number of groups. Table 13 presents the number of samples and fire load densities for these groups.

Table 13. Number of samples and fire load densities of the various groups

\begin{tabular}{|c|c|c|c|c|c|c|}
\hline \multirow[b]{2}{*}{ Group } & \multirow[b]{2}{*}{ 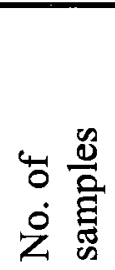 } & \multicolumn{5}{|c|}{ Fire load density $\left(\mathrm{MJ} / \mathrm{m}^{2}\right)$} \\
\hline & & 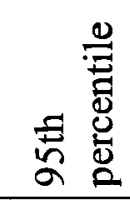 & $\sum_{\text {¿ }}^{\mathbb{E}}$ & 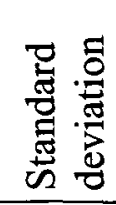 & 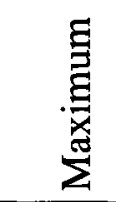 & $\stackrel{\Xi}{\Xi}$ \\
\hline All stores & 168 & 2050 & 747 & 833 & 5305 & 56 \\
\hline Shoe store & 3 & ----- & 2547 & --- & 4896 & 686 \\
\hline Storage areas & 43 & 4289 & 1196 & 1208 & 4899 & 56 \\
\hline Fast food outlets & 18 & 881 & 526 & 320 & 1592 & 151 \\
\hline Clothing stores & 14 & 661 & 393 & 164 & 755 & 142 \\
\hline Restaurants & 11 & 582 & 298 & 190 & 625 & 84 \\
\hline Kitchens & 8 & ----- & 314 & 161 & 602 & 149 \\
\hline
\end{tabular}

The contribution of different combustibles (textiles, plastics, wood/paper, food, and misc.) was identified for the various groups, as shown in Table 14. 
Table 14. Contribution of different combustibles of the various groups

\begin{tabular}{|c|c|c|c|c|c|c|c|c|c|c|}
\hline \multirow[b]{3}{*}{ Group } & \multicolumn{10}{|c|}{ Contribution of different combustibles (\%) } \\
\hline & \multicolumn{2}{|c|}{ Textiles } & \multicolumn{2}{|c|}{ Plastics } & \multicolumn{2}{|c|}{$\begin{array}{l}\text { Wood/ } \\
\text { paper }\end{array}$} & \multicolumn{2}{|c|}{ Food } & \multicolumn{2}{|c|}{ Misc. } \\
\hline & $\sum_{\Sigma}^{\mathbb{E}}$ & 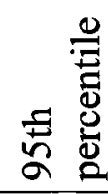 & $\sum_{\text {हี }}^{\mathbb{E}}$ & 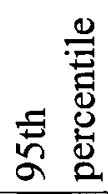 & 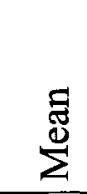 & 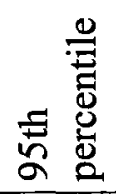 & $\sum_{\Sigma}^{\mathbb{E}}$ & 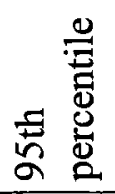 & $\sum^{\mathfrak{g}}$ & 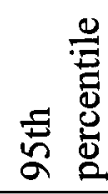 \\
\hline All stores & 8.3 & 47 & 17.9 & 58.8 & 60.3 & 96.2 & 6.9 & 40.9 & 6.7 & 41.1 \\
\hline Shoe store & 0.3 & 0.8 & 0.8 & 1.9 & 18.2 & 31.5 & 0.0 & 0.0 & 80.6 & 88.7 \\
\hline Storage areas & 6.2 & 38.5 & 27.4 & 82.5 & 50.6 & 99.7 & 4.9 & 40.7 & 10.9 & 77.0 \\
\hline Fast food outlets & 0.1 & 0.6 & 22.9 & 38.7 & 55.1 & 78.1 & 21.8 & 41.5 & 0.1 & 0.2 \\
\hline Clothing stores & 48.1 & 85 & 5.3 & 22.9 & 44.5 & 75.3 & 0.0 & 0.0 & 2.1 & 7.6 \\
\hline Restaurants & 3.7 & 13.1 & 5.2 & 10.0 & 84.0 & 94.9 & 2.2 & 11.1 & 4.8 & 23.3 \\
\hline Kitchens & 0.0 & 0.0 & 30.5 & 47.5 & 36.0 & 60.9 & 33.5 & 55.7 & 0.0 & 0.0 \\
\hline
\end{tabular}

The following sections present the analyses of groups of stores with a sufficient number of samples for analysis; this includes storage areas, clothing stores, shoe storage areas, fast food outlets, and restaurants (Hadjisophocleous and Zalok ${ }^{46,47,48}$ ).

\subsubsection{Clothing Stores}

As shown in Figure 3, clothing stores form the largest component, 29.73\%, of the total area of the buildings surveyed. There were 14 different clothing stores surveyed, which allows for development of a good sample size for further statistical analysis. Other stores with activities related to clothing stores, such as tailor shops and custom cloth design were excluded from the sample.

The floor area of surveyed stores ranges from 29 to $1707 \mathrm{~m}^{2}$. The total fire load ranges from 6,256 to 511,413 MJ. As seen in Figure 9, the fire load density ranges from 142 to $755 \mathrm{MJ} / \mathrm{m}^{2}$, with one peak ranging from 400 to $500 \mathrm{MJ} / \mathrm{m}^{2}$, with a 95 th percentile value of $661 \mathrm{MJ} / \mathrm{m}^{2}$, a mean value of $393 \mathrm{MJ} / \mathrm{m}^{2}$, and standard deviation of $164 \mathrm{MJ} / \mathrm{m}^{2}$. 


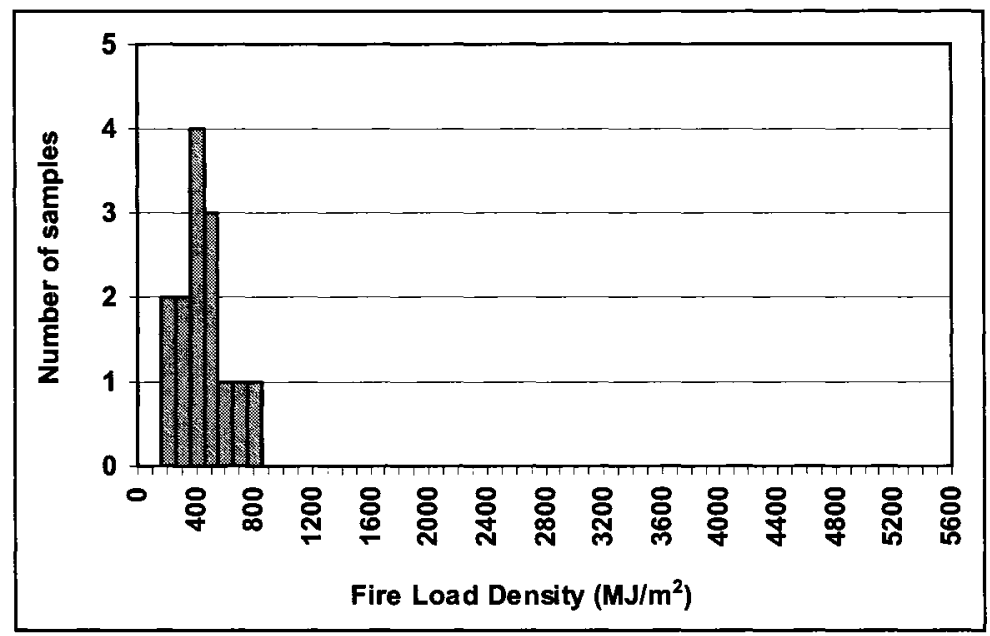

Figure 9. Fire load density of clothing stores

Further analysis of the data indicated that textiles ranged from 16 to $86 \%$ of the total fire load density in clothing stores. In $40 \%$ of these stores, textiles were the main combustible, with over $50 \%$ of the total fire load density. Wood in tables, shelves, and lining materials was another major combustible in clothing stores, with values ranging from 7 to $76 \%$. In $60 \%$ of the stores, wood was the main combustible, contributing over $50 \%$ of the total fire load density. Contributions from plastic materials ranged from 0 to $23 \%$, as depicted in Figure 10. 


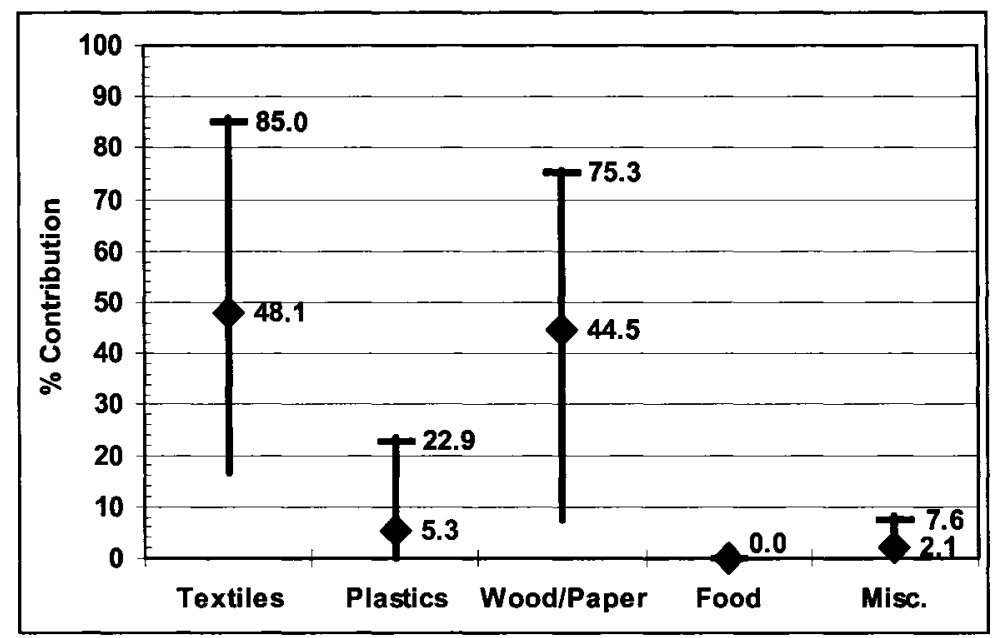

Figure 10. Combustible contributions in clothing stores $\left[95^{\text {th }}\right.$ percentile $(-)$, mean $\left.(\bullet)\right]$

A close look at the data collected from clothing stores, Figure 11, shows the influence of floor area on maximum, minimum, and mean fire load densities. A clear decrease in the maximum, mean, and the 95 th percentile values of fire load density can be attributed to the increase in floor area. The data does not indicate a clear, definitive relationship between minimum fire load density and floor area.

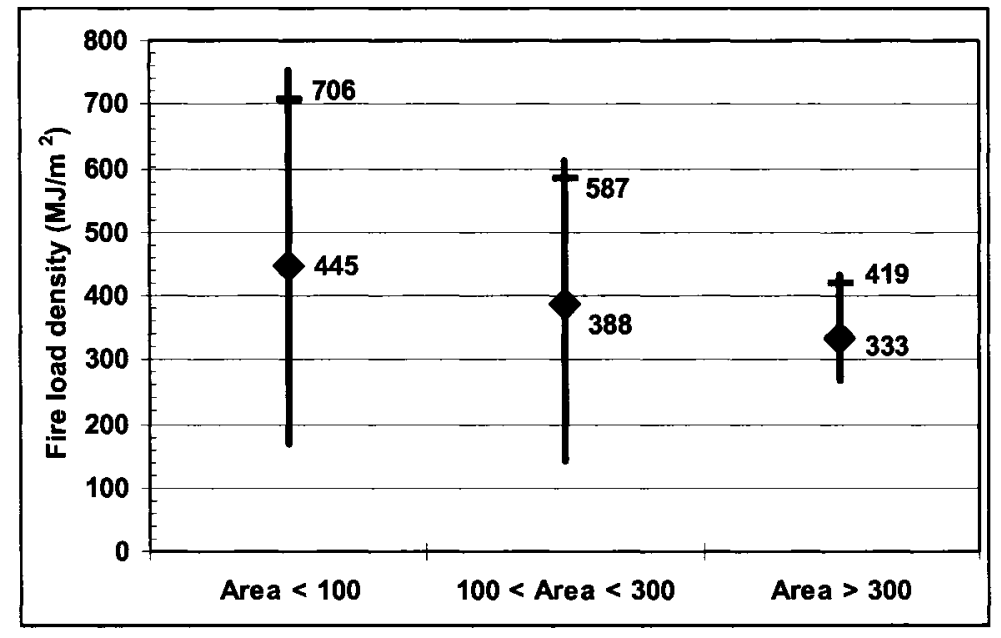

Figure 11. Effect of floor area on the fire load density of clothing stores $\left[95^{\text {th }}\right.$ percentile $(-)$, mean $\left.(\bullet)\right]$ 
Based on the survey results, and the differences noticed in the contribution of different combustibles, which can affect the heat release rate and production rates of toxic gases, clothing stores were then split into three groups for further analysis. Details of contribution of different types of combustible are shown in Table 15.

The first group, CLS, represents the combination of combustibles in small stores, which were less than $100 \mathrm{~m}^{2}$ in floor area. The second group, CLW, comprises stores that had high wood content and low textile content. The CLW represents the high-end clothing stores that use wood as a decorative material for shelving, flooring, and wall and ceiling panelling. The third group, CLC, represents stores with low wood content and high textile content. In CLC stores, shelving is mainly made of steel with a few wooden tables, and the internal store lining consists mainly of non-combustible materials, such as cement floor tiles, bricks for walls, and reinforced concrete ceilings. The above three fuel load packages had the same fire load density of $661 \mathrm{MJ} / \mathrm{m}^{2}$, which is the 95 th percentile of all clothing store samples, but with different composition of combustible materials.

For determining the fuel package for CLS, a combination of combustibles representing the average contribution of all combustibles to the total fire load of small floor size clothing stores was chosen. Values used are shown in Table 15. For determining the fuel package for clothing stores that were high in wood and paper content (CLW), a combination of combustibles was chosen representing the 95th percentile of the contribution of textiles to the total fire load, which is $75.3 \%$. A sample store that has this specific value was then used to calculate the remaining $24.7 \%$ contribution of other combustibles. The 95 th percentile is close to the maximum value of $76 \%$, so the $76 \%$ 64 
value was chosen. Final values are shown in Table 15. For determining the fuel package for the clothing stores that are high in textile content (CLC), a combination of combustibles using the 95 th percentile of the contribution of textiles to the total fire load of $85 \%$ was chosen. A sample store that has this specific value was then used to calculate the remaining $15 \%$ contribution of other combustibles. The 95 th percentile is close to the maximum value of $86 \%$, so the $86 \%$ value was chosen. Final values are shown in Table 15.

Table 15. Fire load densities and contribution of combustible materials to fire load density of clothing stores

\begin{tabular}{|c|c|c|c|c|c|c|c|}
\hline No. & Store & 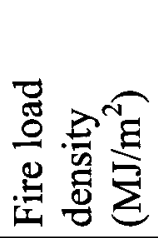 & 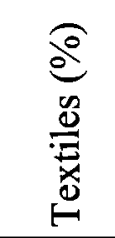 & $\frac{\widehat{o}}{0}$ & 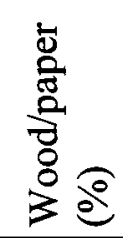 & 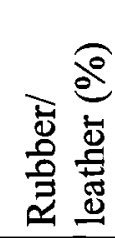 & 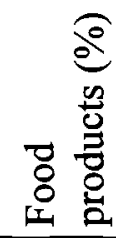 \\
\hline CLS & $\begin{array}{l}\text { Clothing store, } \\
\text { small store }\end{array}$ & 661 & 55.00 & 6.00 & 37.00 & 2.00 & 0.00 \\
\hline CLW & $\begin{array}{l}\text { Clothing store, } \\
\text { mostly wood }\end{array}$ & 661 & 23.00 & 1.00 & 76.00 & 0.00 & 0.00 \\
\hline CLC & $\begin{array}{l}\text { Clothing store, } \\
\text { mostly textiles }\end{array}$ & 661 & 86.00 & 2.00 & 12.00 & 0.00 & 0.00 \\
\hline
\end{tabular}

\subsubsection{Restaurants}

During the fire load survey, eleven restaurants were surveyed. As shown in Figure 3, restaurants form the second-highest floor area contribution to the total area of the buildings surveyed, with a floor area that is $12.93 \%$ of the total area of surveyed stores. Eleven restaurants were surveyed, which gave a good sample size for further statistical analysis. The floor area of surveyed restaurants ranges from 49 to $462 \mathrm{~m}^{2}$. The total fire load ranges from 17,656 to $69,843 \mathrm{MJ}$. The fire load density ranges from 84 to $625 \mathrm{MJ} / \mathrm{m}^{2}$, with a 95 th percentile of $582 \mathrm{MJ} / \mathrm{m}^{2}$, a mean of $298 \mathrm{MJ} / \mathrm{m}^{2}$, and a standard 
deviation of $190 \mathrm{MJ} / \mathrm{m}^{2}$ (see Figure 12). The mean fire load density is close to the reported value form the survey of Chinese restaurant $\left(\mathrm{Chow}^{25}\right)$.

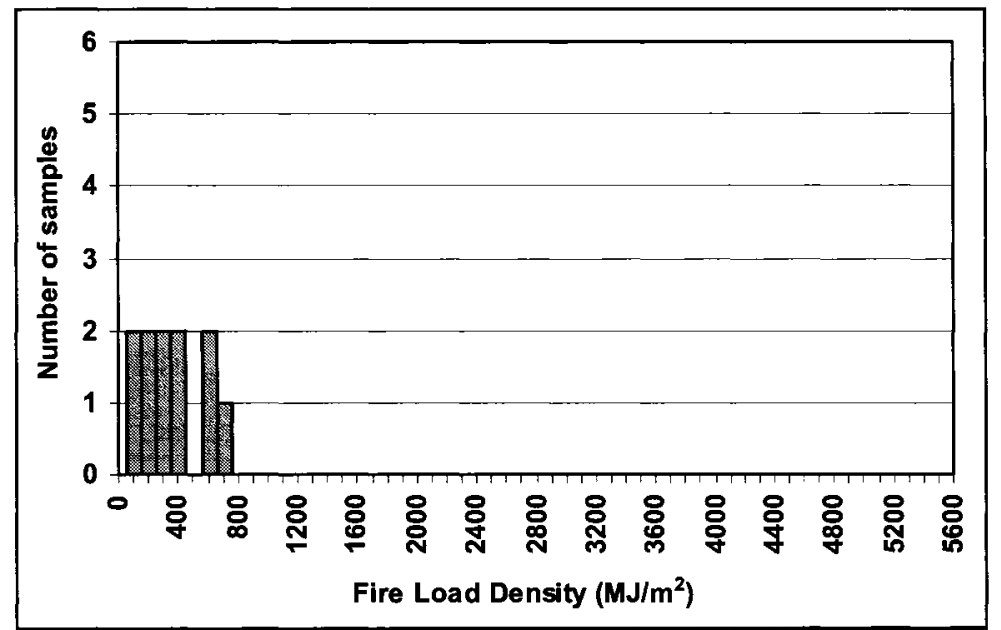

Figure 12. Fire load density of restaurants

Food had a low contribution to the fire load density, except for one restaurant where the cooking and handling area was enclosed within the restaurant. Wood and paper found in tables, chairs, and decoration materials were the major fuel loads for $90 \%$ of the restaurants with 50 to $95 \%$ of the total fire load, as depicted in Figure 13. Textiles like carpets, table covers, and curtains represented the minor fuel loads. 


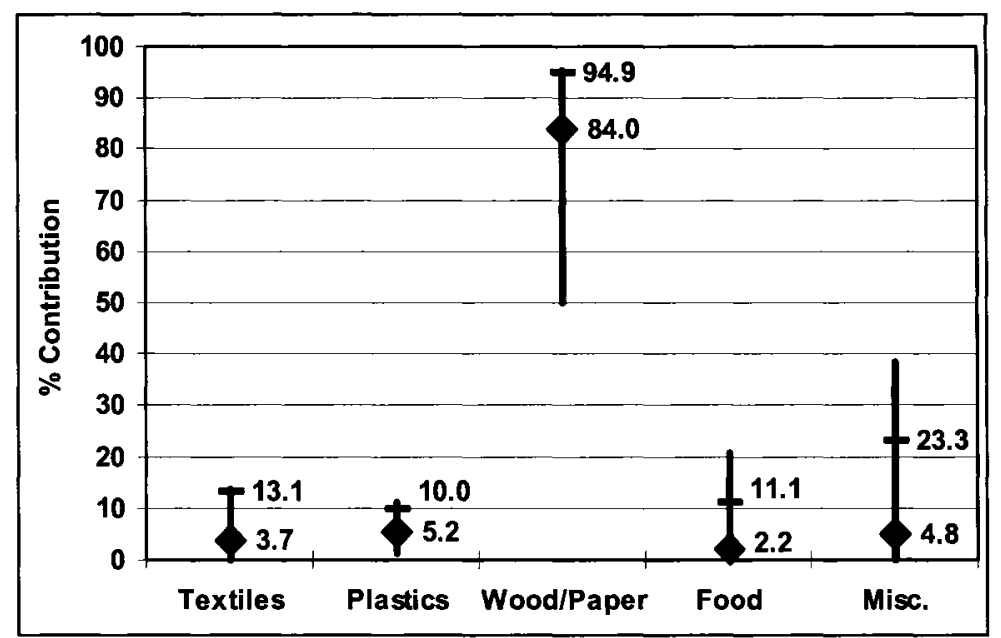

Figure 13. Combustible contributions in restaurants $\left[95^{\text {th }}\right.$ percentile $(-)$, mean $\left.(\bullet)\right]$

A close look at the data collected from restaurants, as presented in Figure 14, shows the influence of the floor area on fire load density. With an increase in floor area, a clear decrease in the maximum, minimum, mean, and 95th percentile values of fire load density was observed. In contrast to most of the other surveyed premises, the data showed a clear, definite relationship between minimum fire load density and floor area.

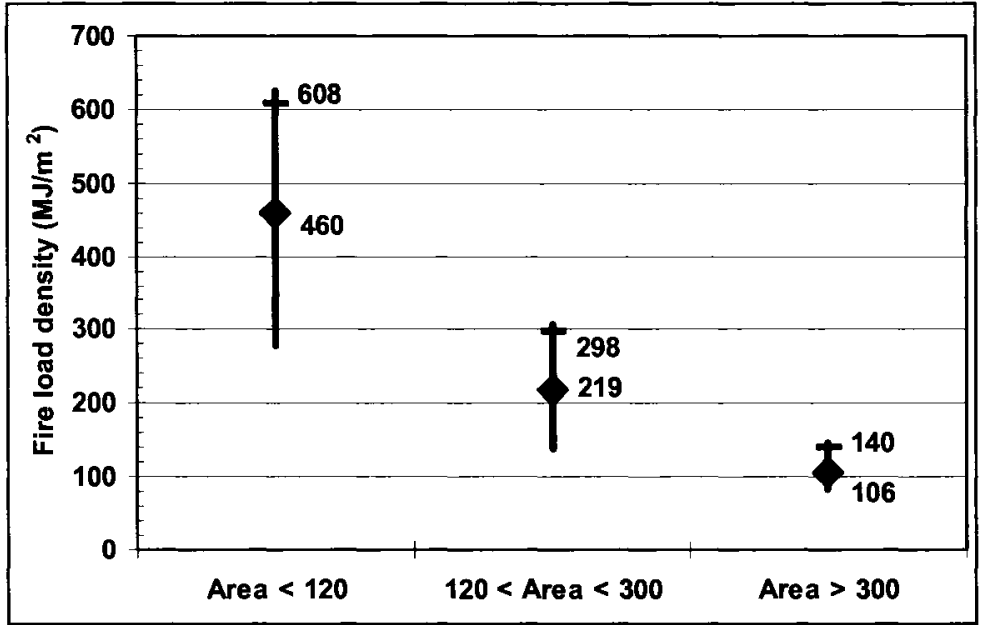

Figure 14. Effect of floor area on the fire load density of restaurants $\left[95^{\text {th }}\right.$ percentile $(-)$, mean $\left.(\bullet)\right]$ 


\subsubsection{Fast Food Outlets; and Fast Food Outlets and Grocery Stores}

Eighteen fast food outlets, and four fast food outlets and grocery stores were surveyed. As shown in Figure 3, fast food outlets, and fast food outlets and grocery stores form the fourth highest floor area contribution to the total area of the buildings surveyed, with floor areas of 3.9 and $2.95 \%$, respectively, of the total area of surveyed stores.

The floor area of the surveyed stores ranged from 9 to $211 \mathrm{~m}^{2}$. The total fire load ranged from 2,953 to $117,592 \mathrm{MJ}$. The fire load density ranged from 151 to $1,592 \mathrm{MJ} / \mathrm{m}^{2}$, with a peak ranging from 455 to $550 \mathrm{MJ} / \mathrm{m}^{2}$. The fire load densities for fast food outlets, and fast food outlets and grocery stores had a 95 th percentile values of 881 and $1,052 \mathrm{MJ} / \mathrm{m}^{2}$, mean values of 526 and $654 \mathrm{MJ} / \mathrm{m}^{2}$, and standard deviations of 320 and $328 \mathrm{MJ} / \mathrm{m}^{2}$ (Figure 15 and Figure 16).

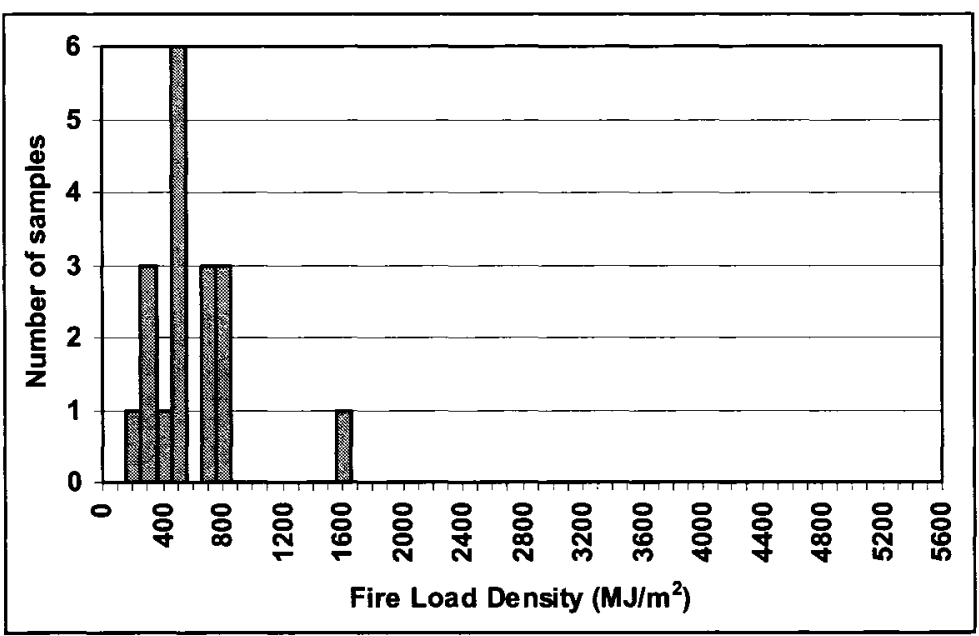

Figure 15. Fire load density of fast food outlets 


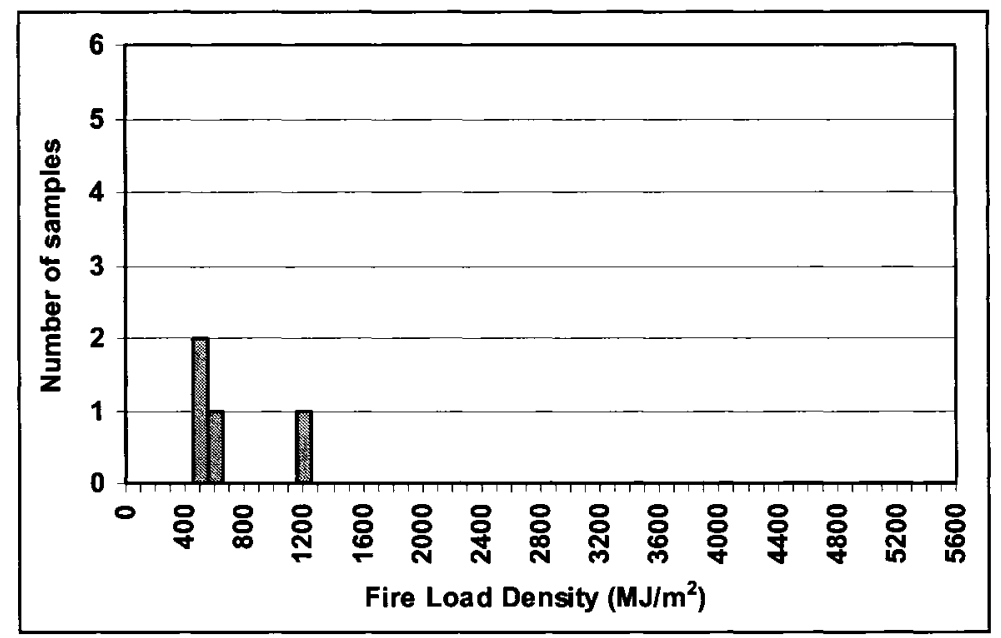

Figure 16. Fire load density of fast food outlets and grocery stores

Data for fast food outlets presented in Figure 17 shows that food contribution (grains, cooking oil, etc.) ranges from 12 to $63 \%$. For $95 \%$ of the shops, the food contribution as a combustible ranges from 12 to $38 \%$. Food items were not the main combustible in about $94 \%$ of the shops. Wood and paper (shelves, tables, wrapping paper and napkins, etc.) were the main fuel load, with values ranging from 40 to $80 \%$ for about $90 \%$ of the stores. Plastic materials had a contribution that ranged from 4 to $50 \%$. A similar trend of the combustible contributions was also observed in fast food outlets and grocery stores, Figure 18. 


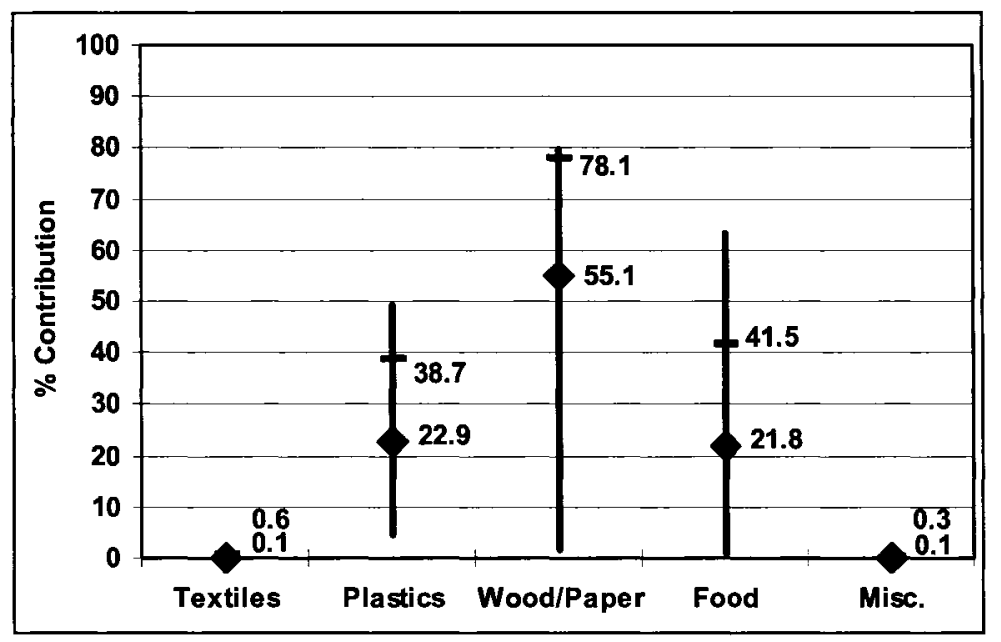

Figure 17. Combustible contributions in fast food outlets $\left[95^{\text {th }}\right.$ percentile $(-)$, mean $\left.(\diamond)\right]$

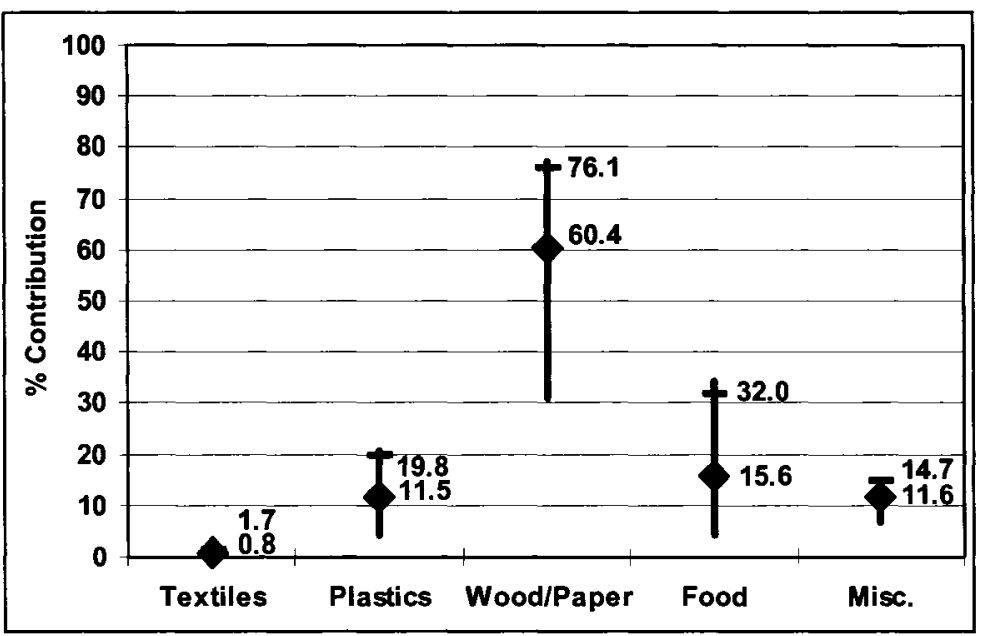

Figure 18. Combustible contributions in fast food outlets and grocery stores $\left[95^{\text {th }}\right.$ percentile $(-)$, mean $\left.(\bullet)\right]$

A close look at the data collected from fast food outlets, presented in Figure 19, shows the influence of the floor area on fire load density. A clear decrease in the maximum, mean, and the 95th percentile values of fire load density occurred with an increase in floor area; the same was also noticed for fast food outlets and grocery stores. The data do not show a clear, definite relationship between minimum fire load density and floor area. 


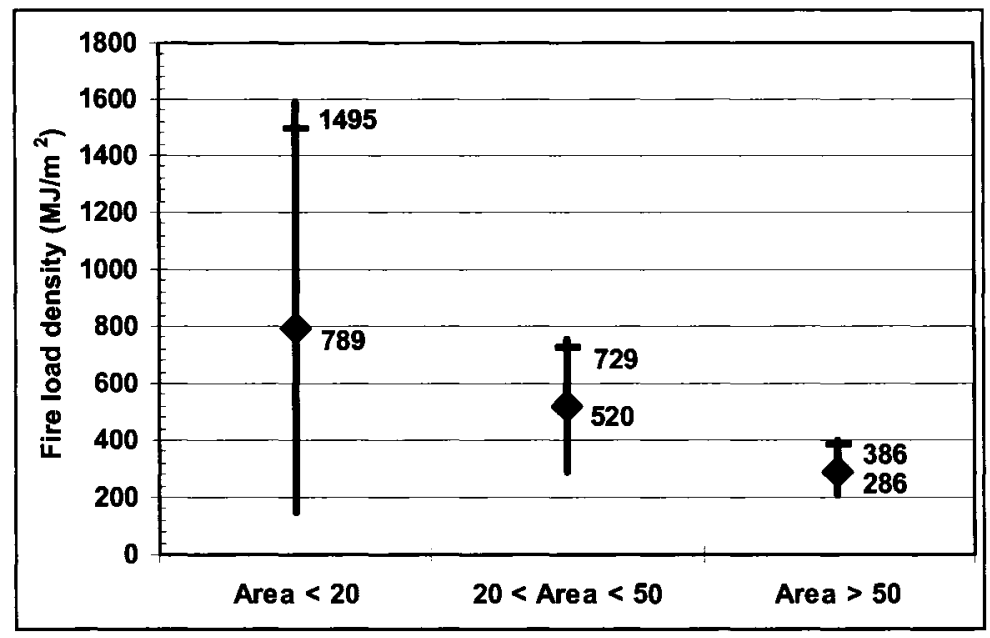

Figure 19. Effect of floor area on the fire load density of fast food outlets $\left[95^{\text {th }}\right.$ percentile $(-)$, mean $\left.(*)\right]$

\subsubsection{Storage Areas}

Forty-three storage areas were surveyed. They served as storage for various surveyed stores, such as clothing stores, bookstores, fast food outlets, and restaurants. As shown in Figure 3, storage areas form the third-highest floor area contribution to the total area of the buildings surveyed, with a floor area of $8.74 \%$ of the total area of the surveyed stores. A sample size of 43 allowed for the development of a good sample size for further statistical analysis.

The floor area of surveyed storage areas ranged from 3 to $350 \mathrm{~m}^{2}$, and the total fire load ranged from 1,126 to $258,683 \mathrm{MJ}$. As shown in Figure 20, the fire load density ranges from 56 to $4,899 \mathrm{MJ} / \mathrm{m}^{2}$, with one peak value at $400 \mathrm{MJ} / \mathrm{m}^{2}$. The fire load density had a mean value of $1,196 \mathrm{MJ} / \mathrm{m}^{2}$, standard deviation $1,208 \mathrm{MJ} / \mathrm{m}^{2}$, and 95 th percentile value of $4,289 \mathrm{MJ} / \mathrm{m}^{2}$. The three high fire load densities at the extreme right-hand side of the figure are for storage areas of a bookstore, a shoe store, and a greeting card shop. With 
the exception of these three values, the 95 th percentile of the fire load density for storage areas was $2,320 \mathrm{MJ} / \mathrm{m}^{2}$.

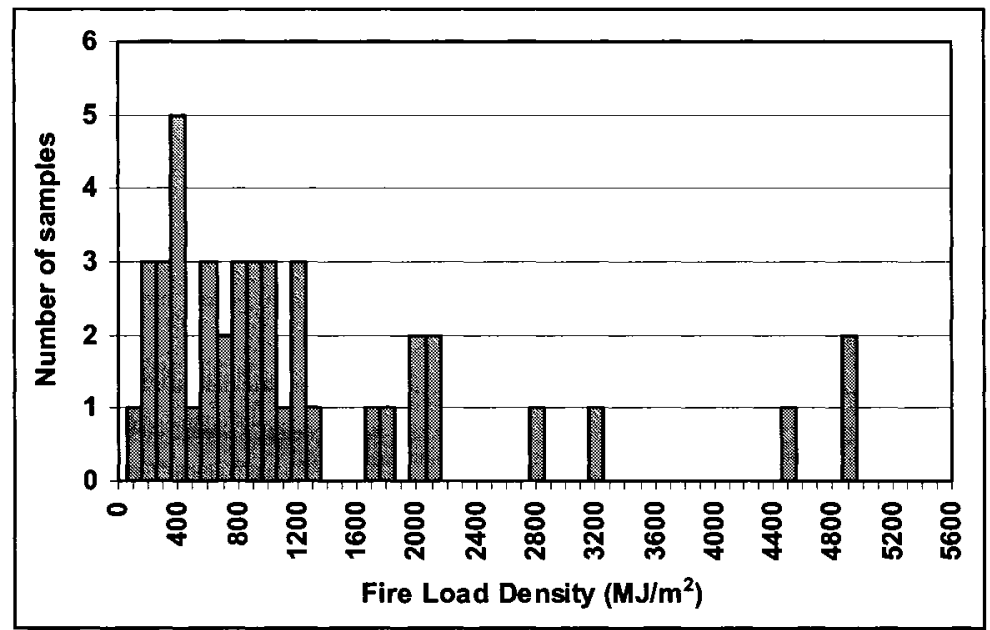

Figure 20. Fire load density of storage areas

Analysis of the contribution of different combustibles to the total fire load density of storage areas, shown in Figure 21, indicates that all types of combustibles have a very wide distribution. Further analysis of the data was conducted to determine the contribution of combustibles to the total fire load for specific storage areas. Figure 22 to Figure 33 show the fire load densities and contribution range of different combustibles for storage area subgroups. 


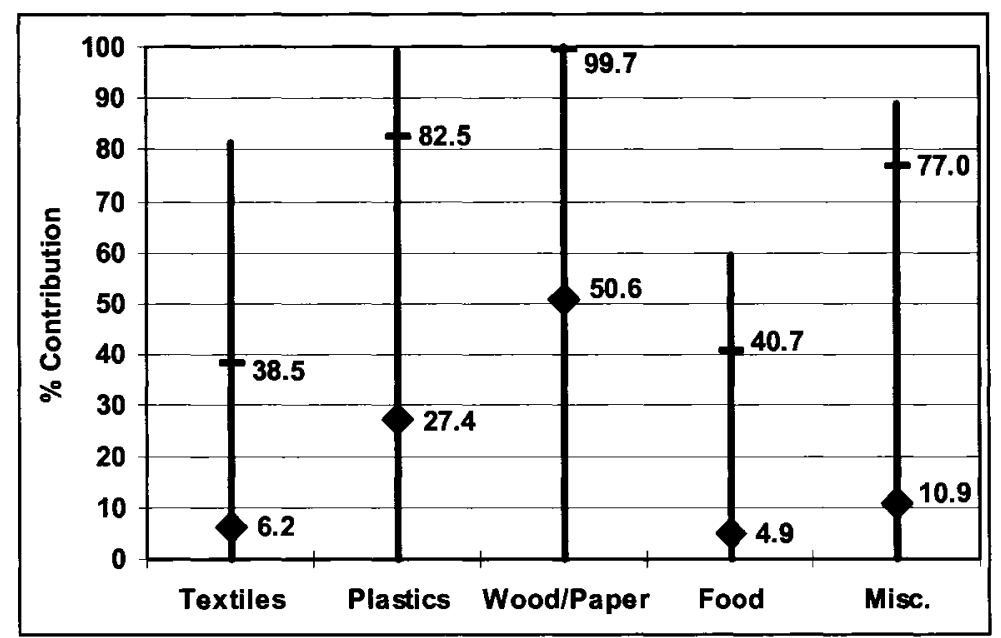

Figure 21. Combustible contributions in storage areas $\left[95^{\text {th }}\right.$ percentile $(-)$, mean $\left.(\bullet)\right]$ 


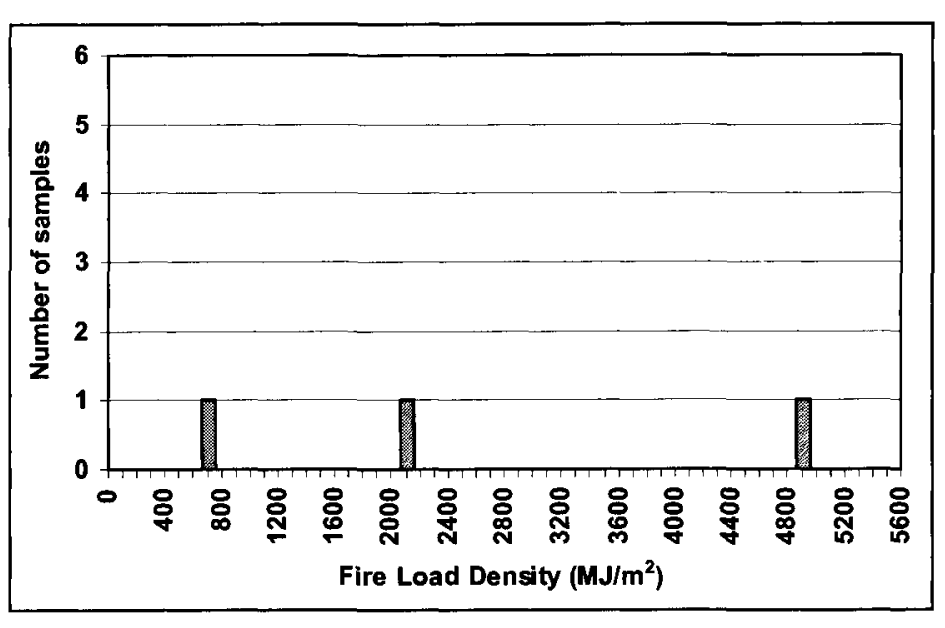

Figure 30 . Fire load density of 3 shoe store storage areas

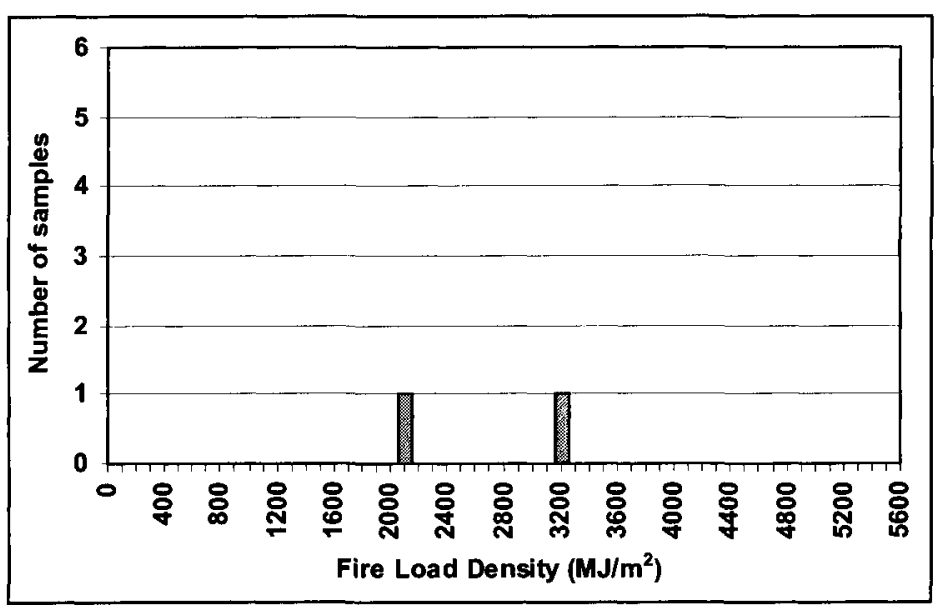

Figure 32. Fire load density of 2 luggage store storage areas

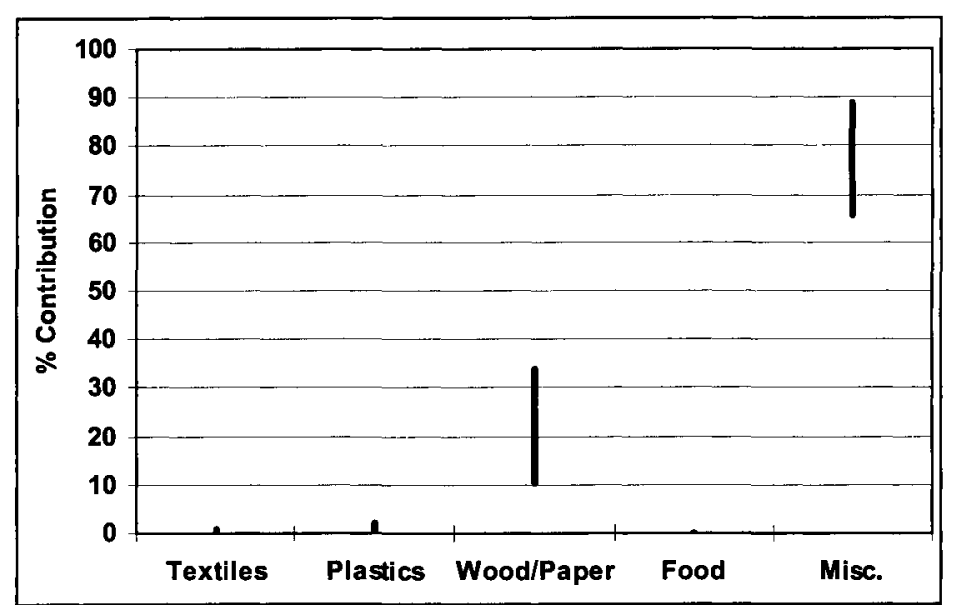

Figure 31. Combustible contributions in 3 shoe store storage areas

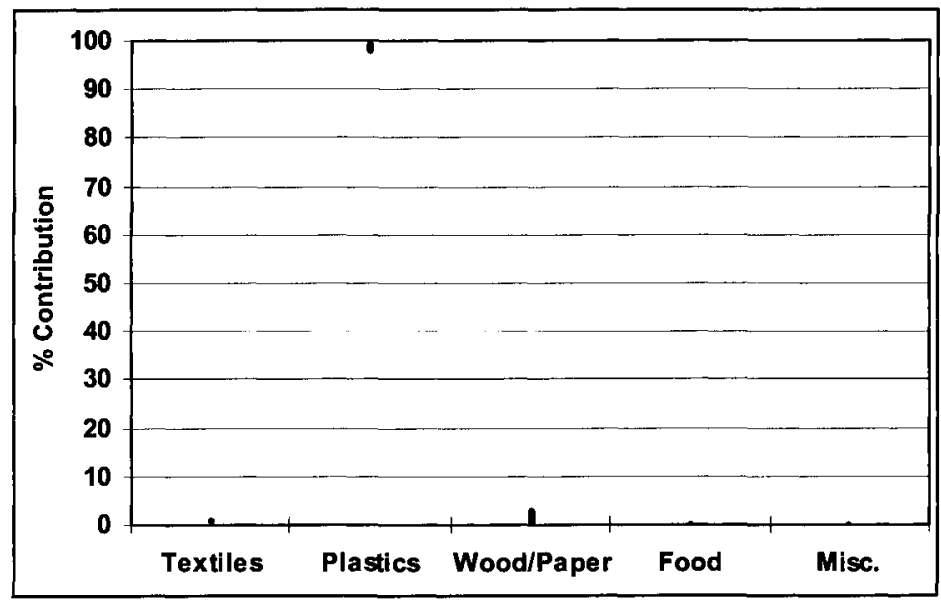

Figure 33. Combustible contributions in 2 luggage shop storage areas 


\subsubsection{Small Sample Size Groups}

For these groups, further statistical analysis was not feasible, because they had small sample sizes and a narrow fire load density range. Some exceptions can be seen in tailor shops (400 to $2,300 \mathrm{MJ} / \mathrm{m}^{2}$ ), travel agencies (400 to $2,300 \mathrm{MJ} / \mathrm{m}^{2}$ ), computer accessory shops (400 to $2,300 \mathrm{MJ} / \mathrm{m}^{2}$ ), and arts \& crafts supply shops (300 to $1,500 \mathrm{MJ} / \mathrm{m}^{2}$ ). A similar trend can be seen for contributions of combustibles, where most stores show a small range of combustible contributions, except hair-stylist salons, kitchens, and luggage shops. The fire load densities and contribution range for different combustibles to the total fire load are presented in Figure 34 to Figure 67. 


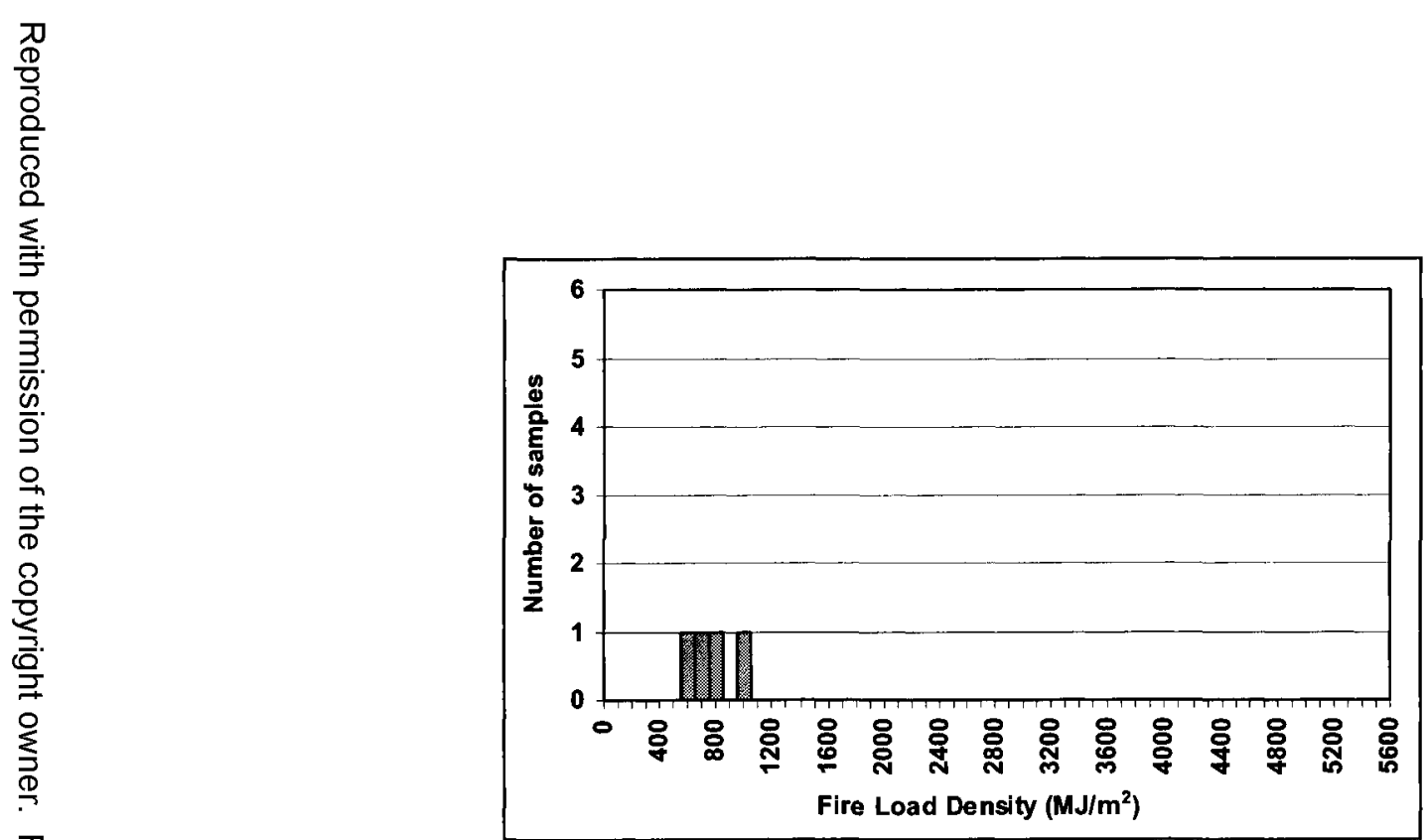

Figure 34. Fire load density of cafés

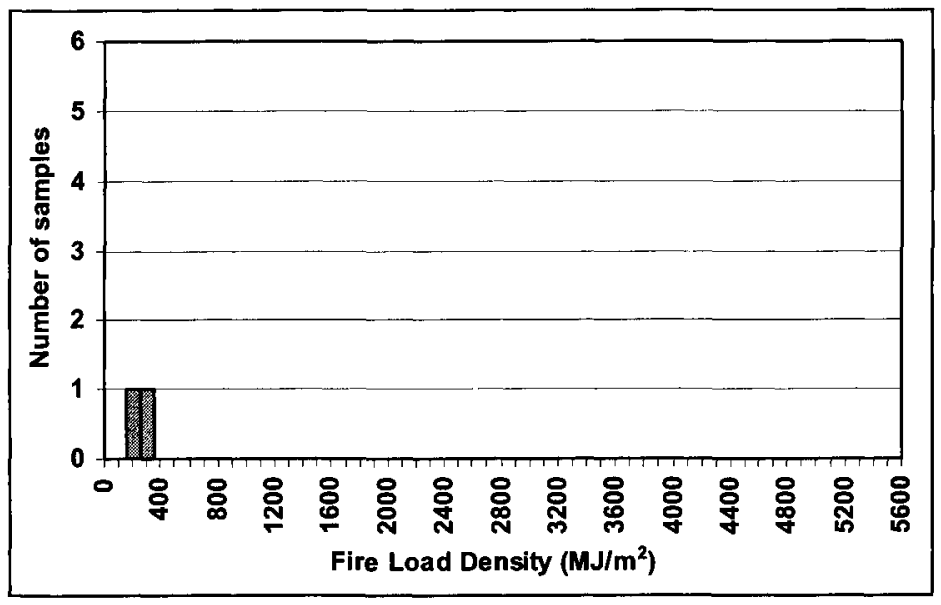

Figure 36. Fire load density of tailor shops

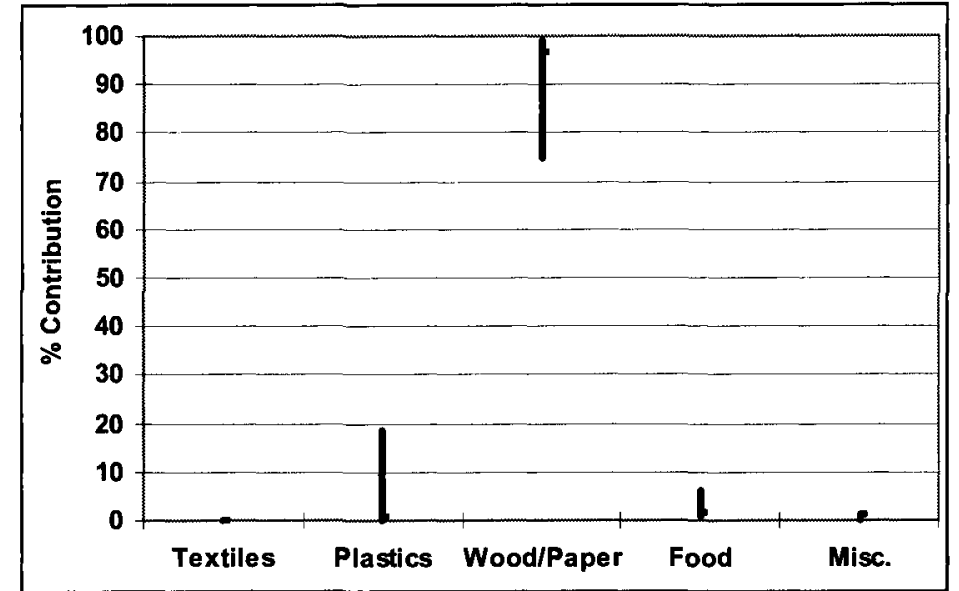

Figure 35. Combustible contributions in cafés

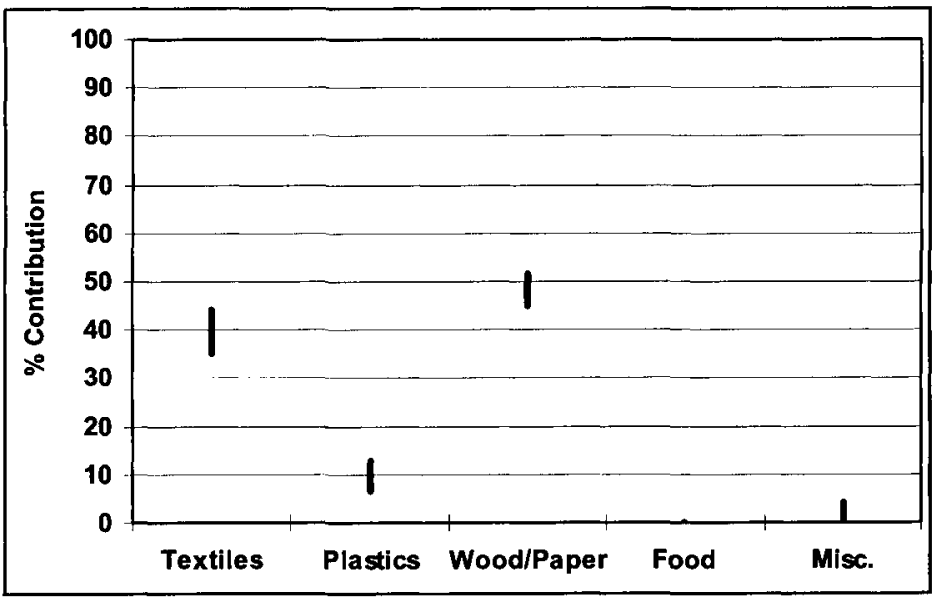

Figure 37. Combustible contributions in tailor shops 


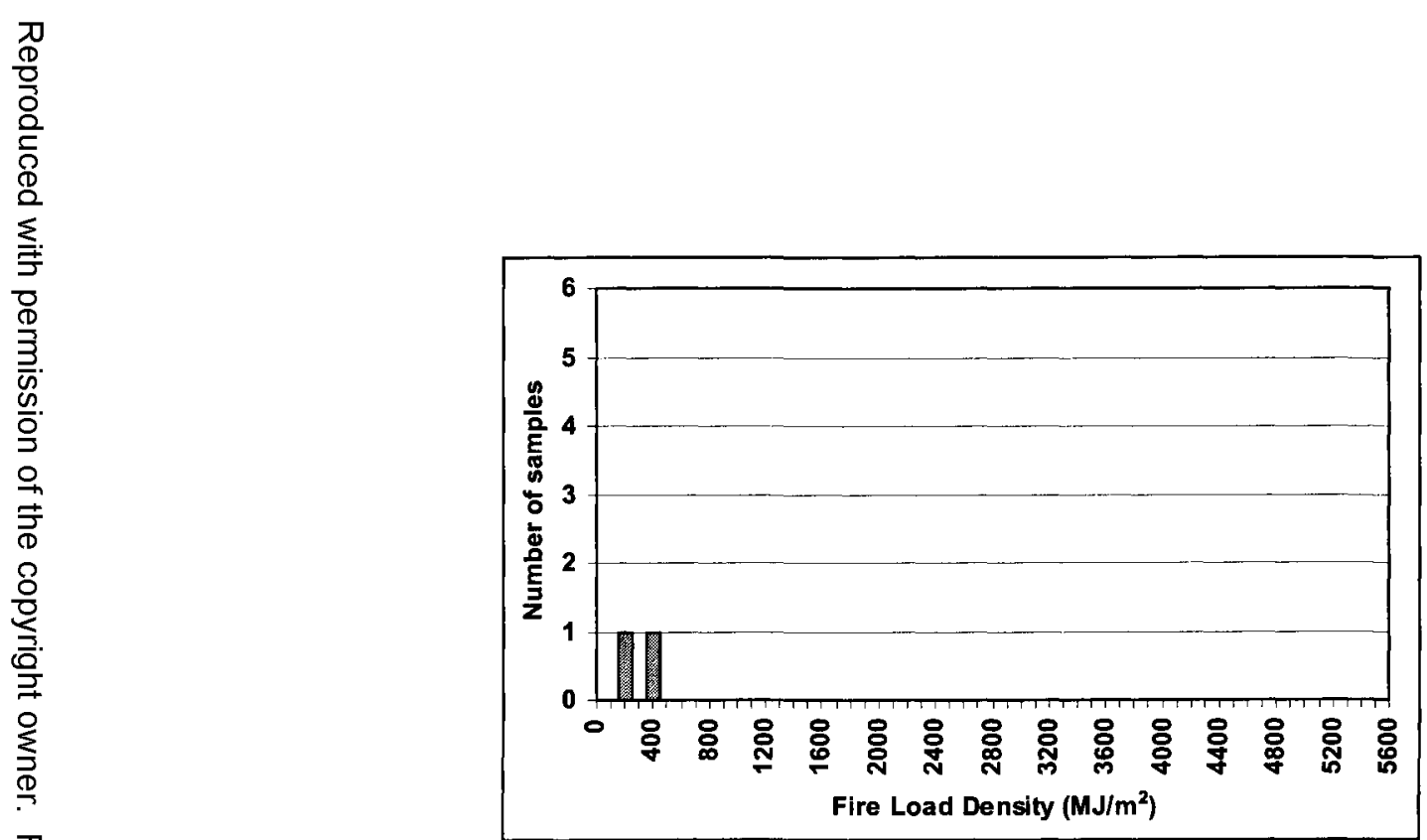

Figure 38. Fire load density of dry-cleaning shops

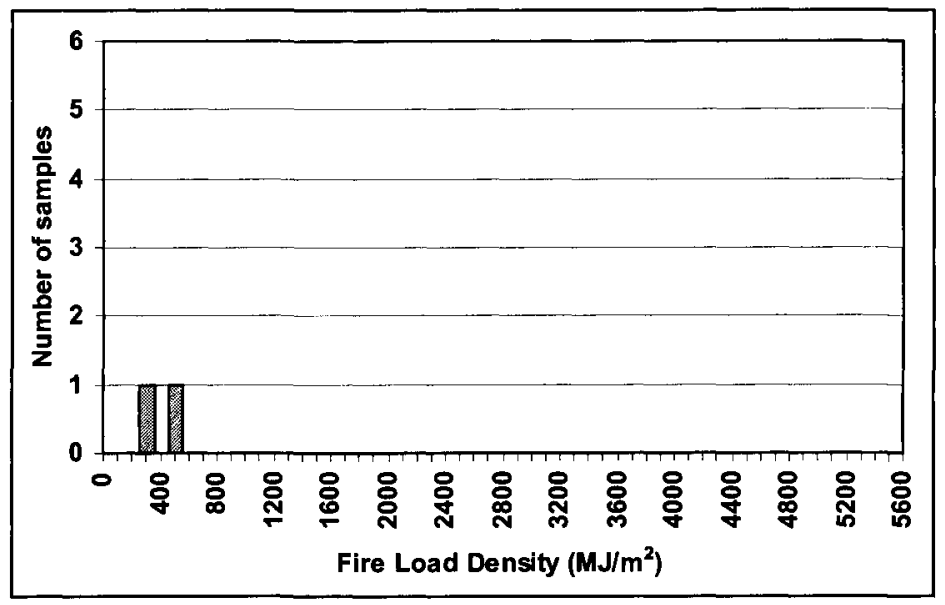

Figure 40. Fire load density of florist shops

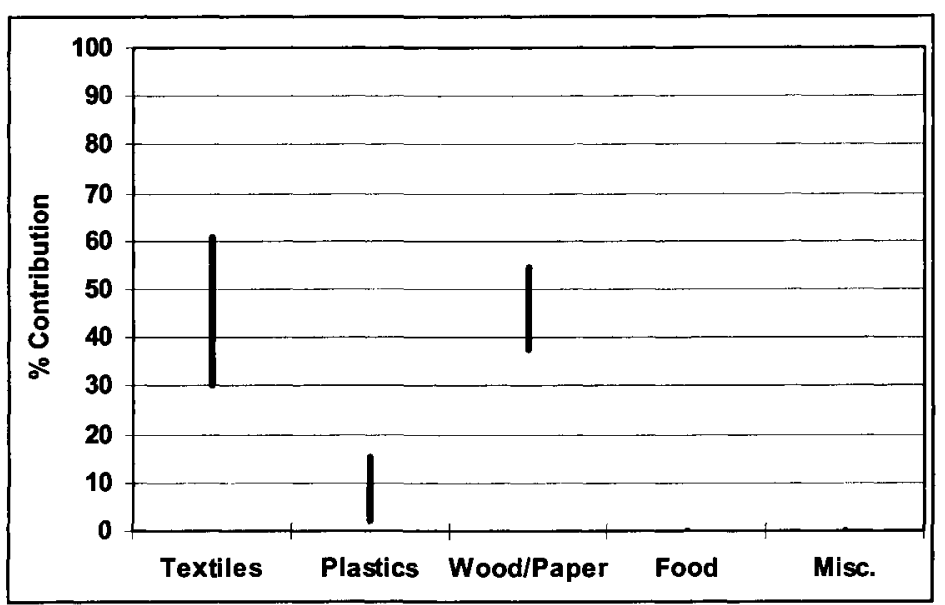

Figure 39. Combustible contributions in dry-cleaning shops

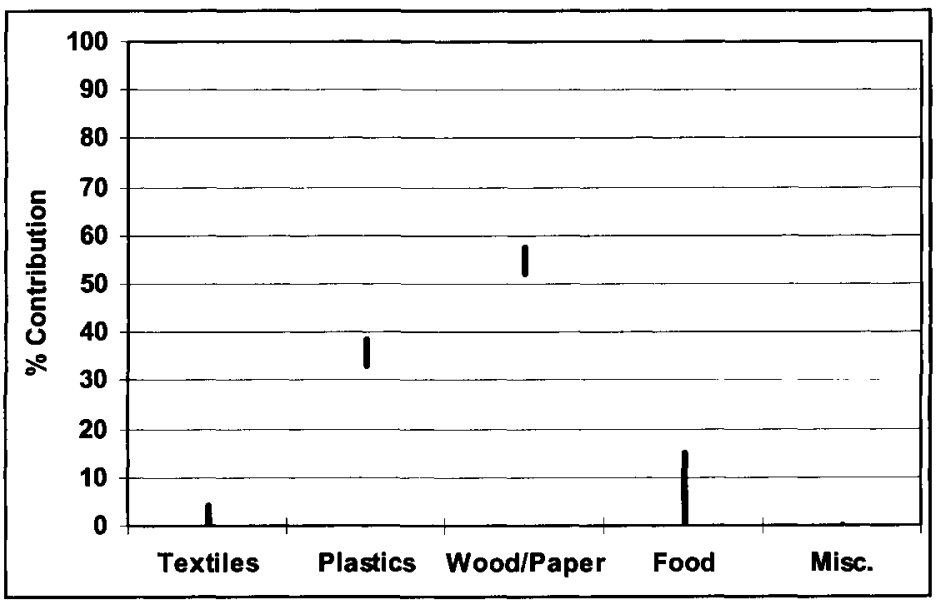

Figure 41. Combustible contributions in florist shops 


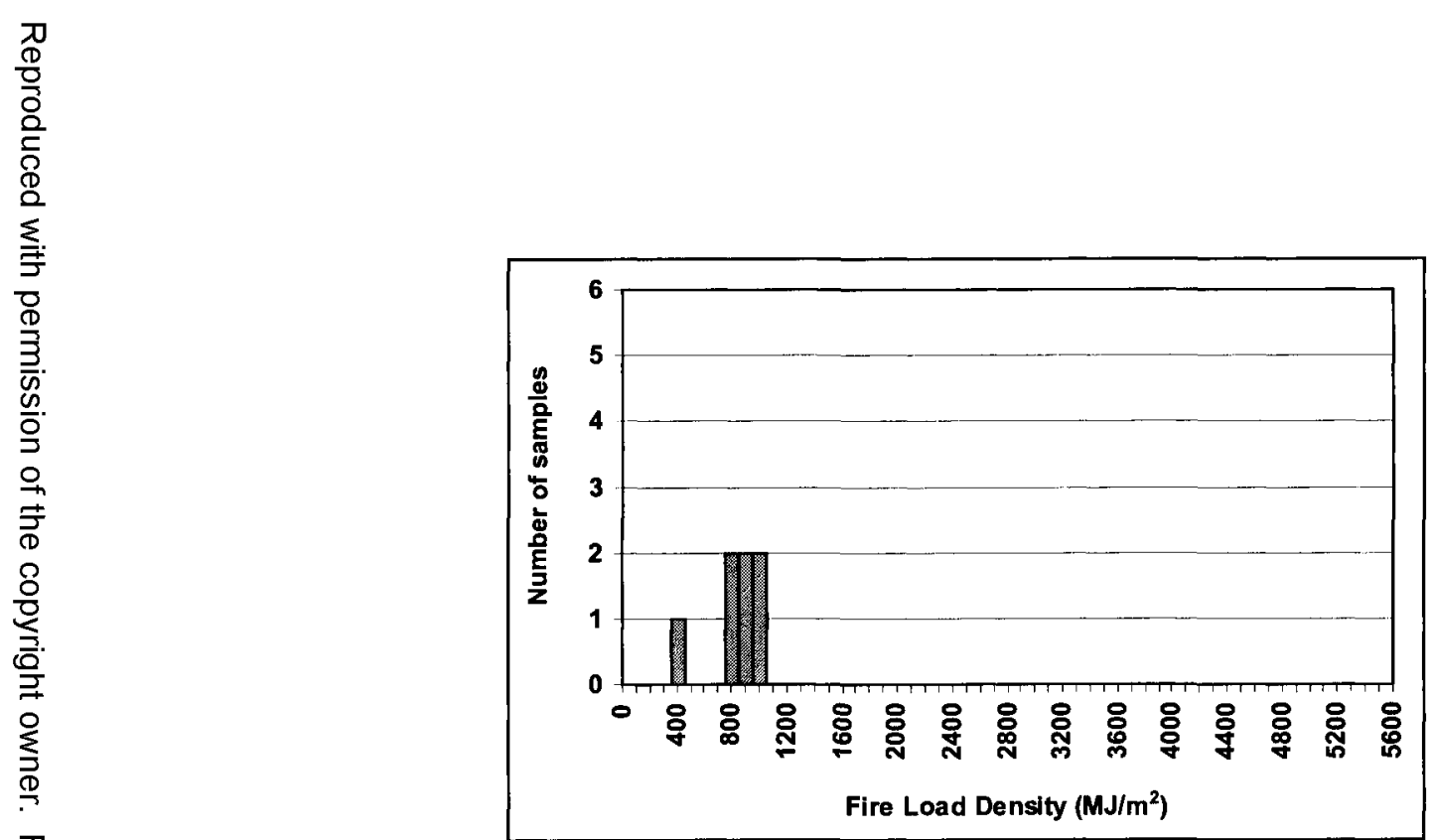

Figure 42. Fire load density of gift shops

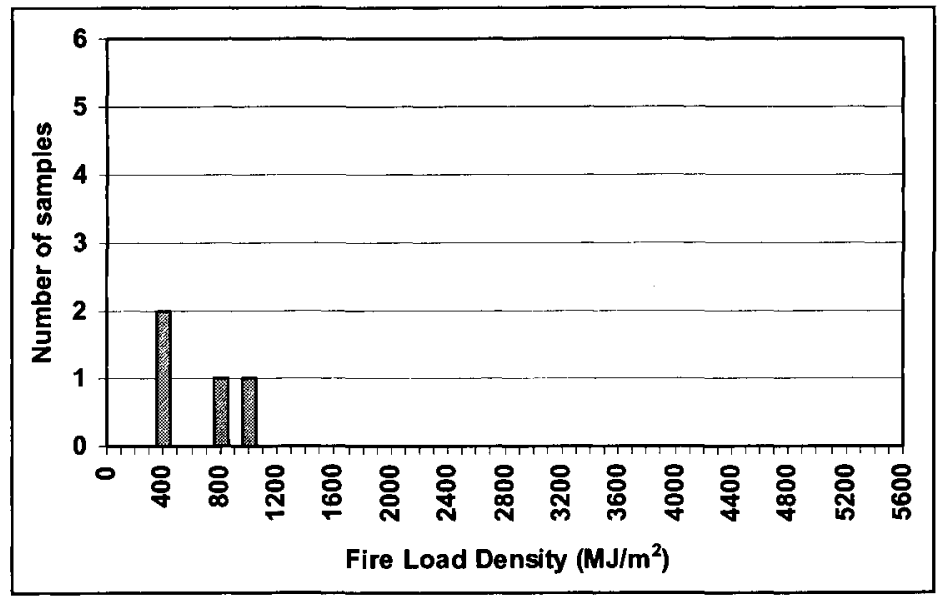

Figure 44. Fire load density of grocery stores

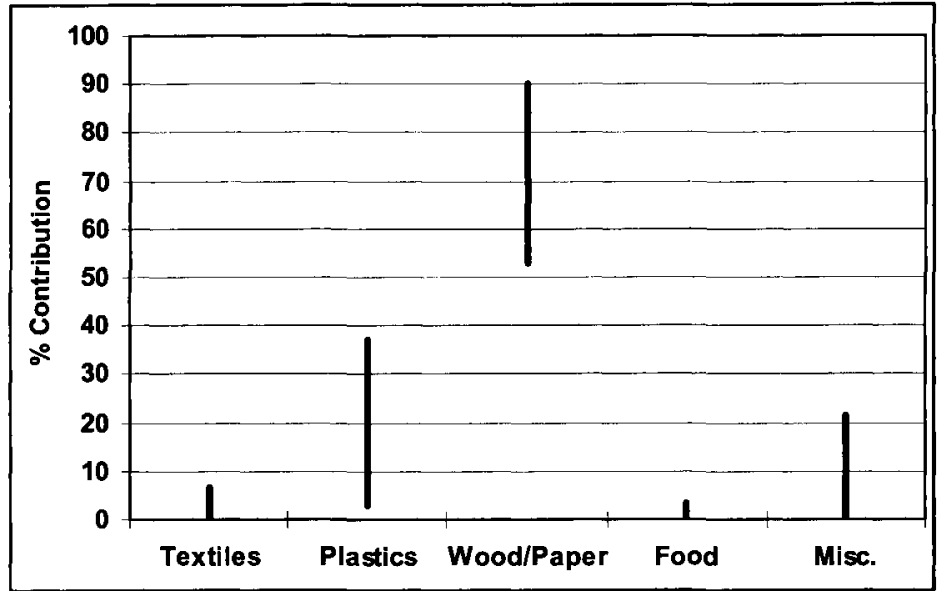

Figure 43. Combustible contributions in gift shops

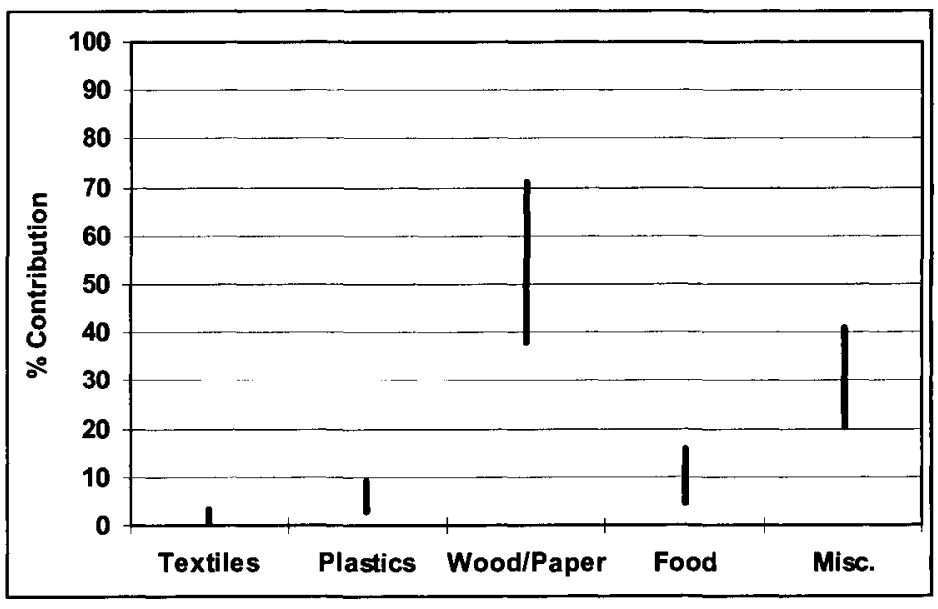

Figure 45. Combustible contributions in grocery stores 


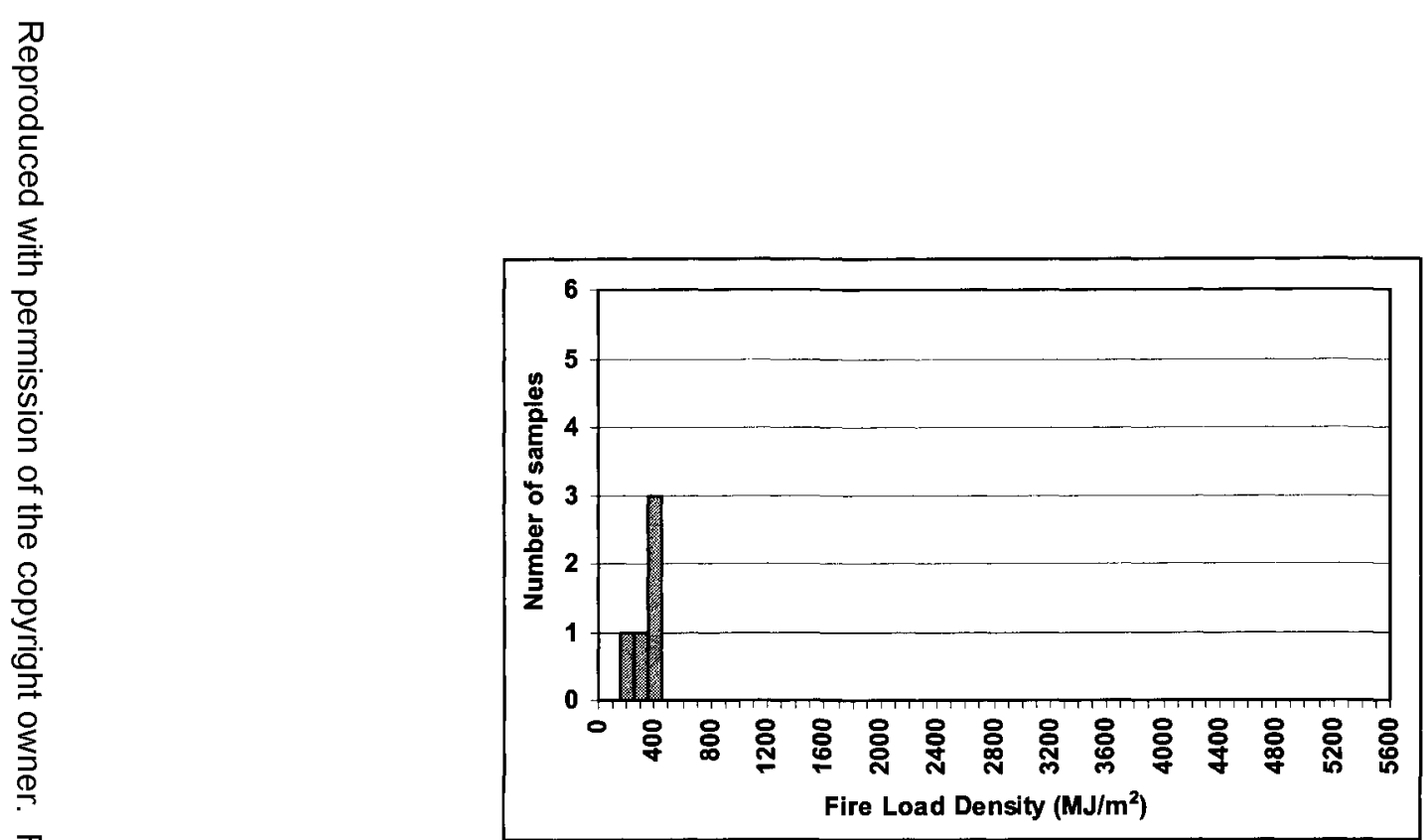

Figure 46. Fire load density of hair-stylist salons

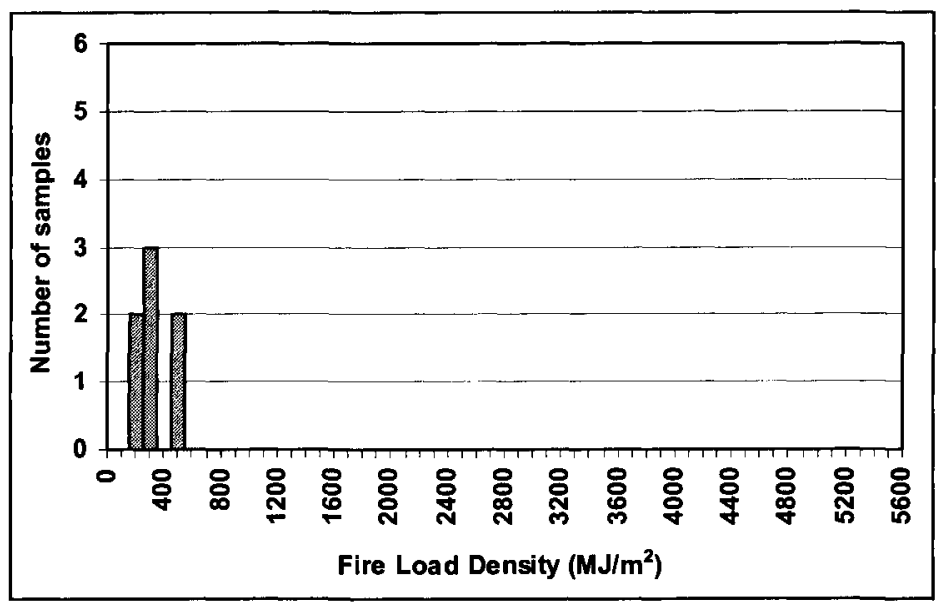

Figure 48 . Fire load density of kitchens

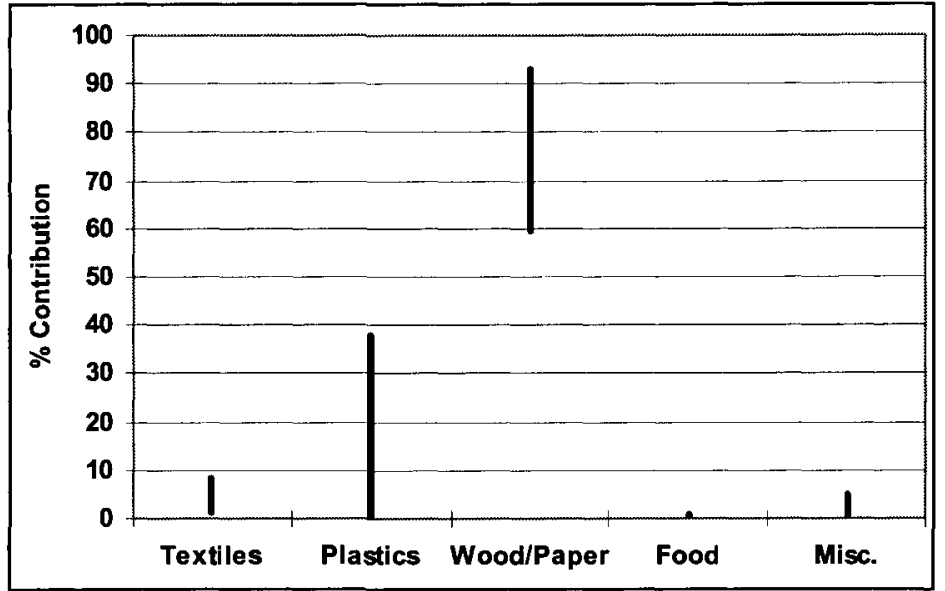

Figure 47. Combustible contributions in hair-stylist salons

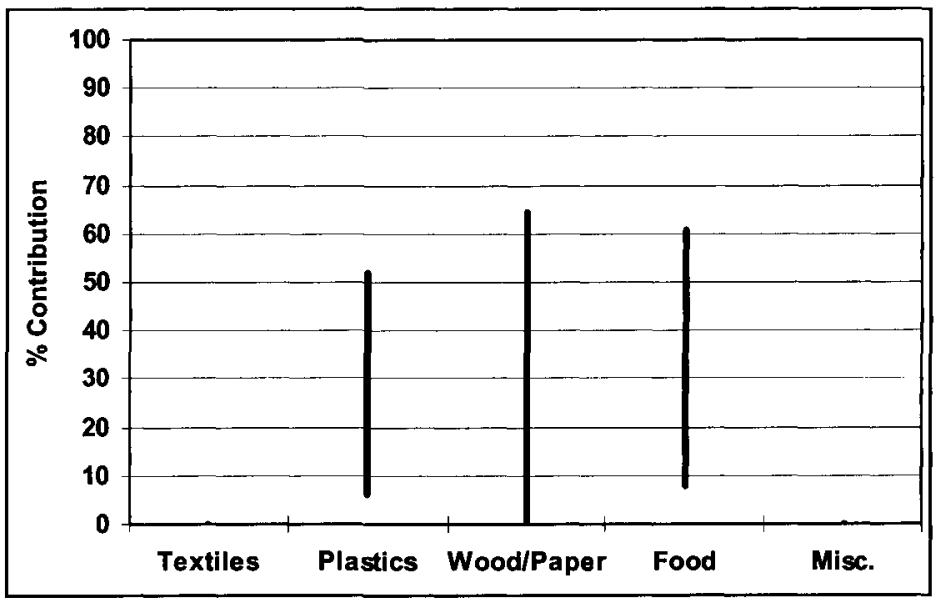

Figure 49. Combustible contributions in kitchens 


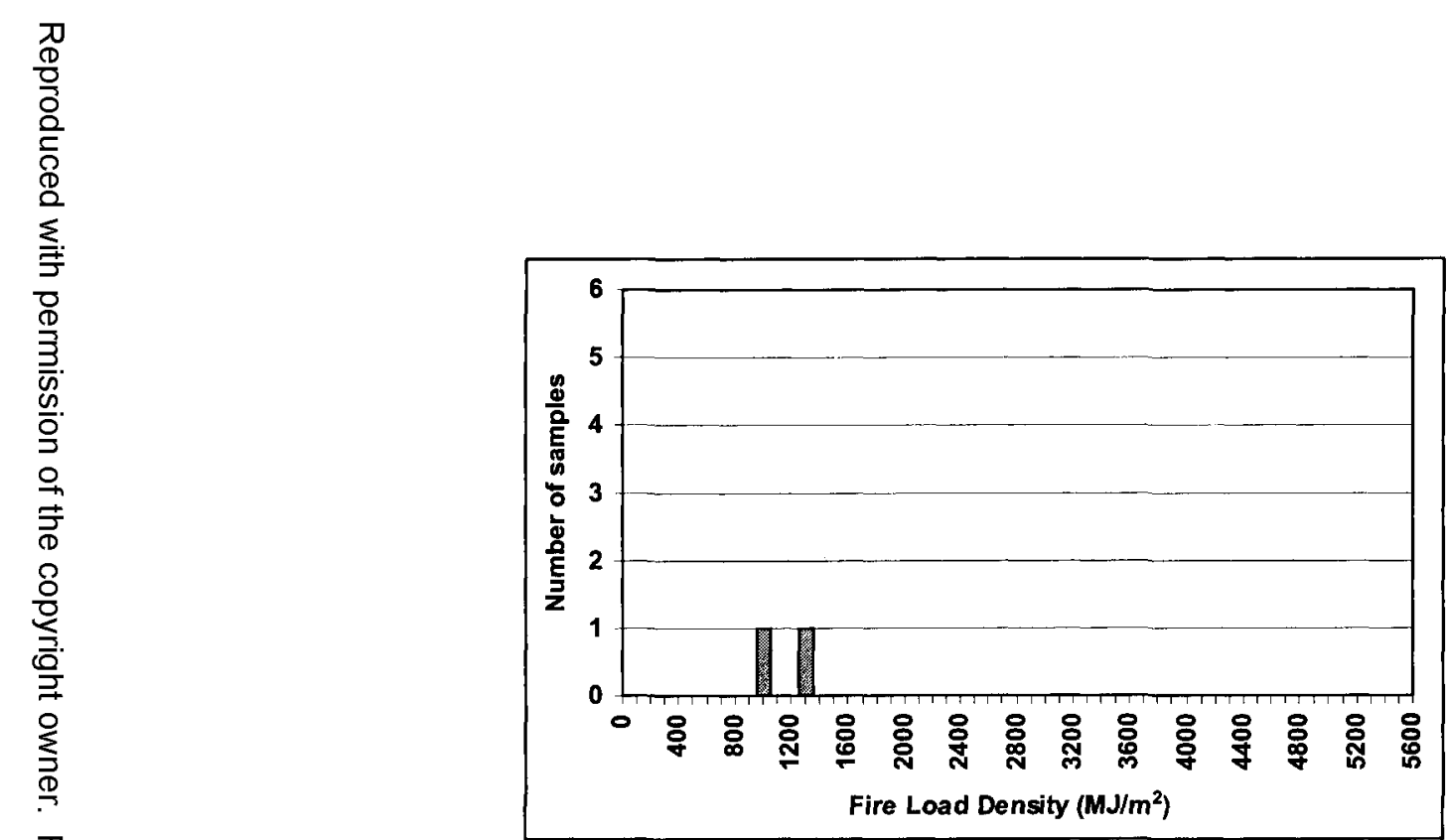

Figure 50. Fire load density of luggage shops

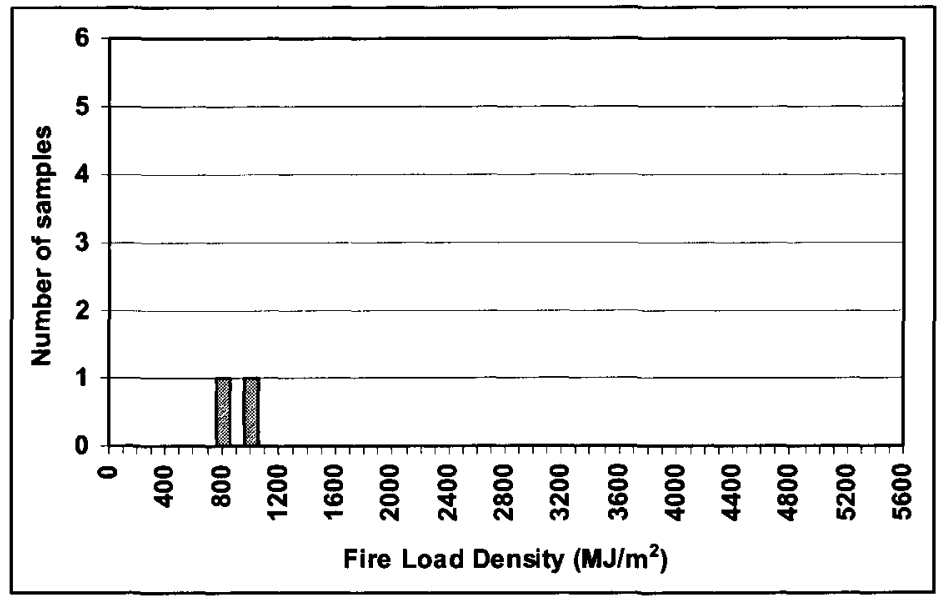

Figure 52. Fire load density of photo-finishing

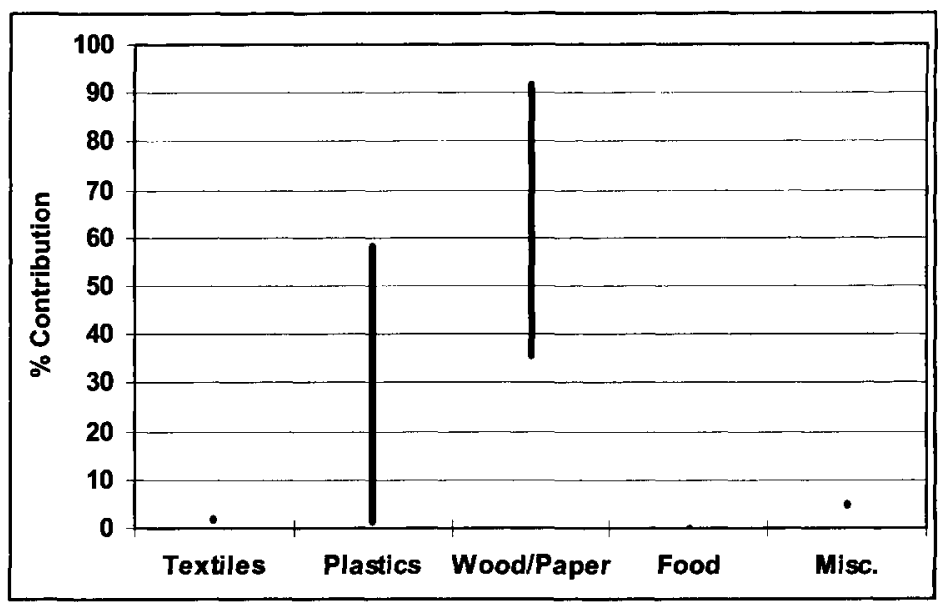

Figure 51. Combustible contributions in luggage shops

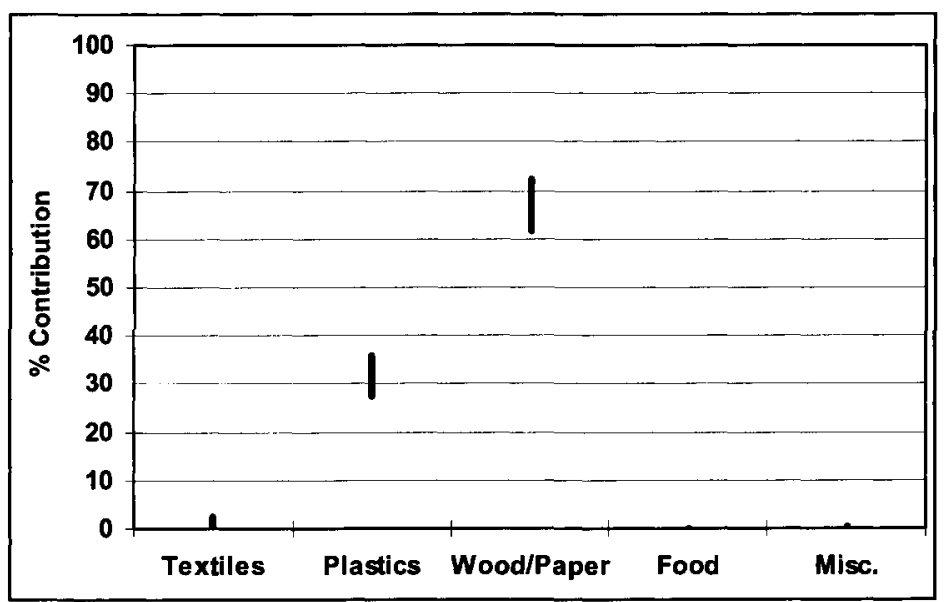

Figure 53. Combustible contributions in photo-finishing 


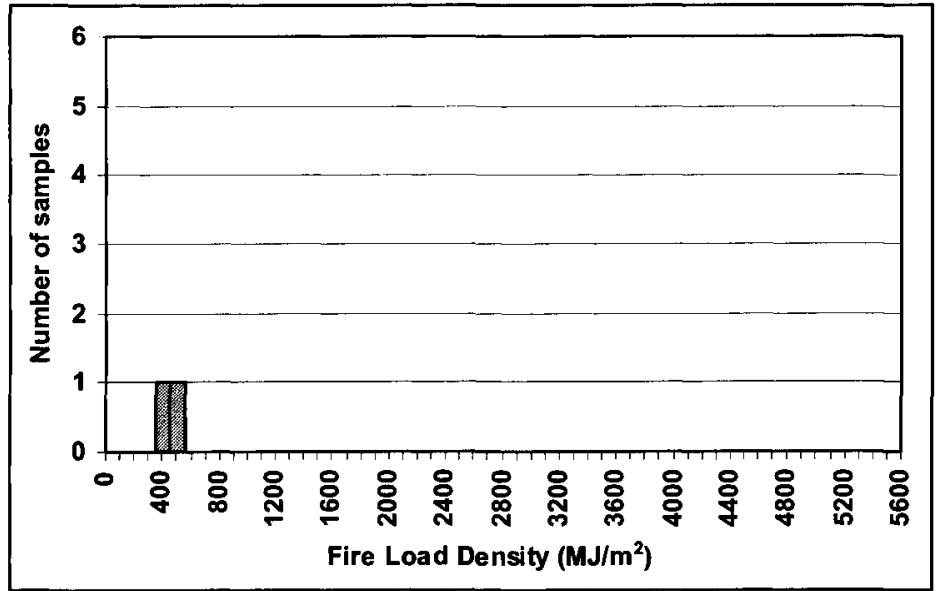

Figure 54. Fire load density of printing \& photocopy shops

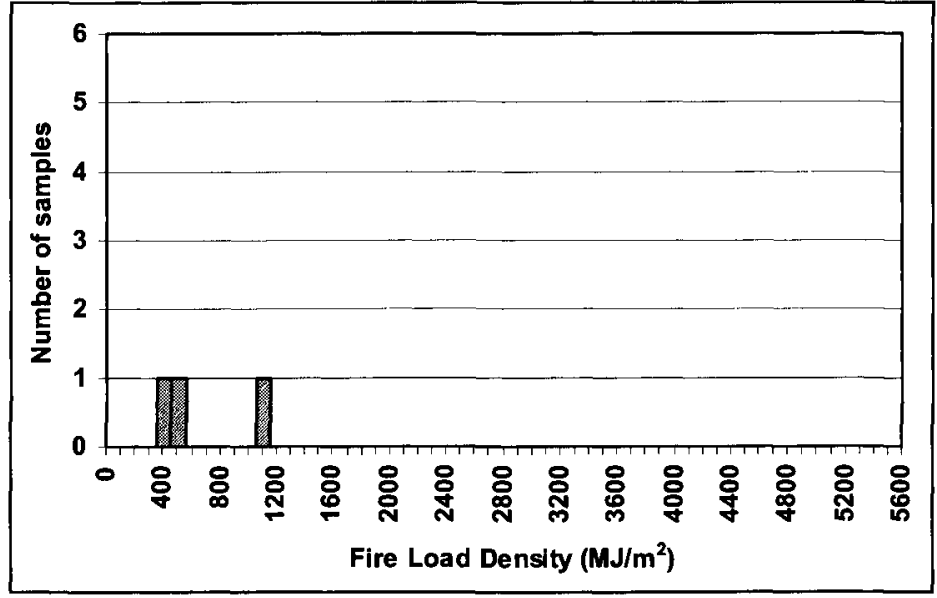

Figure 56. Fire load density of shoe retail shops

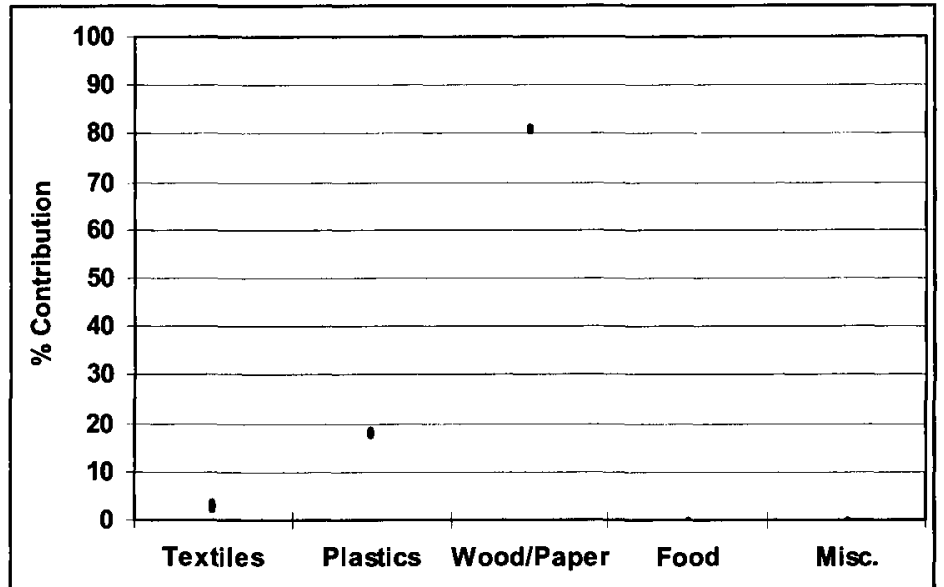

Figure 55. Combustible contributions in printing $\&$ photocopy shops

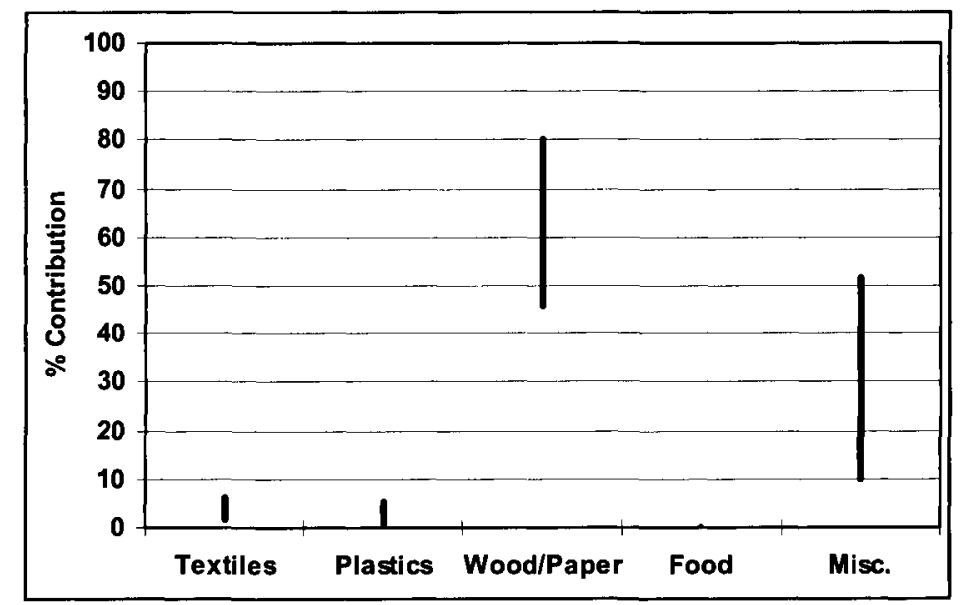

Figure 57. Combustible contributions in shoe retail shops 


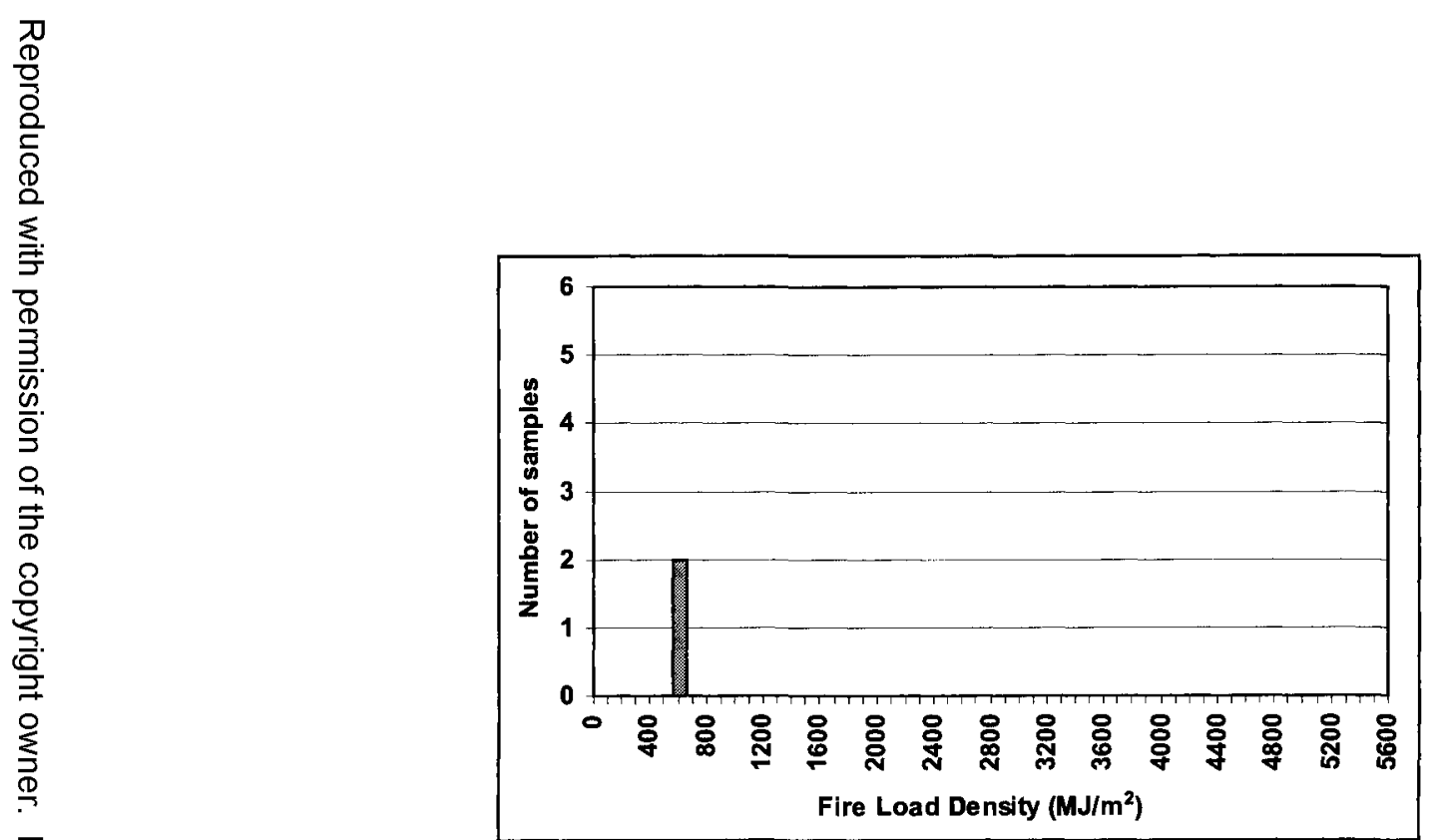

Figure 58. Fire load density of shoe-repair shops

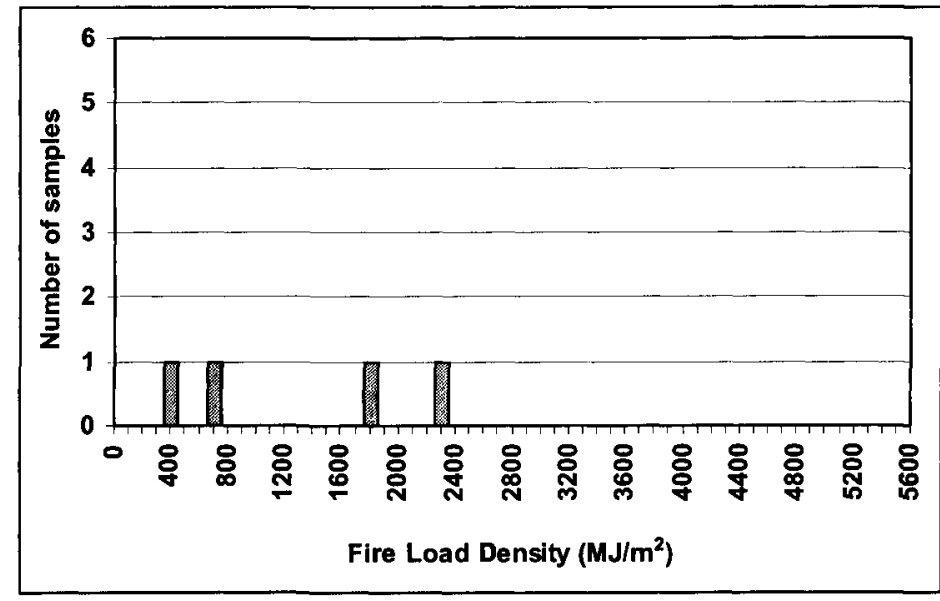

Figure 60. Fire load density of travel agencies

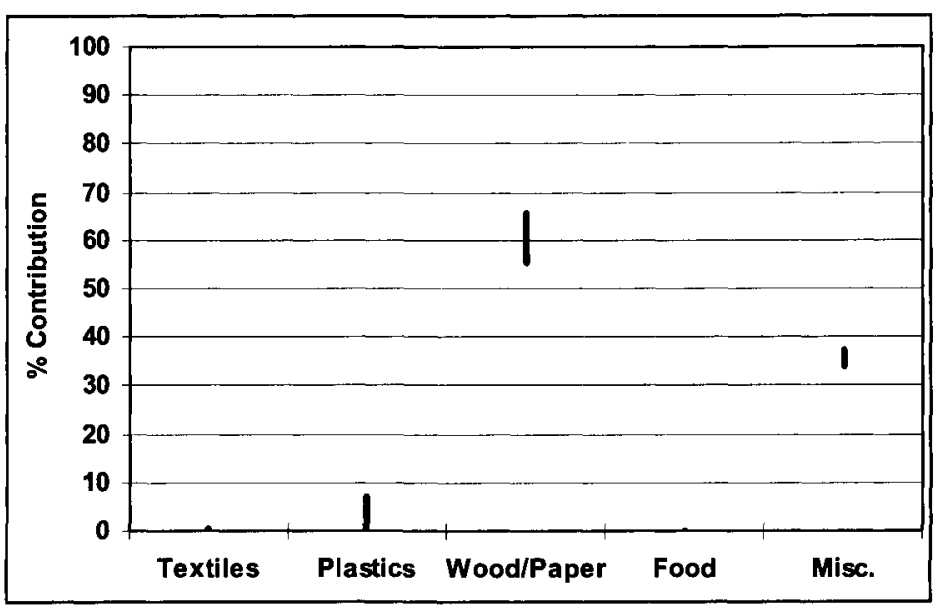

Figure 59. Combustible contributions in shoe-repair shops

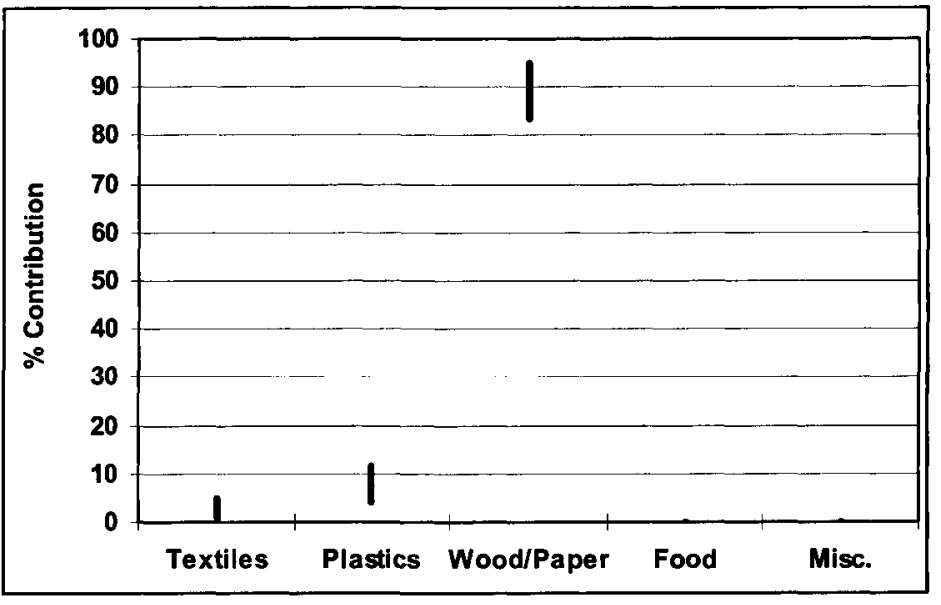

Figure 61. Combustible contributions in travel agencies 


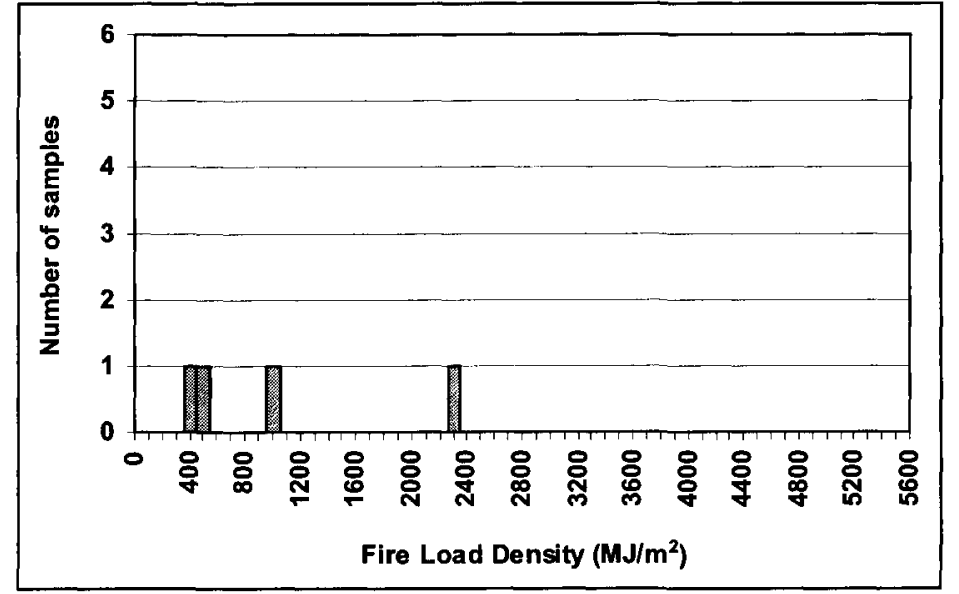

Figure 62. Fire load density of computer accessory \& stationary shops

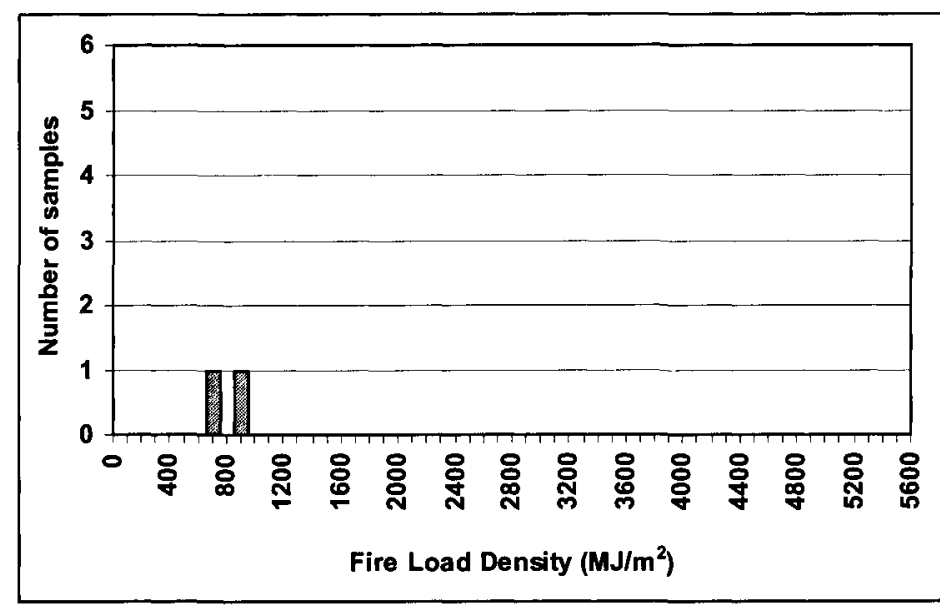

Figure 64. Fire load density of liquor stores

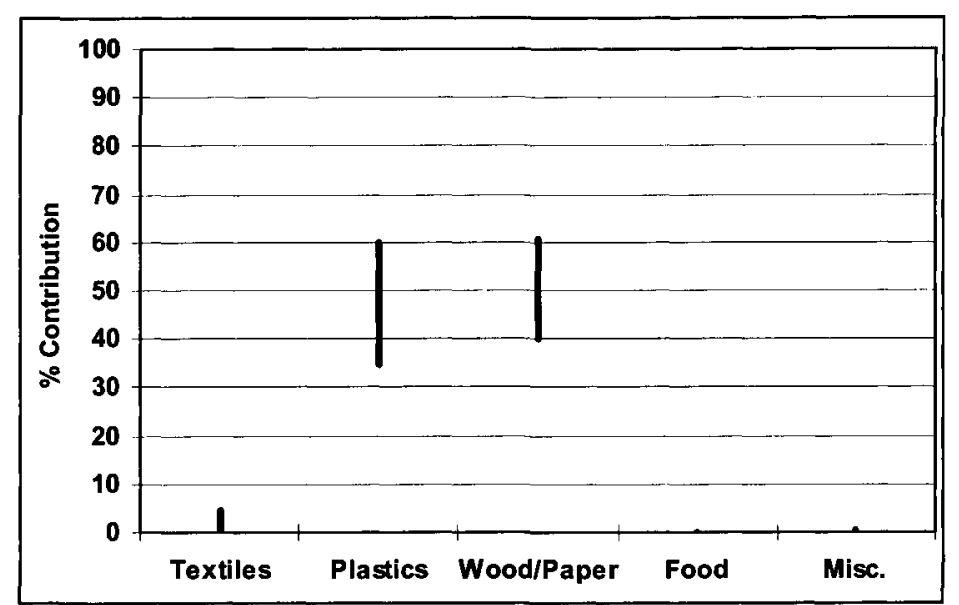

Figure 63. Combustible contributions in computer accessory \& stationary shops

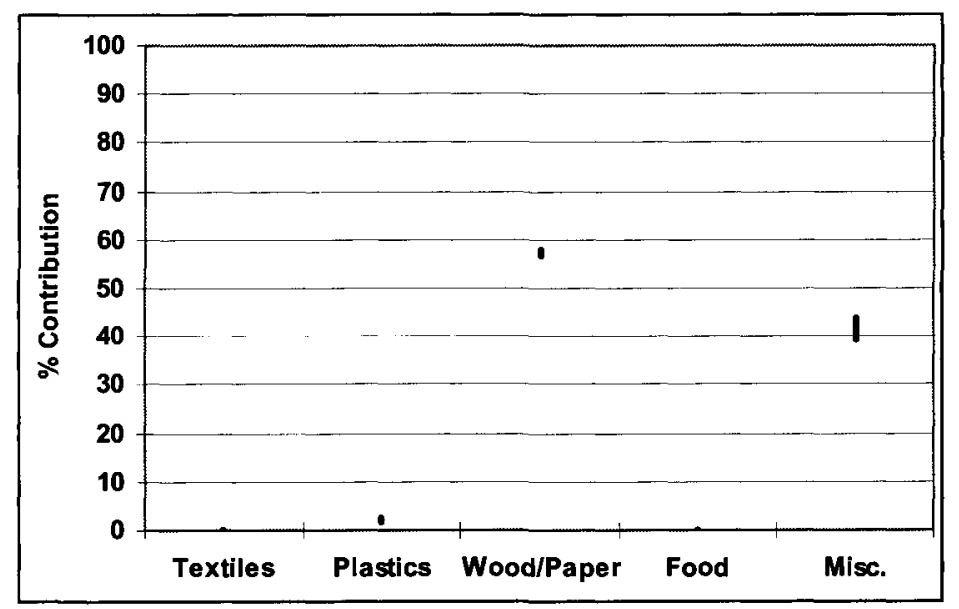

Figure 65. Combustible contributions in liquor stores 


\subsection{Summary}

This section presents the procedures used and results of the survey performed to determine fire loads, types of combustibles and fuel arrangements in commercial premises. Results of the analysis were used to develop fuel packages for the tests conducted to characterize the fires in specific stores.

The buildings surveyed were in the National Capital Region of Canada. They were multi-storey buildings with the first two floors used for services and shopping facilities and the upper floors for offices, as well as stores along one of the main streets in the city of Ottawa. The analysis showed no evidence of differences between the two groups. The establishments surveyed were retail stores providing various goods and services such as shoes, food items, toys, as well as restaurants, bookstores, travel agencies, and storage areas. In addition, if stores had storage areas associated with them, the storage areas were also surveyed and data for these storage areas were kept separate.

The fire load densities of the 168 surveyed stores had a lognormal distribution with a mean value of $747 \mathrm{MJ} / \mathrm{m}^{2}$, a maximum value of $5,305 \mathrm{MJ} / \mathrm{m}^{2}$, a minimum value of $56 \mathrm{MJ} / \mathrm{m}^{2}$, and a standard deviation of $833 \mathrm{MJ} / \mathrm{m}^{2}$. Five different types of combustible groups were identified and formed the main components of the fuel packages in these stores: textiles, plastics, wood/paper, food, and miscellaneous. It is worth noting that the calculated mean value from this survey $\left(747 \mathrm{MJ} / \mathrm{m}^{2}\right)$ is relatively higher than the mean value reported in the CIB report $\left(600 \mathrm{MJ} / \mathrm{m}^{2}\right)$.

The total floor area of clothing stores represented $29.7 \%$ of the total area of the surveyed stores; restaurants $12.9 \%$, storage areas $8.74 \%$, arts \& crafts supply shops $5.26 \%$, and fast 
food outlets $3.9 \%$. The 168 surveyed stores were categorized into different groups to allow for further statistical analysis.

In storage areas, the fire load density ranged from 56 to $4,899 \mathrm{MJ} / \mathrm{m}^{2}$, with a 95 th percentile value of $4,289 \mathrm{MJ} / \mathrm{m}^{2}$ and mean value of $1,196 \mathrm{MJ} / \mathrm{m}^{2}$. In clothing stores, the fire load density ranged from 142 to $755 \mathrm{MJ} / \mathrm{m}^{2}$, with a 95 th percentile value of $661 \mathrm{MJ} / \mathrm{m}^{2}$ and a mean value of $393 \mathrm{MJ} / \mathrm{m}^{2}$. In $40 \%$ of these stores, textiles were the main combustible, with over $50 \%$ of the total fire load density; while in $60 \%$ of the stores, wood was the main combustible with over $50 \%$ of the total fire load density. In the fast food outlets, and fast food outlets and grocery stores, the fire load density had 95th percentile values of 881 and $1052 \mathrm{MJ} / \mathrm{m}^{2}$ respectively, and mean values of 526 and $654 \mathrm{MJ} / \mathrm{m}^{2}$, respectively. In restaurants, the fire load density of had a 95 th percentile of $582 \mathrm{MJ} / \mathrm{m}^{2}$, and mean value of $298 \mathrm{MJ} / \mathrm{m}^{2}$.

Figure 68 shows the range, mean, and 95th percentile values of the fire load densities for the major groups. Storage areas of shoe stores had the highest 95 th percentile value at $4,612 \mathrm{MJ} / \mathrm{m}^{2}$, which is close to the 95 th percentile value of all storage areas $\left(4,289 \mathrm{MJ} / \mathrm{m}^{2}\right)$. All storage areas, and in particular storage areas of shoe stores, had significantly high fire load densities compared to other groups, and also had a wide range of fire load densities. All other groups had a fire load density with 95th percentile ranging from 217 to $2156 \mathrm{MJ} / \mathrm{m}^{2}$. The 95 th percentile and mean fire load density values showed a tendency to decrease with the increase of floor area of clothing stores, fast food outlets, and restaurants. 
In both fast food outlets and restaurants, food items were not the main combustible, while wood and papers found in tables, chairs, and decoration materials were the major combustibles. 


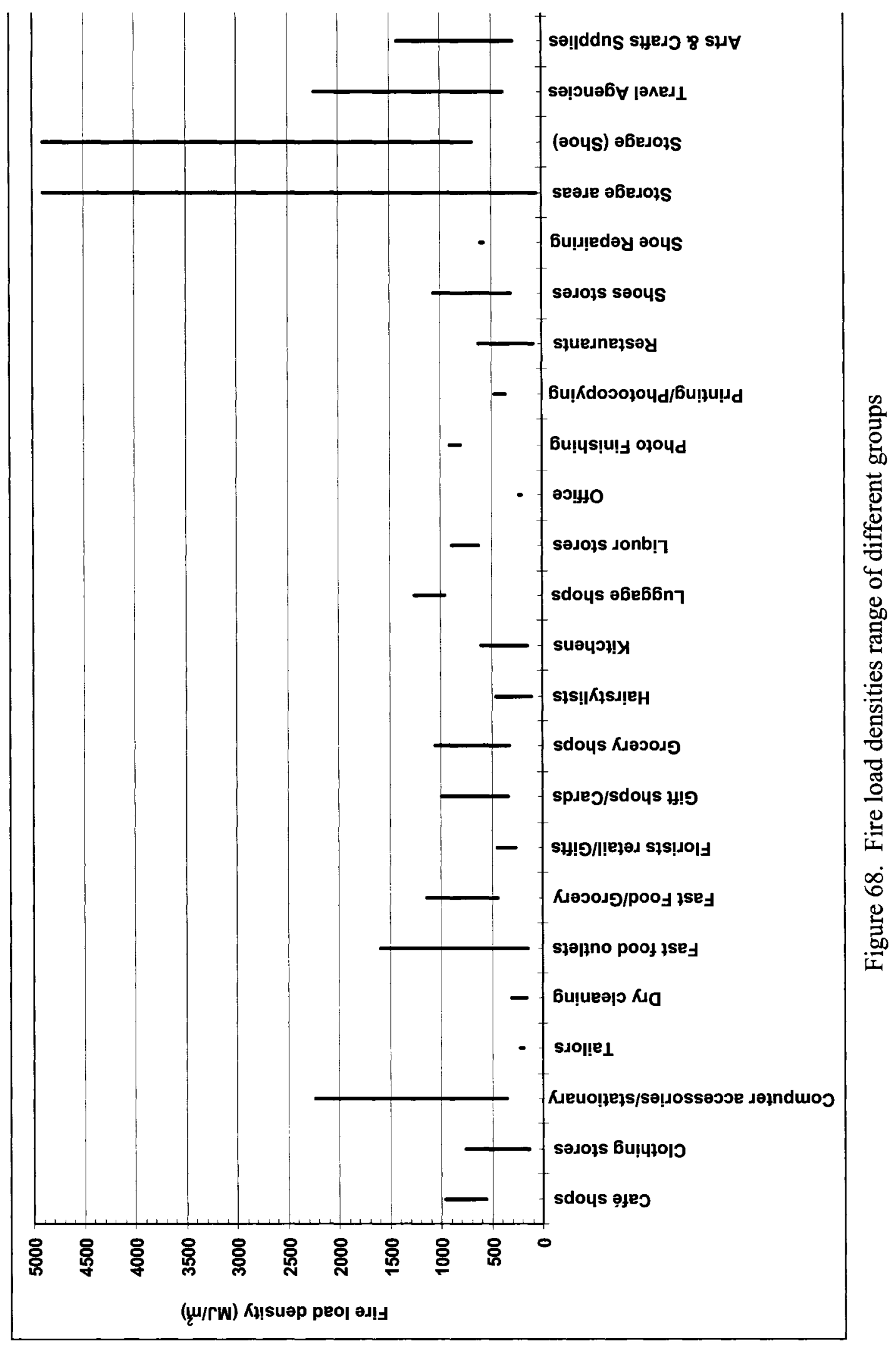

Reproduced with permission of the copyright owner. Further reproduction prohibited without permission. 


\section{EXPERIMENTAL WORK}

\subsection{Introduction}

The probability of occurrence of different fire types for apartment buildings reported from statistics shown in Table 3, suggests that flashover fires are as important as smouldering and non-flashover fires. Also, the percentage of fires with extent of flame damage beyond the room of fire origin in the USA, suggests that retail premises would have the same trend as apartments, Table 6. For the above two reasons, it was decided to investigate fire characteristics in the post-flashover stage.

A series of experiments was conducted to determine the burning characteristics of different fuel packages in order to develop data to characterize design fires for commercial premises. These packages represented fuel loads determined from the survey of commercial buildings, and were selected based on the reported statistics about the area of fire origin in commercial premises, Table 8 .

Two series of experiments, Phase I and II, were conducted. Phase I was conducted in an ISO 9705 standard room ${ }^{3}$, and Phase II in a larger facility that allowed post-flashover fires to be studied. The results of these tests are discussed in the following sections.

\subsection{The Test Facilities}

Two different test facilities were used for Phase I and II. Both facilities are located inside the burn-hall of the National Research Council of Canada (NRCC). Details of the burn room geometries, construction materials and instrumentations used in conducting the tests are given in the following sections. 


\subsubsection{Phase I Series - ISO room}

In Phase I, nine tests were conducted in a test room with dimensions $2.4 \times 3.6 \times 2.4 \mathrm{~m}$ high, with a $0.8-\mathrm{m}$ wide $\times 2.0-\mathrm{m}$ high doorway. The size and construction of the burn room, the configuration of the duct, and associated instrumentation were based on applicable portions of ISO $9705-1993^{3}$ requirements, fire tests-full-scale room test for surface products, see Figure 69 for details. The room was fitted with an exhaust collection hood and a calorimetric measuring system. The hood exhaust system and instrumentation were calibrated using a propane burner prior to conducting the tests in the burn room. The test room was constructed from non-combustible materials, with the walls and ceiling lined with cement board and the floor lined with concrete tiles. The $3.6 \mathrm{~m}$ sides of the room were on the north and south sides of the room, while the $2.4 \mathrm{~m}$ sides were toward the east and west. The doorway was located on the west wall directly under a hood connected to an exhaust duct having a diameter of $406 \mathrm{~mm}$.

To facilitate calculation of the heat release rate using the oxygen consumption method $\left(\right.$ Janssens $^{34}$ ), gas sampling probes located in the duct, continuously sampled and monitored oxygen $\left(\mathrm{O}_{2}\right)$ concentration, and production rates of carbon monoxide $(\mathrm{CO})$ and carbon dioxide $\left(\mathrm{CO}_{2}\right)$ in the combustion gases collected from the burn room. The smoke optical density was measured in the duct using a pulsed white light meter. 


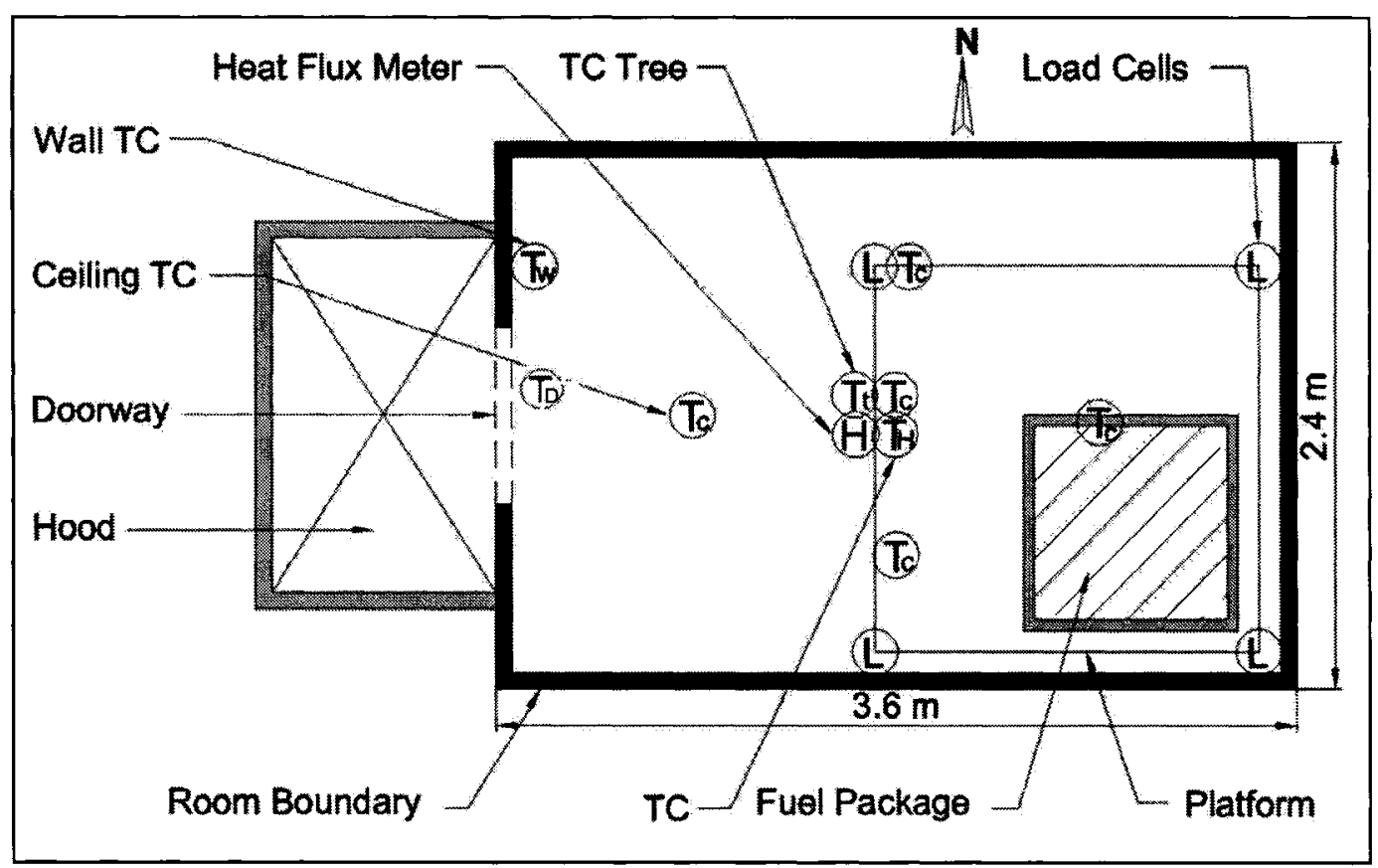

Figure 69. Test setup in the ISO-9705 compatible room

The following instrumentation was used to record gas temperatures, concentrations of $\mathrm{O}_{2}$ and production rates of $\mathrm{CO}$ and $\mathrm{CO}_{2}$, mass loss rate, and heat flux.

\subsubsection{Thermocouples}

K-Type thermocouples (TCs) were used to monitor the temperature at different locations as follows:

1. To measure the hot layer temperature, a thermocouple tree (labelled $T_{w}$ in Figure 69) was placed close to the doorway, $300 \mathrm{~mm}$ from the corner, with thermocouples located at various heights from the floor as follows: $2.10,1.72$, $1.57,1.42,1.27,0.97$, and $0.67 \mathrm{~m}$.

2. To measure the hot layer temperature in the middle of the room, a thermocouple tree (labelled $T_{t}$ in Figure 69) was installed at the centre of the room with 
thermocouples at various heights from the floor as follows: $2.4,2.36,2.26,2.16$, $2.05,1.46,0.98$, and $0.46 \mathrm{~m}$.

3. To monitor the temperature at the room ceiling level, five thermocouples were installed $25 \mathrm{~mm}$ below the ceiling (labelled $\mathrm{T}_{\mathrm{c}}$ in Figure 69).

4. To measure the temperature of gases leaving the room, a thermocouple was installed $25 \mathrm{~mm}$ below the top of the doorframe (labelled $\mathrm{T}_{\mathrm{D}}$ in Figure 69).

5. To record the temperature close to a heat flux meter, a thermocouple (labelled $T_{H}$ in Figure 69) was placed on the floor close to the heat flux meter.

\subsubsection{Load Cells}

For measuring the mass loss of the fuel package during the tests, a $1.8 \times 1.8-\mathrm{m}$ suspended steel platform was constructed in the test room, $0.2 \mathrm{~m}$ above the floor. The platform was suspended and connected at the corners using four cables to four load cells with a total capacity of $1,814 \mathrm{~kg}$. The platform was covered with a cement board to protect it from flames and burning materials.

\subsubsection{Gas Analyzers}

Outside the doorway, a hood leading to an exhaust system was used to collect all smoke produced by the fire. The hood was connected to an exhaust duct where the smoke temperature, pressure, and mole fractions of $\mathrm{CO}, \mathrm{CO}_{2}$, and $\mathrm{O}_{2}$, were measured. Measurements of optical density were recorded using a pulsed white light smoke meter. 


\subsubsection{Other Instrumentation}

1. To determine the onset of flashover, heat flux measurements were collected using a heat flux meter (labelled $\mathrm{H}$ in Figure 69) located at floor level at the centre of the room.

2. For measuring smoke layer height, a scale bar was placed by the room door.

3. To record major events, such as fire ignition and growth, flashover, and fullydeveloped and decay phases, a digital video camera, and a digital still point-andshoot camera were used.

\subsubsection{Phase II Series, Post-Flashover Facility}

Testing Phase I fuel packages beyond flashover was not possible in the ISO 9705 standard room; as a result, another facility called the 'post-flashover facility' was used to conduct the Phase II experiments. The post-flashover facility was constructed from noncombustible materials, with walls and ceiling lined with cement board, and covered with sheets of ceramic fibres, and the floor was lined with cement tiles. The dimensions of the room were $3.6 \times 2.7 \times 2.4-\mathrm{m}$ high, with a doorway $0.9-\mathrm{m}$ wide $\times 2.2-\mathrm{m}$ high. The $3.6 \mathrm{~m}$ sides of the room were the east and west sides of the room, while the $2.7 \mathrm{~m}$ sides were towards the north and south; the doorway was located in the south wall. The door opened to an $11.0 \mathrm{~m}$ long corridor that was used to accommodate extended flames and to cool the smoke products before entering the exhaust duct. Figure 70 shows the layout of the postflashover facility. The following instrumentations were used to record gas temperatures, concentrations of $\mathrm{O}_{2}$, and production rates of $\mathrm{CO}$ and $\mathrm{CO}_{2}$, and heat flux. 


\subsubsection{Thermocouples}

K-Type thermocouples (TCs) were used to monitor the temperature at different locations described as follows:

1. To measure the hot layer temperature, a thermocouple tree was placed close to the doorway, $300 \mathrm{~mm}$ from the corner, with thermocouples located at different heights from the floor as follows: $2.10,1.72,1.57,1.42,1.27,0.97$, and $0.67 \mathrm{~m}$.

2. To monitor smoke temperatures in the corridor, a set of thermocouples was placed at the ceiling level along the corridor leading to the hood. The first thermocouple was located at the centerline of the doorway, followed by 10 thermocouples at $0.5-\mathrm{m}$ intervals, and then followed by 4 thermocouples at $0.75-\mathrm{m}$ intervals. The exact TC locations measured from the centerline of the door were as follows: $0.00,0.50,1.00,1.50,2.00,2.50,3.00,3.50,4.00,4.50,5.00,5.75,6.50,7.25$, $8.00 \mathrm{~m}$.

3. To monitor the temperature at the room ceiling level, five thermocouples were installed $25 \mathrm{~mm}$ below the ceiling.

\subsubsection{Gas Analyzers}

Outside the exit doorway, a hood leading to an exhaust system was used to collect the smoke produced by the fire and direct it to a duct where its temperature, pressure, and optical density were measured. The mole fractions of $\mathrm{CO}, \mathrm{CO}_{2}$, and $\mathrm{O}_{2}$, were recorded.

\subsubsection{Other Instrumentations}

1. To determine the onset of flashover, heat flux measurements were collected using a heat flux meter located at floor level at the centre of the room. 
2. For measuring smoke layer height, a scale bar was placed by the door.

3. To record major events, such as fire ignition and growth, flashover, and fullydeveloped and decay phases, two digital video cameras (one facing the burn room, and the second facing the corridor), and a digital still point-and-shoot camera were used.

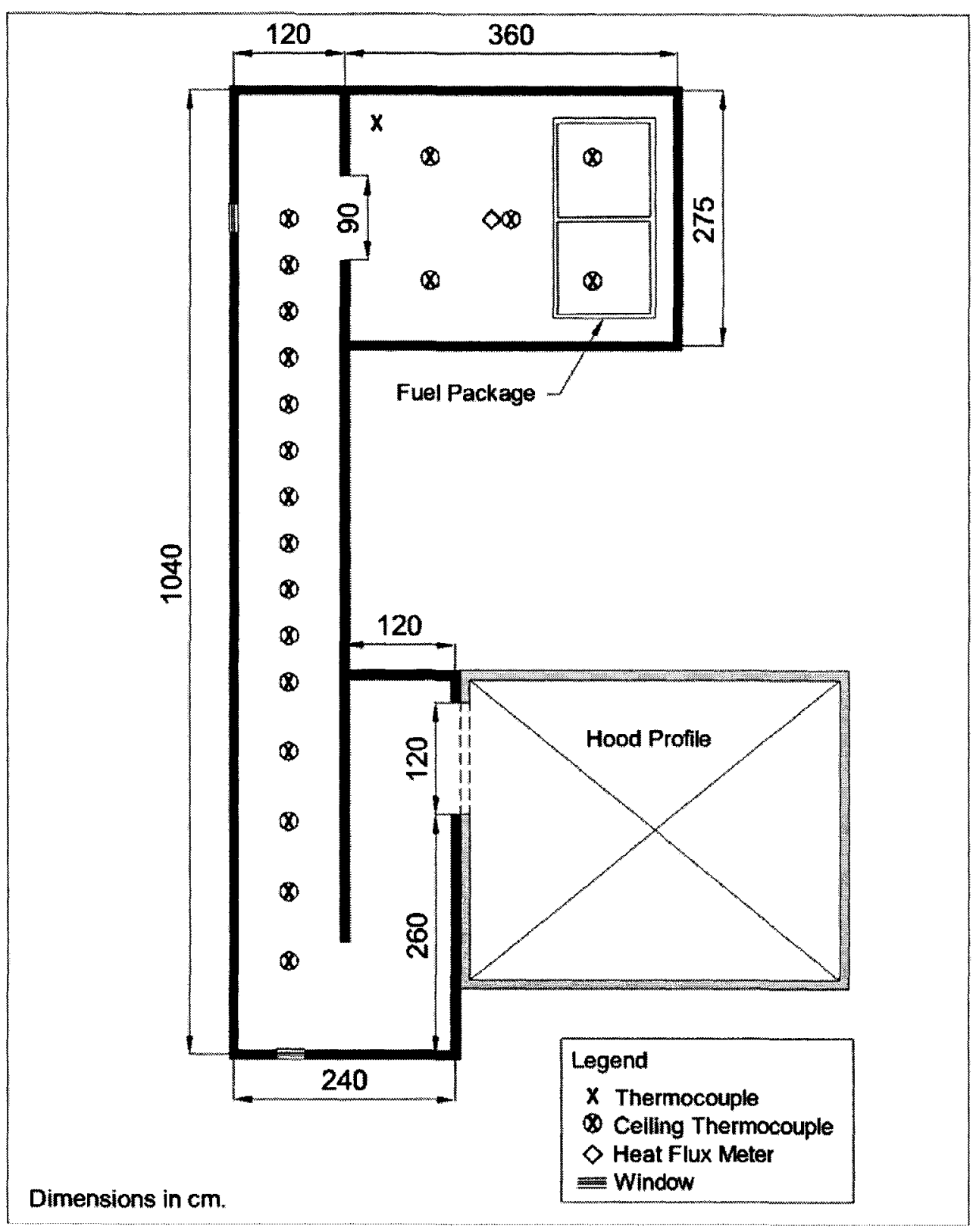

Figure 70. Layout of the Phase II test facility 97 


\subsection{Fuel Packages}

The fuel packages used in Phase I and II experiments were determined based on the survey results discussed before, and the statistics reports about the area of fire origin in retail buildings, Table 8 and Table 10 . The following sections explain the fuel packages tested in Phase I and II experiments.

\subsubsection{Phase I Fuel Packages}

All Phase I experiments were conducted in the standard ISO $9705^{3}$ room. The fuel packages were designed to represent a fuel load of $1 \mathrm{~m}^{2}$ of combustibles. Based on the sample size of the premises surveyed, the fuel packages represented the 90th, 95th percentile or the maximum fire load density found in these premises. Fire load density $\left(\mathrm{MJ} / \mathrm{m}^{2}\right)$ and contribution of different types of combustibles (\%) to the fuel load of each test are shown in Table 16.

The types and distribution of the fuel load inside the fire compartment are critical during the course of the fire, and especially during the fire growth period; therefore, every effort was made to include the exact type and arrangement of fuel for each store. The combinations of combustibles used were chosen to represent as closely as possible the combustibles in the actual stores. Photographs from the surveyed stores were very useful in creating a representative arrangement for the fuel packages. The items used in the fuel packages included computers, printers, shoes, toys (hard and soft), electronics, cardboards, and different types of plastics, wood, papers, and textiles.

For measuring the mass loss, each fuel package was placed on top of the suspended platform, inside the test room. Fire tests should reflect appropriate ignition sources likely 
to occur in commercial premises as ignition sources may vary from small flames (e.g., mechanical failure or electrical fault) to large flames (e.g., fuel fire), Table 9 and Table 11. In all experiments conducted described in this work, fuel packages were ignited using a $75-\mathrm{kW}$ propane T-burner running for 4 minutes to simulate an ignition source from a large wastepaper basket.

To represent the fuel characteristics found in clothing stores in the survey, three fuel packages were developed (see Table 15). The photographs in Figure 79 to Figure 81 depict the tests setups and the developed stage of the fire.

\subsubsection{Phase II Fuel Packages}

Based on the analysis of the results of the nine Phase I experiments presented later in this section, seven different fuel packages were selected for testing in the post-flashover facility. Phase II experiments were conducted using fuel packages, which had twice the area of the Phase I fuel packages, with the exception of the shoe store test. In the Phase I shoe store test, SHO-I, the test had to be terminated early ( 5 minutes after ignition) because gas temperatures inside the duct exceeded the temperature for safe operation of the exhaust system. For this reason, in Phase II, the shoe store test was conducted with a $1.0 \mathrm{~m}^{2}$ fuel package, the same as in Phase I. Fire load details of the Phase II fuel packages are shown in Table 16. Only one fuel package was used for clothing stores in Phase II representing stores with mostly textiles. This package had the highest heat release rate, as well as $\mathrm{CO}$ and $\mathrm{CO}_{2}$ production rates for all clothing store fuel packages tested in Phase I. 
As in Phase I, the packages were ignited using a $75-\mathrm{kW}$ propane T-burner running for 4 minutes to simulate an ignition source from a large wastepaper basket. 
Table 16. Details of Phase I and II fuel packages, fire load densities, and combustible materials

\begin{tabular}{|c|c|c|c|c|c|c|c|c|c|c|c|c|c|}
\hline \multirow[b]{3}{*}{ Test Title } & \multirow[b]{3}{*}{ ID } & \multirow[b]{3}{*}{ 星 } & \multicolumn{11}{|c|}{ Combustible materials } \\
\hline & & & \multicolumn{2}{|c|}{ Textiles } & \multicolumn{2}{|c|}{ Plastics } & \multicolumn{2}{|c|}{ Wood/paper } & \multicolumn{2}{|c|}{$\begin{array}{c}\text { Rubber/ } \\
\text { leather }\end{array}$} & \multicolumn{2}{|c|}{$\begin{array}{c}\text { Food } \\
\text { products }\end{array}$} & \multirow[b]{2}{*}{$\begin{array}{l}\text { Total } \\
\text { mass }^{2} \\
(\mathrm{~kg})\end{array}$} \\
\hline & & & 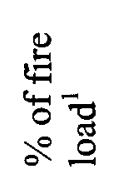 & 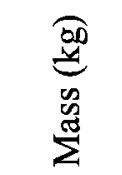 & 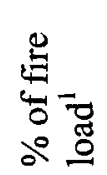 & 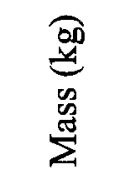 & 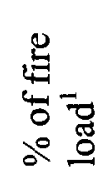 & 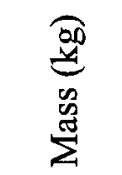 & 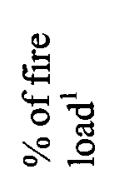 & 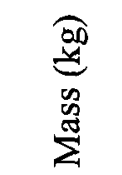 & 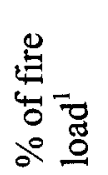 & 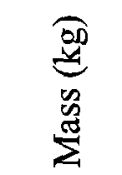 & \\
\hline \multirow[t]{2}{*}{ Computer store } & CMP-I & 812 & 3.08 & 1.35 & 50.6 & 9.44 & 46.3 & 20.90 & 0.00 & 0.00 & 0.00 & 0.00 & 31.69 \\
\hline & CMP-II & 1624 & 3.08 & 2.70 & 50.6 & 18.88 & 46.3 & 41.80 & 0.00 & 0.00 & 0.00 & 0.00 & 63.38 \\
\hline \multirow[t]{2}{*}{ Storage area } & SA-I & 2320 & 5.60 & 6.85 & 31.1 & 16.59 & 49.1 & 64.16 & 8.50 & 5.329 & 5.70 & 9.227 & 102.1 \\
\hline & SA-II & 4640 & 5.60 & 13.70 & 31.1 & 33.18 & 49.1 & 128.3 & 8.50 & 10.66 & 5.70 & 18.45 & 204.3 \\
\hline Clothing store & CLS-I & 661 & 55.0 & 19.65 & 6.00 & 0.912 & 37.0 & 13.59 & 2.00 & 0.497 & 0.00 & 0.00 & 34.65 \\
\hline Clothing store & CLW-I & 661 & 23.0 & 8.218 & 1.00 & 0.152 & 76.0 & 27.91 & 0.00 & 0.00 & 0.00 & 0.00 & 36.28 \\
\hline \multirow[t]{2}{*}{ Clothing store } & CLC-I & 661 & 86.0 & 30.73 & 2.00 & 0.304 & 12.0 & 4.407 & 0.00 & 0.00 & 0.00 & 0.00 & 35.44 \\
\hline & CLC-II & 1322 & 86.0 & 61.46 & 2.00 & 0.608 & 12.0 & 8.814 & 0.00 & 0.00 & 0.00 & 0.00 & 70.88 \\
\hline \multirow[t]{2}{*}{ Toy store } & TOY-I & 1223 & 6.59 & 4.360 & 18.6 & 5.245 & 74.8 & 50.81 & 0.00 & 0.00 & 0.00 & 0.00 & 60.42 \\
\hline & TOY-II & 2446 & 6.59 & 8.720 & 18.6 & 10.49 & 74.8 & 101.6 & 0.00 & 0.00 & 0.00 & 0.00 & 120.8 \\
\hline \multirow[t]{2}{*}{ Shoe storage } & SHO-I & 4900 & 1.00 & 2.649 & 0.00 & 0.00 & 34.0 & 92.56 & 65.0 & 119.6 & 0.00 & 0.00 & 214.8 \\
\hline & SHO-II ${ }^{3}$ & 4900 & 1.00 & 2.649 & 0.00 & 0.00 & 34.0 & 92.56 & 65.0 & 119.6 & 0.00 & 0.00 & 214.8 \\
\hline \multirow[t]{2}{*}{ Bookstore } & BK-I & 5305 & 0.40 & 1.147 & 0.00 & 0.00 & 99.6 & 301.8 & 0.00 & 0.00 & 0.00 & 0.00 & 302.9 \\
\hline & BK-II & 10610 & 0.40 & 2.294 & 0.00 & 0.00 & 99.6 & 603.6 & 0.00 & 0.00 & 0.00 & 0.00 & 605.8 \\
\hline \multirow[t]{2}{*}{ Fast food outlet } & FF-I & 881 & 0.30 & 0.142 & 19.3 & 3.907 & 38.9 & 19.05 & 0.00 & 0.00 & 41.5 & 8.708 & 31.81 \\
\hline & FF-II & 1762 & 0.30 & 0.284 & 19.3 & 7.814 & 38.9 & 38.10 & 0.00 & 0.0 & 41.5 & 17.42 & 63.61 \\
\hline
\end{tabular}




\subsection{Experimental Results}

The following sections provide a description of the tests setup, observations, and discussion of the results, such as $\mathrm{HRR}, \mathrm{CO}$ and $\mathrm{CO}_{2}$ production rates, hot layer temperature, mass loss rate, heat fluxes, and optical density. Photographs of the tests setup and fire development are also presented.

\subsubsection{Phase I Experiments-Results And Discussions}

\subsubsection{Hot Layer Temperature}

K-Type thermocouples (TCs) were used to monitor the temperature at different locations as follows: (1) corner of the room; (2) ceiling level; (3) middle of the room; (4) door way; and (5) inside the duct.

The TC tree at the corner of the room was a good indicator of the hot layer temperature, and these TCs are used for the analysis below. The TCs at the ceiling level, especially the TCs above the fire, and the TC tree in the middle of the room were affected by direct flame impingement and the temperatures were higher than the hot layer temperature. The duct TC was used in the HRR calculations, as well as to monitor the temperature in the duct, which was used as the criterion for evaluating whether the duct instrumentation was safe.

Table 17 shows peak temperatures at different locations inside the burn room, as well as the heat flux values for all Phase I experiments. Figure 71 shows that the hot layer temperature in the corner of the room, $2.1 \mathrm{~m}$ from floor, varies from $180^{\circ} \mathrm{C}$ in $\mathrm{CMP}-\mathrm{I}$ to $600^{\circ} \mathrm{C}$ in SHO-I. The recorded hot layer temperature correlate well with the recorded heat flux values (see Figure 72).

Peak heat flux values ranged from 1 to $21 \mathrm{~kW} / \mathrm{m}^{2}$. The hot layer temperature and the recorded 
heat flux suggest that flashover did not occur in most Phase I experiments, with the exception of test SHO-I that had a peak hot layer temperature of $600^{\circ} \mathrm{C}$ with a heat flux of $21 \mathrm{~kW} / \mathrm{m}^{2}$, and in tests TOY-I and BK-I, where temperatures were close to $600^{\circ} \mathrm{C}$ and heat fluxes reached about $18 \mathrm{~kW} / \mathrm{m}^{2}$.

Table 17. Peak temperatures and heat flux of Phase I experiments

\begin{tabular}{|c|c|c|c|c|c|c|c|}
\hline \multirow[b]{2}{*}{ Test title } & \multirow[b]{2}{*}{ Test ID } & \multicolumn{5}{|c|}{ Peak temperatures $\left({ }^{\circ} \mathrm{C}\right)$} & \multirow[b]{2}{*}{ 焉 } \\
\hline & & 灾 & 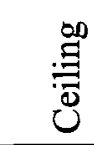 & $\frac{0}{\frac{0}{g}}$ & 苍 & $\overline{\mathrm{g}}$ & \\
\hline Computer store & CMP-I & 180 & 353 & 316 & 227 & 50 & 1.14 \\
\hline Storage area & SA-I & 450 & 724 & 662 & 458 & 196 & 11.56 \\
\hline Clothing store & CLS-I & 340 & 708 & 529 & 401 & 65 & 3.74 \\
\hline Clothing store & CLW-I & 380 & 870 & 488 & 424 & 75 & 4.22 \\
\hline Clothing store & CLC-I & 470 & 867 & 731 & 567 & 193 & 11.36 \\
\hline Toy store & TOY-I & 510 & 909 & 773 & 498 & 129 & 18.40 \\
\hline Shoe store & SHO-I & 600 & 854 & 906 & 687 & 211 & 21.21 \\
\hline Bookstore & BK-I & 580 & 782 & 709 & 631 & 230 & 17.64 \\
\hline Fast food outlet & FF-I & 460 & 735 & 633 & 505 & 173 & 13.96 \\
\hline
\end{tabular}




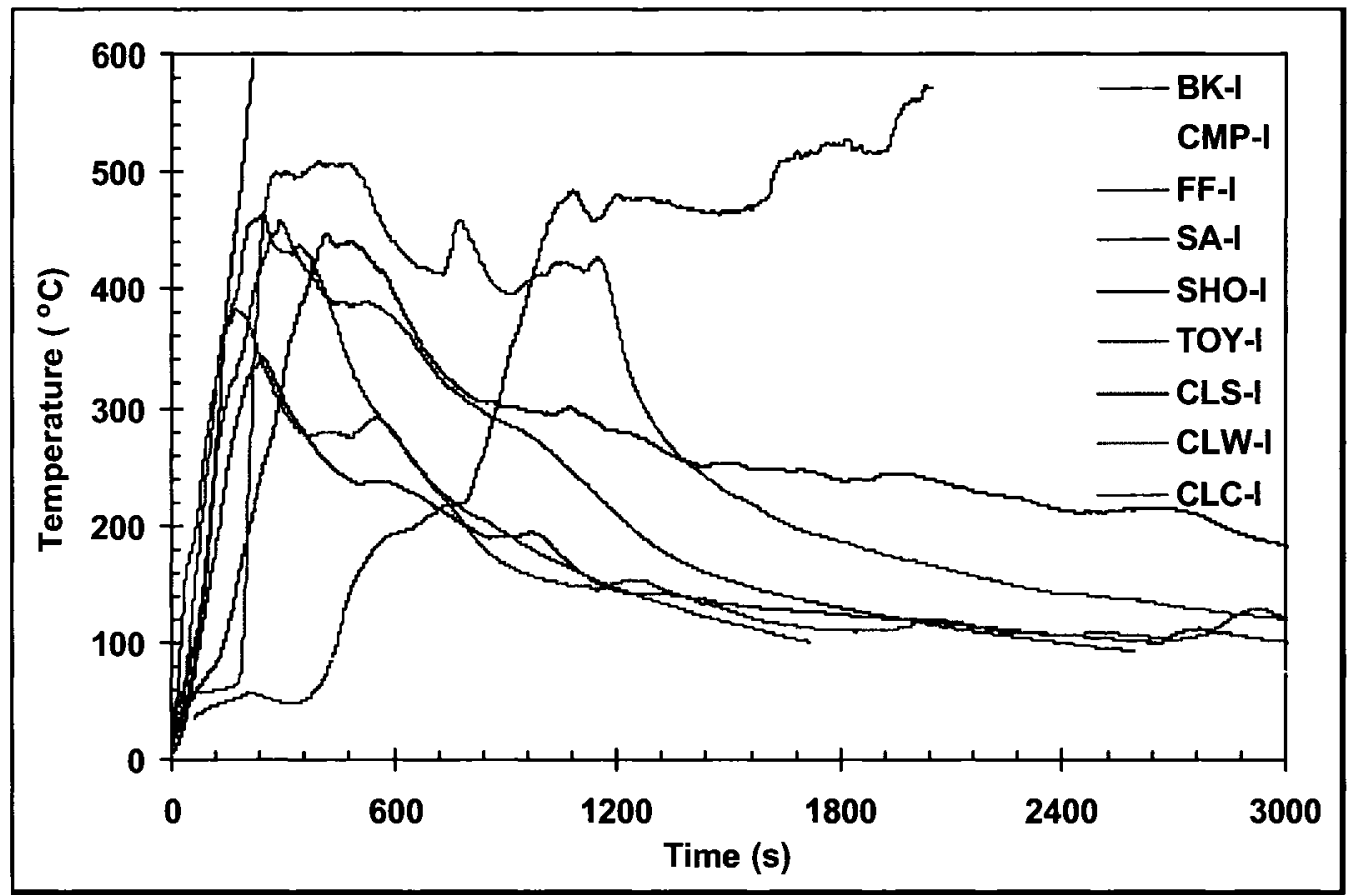

Figure 71. Temperature $2.1 \mathrm{~m}$ from floor, Phase I experiments

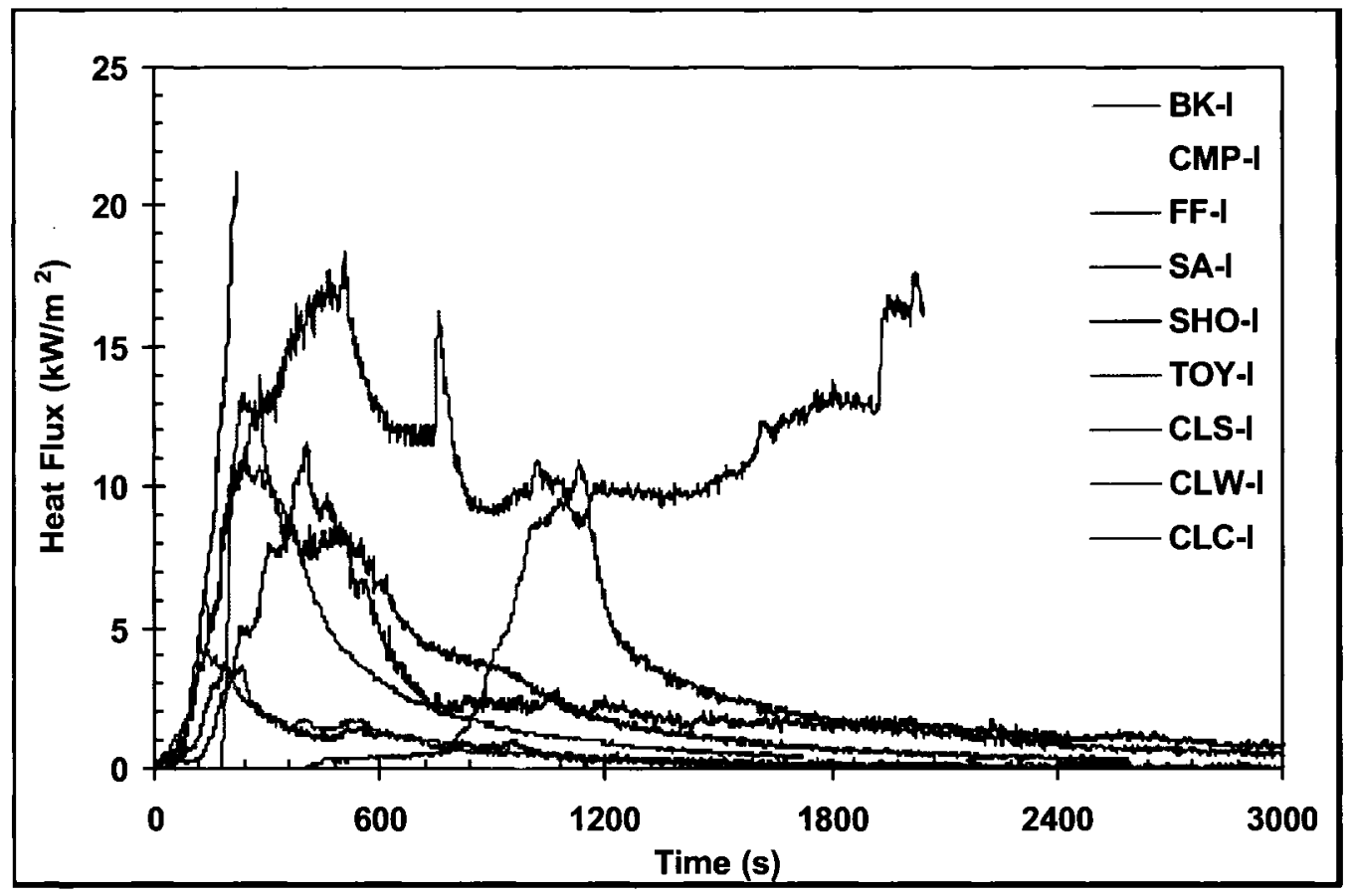

Figure 72. Heat flux, Phase I experiments 


\subsubsection{Gas Production Rates Measurements}

All Phase I fuel packages were tested in the ISO room and the smoke produced was collected through a hood leading to an exhaust system including a duct where its temperature, pressure, and mole fractions of $\mathrm{CO}, \mathrm{CO}_{2}$, and $\mathrm{O}_{2}$ were measured. Measurements of optical density were also recorded using a pulsed white light meter.

Production rates of $\mathrm{CO}$ and $\mathrm{CO}_{2}$ are shown in Table 18, Figure 73, and Figure 74. The incomplete shoe store test (SHO-I) had the highest production rates of $\mathrm{CO}$ and $\mathrm{CO}_{2}, 5195 \mathrm{ppm}$ and $4.38 \%$, respectively, and hence, the lowest value of $\mathrm{O}_{2}$ concentration at $15.4 \%$. Tests TOYI, SA-I, and FF-I were among the tests that had high peak $\mathrm{CO}$ levels with production rates of 1390,670 , and $640 \mathrm{ppm}$, respectively. The remaining tests had CO production rates ranging from $370 \mathrm{ppm}$ down to $115 \mathrm{ppm}$. In the shoe store test (SHO-I), values of total $\mathrm{CO}$ and $\mathrm{CO}_{2}$ production rates, as well as total smoke released, suggest that this 4-minute test was among the highest in smoke production. This effect could also be seen in the optical density value $(2.7 \mathrm{OD} / \mathrm{m})$. Test BK-I recorded the highest value at $3.6 \mathrm{OD} / \mathrm{m}$, Figure 75 . 
Table 18. Smoke data and visibility analysis of Phase I experiments

\begin{tabular}{|c|c|c|c|c|c|c|c|c|c|}
\hline \multirow[b]{2}{*}{ Test title } & \multirow[b]{2}{*}{ Test ID } & \multicolumn{8}{|c|}{ Smoke Data } \\
\hline & & 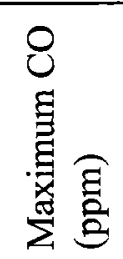 & 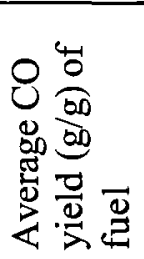 & 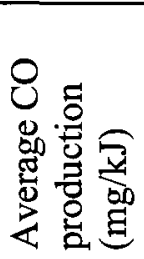 & 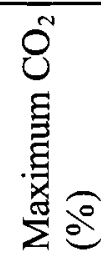 & 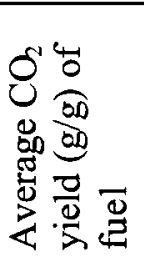 & 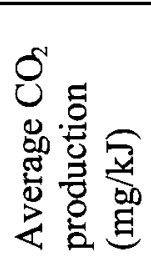 & 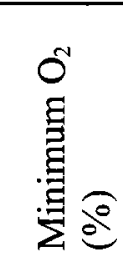 & 急 \\
\hline Computer store & CMP-I & 300 & 0.07 & 3.17 & 0.77 & 1.31 & 58 & 20.2 & 1.92 \\
\hline Storage area & SA-I & 670 & 0.03 & 1.55 & 2.87 & 1.35 & 71 & 17.5 & 0.96 \\
\hline Clothing store $^{1}$ & CLS-I ${ }^{1}$ & 115 & 0.02 & 0.72 & 1.32 & 1.14 & 40 & 19.5 & 0.30 \\
\hline Clothing store $^{2}$ & CLW-I ${ }^{2}$ & 145 & 0.04 & 2.93 & 1.47 & 1.35 & 101 & 19.5 & 0.38 \\
\hline Clothing store ${ }^{3}$ & CLC-I ${ }^{3}$ & 370 & 0.02 & 1.20 & 4.10 & 1.46 & 73 & 16.7 & 1.07 \\
\hline Toy store & TOY-I & 1390 & 0.03 & 1.66 & 2.22 & 1.20 & 62 & 18.5 & 1.35 \\
\hline Shoe store ${ }^{4}$ & SHO-I $^{4}$ & 5195 & ----- & $-\cdots$ & 4.38 & -.-- & ---- & 15.4 & 2.70 \\
\hline Bookstore $^{4}$ & $\mathrm{BK}-\mathrm{I}^{4}$ & 170 & ----- & ---- & 3.46 & ---- & ----- & 17.4 & 3.60 \\
\hline Fast food outlet & FF-I & 640 & 0.03 & 1.10 & 3.61 & 1.65 & 63 & 16.9 & 2.00 \\
\hline
\end{tabular}

${ }^{1}$ small stores ${ }^{2}$ mostly wood ${ }^{3}$ mostly textiles ${ }^{4}$ incomplete test

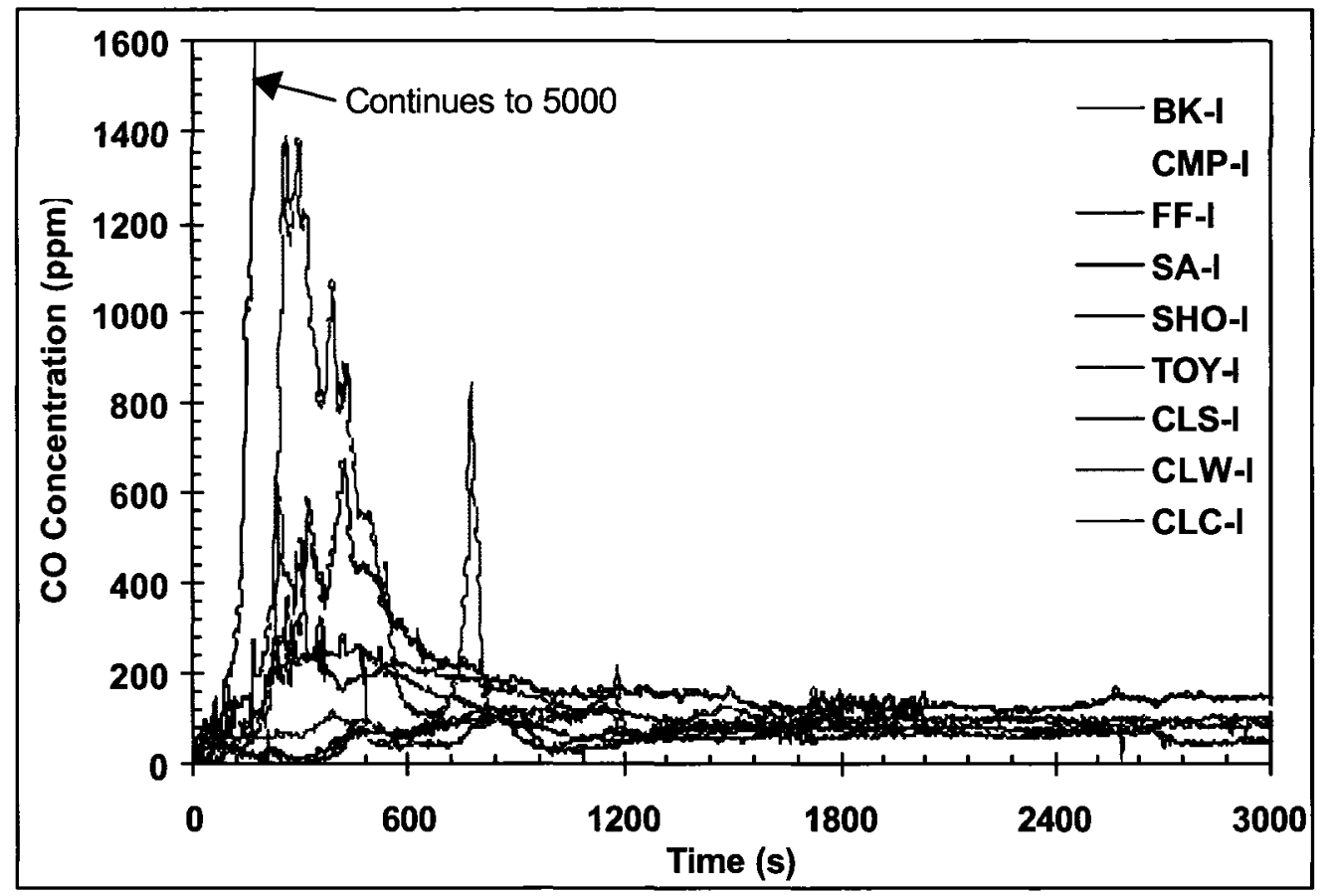

Figure 73. Carbon monoxide production rates, Phase I experiments 


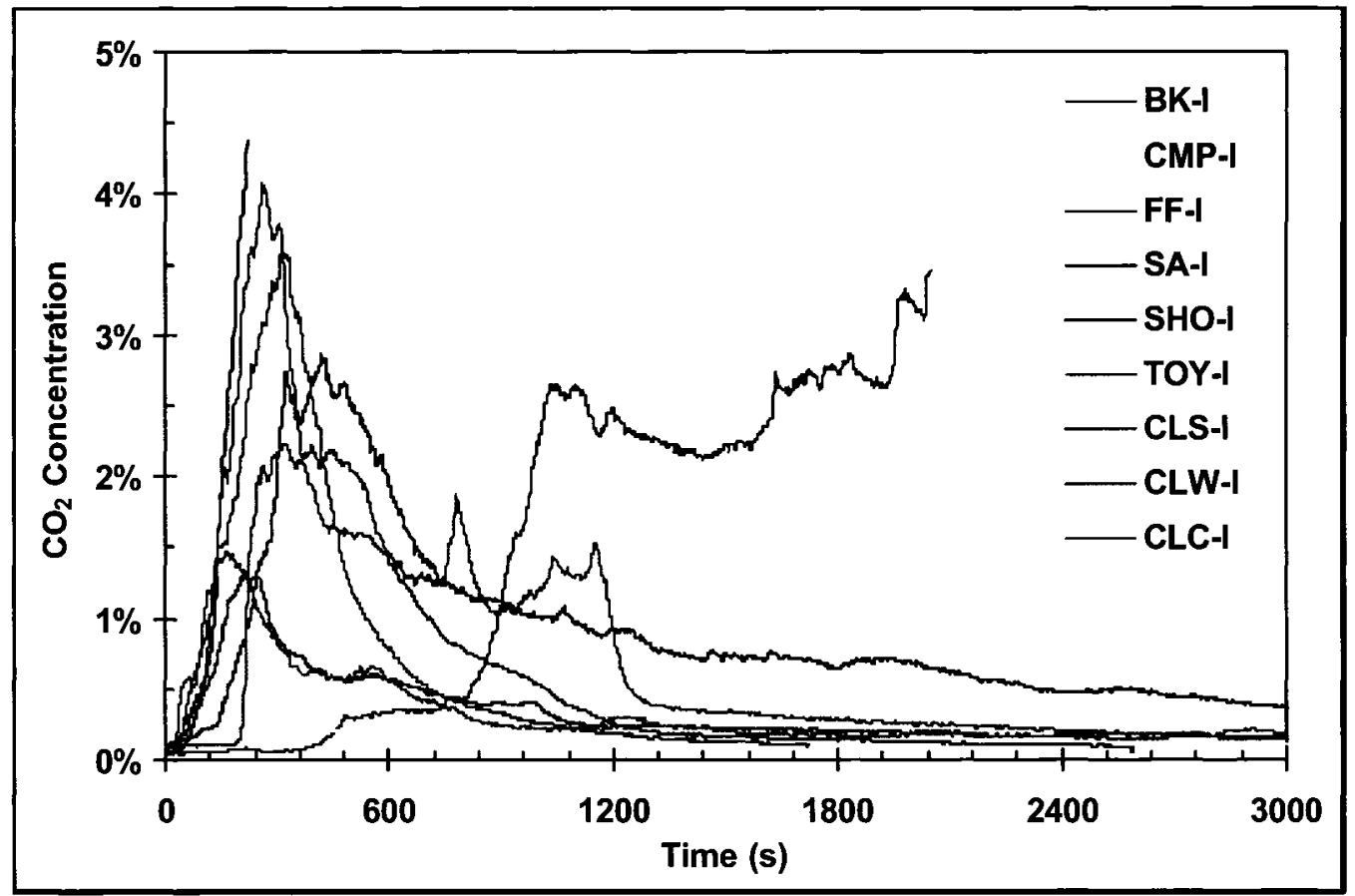

Figure 74. Carbon dioxide production rates, Phase I experiments

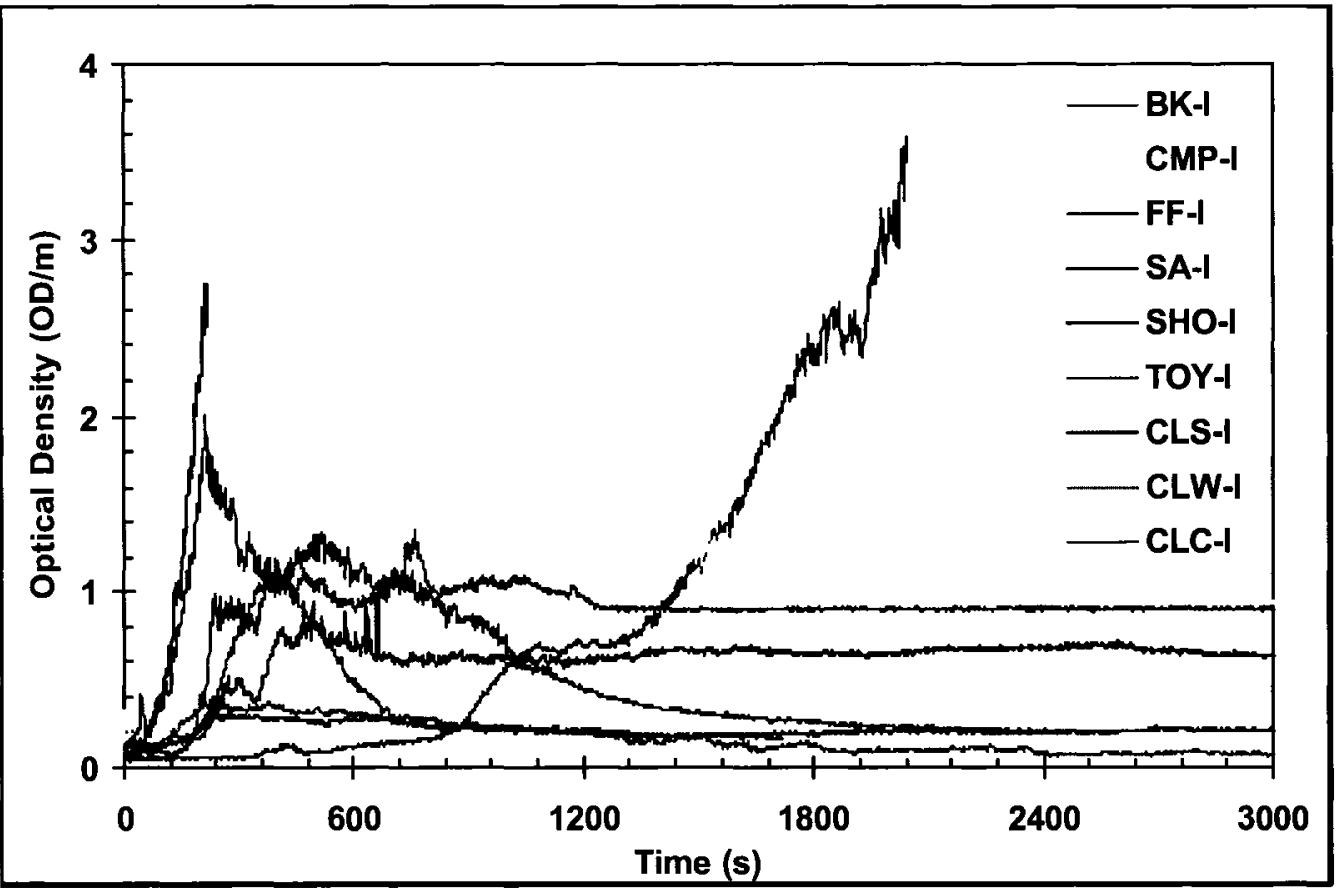

Figure 75. Optical density, Phase I experiments 
To better understand the burning characteristics of the different fuel packages, the mass of $\mathrm{CO}$ and $\mathrm{CO}_{2}$ released was divided by the total heat release to give $\mathrm{CO}$ and $\mathrm{CO}_{2}$ yields in milligram per kilojoules $(\mathrm{mg} / \mathrm{kJ})$. These results are shown in Table 18, Figure 76, and Figure 77.

Based on the average yield $\mathrm{CO}$ released per kilojoules, the $\mathrm{CO}$ results could be divided into four groups: (1) tests CMP-I and CLW-I with CO production rate of 3.17 and $2.93 \mathrm{mg} / \mathrm{kJ}$, respectively; (2) tests TOY-I and SA-I with values of 1.66 and $1.55 \mathrm{mg} / \mathrm{kJ}$, respectively; (3) tests CLC-I and FF-I with values of 1.20 and $1.10 \mathrm{mg} / \mathrm{kJ}$, respectively; and (4) CLS-I with a value of $0.72 \mathrm{mg} / \mathrm{kJ}$. From the above results, it could be noticed that cellulosic fires are among the lowest in CO production rates per kilojoules produced (with the exception of test CLW-I), and tests that have high plastic contents produced higher rate of $\mathrm{CO}(\mathrm{mg} / \mathrm{kJ})$, example, CMP-I and TOY-I tests.

Based on the average yield of $\mathrm{CO}_{2}$ per kilojoules consumed, the $\mathrm{CO}_{2}$ results $(\mathrm{mg} / \mathrm{kJ})$ could be divided into four groups: (1) test CLW-I with $\mathrm{CO}_{2}$ production rate of $101 \mathrm{mg} / \mathrm{kJ}$; (2) tests CLC-I and SA-I with values of 73 and $71 \mathrm{mg} / \mathrm{kJ}$, respectively; (3) tests FF-I, TOY-I, and CMP-I with values of 63,62 , and $58 \mathrm{mg} / \mathrm{kJ}$, respectively; and (4) test CLS-I with a value of $40 \mathrm{mg} / \mathrm{kJ}$. The above results show almost the exact opposite of the ranking in the $\mathrm{CO}$ groups. Cellulosic fires are among the highest in $\mathrm{CO}_{2}$ production $(\mathrm{mg} / \mathrm{kJ})$, and tests that have high plastic contents produced lower values of $\mathrm{CO}_{2}$ production $(\mathrm{mg} / \mathrm{kJ})$.

Tewarson $^{50}$ reported that burning wood in a well-ventilated fire configuration yielded $\mathrm{CO}$ ranging from 0.002 to $0.005(\mathrm{~g} / \mathrm{g})$ of the fuel, and $\mathrm{CO}_{2}$ ranging from 1.2 to $1.33(\mathrm{~g} / \mathrm{g})$ of the fuel. Based on the mass loss of different fuel packages tested in Phase I and the total $\mathrm{CO}$ and $\mathrm{CO}_{2}$ 
produced, an analysis was performed to determine the yield of $\mathrm{CO}\left(Y_{\mathrm{CO}}, \mathrm{g} / \mathrm{g}\right)$ and $\mathrm{CO}_{2}\left(Y_{\mathrm{CO}_{2}}\right.$, g/g). The results showed that the fuel packages with high cellulosic contents (e.g., SA-I, CLW-I, CLC-1, and TOY-I) yielded $\mathrm{CO}$ ranging from 0.02 to $0.04(\mathrm{~g} / \mathrm{g})$, and $\mathrm{CO}_{2}$ ranging from 1.14 to $1.46(\mathrm{~g} / \mathrm{g})$, Table 18. It was found that the $\mathrm{CO}$ yield was about 10 times higher than the wellventilated average values; however, $\mathrm{CO}_{2}$ yields compared well with the values reported by Tewarson ${ }^{50}$.

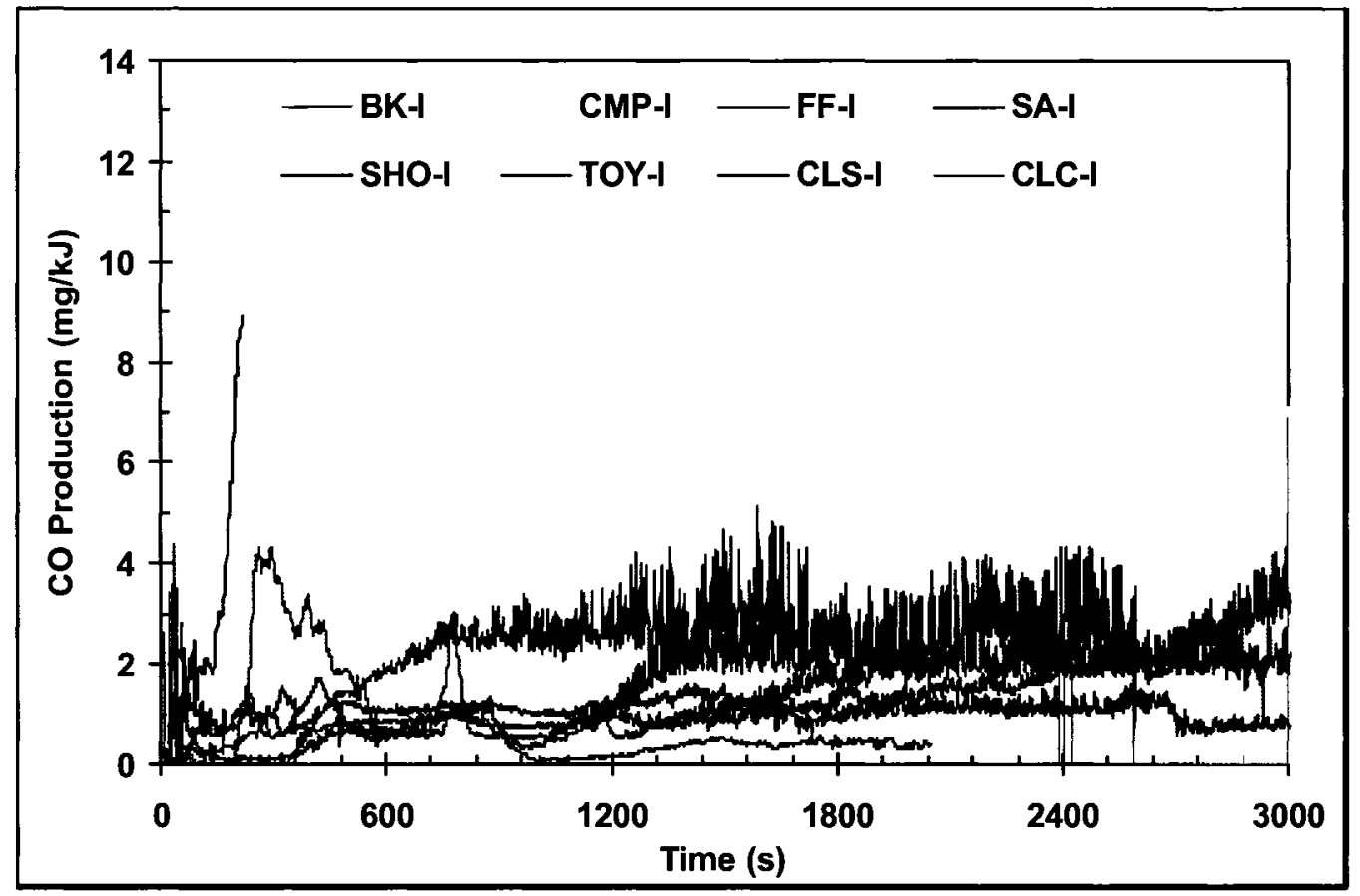

Figure 76. Carbon monoxide production rate, Phase I experiments 


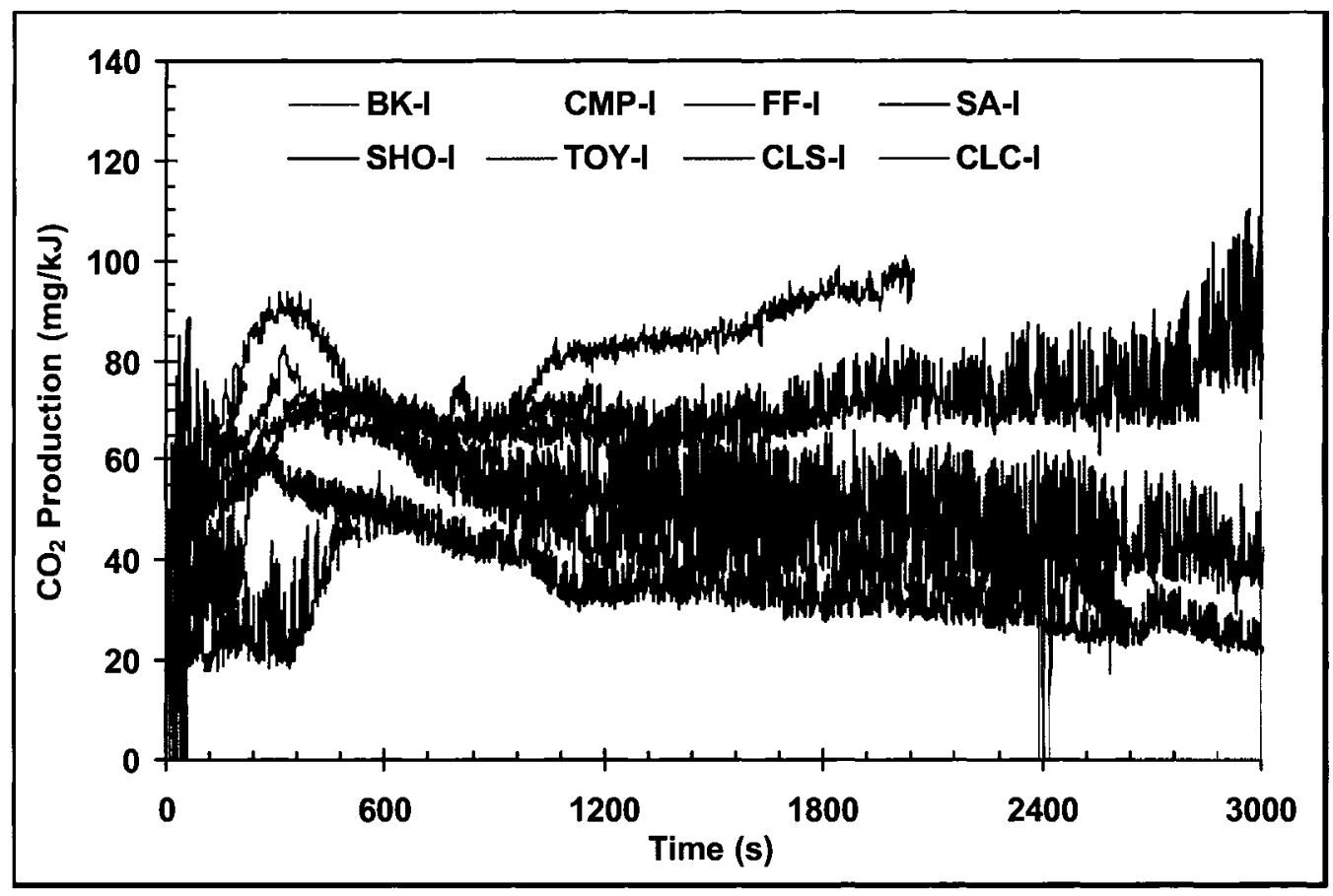

Figure 77. Carbon dioxide production rate, Phase I experiments

The experimental data obtained from the tests were used to perform a comparative analysis to determine the impact of $\mathrm{CO}$ and $\mathrm{CO}_{2}$ on visibility. In this analysis, the assumption was that all smoke produced during the test is accumulated in the average store size as determined from the survey data, Table 19, Lougheed $^{51,52}$ ). This analysis provides a comparison of the relative impact of $\mathrm{CO}$ and $\mathrm{CO}_{2}$ on visibility. Visibility is calculated using the relation from Klote and Milke $^{53}$ :

$S=\frac{k}{2.303 \delta_{m} m_{f}}$

Equation 15

Where, $S=$ visibility $(\mathrm{m}), k=$ proportionality constant $(8$ for illuminated signs and 3 for reflective signs), $\delta_{m}=$ mass optical density, $\mathrm{m}^{2} / \mathrm{g}$; (The mass optical density is determined using 
a log base- 10 calculation for the smoke parameters whereas the results were determined using base-e calculations), $m_{f}=$ fuel mass loss divided by the total volume, $\mathrm{g} / \mathrm{m}^{3}$.

A virtual room had been selected based on the survey results. For each test, which represents certain type of stores, the average volume $\left(\mathrm{m}^{3}\right)$ of this type of stores was used. The total smoke produced during the test was released into that room and the visibility was calculated accordingly, Table 19. The visibility was the highest in test CLW-I, $3.63 \mathrm{~m}$ for illuminated signs and $1.36 \mathrm{~m}$ for reflective signs, followed by SHO-I and CLC-I with values of about $2.3 \mathrm{~m}$ for illuminated signs and $0.87 \mathrm{~m}$ for reflective signs. The remaining tests had values ranging from 0.29 to $0.04 \mathrm{~m}$ for illuminated signs and 0.11 to $0.02 \mathrm{~m}$ for reflective signs.

Total smoke released $\left(\mathrm{m}^{2}\right)$ is the product of the volumetric flow rate $\left(\mathrm{m}^{3} / \mathrm{s}\right)$, the extinction coefficient, $\mathrm{k}(1 / \mathrm{m})$, and the duration of the test (s). When analysing the total smoke released data $\left(\mathrm{m}^{2}\right)$, one can notice that even though the computer store test (CMP-I) had the second smallest fuel package, it produced the highest total smoke released among all tests $\left(35,940 \mathrm{~m}^{2}\right)$. However, when this amount of smoke was released in the virtual room, the calculated visibilities were among the least values, due to the size of the average computer store determined from the survey. 
Table 19. Visibility data of Phase I experiments

\begin{tabular}{|c|c|c|c|c|c|}
\hline \multirow[b]{2}{*}{ Test title } & \multirow[b]{2}{*}{ Test ID } & \multicolumn{2}{|c|}{ Smoke data } & \multicolumn{2}{|c|}{ Visibility } \\
\hline & & 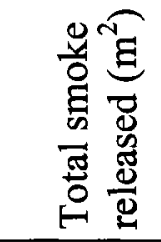 & 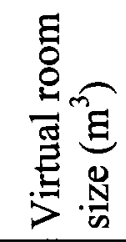 & 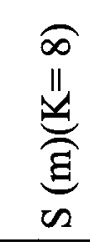 & 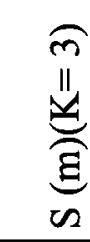 \\
\hline Computer store & CMP-I & 35,939 & 372 & 0.08 & 0.03 \\
\hline Storage area & SA-I & 19,005 & 105 & 0.04 & 0.02 \\
\hline Clothing store $^{1}$ & CLS-I $^{1}$ & 4,283 & 156 & 0.29 & 0.11 \\
\hline Clothing store ${ }^{2}$ & CLW-I ${ }^{2}$ & 2,350 & 1065 & 3.63 & 1.36 \\
\hline Clothing store ${ }^{3}$ & $\mathrm{CLC}-\mathrm{I}^{3}$ & 3,713 & 1065 & 2.29 & 0.86 \\
\hline Toy store & TOY-I & 21,186 & 246 & 0.09 & 0.03 \\
\hline Shoe store ${ }^{4}$ & SHO-I ${ }^{4}$ & 1,390 & 402 & 2.31 & 0.87 \\
\hline Bookstore $^{4}$ & BK-I ${ }^{4}$ & 12,966 & 273 & 0.17 & 0.06 \\
\hline Fast food outlet & FF-I & 10,680 & 111 & 0.08 & 0.03 \\
\hline
\end{tabular}

\subsubsection{Heat Release Rate (HRR)}

For all tests, HRR was calculated using the oxygen depletion method from Janssens ${ }^{34}$. The inputs used for this calculation were the concentrations of $\mathrm{O}_{2}$, production rates of $\mathrm{CO}$ and $\mathrm{CO}_{2}$, as well as gas temperature and mass flow rate in the duct. It was assumed that when a $20^{\circ} \mathrm{C}$ temperature rise in the hot layer occurs the fire becomes self-sustaining and grows without the need for an external ignition source. For this reason, $\mathrm{HRR}$ and other data $\left(\mathrm{CO}, \mathrm{CO}_{2}\right.$, heat flux, temperatures, etc.) were plotted from this onset of ignition.

Figure 78 shows the HRR profile of all tests after ignition to $3000 \mathrm{~s}$. Three additional curves are shown that represent the slow, medium and fast t-squared fires. In the shoe store test (SHO-I), even though the test ran for only 4 minutes, the recorded peak HRR was $1,880 \mathrm{~kW}$, the highest of all Phase I experiments. The fast food outlet test (FF-I) and clothing stores, mostly textiles, 
(CLC-I) had the second highest peak HRR of 1,560 and 1,530 kW, respectively. These were followed by storage area (SA-I) at $1,385 \mathrm{~kW}$, bookstore (BK-I) at $1,180 \mathrm{~W}$, and toy store at (TOY-I) $1,080 \mathrm{~kW}$. The clothing store, mostly wood (CLW-I) had a peak HRR of $730 \mathrm{~kW}$, and small clothing store (CLS-I) $720 \mathrm{~kW}$. The computer test (CMP-I) had the lowest peak HRR at $410 \mathrm{~kW}$.

The fire growth in test BK-I followed a slow t-squared fire; whereas, tests SA-I, CLS-I, and TOY-I grew as slow to medium t-squared fires. Tests CLW-I, CLC-I, and FF-I followed a medium t-squared fire while, CMP-I followed a medium to fast growth, and SHO-I followed a fast growth t-squared fire (see Table 20 and Figure 78).

Based on the survey results, fuel packages in Phase I experiments had different theoretical total heat content (MJ) and material composition (wood, food, plastics, textiles, etc.). The experimental data were analyzed to calculate the total heat released. As shown in Table 20, the theoretical and experimental results were not always in good agreement. This could be attributed to the following reasons: (1) incomplete combustion due to ventilation-controlled conditions that led to lower experimental total heat release than the theoretical; (2) not all combustibles were consumed during the fire, thereby resulting in lower measured total heat released than the theoretical; (3) the uncertainty about the composition of some combustibles might have led to different experimental total heat release compared with the theoretical; and (4) smoke leakage from the test room, hood, and duct, could have also contributed to less than $5 \%$ loss in the experimentally measured values of the total heat released. 
To better understand the inconsistency between the theoretical and experimentally measured total heat released, the weighted average of the heat content $(\mathrm{MJ} / \mathrm{kg})$ was used as a reference. In the Phase I fuel packages the weight and composition of all packages were known and the theoretical weighted average was calculated. Also, in the Phase I experiments, measured mass loss rate and the weight of remaining unburned material enabled the calculation of the experimental average heat content (effective heat of combustion), Table 20.

Tests SA-I, CLC-I, TOY-I and FF-I showed experimental average heat content values that are close to theoretical weighted average. However, tests CMP-I and CLW-I showed lower experimental values than the theoretical. This could be attributed to the reasons $(1,3$, and 4$)$ explained above. Test CLS-I had a high measured average compared with the theoretical value, which could be due to the uncertainty about the textile composition and its heat content $(\mathrm{MJ} / \mathrm{kg})$. The test was conducted during winter and a good part of the clothes used was winter coats with higher wool, polyethylene, nylon, and a limited amount of cotton. Results showed that fuel packages with high cellulosic contents produced an effective heat of combustion within the typical range of heat of combustion of cellulosic materials (13 to $20 \mathrm{MJ} / \mathrm{kg}$ ), (e.g., SA-I, CLW-I, CLC-1, and TOY-I).

In fast food outlet test (FF-I) and computer store test (CMP-I), the effective heat of combustion was 26.2 , and $22.6 \mathrm{MJ} / \mathrm{kg}$, respectively. These values are consistent with the heat of combustion values of the materials used in these tests (plastics, wood, and cooking oil for FF-I, and plastics and wood for CMP-I). The comparison was not made for the two incomplete tests, SHO-I and BK-I. 


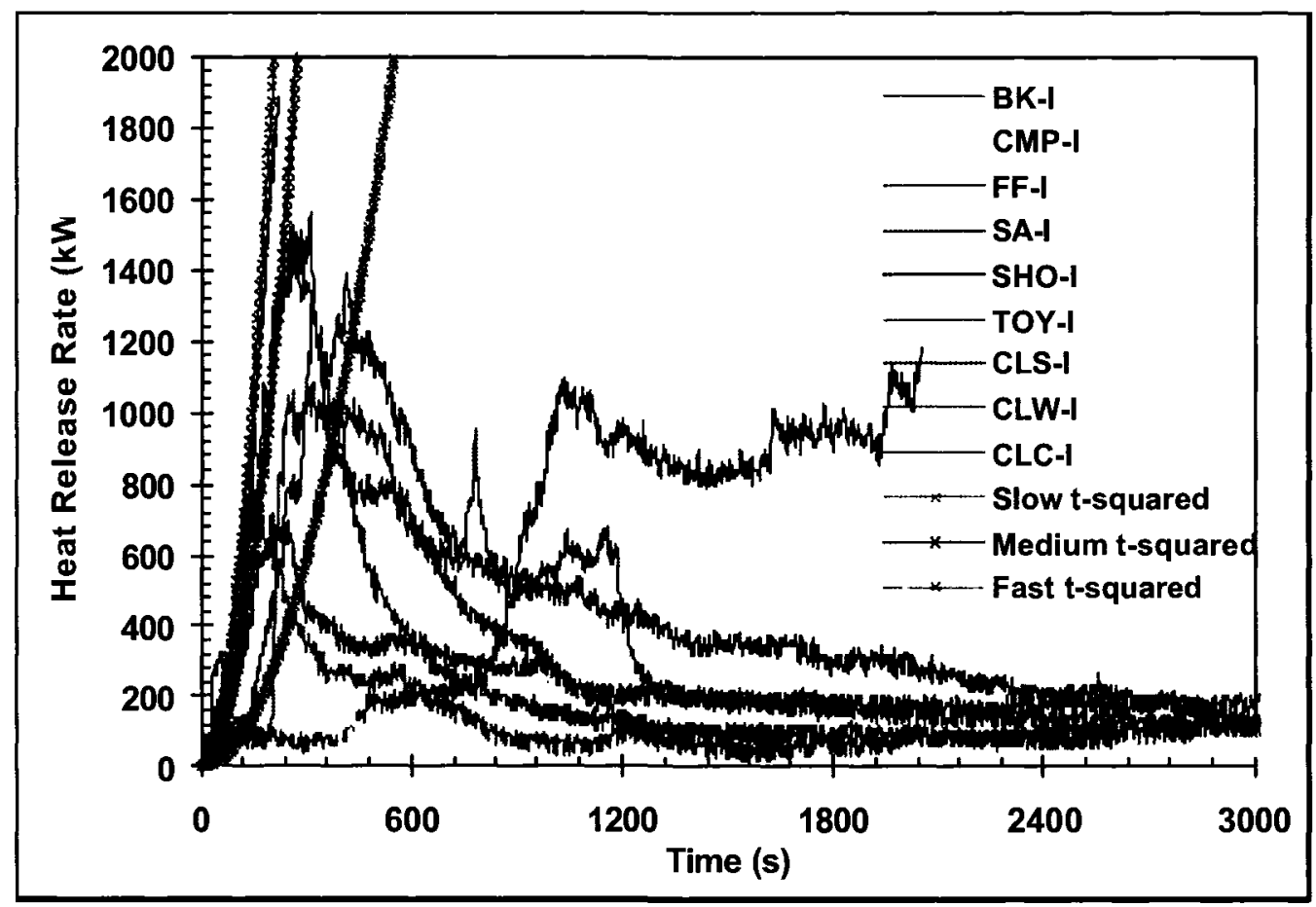

Figure 78. Heat release rates, Phase I experiments

Table 20. Heat released, growth rates, and heat content of Phase I experiments

\begin{tabular}{|c|c|c|c|c|c|c|c|c|}
\hline \multirow[b]{2}{*}{ Test title } & \multirow[b]{2}{*}{ Test ID } & \multicolumn{3}{|c|}{ Heat release data } & \multicolumn{2}{|c|}{$\begin{array}{l}\text { Total heat } \\
\text { content (MJ) }\end{array}$} & \multicolumn{2}{|c|}{$\begin{array}{l}\text { Average heat } \\
\text { content } \\
(\mathrm{MJ} / \mathrm{kg})\end{array}$} \\
\hline & & 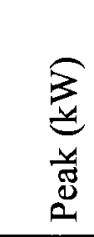 & 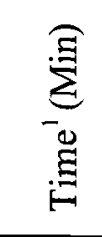 & 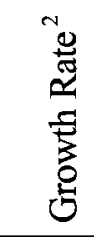 & 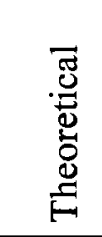 & 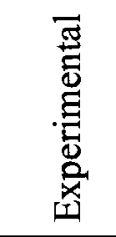 & 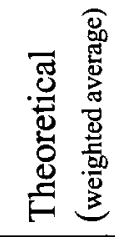 & 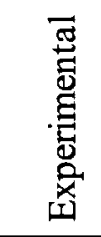 \\
\hline Computer store & CMP-I & $\begin{array}{l}340 \\
410\end{array}$ & $\begin{array}{l}1: 30 \\
28: 00\end{array}$ & $\overline{M-F}$ & 812 & 540 & 25.6 & 22.6 \\
\hline Storage area & SA-I & 1385 & $7: 00$ & S-M & 2320 & 1372 & 22.7 & 19.1 \\
\hline Clothing store ${ }^{3}$ & $\mathrm{CLS}^{3} \mathrm{I}^{3}$ & 720 & $4: 30$ & S-M & 661 & 768 & 19.1 & 28.5 \\
\hline Clothing store $^{4}$ & CLW-I ${ }^{4}$ & 730 & $2: 45$ & M & 661 & 317 & 18.2 & 13.3 \\
\hline Clothing store $^{5}$ & CLC-I ${ }^{5}$ & 1530 & $4: 30$ & M & 661 & 632 & 18.65 & 20.0 \\
\hline Toy store & TOY-I & 1080 & $4: 30$ & S-M & 1223 & 1066 & 20.2 & 19.2 \\
\hline Shoe store ${ }^{6}$ & SHO-I ${ }^{6}$ & 1880 & $3: 40$ & $\mathrm{~F}$ & 4900 & -- & 22.81 & -- \\
\hline Bookstore $^{6}$ & $B K-I^{6}$ & $\begin{array}{l}1090 \\
1180\end{array}$ & $\begin{array}{l}17: 20 \\
34: 00\end{array}$ & S & 5305 & -- & 17.51 & -- \\
\hline Fast food outlet & FF-I & 1560 & 4:30 & $\mathrm{M}$ & 881 & 830 & 27.7 & 26.2 \\
\hline
\end{tabular}

${ }^{1}$ time to corresponding peak, ${ }^{2}$ growth rates of t-squared fires (S: slow, M: medium, F: fast), ${ }^{3}$ small stores,

${ }^{4}$ mostly wood, ${ }^{5}$ mostly textiles, ${ }^{6}{ }_{\text {ncomplete test }}$ 


\subsubsection{Clothing Stores Tests, Tests CLS-I, CLW-I, and CLC-I}

Three clothing store fuel packages were identified based on the survey and tested in Phase I experiments. This section focuses on the comparison of the experimental results of three fuel packages in order to select one clothing store to be tested in Phase II. Photographs in Figure 79 to Figure 81 depict the tests setups and the developed stage of the fire.

Figure 82 depicts the heat release rate (HRR) of the three tests. The HRR of the test representing small clothing stores, CLS-I, reached $720 \mathrm{~kW}$ at $3: 30$ minutes after ignition, dropped down to $350 \mathrm{~kW}$ at 10:00 minutes, and then decayed. The HRR of the test representing stores with mostly wood, CLW-I, reached $730 \mathrm{~kW}$ at $2: 45$ minutes after ignition, dropped down to $250 \mathrm{~kW}$ at 6:00 minutes, and then decayed. The HRR of the test representing stores with mostly textiles, CLC-I, had a maximum heat release rate of $1530 \mathrm{~kW}$ at $4: 30$ minutes after ignition, dropped down to $200 \mathrm{~kW}$ at 12:00 minutes, and then decayed. Both CLS-I and CLW-I had almost the same maximum HRR and the same trend during the tests. However, CLC-I produced twice the HRR than in CLS-I and CLW-I. The fire growth for all three tests followed a medium t-squared fire during the early growth stage.

Production rate profiles of $\mathrm{CO}$ and $\mathrm{CO}_{2}$ for the three tests are shown in Figure 83 and Figure 84, respectively. During test CLS-I, $\mathrm{CO}$ and $\mathrm{CO}_{2}$ concentrations in the duct reached a maximum of $116 \mathrm{ppm}$ and $1.3 \%$, respectively, $145 \mathrm{ppm}$ and $1.5 \%$ in CLW-I, and $370 \mathrm{ppm}$ and $4.1 \%$ in CLC-I. The clothing stores that had wood as the main combustible (test CLW-I) had almost the same CO and $\mathrm{CO}_{2}$ production rates as the small clothing stores (test CLS-I), and both had almost the same 
characteristics during the test; however, test CLC-I produced three times more carbon monoxide and carbon dioxide than test CLS-I or CLW-I, see Figure 83 and Figure 84.

CO production rates have average values of $0.72,2.93$, and $1.2(\mathrm{mg} / \mathrm{kJ})$ in CLS-I, CLW-I, and CLC-I, respectively. $\mathrm{CO}_{2}$ production rates have average values of 40,101 , and $73(\mathrm{mg} / \mathrm{kJ})$ in CLS-I, CLW-I, and CLC-I, respectively. These values are relatively different, and the values in the upper limit should be used in identifying the toxic gases produced from a clothing store fuel package.

Gas temperatures were measured at the corner of the room and at the ceiling, see Figure 85 and Figure 86. For test CLS-I, the maximum temperatures measured were 340 and $710^{\circ} \mathrm{C}$, respectively, 380 and $870^{\circ} \mathrm{C}$ in CLW-I, and 470 and $870^{\circ} \mathrm{C}$ in CLC-I. It can be seen that CLC-I has higher room temperature than CLS-I or CLW-I.

In the three tests, CLS-I, CLW-I, and CLC-I, the maximum heat flux recorded was 4 , 4, and $11 \mathrm{~kW} / \mathrm{m}^{2}$, respectively, and the temperature at the thermocouple beside the heat flux meter was 46,48 , and $142^{\circ} \mathrm{C}$, respectively, see Figure 87 .

Test CLC-I had high optical density values between $240 \mathrm{~s}$ and $720 \mathrm{~s}$, which correspond to the high HRR during the same period. After the initial $720 \mathrm{~s}$, the fuel package produced the same optical density until $1560 \mathrm{~s}$ when the optical density of test CLC-I decreases at a faster rate than test CLS-I or test CLW-I. The optical density for test CLS-I, CLW-I, and CLC-I reached a maximum of $0.3,0.4,1.1 \mathrm{OD} / \mathrm{m}$, respectively, Figure 88 . 
From the comparisons above, it can be seen that clothing stores with mostly textiles CLC-I showed higher risk values such as HRR, temperatures, and gas production rates. Based on this reasoning, test CLC-I was tested in a post-flashover test in Phase II experiments, where it was called test CLC-II. 

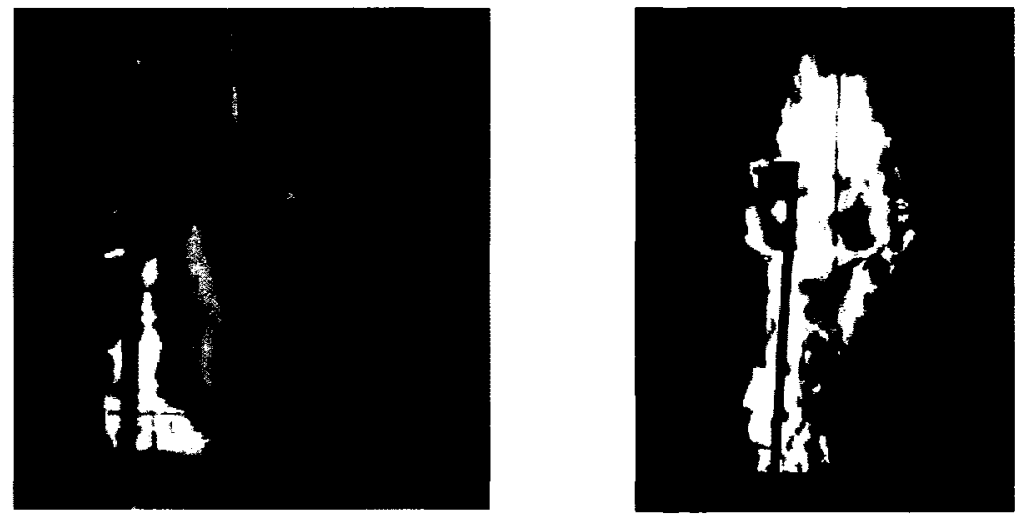

Figure 79. Photographs depicting the test in progress, Test CLS-I
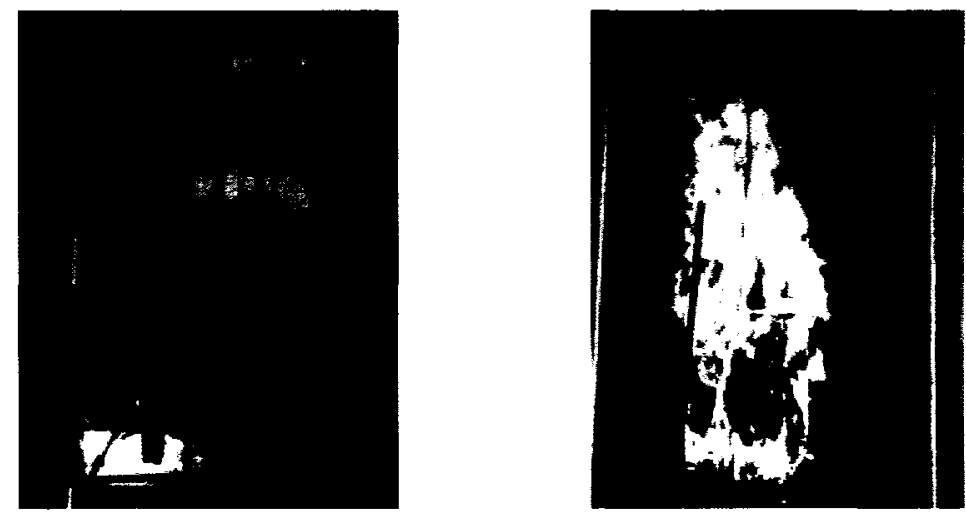

Figure 80. Photographs depicting the test in progress, Test CLW-I
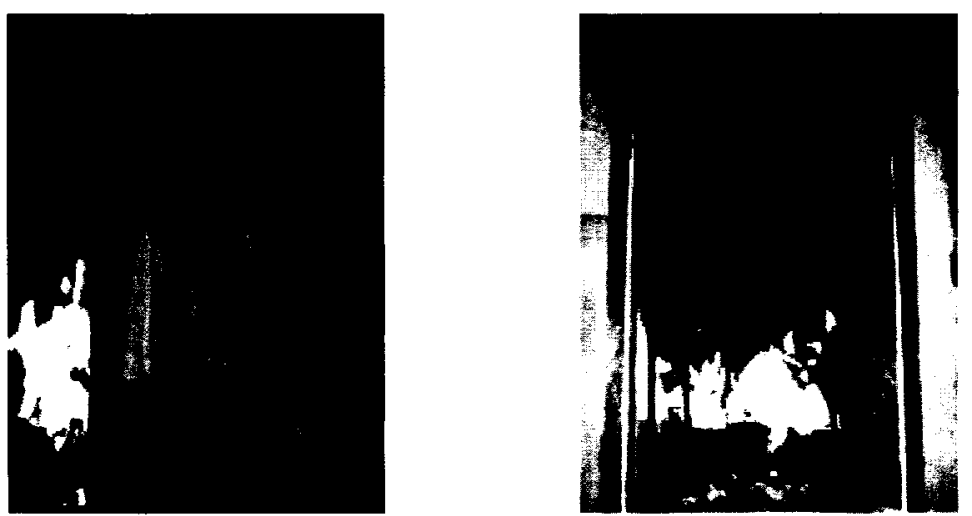

Figure 81. Photographs depicting the test in progress, Test CLC-I 


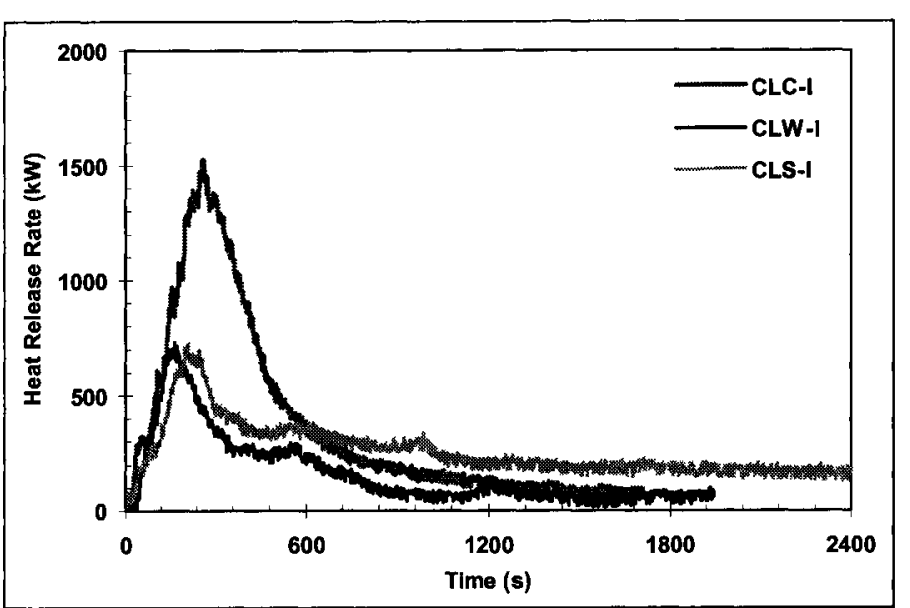

Figure 82. Heat release rate

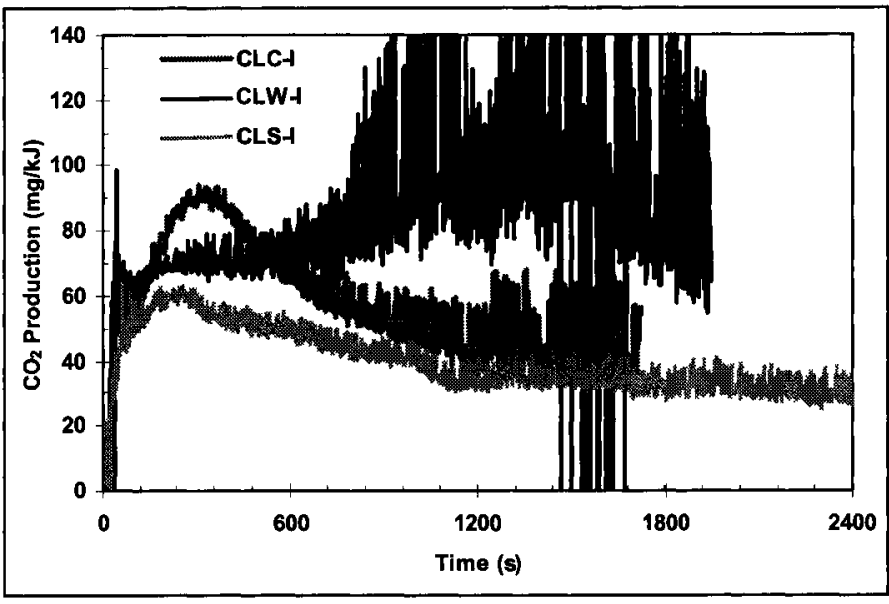

Figure 84. Carbon dioxide production rates

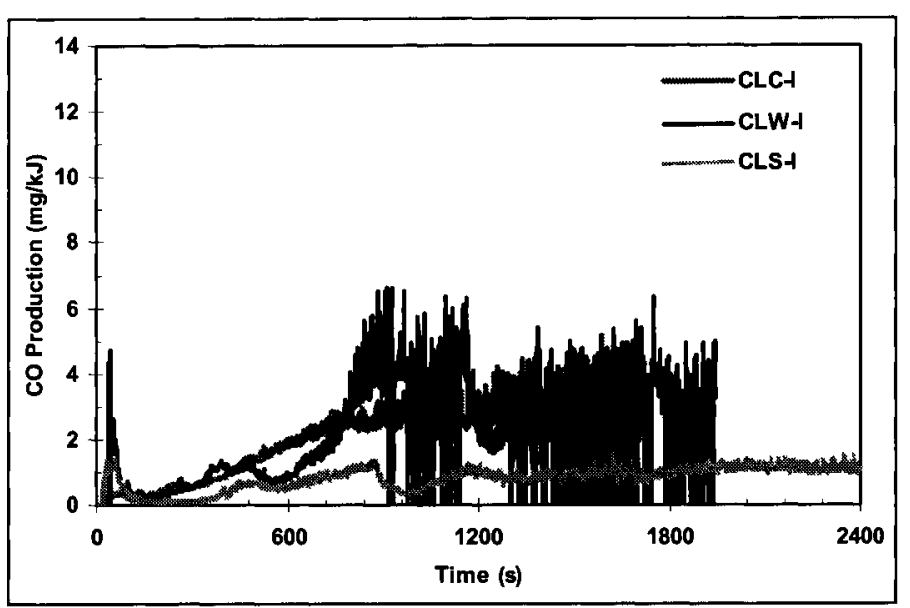

Figure 83. Carbon monoxide production rates 


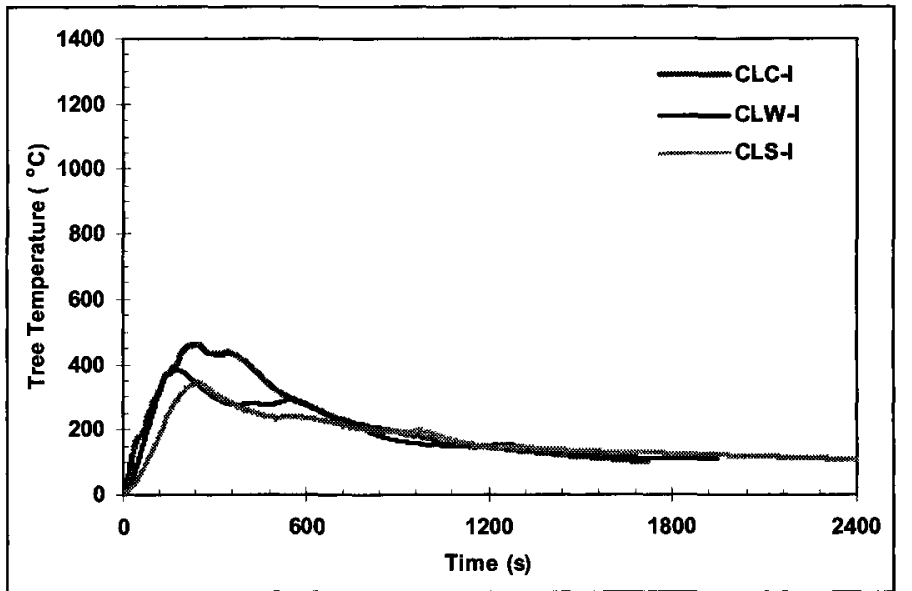

Figure 85 . Temperature TC tree $(2.1 \mathrm{~m}$ high $)$

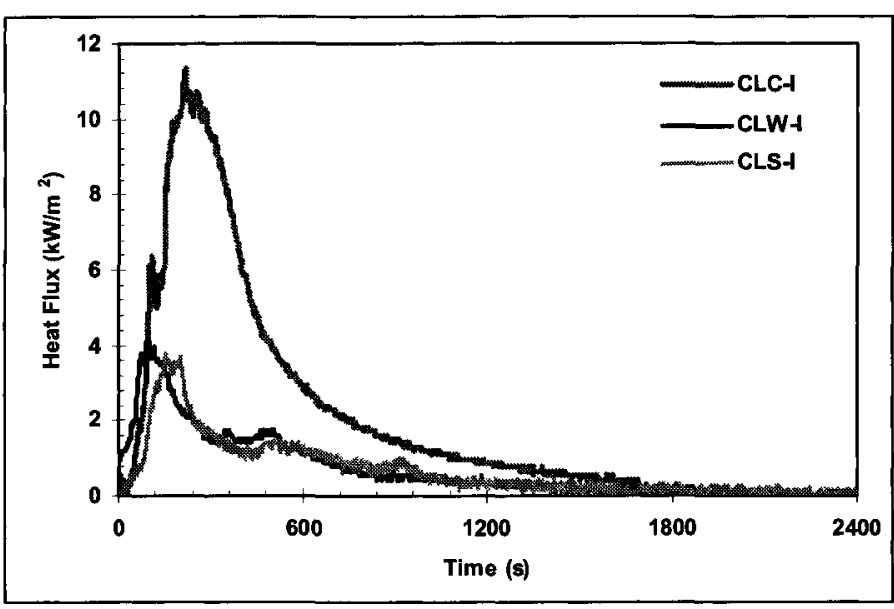

Figure 87. Heat flux

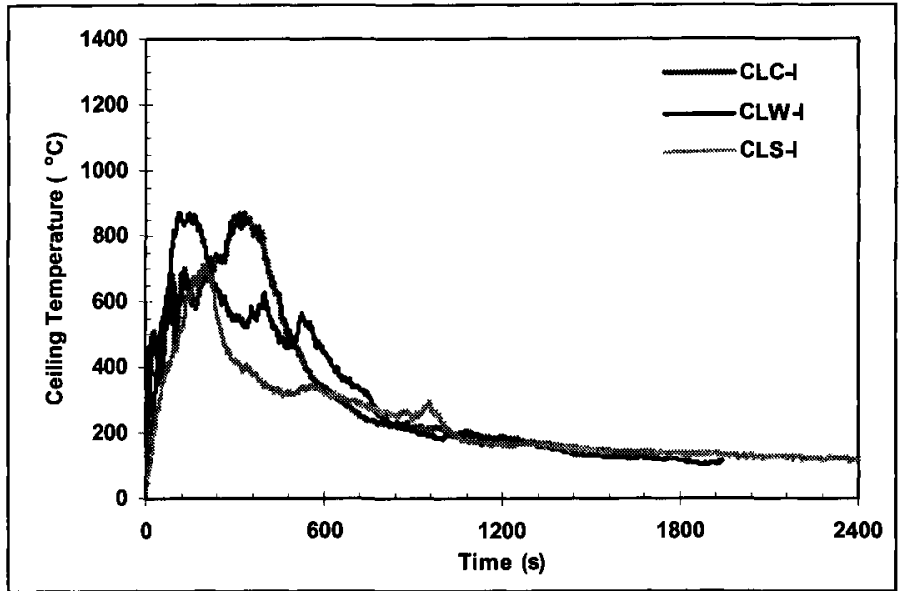

Figure 86. Temperature at the ceiling $(2.4 \mathrm{~m}$ high $)$

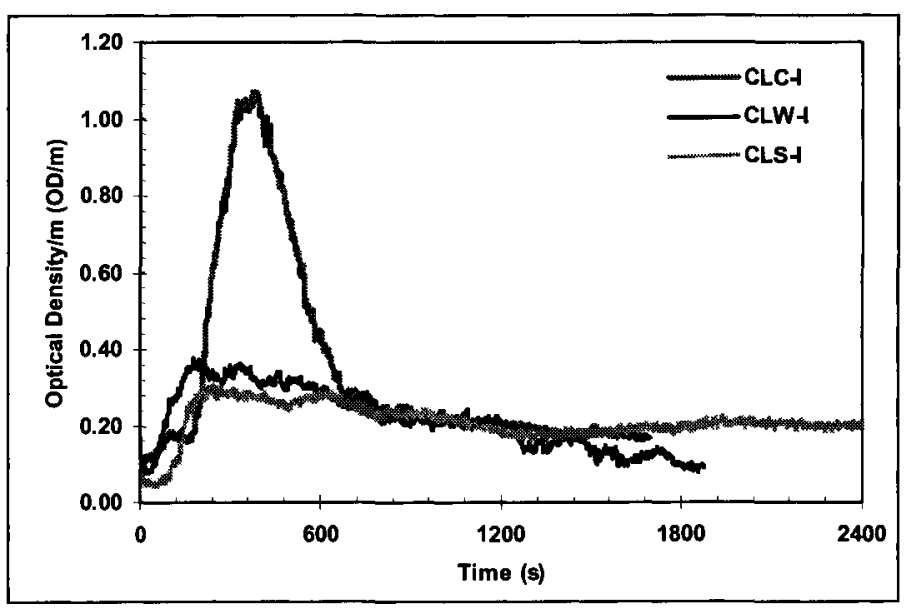

Figure 88. Optical density 


\subsubsection{Phase II Tests-Results and Discussions}

\subsubsection{Hot Layer Temperature}

In the Phase II tests, K-Type thermocouples (TCs) were used to monitor the temperature at various locations described as follows: (1) at the corner of the burn room; (2) at the ceiling level in the burn room; (3) at the ceiling level along the corridor; and (4) in the duct.

The TC tree at the corner of the room was a good indicator of the hot layer temperature, and these TCs are used for the analysis below. The TCs at the ceiling level, especially the TCs above the fire, and the TC tree in the middle of the room, were affected by direct flames impingement and the temperatures were much higher than the hot layer temperature. The TCs along the corridor were used to assess the cooling of the smoke leaving the burn room along the corridor and whether combustion was taking place in the corridor. The duct thermocouple was used to monitor the temperature in the duct, which was used as the criterion for evaluating whether the duct instrumentation was safe.

Peak temperatures of the hot layer in Phase II experiments ranged from 1010 to $1210^{\circ} \mathrm{C}$. The highest temperature was for the SHO-II test and the lowest temperature was for the CLC-II test. The hot layer temperature indicate that flashover occurred, in all Phase II experiments, within 4 minutes of ignition, Table 21 and Figure 89.

The hot layer temperature affects the measured heat flux in the test room. Heat flux values are presented in Table 21 and Figure 90. Flashover occurs when the hot layer temperature reaches about $600^{\circ} \mathrm{C}$ and heat flux of about $21 \mathrm{~kW} / \mathrm{m}^{2}$. In Phase II experiments, heat flux values ranged from 77 to $207 \mathrm{~kW} / \mathrm{m}^{2}$, which suggest that all 
experiments experienced flashover. These values are much higher than the Phase I heat flux values. Details of this comparison between Phase I and II experiments are discussed later in this section.

The TCs along the corridor indicate that the temperatures in the corridor within $3.5 \mathrm{~m}$ from the door were almost the same as the temperatures of the hot layer inside the burn room. In SHO-II and FF-II, the recorded temperatures in the corridor were higher than the temperatures of the hot layer inside the room. This indicates that burning was taking place outside the room and that fires were ventilation-controlled. The corridor cooling effect decreased the temperature of the hot smoke leaving the room by a maximum of $200^{\circ} \mathrm{C}$ at $6.5 \mathrm{~m}$ away from the room. In the shoe store test (SHO-II), at the ventilationcontrolled stage, temperature at $6.5 \mathrm{~m}$ away from the door was higher than at $3.5 \mathrm{~m}$ because most of the flaming combustion was occurring in the corridor. Corridor temperatures are shown in Table 21 and Figure 91 to Figure 97.

Table 21. Hot layer temperature and heat flux of Phase II experiments

\begin{tabular}{|c|c|c|c|c|c|c|c|c|c|}
\hline \multirow[b]{2}{*}{ Test title } & \multirow[b]{2}{*}{ Test ID } & \multirow[b]{2}{*}{ 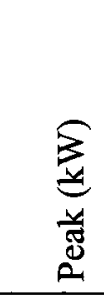 } & \multicolumn{6}{|c|}{ Peak temperatures $\left({ }^{\circ} \mathrm{C}\right)$} & \multirow[b]{2}{*}{ 总 } \\
\hline & & & छ̈ & : & 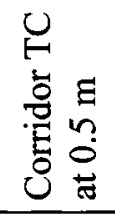 & 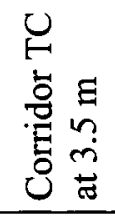 & 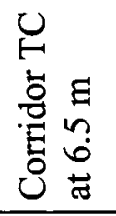 & $\begin{array}{c}\overrightarrow{0} \\
\overline{0}\end{array}$ & \\
\hline Computer store & CMP-II & 2475 & 1070 & 1250 & 1035 & 960 & 860 & 180 & 124 \\
\hline Storage area & SA-II & 2385 & 1080 & 1140 & 1080 & 985 & 860 & 220 & 207 \\
\hline Clothing store & CLC-II & 2660 & 1010 & 1170 & 950 & 825 & 750 & 170 & 107 \\
\hline Toy store & TOY-II & 2570 & 1070 & 1210 & 940 & 1010 & 970 & 260 & 194 \\
\hline Shoe store & SHO-II & 2555 & 1210 & 1280 & 1370 & 1030 & 1225 & 240 & 181 \\
\hline Bookstore & BK-II & 2375 & 1120 & 1230 & 1040 & 1020 & 900 & 235 & 77 \\
\hline Fast food outlet & FF-II & 2700 & 1100 & 1320 & 1360 & 1370 & 1040 & 215 & 150 \\
\hline
\end{tabular}




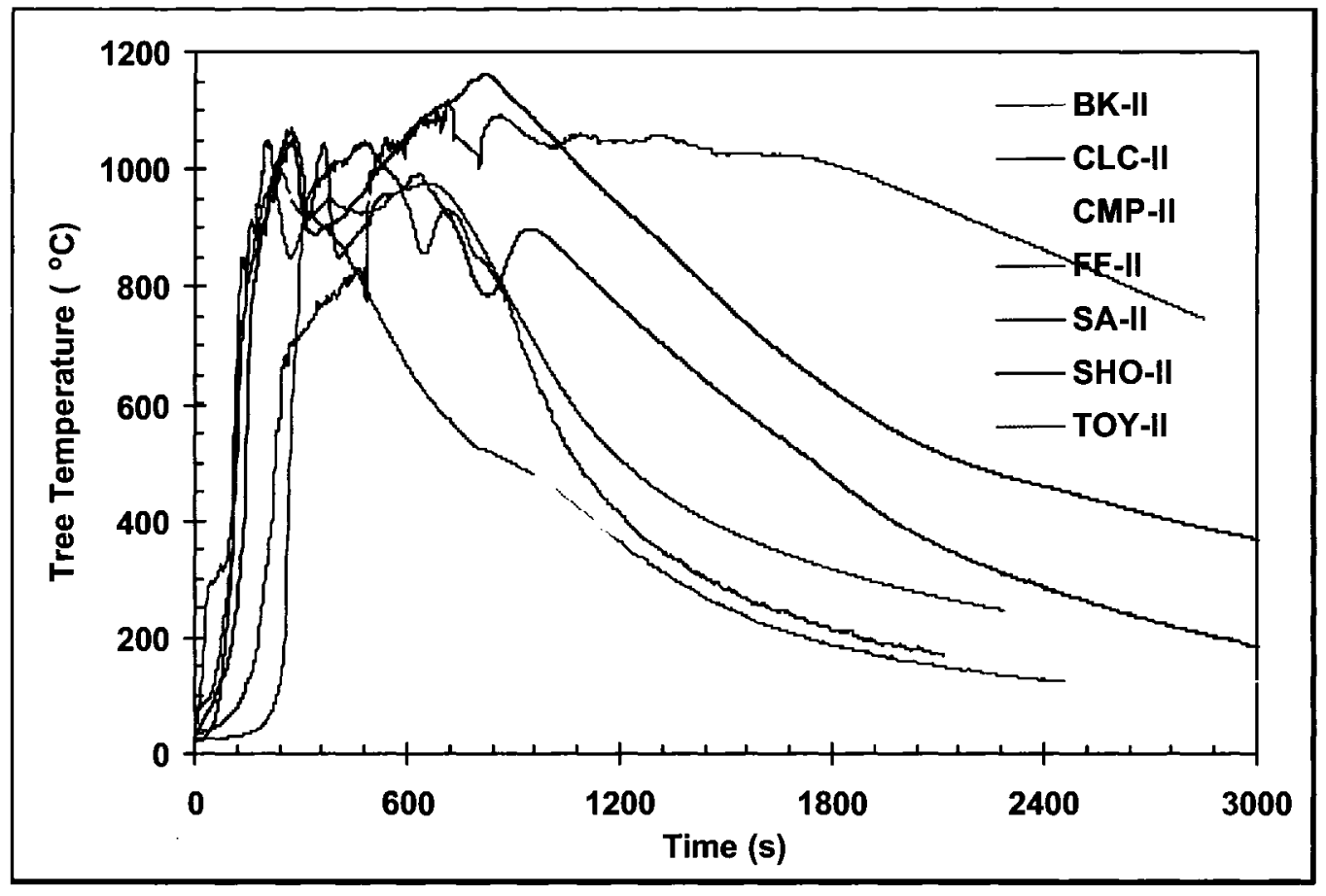

Figure 89. Temperature $2.1 \mathrm{~m}$ high, Phase II experiments

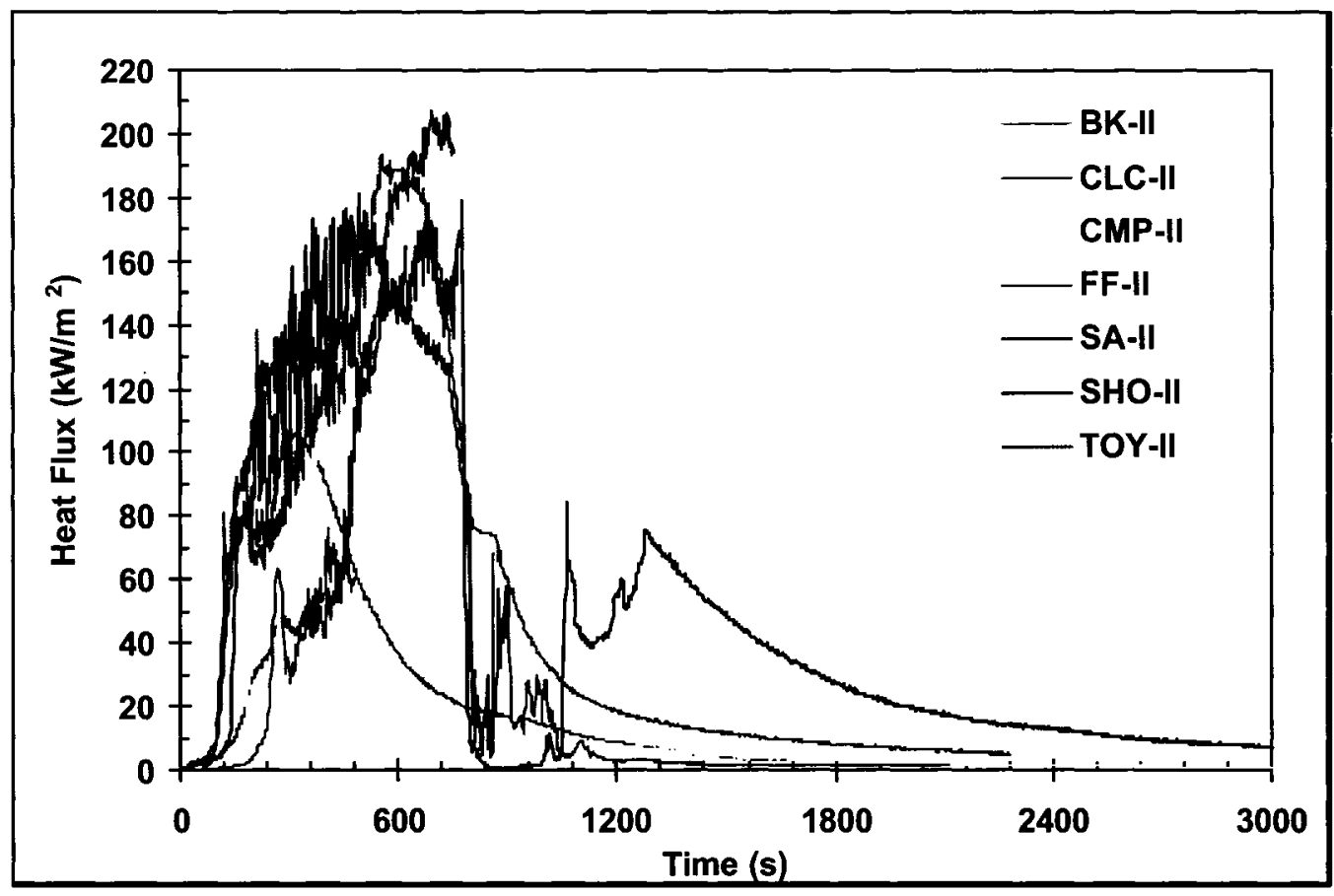

Figure 90. Heat flux, Phase II experiments 


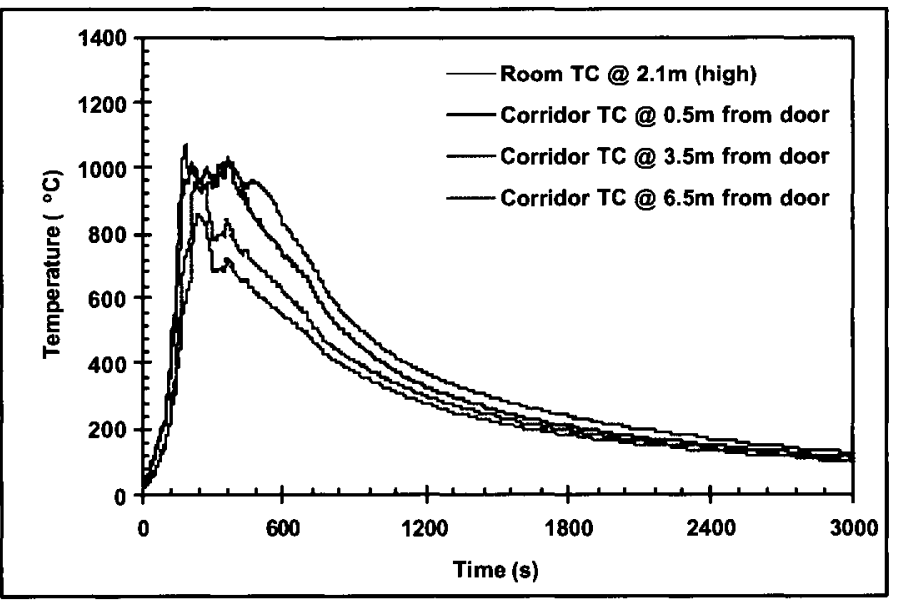

Figure 91. Temperature of test CMP-II, room \& corridor

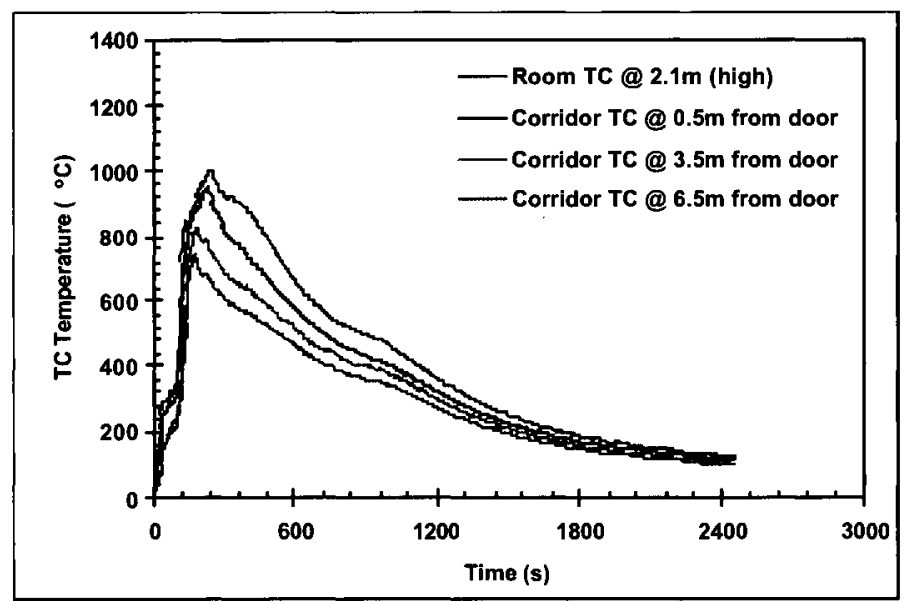

Figure 93. Temperature of test CLC-II, room \& corridor

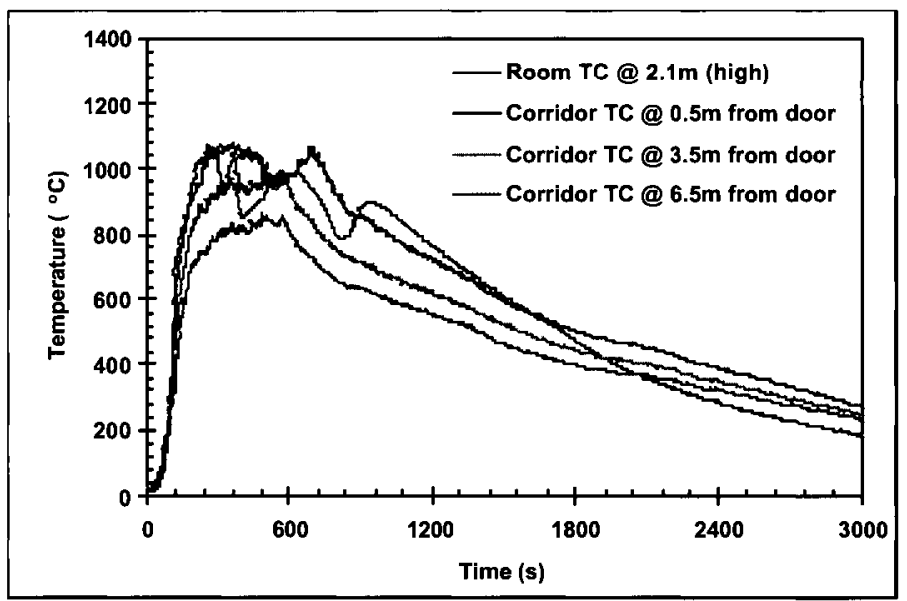

Figure 92. Temperature of test SA-II, room \& corridor

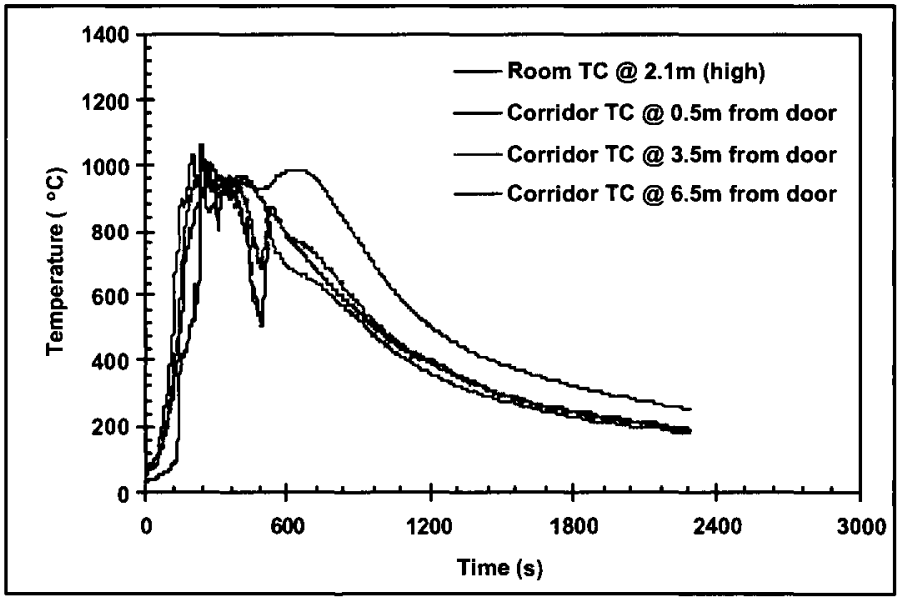

Figure 94. Temperature of test TOY-II, room \& corridor 


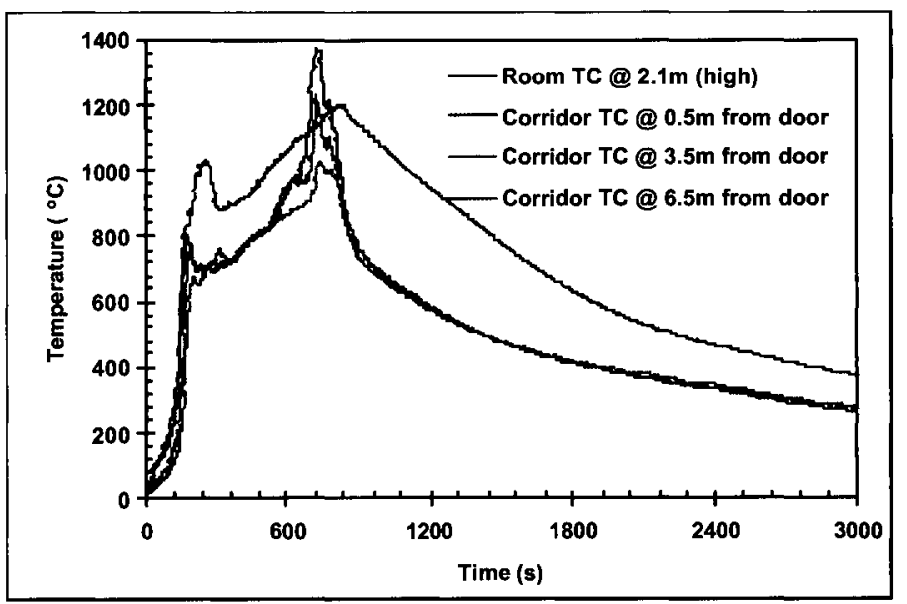

Figure 95. Temperature of test SHO-II, room \& corridor

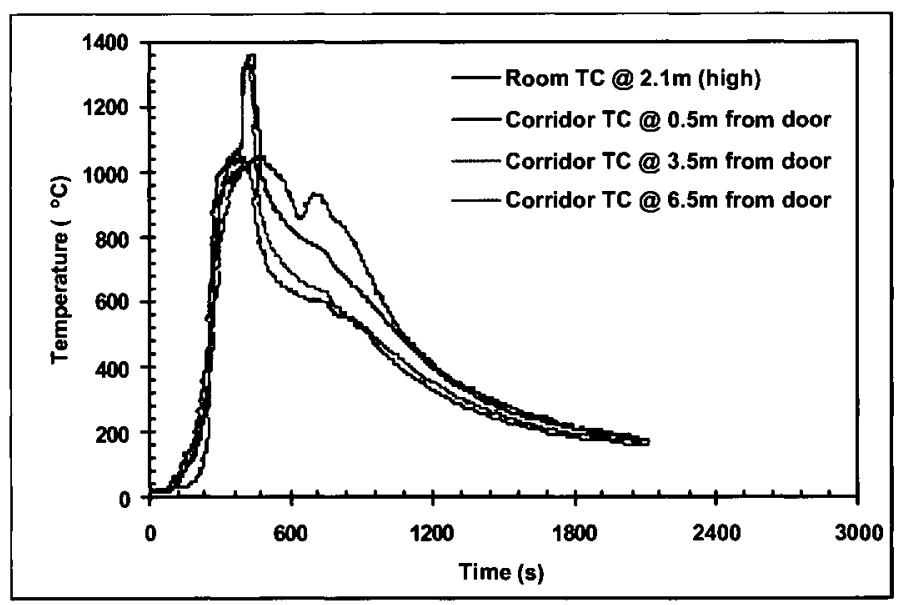

Figure 97. Temperature of test FF-II, room \& corridor

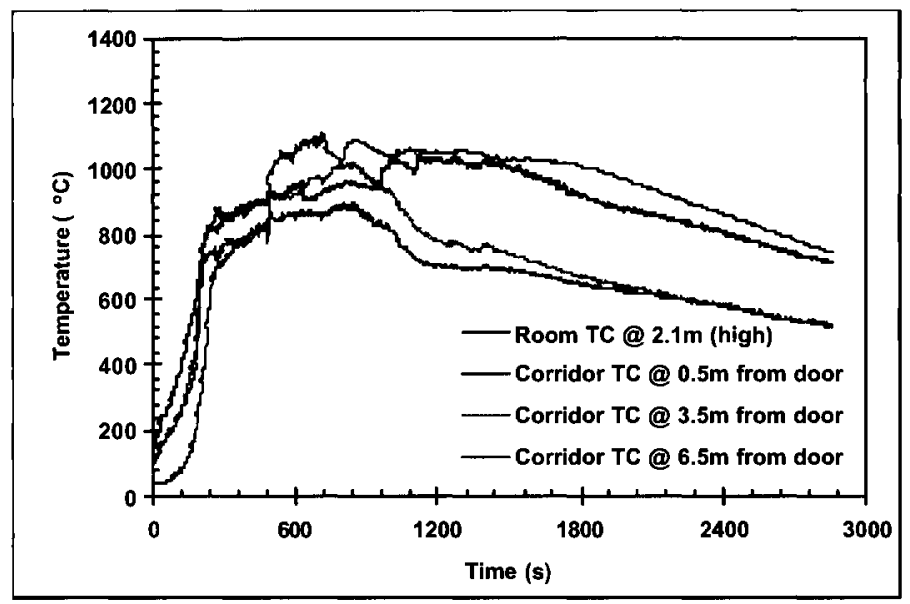

Figure 96. Temperature of test BK-II, room \& corridor 


\subsubsection{Gas Production Rate Measurements}

The experimental data obtained from the post-flashover facility were used to perform a comparative analysis of the concentraction and yield of $\mathrm{CO}$ and $\mathrm{CO}_{2}$.

Concentrations of $\mathrm{CO}$ and $\mathrm{CO}_{2}$ are shown in Table 22, as well as in Figure 98 and Figure 99. Phase II experiments can be grouped into four groups based on the peak $\mathrm{CO}$ production rates (1) SHO-II has the highest peak CO (5576 ppm); (2) BK-II, SA-II, and CMP-II with 4560, 4050, and 4015 ppm, respectively; (3) CLC 3640 ppm; and (4) TOYII and FF-I with values of 1994 and 1640 ppm, respectively. Peak carbon dioxide concentration for all tests ranged from 4 to $5.10 \%$.

Table 22. Smoke data and visibility analysis of Phase II experiments

\begin{tabular}{|c|c|c|c|c|c|}
\hline \multirow[b]{2}{*}{ Test title } & \multirow[b]{2}{*}{ Test ID } & \multicolumn{4}{|c|}{$\mathrm{CO}$ and $\mathrm{CO}_{2}$ Data } \\
\hline & & 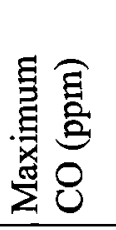 & 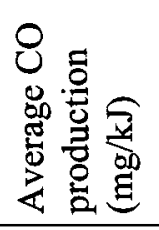 & 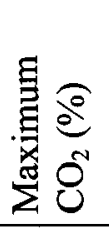 & 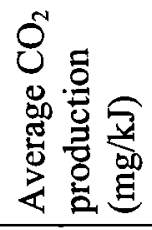 \\
\hline Computer store & CMP-II & 4015 & 2.90 & 4.0 & 52 \\
\hline Storage area & SA-II & 4050 & 2.09 & 4.0 & 84 \\
\hline Clothing store & CLC-II & 3640 & 1.31 & 4.9 & 63 \\
\hline Toy store & TOY-II & 1994 & 1.90 & 4.9 & 82 \\
\hline Shoe store ${ }^{1}$ & SHO-II ${ }^{1}$ & 5576 & 2.02 & 4.7 & 78 \\
\hline Bookstore & BK-II & 4560 & 1.44 & 5.1 & 99 \\
\hline Fast food outlet & FF-II & 1640 & 1.29 & 4.3 & 68 \\
\hline
\end{tabular}




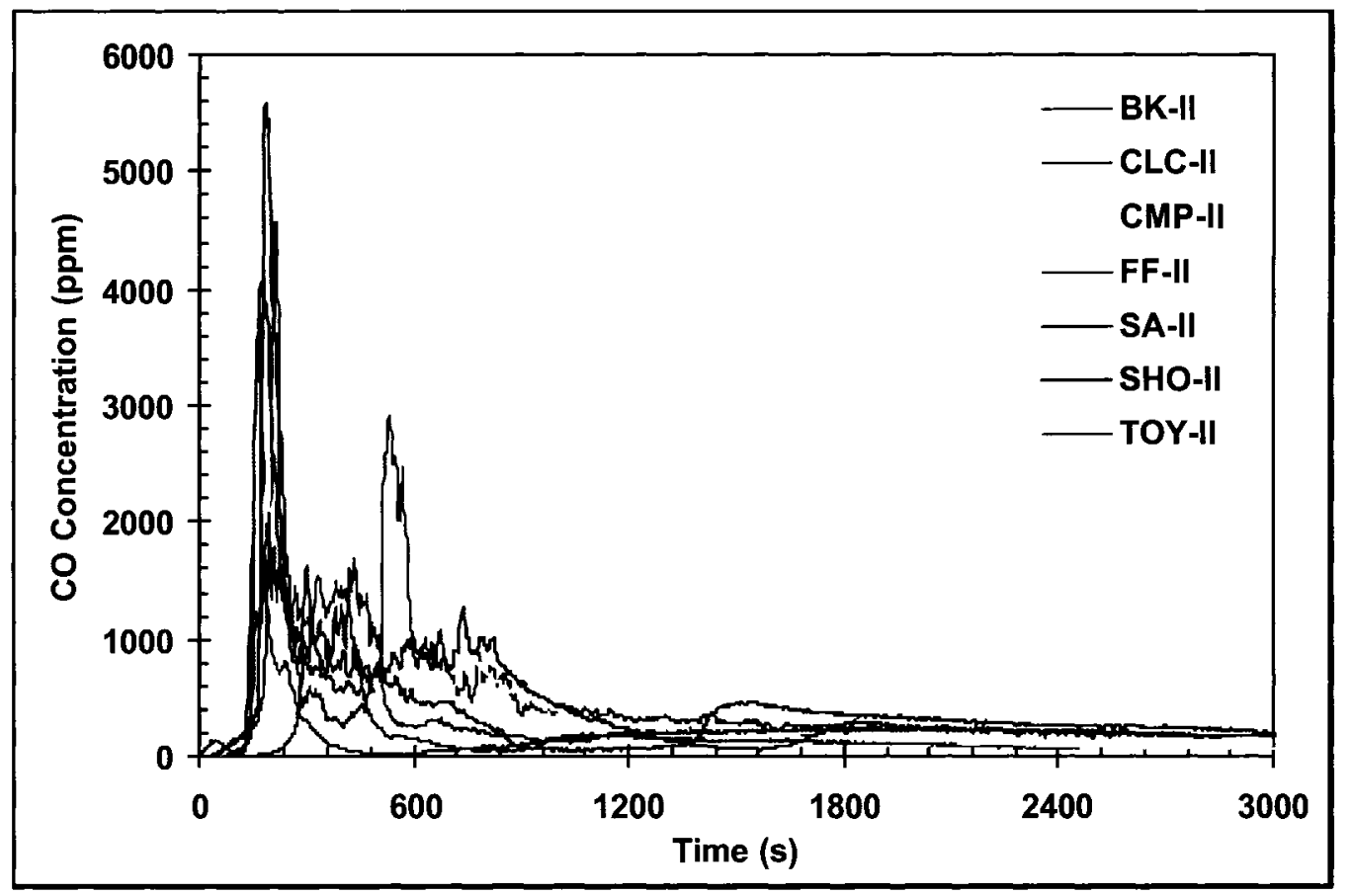

Figure 98. Carbon monoxide concentration, Phase II experiments

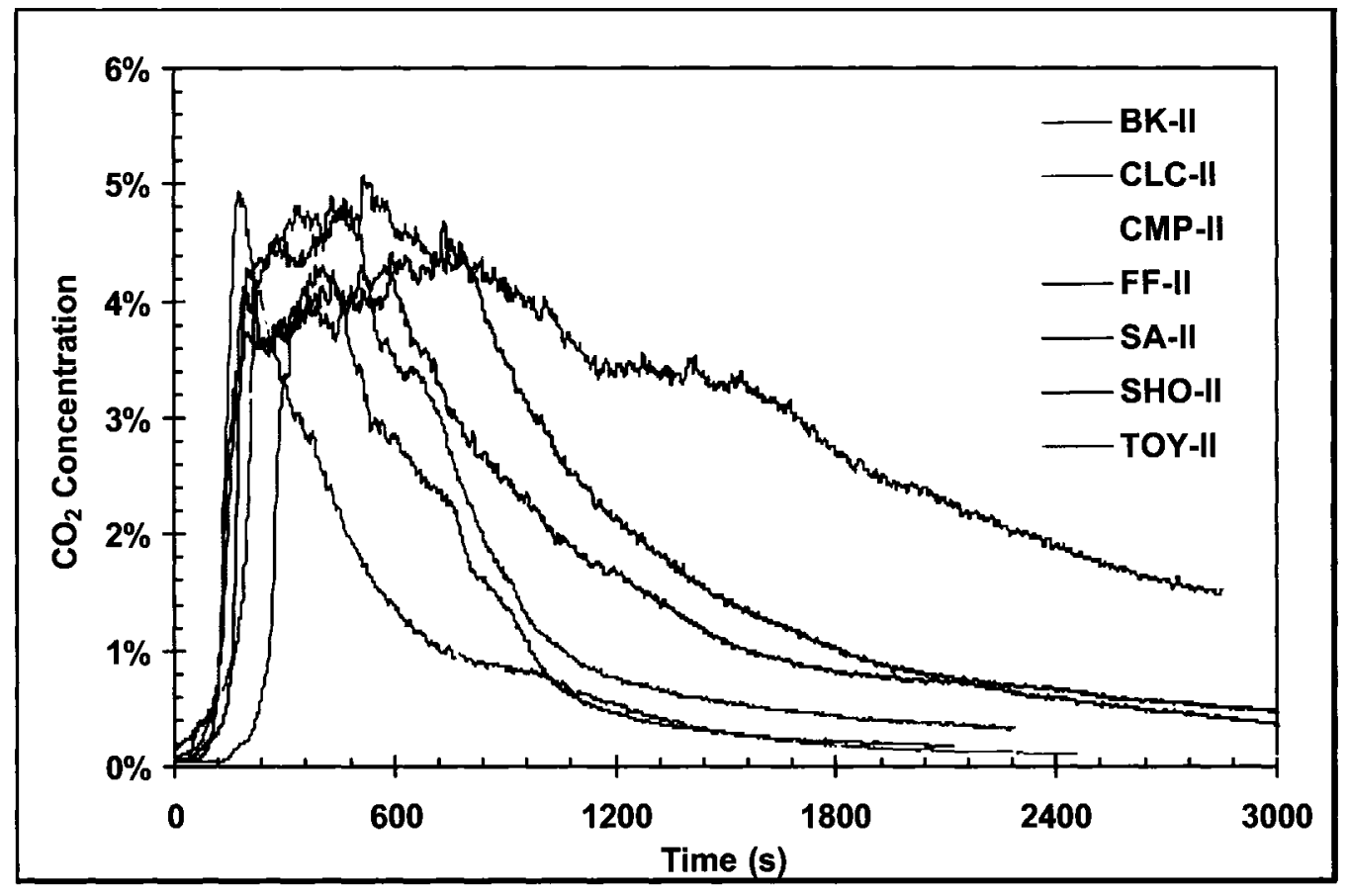

Figure 99. Carbon dioxide concentration, Phase II experiments 
To investigate $\mathrm{CO}$ and $\mathrm{CO}_{2}$ production rates, the mass of $\mathrm{CO}$ and $\mathrm{CO}_{2}$ released was divided by the heat release rate. This gives the production of $\mathrm{CO}$ and $\mathrm{CO}_{2}$ in milligram per kilojoule $(\mathrm{mg} / \mathrm{kJ})$. These results are shown in Table 22, Figure 100, and Figure 101.

Based on the average $\mathrm{CO}$ production rates $(\mathrm{mg} / \mathrm{kJ})$, the fuel packages can be divided into three groups: (1) tests CMP-II $2.9 \mathrm{mg} / \mathrm{kJ}$; (2) tests SA-II, SHO-II, TOY-II with values of 2.09, 2.02, and $1.9 \mathrm{mg} / \mathrm{kJ}$, respectively; and (3) tests BK-II, CLC-II, and FF-II with values of $1.44,1.31$, and $1.29 \mathrm{mg} / \mathrm{kJ}$, respectively. From the above results, the third group of fuel packages had the lowest $\mathrm{CO}$ production rates per kilojoules, for example, FF-II, CLC-II, and BK-II; however, tests that have high plastic contents produced higher values of $\mathrm{CO}$ per kilojoules, example, CMP-II.

To further investigate the impact of fire condition on the production of $\mathrm{CO}$, average production rates of $\mathrm{CO}(\mathrm{mg} / \mathrm{kJ})$ were calculated for each fuel package at four different stages during the experiments: (1) growth; (2) ventilation-controlled; (3) fuel-controlled, early decay; (4) smouldering, late decay, Table 23. In addition Table 23 shows the peak $\mathrm{CO}$ production rate at the ventilation-controlled stage. During the growth stage, production rates range from 0.2 to $2.3(\mathrm{mg} / \mathrm{kJ}), 1.7$ to 4.8 during ventilation-controlled, 0.4 to 1.6 during fuel-controlled, and 1.1 to 3.2 during smouldering stage, exact values are shown in Table 23 .

It is clear from the table that $\mathrm{CO}$ production rates were very low during the growth phase and the fuel-controlled flaming conditions during the decay phase. During the postflashover fully-developed phase, the average CO production was the highest for all fuel packages, with a peak value that is two to four times the average. From the table it can 
also be seen that $\mathrm{CO}$ production during smouldering condition was also higher than flaming condition, due to the combustibles that were burning at low temperature. Comparing $\mathrm{CO}$ production rates of the different fuel packages during the ventilationcontrolled conditions, it is clear that shoe stores, computer stores, and storage areas, which had high plastics and rubber contribution, had the highest $\mathrm{CO}$ production rates, while packages high in cellulosic materials had the lowest $\mathrm{CO}$ production rates.

Table 23. Average production of carbon monoxide in Phase II experiments

\begin{tabular}{|c|c|c|c|c|c|c|}
\hline \multirow[b]{3}{*}{ Test title } & \multirow[b]{3}{*}{ Test ID } & \multicolumn{5}{|c|}{ Production at different stages $(\mathrm{mg} / \mathrm{kJ})$} \\
\hline & & \multirow{2}{*}{ 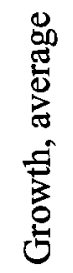 } & \multicolumn{2}{|c|}{$\begin{array}{l}\text { Ventilation } \\
\text { controlled }\end{array}$} & \multirow{2}{*}{ 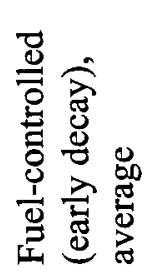 } & \multirow{2}{*}{ 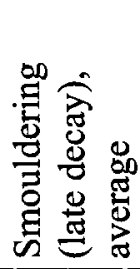 } \\
\hline & & & 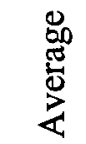 & 苟 & & \\
\hline Computer store & CMP-II & 2.3 & 3.8 & 8.2 & 1.6 & 1.6 \\
\hline Storage area & SA-II & 1.0 & 4.8 & 9.2 & 1.0 & 3.2 \\
\hline Clothing store & CLC-II & 0.2 & 3.0 & 6.7 & 0.5 & 1.8 \\
\hline Toy store & TOY-II & 0.2 & 2.4 & 4.0 & 0.9 & 2.3 \\
\hline Shoe store & SHO-II & 0.3 & 4.5 & 12.3 & 1.3 & 2.2 \\
\hline Bookstore & BK-II & 1.5 & 2.8 & 11.7 & 1.1 & 1.1 \\
\hline Fast food outlet & FF-II & 0.2 & 1.7 & 3.5 & 0.4 & 1.8 \\
\hline
\end{tabular}

Based on the average $\mathrm{CO}_{2}$ production rate $(\mathrm{mg} / \mathrm{kJ})$, the fuel packages can be divided into three groups: (1) test BK-II $99 \mathrm{mg} / \mathrm{kJ}$; (2) tests SA-II, TOY-II, and SHO-II with values of 84,82 , and $78 \mathrm{mg} / \mathrm{kJ}$, respectively; and (3) tests FF-II, CLC-II and CMP-II with values of 68,63 , and $52 \mathrm{mg} / \mathrm{kJ}$, respectively. The ranking for $\mathrm{CO}_{2}$ is the exact opposite of the ranking in $\mathrm{CO}$ groups. Cellulosic fires are among the highest in $\mathrm{CO}_{2}$ production rates $(\mathrm{mg} / \mathrm{kJ})$, example BK-II, and tests that have high plastic contents produced lower values of $\mathrm{CO}_{2}$ production rates $(\mathrm{mg} / \mathrm{kJ})$, example CMP-II. 
As observed in Phase $\mathrm{I}$, when analysing the total smoke released data $\left(\mathrm{m}^{2}\right)$, it was found that the computer store, test CMP-II, which has the smaller fuel package mass, produced the highest amount of smoke $\left(57,300 \mathrm{~m}^{2}\right)$. Tests CMP-II, SA-II, and FF-II had the highest optical density of $7.4 \mathrm{OD} / \mathrm{m}$, followed by TOY-II, and SHO-II, with 6.8 and 5.2 OD/m, respectively. Tests CLC-II and BK-II had the lowest values at 2.7 and $1.48 \mathrm{OD} / \mathrm{m}$, respectively. Detailed results are shown in Table 22 and Figure 102.

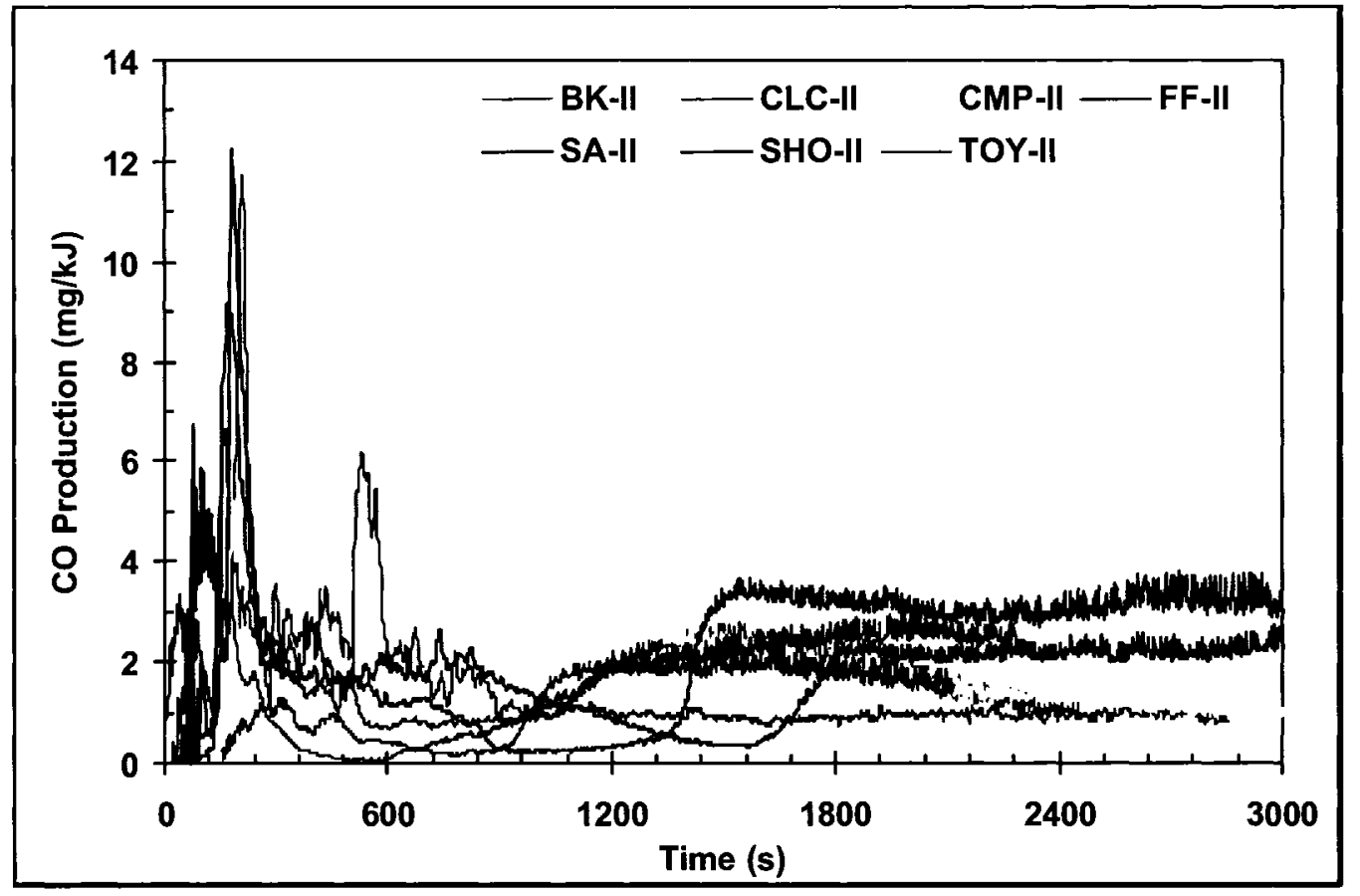

Figure 100. Carbon monoxide production rates, Phase II experiments 


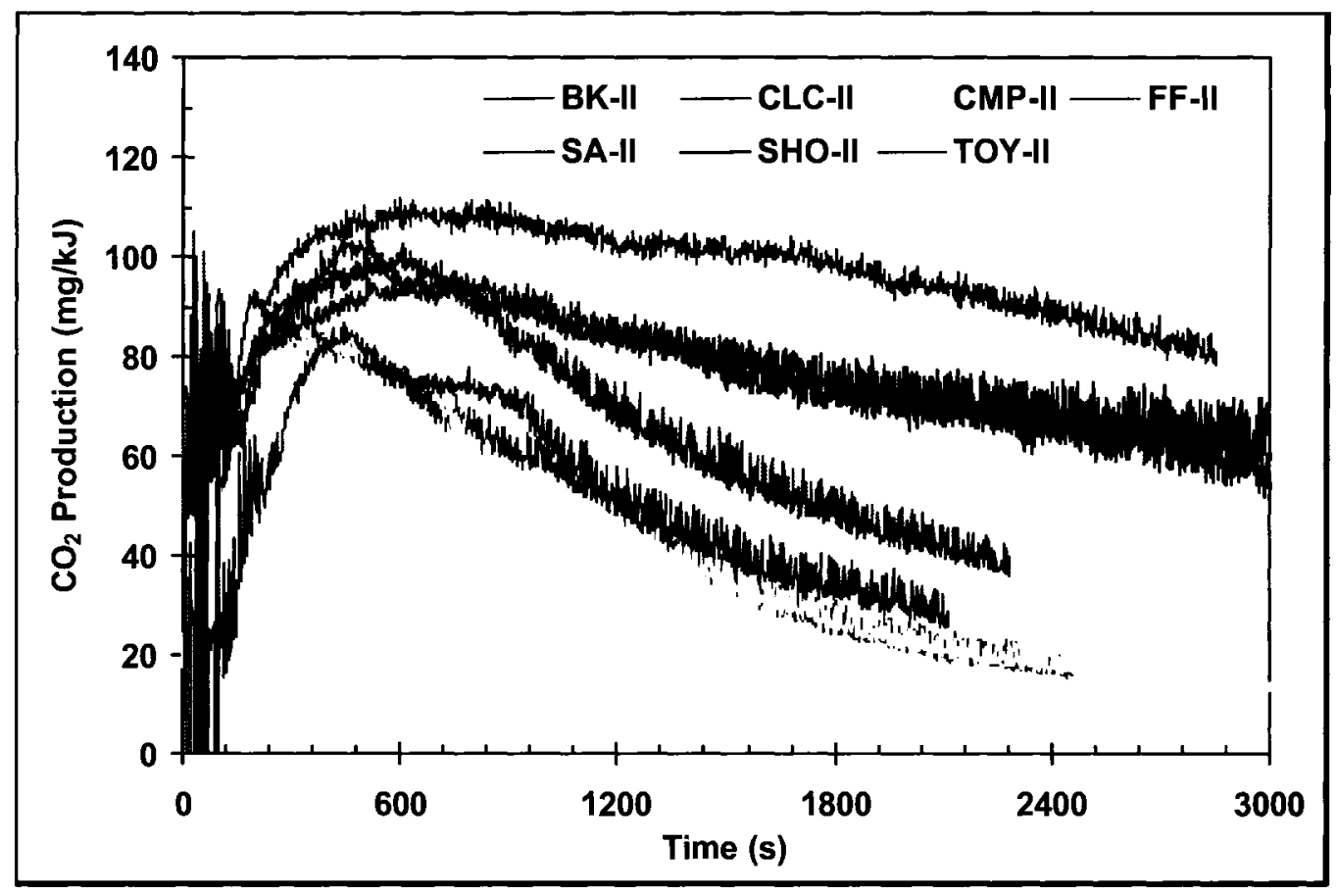

Figure 101. Carbon dioxide production rates, Phase II experiments

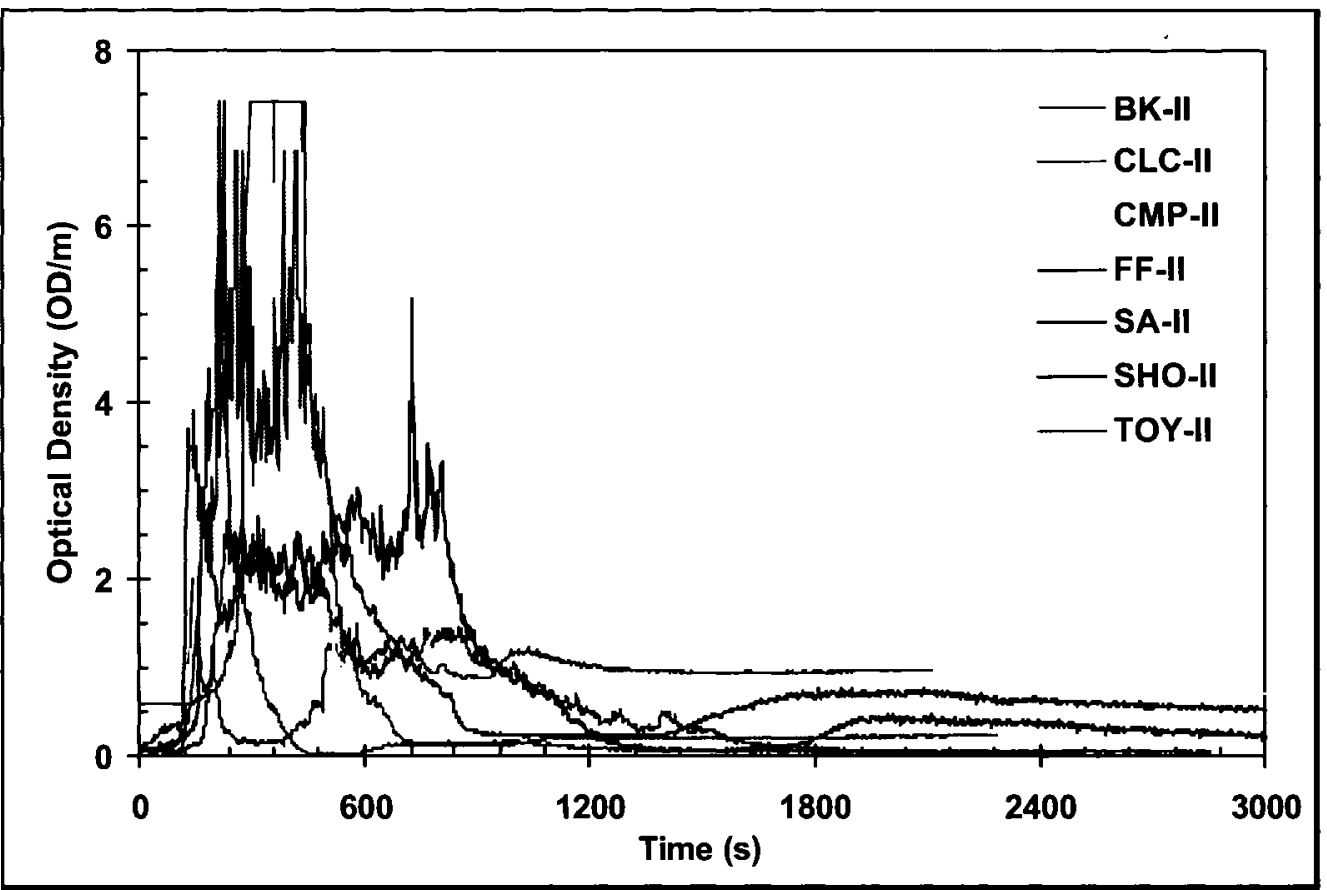

Figure 102. Optical density, Phase II experiments 


\subsubsection{Heat Release Rate (HRR)}

For Phase II, same as for Phase I, the HRR was calculated using the oxygen depletion method. The inputs used for this calculation were the concentrations of $\mathrm{O}_{2}$, and production rates of $\mathrm{CO}$ and $\mathrm{CO}_{2}$, as well as gas temperature and mass flow rate in the duct. It was assumed that when a $20^{\circ} \mathrm{C}$ temperature rise in the hot layer occurs, the fire becomes self-sustained and grows without the need for an external ignition source. For this reason, $\mathrm{HRR}$ and other data $\left(\mathrm{CO}, \mathrm{CO}_{2}\right.$, heat flux, temperatures, etc.) are plotted from this onset of ignition. Table 24 shows the heat release rate results from Phase II and Figure 103 shows the HRR profile of all tests after ignition to $3000 \mathrm{~s}$. Figure 103 includes three curves that represent the slow, medium, and fast $\mathrm{t}$-squared fires.

All Phase II tests have a peak HRR that ranges from 2.4 to $2.7 \mathrm{MW}$. The site of the door and the corridor contributed to limiting the amount of combustion (fresh) air available in the room. In all tests, burning continued in the corridor and for some tests flames were noticed at the end of the 11-m long corridor.

As shown in Figure 103, the fire growth in tests BK-II, and FF-II follow a slow to medium t-squared fire, while tests CLS-II, SHO-II, and CMP-II grew as a slow to medium to fast $t$-squared fire. Tests TOY-II and SA-II followed a fast $t$-squared fire.

Based on the survey results, fuel packages in Phase II experiments had different theoretical total heat content (MJ) and material composition (wood, food, plastics, textiles, etc.). The experimental data were analyzed to calculate the experimental total heat released. As shown in Table 24 the theoretical and experimental results were not in good agreement, as in Phase I experiments, and this could be attributed to the following 
reasons: (1) incomplete combustion due to ventilation-controlled conditions that led to lower experimental total heat release than the theoretical; (2) not all combustibles were consumed during the fire and this also resulted in lower measured total heat released than the theoretical; (3) the uncertainty about the composition of some combustibles might have lead to different experimental total heat release compared to the theoretical; and (4) smoke leakage from the test room, hood, and duct, could have also contributed to about $5 \%$ loss in the experimentally measured values of the total heat released. 
Table 24. Heat released, growth rates, and heat content of Phase II experiments

\begin{tabular}{|c|c|c|c|c|c|c|c|}
\hline \multirow[b]{2}{*}{ Test Title } & \multirow[b]{2}{*}{ Test ID } & \multicolumn{3}{|c|}{ Heat Release Data } & \multicolumn{2}{|c|}{$\begin{array}{c}\text { Total Heat } \\
\text { Content (MJ) } \\
\end{array}$} & \multirow{2}{*}{$\begin{array}{c}\text { Average } \\
\text { Heat } \\
\text { Content } \\
\text { (MJ } / \mathrm{kg} \text { ) } \\
\text { (Theoretical) }\end{array}$} \\
\hline & & $\frac{\sqrt[y]{y}}{\substack{y \\
0}}$ & 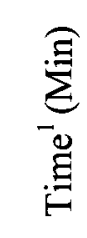 & 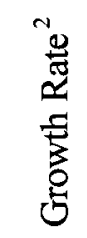 & 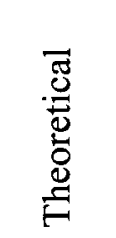 & 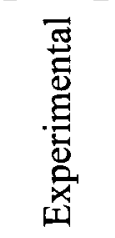 & \\
\hline Computer store & CMP-II & 2475 & $4: 10$ & $\overline{\mathrm{M}-\mathrm{F}}$ & 1624 & 2100 & 25.60 \\
\hline Storage area & SA-II & 2385 & $2: 45$ & F & 4640 & 2751 & 22.70 \\
\hline Clothing store & $\mathrm{CLC}-\mathrm{II}^{3}$ & 2660 & $3: 30$ & M-F & 1322 & 1610 & 19.10 \\
\hline Toy store & TOY-II & 2570 & $4: 15$ & $\mathrm{~F}$ & 2446 & 2125 & 20.20 \\
\hline Shoe store & $\mathrm{SHO}^{-\mathrm{II}^{4}}$ & 2555 & 4:00 & $\mathrm{M}-\mathrm{F}$ & 4900 & 3990 & 22.81 \\
\hline Bookstore & BK-II & 2375 & $2: 50$ & S-M & 10610 & 4154 & 17.51 \\
\hline Fast food outlet & FF-II & 2700 & $6: 15$ & S-M & 1762 & 1660 & 27.7 \\
\hline
\end{tabular}

${ }^{1}$ time to corresponding peak, ${ }^{2}$ growth rates of $t$-squared fires (S: slow, M: medium, $F$ : fast)

${ }^{3}$ same fuel package as in Phase I test SHO-I

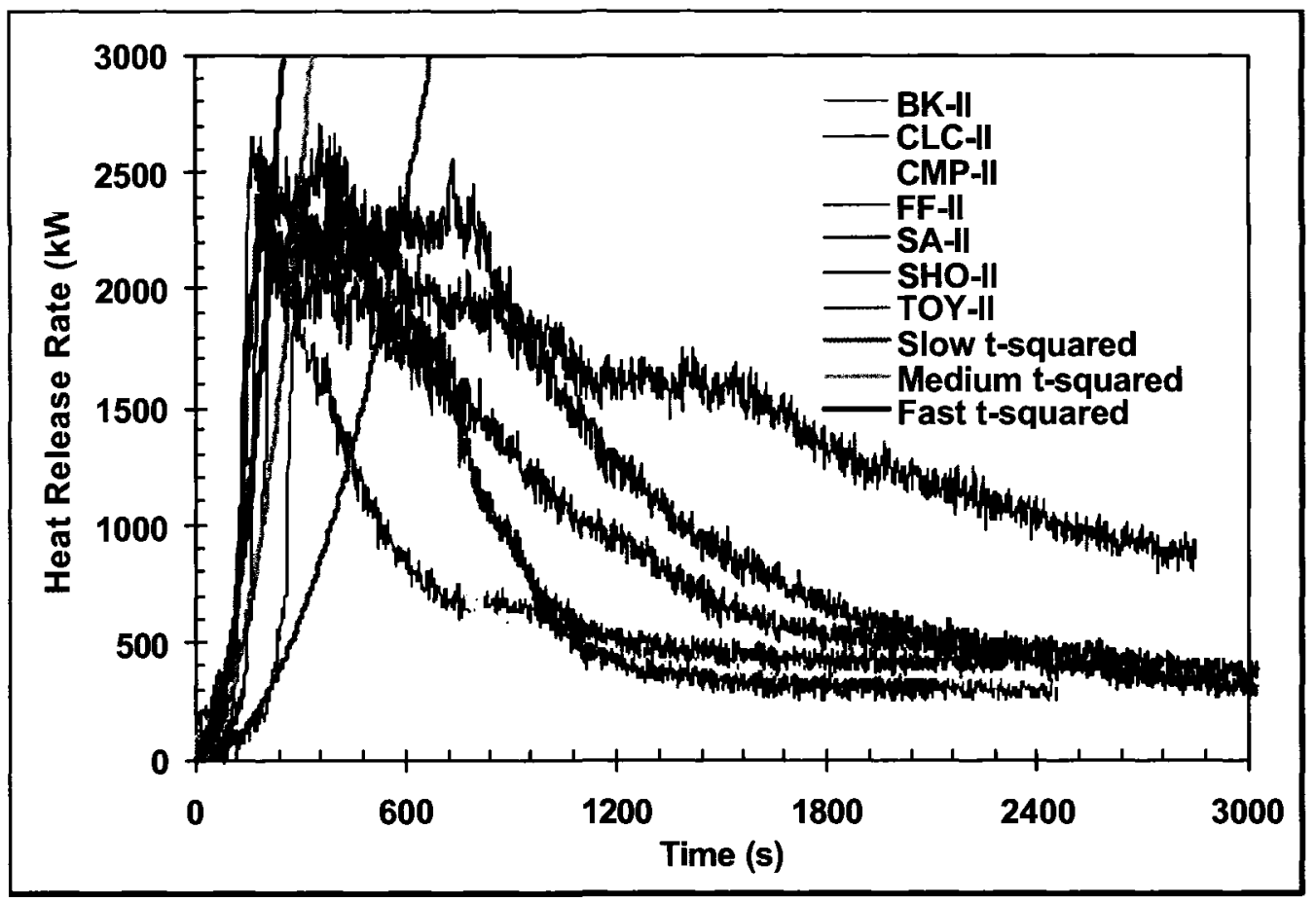

Figure 103. Heat release rates, Phase II experiments 


\subsubsection{Comparisons of Phase I and Phase II Tests}

This section provides comparisons of the results of the Phase I and Phase II experiments. The aspects for this comparative study include; (1) hot layer temperature, and heat flux; (2) $\mathrm{CO}$ and $\mathrm{CO}_{2}$ production rates, and $\mathrm{HRR}$.

\subsubsection{Computer Store, Test CMP-I and CMP-II}

The fuel package in test CMP-I had a fire load of $812 \mathrm{MJ}$ and an area of $1 \mathrm{~m}^{2}$, while the fuel package in Phase II consisted of two Phase I fuel packages with a total area of $2 \mathrm{~m}^{2}$ and a fuel load of 1624 MJ. Details of the combustibles used in Phase I and II are shown in Table 16. The photographs in Figure 104 and Figure 105 depict the tests setup and developing stage of the fires.

As shown in Figure 106 the HRR profile of CMP-I had an almost constant HRR with no clear distinction between the growth, developed, or decay phases. The HRR was $0.4 \mathrm{MW}$ at 28 minutes, whereas, in CMP-II, the HRR reached $2.47 \mathrm{MW}$ in 4:10 minutes and remained between 2 and $2.47 \mathrm{MW}$ for about 4 minutes before it decayed. While the fuel loads in CMP-I and CMP-II packages were 812 and $1624 \mathrm{MJ}$, respectively, the total computed heat released (HR), using the experimental data, was 540 and $2100 \mathrm{MJ}$, respectively. The lower total heat output in CMP-I can be attributed to the remaining unburned materials, while the excess of HR in CMP-II can be attributed to the uncertainty of the exact heat content of the kind of plastics used in manufacturing the CPUs, monitors, and printers used in both tests. In CMP-I, the mass loss was recorded and it was possible to determine the mass of the unburned materials, and hence the mass of the burned materials. Based on the mass loss and the total heat produced by the average fire, the heat content was computed and found to be $27.6 \mathrm{MJ} / \mathrm{kg}$. This value is 
higher than the theoretical value of $25.6 \mathrm{MJ} / \mathrm{kg}$ used to determine the fire load of this fuel package.

Figure 107 and Figure 108show the production rates of $\mathrm{CO}$ and $\mathrm{CO}_{2}(\mathrm{mg} / \mathrm{kJ}) . \quad \mathrm{CO}$ and $\mathrm{CO}_{2}$ production rates have relatively similar average values of 3.17 and $58(\mathrm{mg} / \mathrm{kJ})$ in CMP-I, and 2.9 and $52(\mathrm{mg} / \mathrm{kJ})$ in CMP-II.

Gas temperatures were measured at the corner of the room and at the ceiling level, Figure 109 and Figure 110. In CMP-I and CMP-II, at 2.1-m height, the hot layer gas temperatures measured 180 and $1070^{\circ} \mathrm{C}$, respectively, showing a high increase in room temperature with the use of 2 packages. As expected, the heat flux had a maximumrecorded value of 1 in CMP-I test and $124 \mathrm{~kW} / \mathrm{m}^{2}$ in CMP-II test, Figure 111 . The optical density of the two tests is shown in Figure 112, which follows a similar trend as the HRR. 

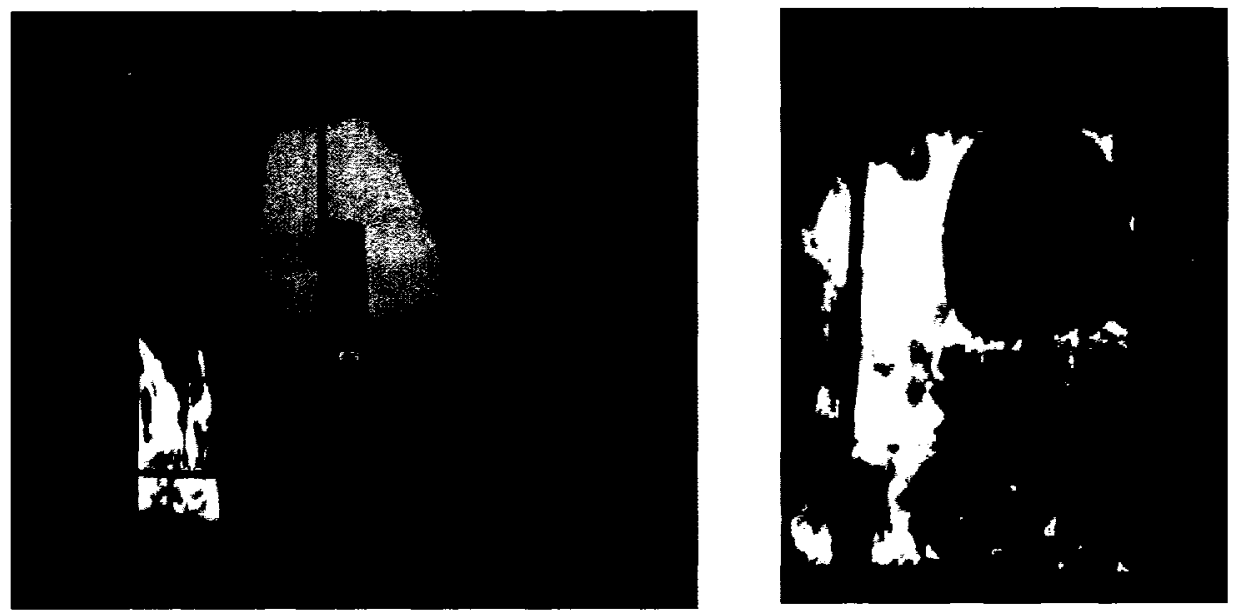

Figure 104. Photographs depicting test CMP-I progress
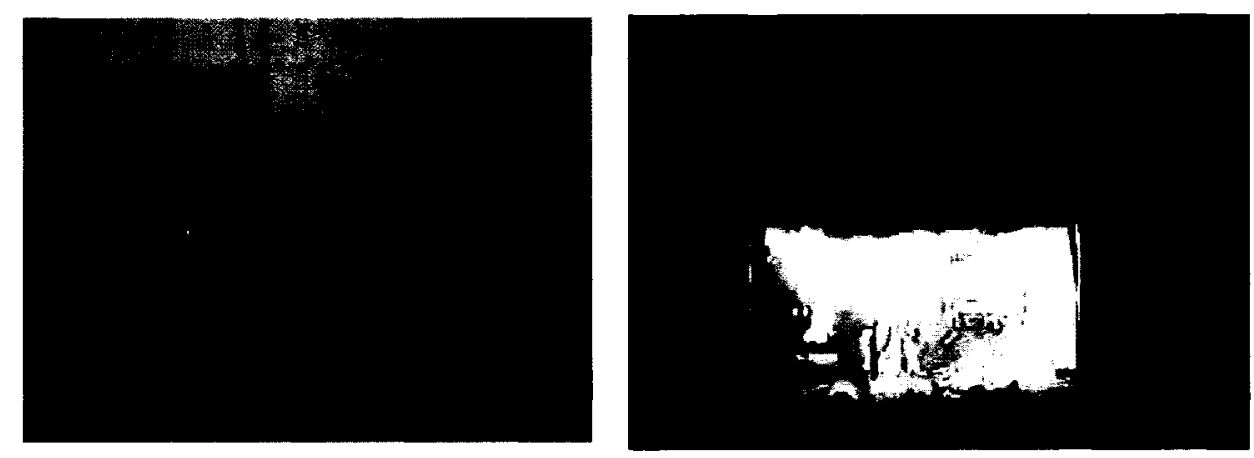

Figure 105. Photographs depicting test CMP-II progress 


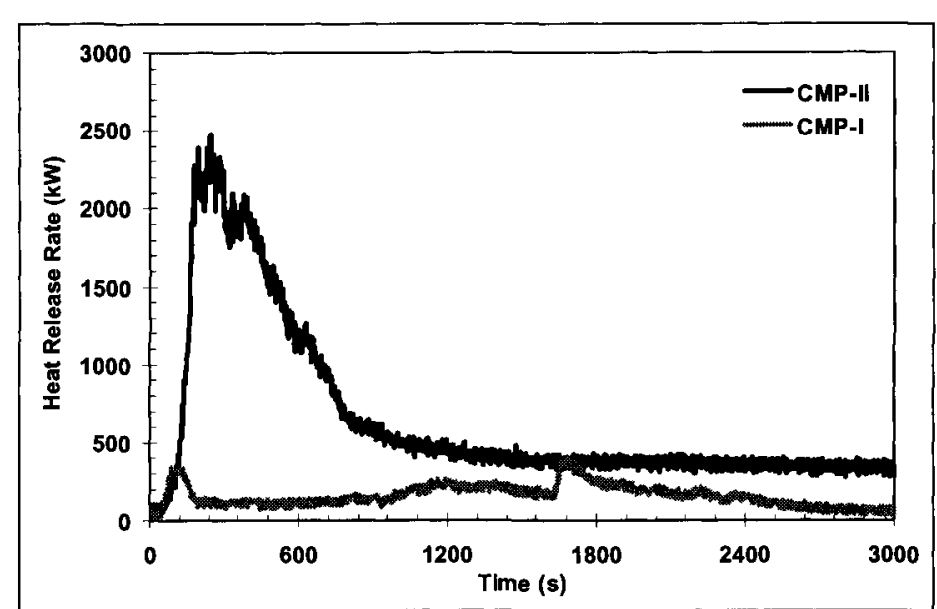

Figure 106. Heat release rate

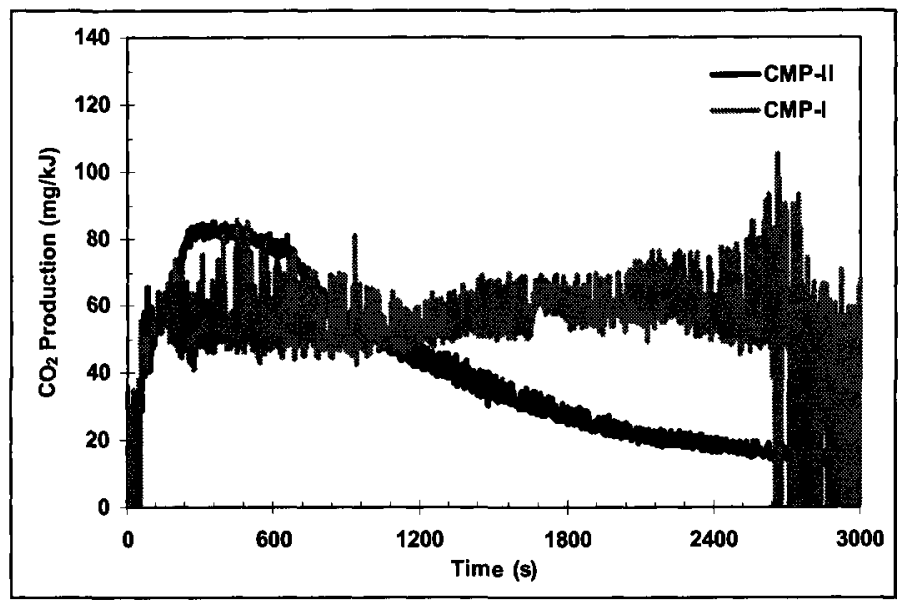

Figure 108. Carbon dioxide production rate

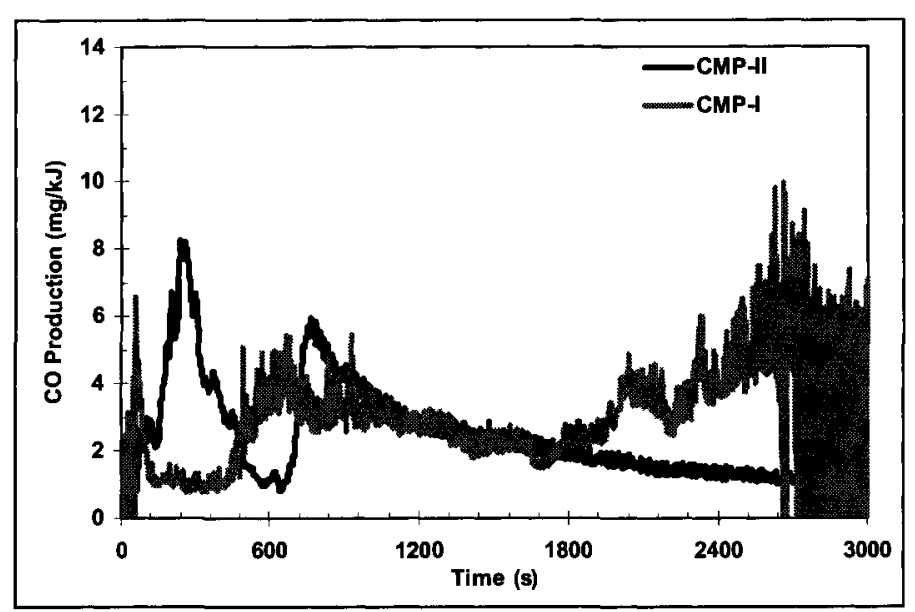

Figure 107. Carbon monoxide production rate 


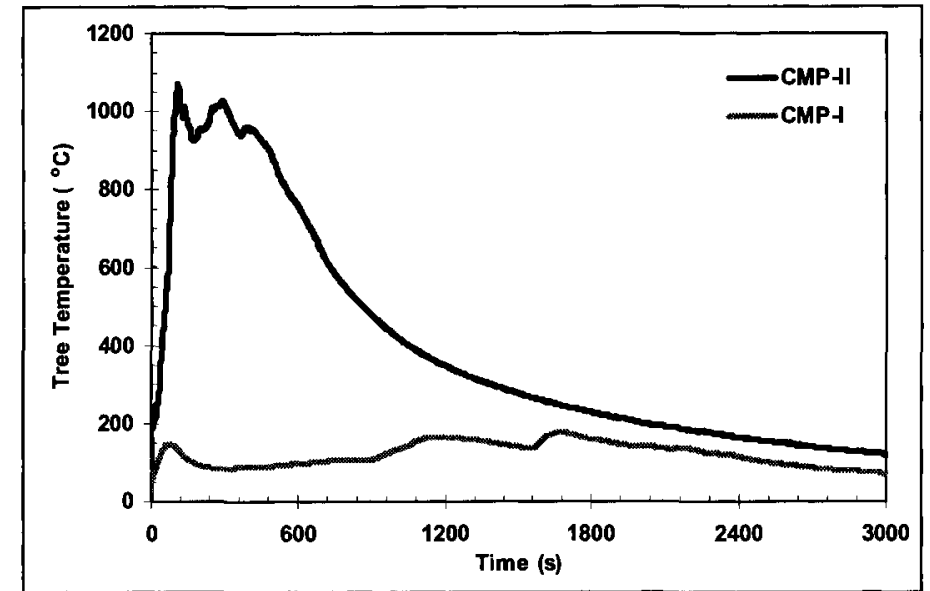

Figure 109. Temperature $2.1 \mathrm{~m}$ from floor

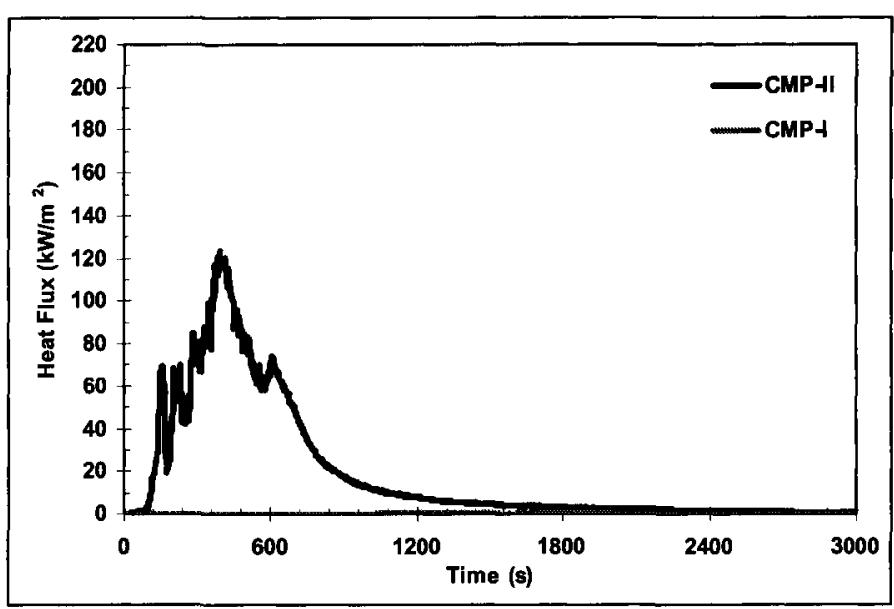

Figure 111. Heat flux

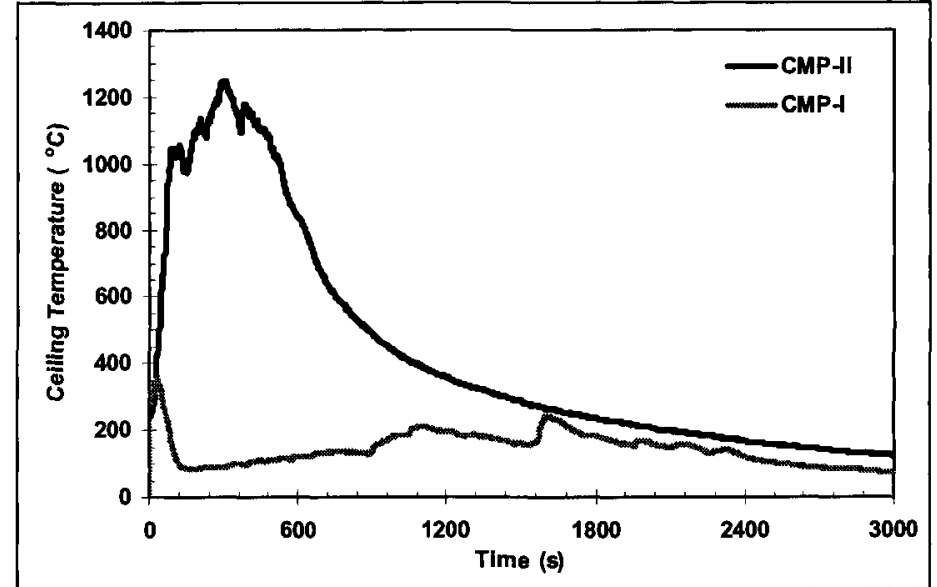

Figure 110. Temperature at the ceiling level

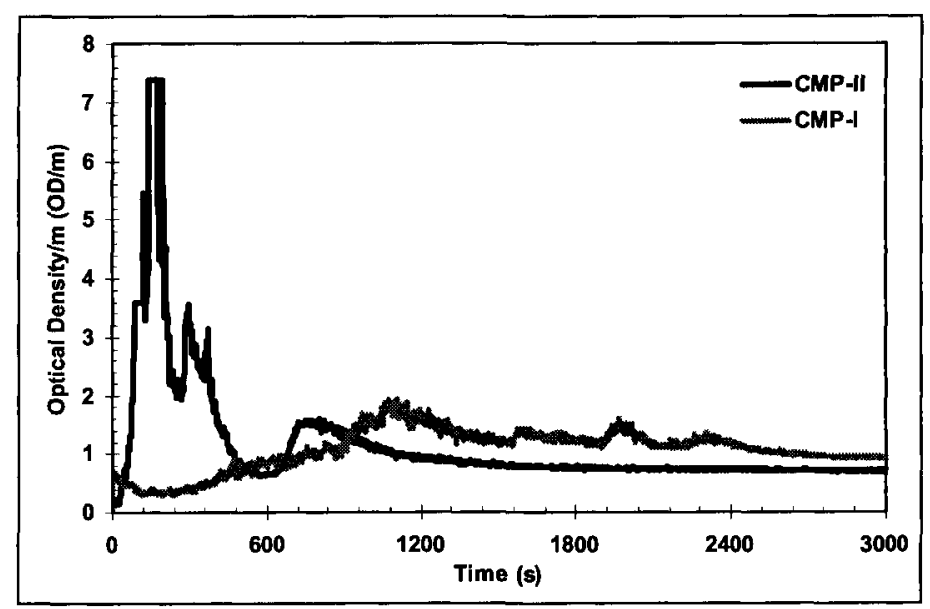

Figure 112. Optical density in the duct 


\subsubsection{Storage Area, Test SA-I and SA-II}

The fuel load density used in storage area tests was $2320 \mathrm{MJ} / \mathrm{m}^{2}$. For the test SA-I $1 \mathrm{~m}^{2}$ of combustibles was tested, while $2 \mathrm{~m}^{2}$ were tested in SA-II, with total fire loads of 2320 and $4640 \mathrm{MJ}$, respectively. The packages were arranged in a fashion usually seen in storage areas, and represented combustibles, such as cardboards, paper files, plastic containers and chairs (different types of plastics), wood, wrapped magazines, food products, textiles, leather, and rubber. Details of the combustibles used in the tests are shown in Table 16. The photographs in Figure 113 and Figure 114 depict the tests setup and the developing stage of the fire.

The HRR of SA-I reached 1.4 MW in 7:00 minutes, and then remained between $1 \mathrm{MW}$ and 1.4 MW for about 4 minutes. The HRR in SA-II reached $2.4 \mathrm{MW}$ in 3:30 minutes and remained between 2 and $2.4 \mathrm{MW}$ for about 7 minutes, Figure 115 . While the fuel loads in SA-I and SA-II packages were 2320 and $4640 \mathrm{MJ}$, respectively, the total measured HR was 1372 and $2751 \mathrm{MJ}$, respectively. This is due to the fact that there was a lot of unburned materials remaining in the room. In Phase I, the mass loss was recorded. Based on the initial weight and the remaining unburned weight, the weighted average of the heat content per kilogram $(\mathrm{MJ} / \mathrm{kg})$ was determined. The experimental weighted average was $19.1 \mathrm{MJ} / \mathrm{kg}$, which is close to the theoretical weighted average $22.71 \mathrm{MJ} / \mathrm{kg}$.

Production rates of $\mathrm{CO}$ and $\mathrm{CO}_{2}(\mathrm{mg} / \mathrm{kJ})$ are shown in Figure 116 and Figure 117. $\mathrm{CO}$ and $\mathrm{CO}_{2}$ production rates have average values of 1.55 and $71(\mathrm{mg} / \mathrm{kJ})$ in SA-I, and 2.09 and $84(\mathrm{mg} / \mathrm{kJ})$ in CMP-II. Figure 116 shows that about 4 times more $\mathrm{CO}$ is produced during ventilation-controlled conditions. Gas temperatures measured at the corner of the 
room and the ceiling level are depicted in Figure 118 and Figure 119. In SA-I and SAII tests, at a level of $2.1 \mathrm{~m}$ at the corner, the gas temperatures were 450 and $1080^{\circ} \mathrm{C}$, respectively, showing a high increase in rom temperature with the use of 2 packages in SA-II versus 1 package in SA-I. Accordingly, the heat flux had a maximum-recorded value of $12 \mathrm{~kW} / \mathrm{m}^{2}$ for SA-I test; and $207 \mathrm{~kW} / \mathrm{m}^{2}$ for SA-II test, before the heat flux measurements for the SA-II test stopped when a falling object covered the heat flux meter, Figure 120. Values of optical density followed the above trend with a maximum of 0.96 and $7.4 \mathrm{OD} / \mathrm{m}$, Figure 121 .
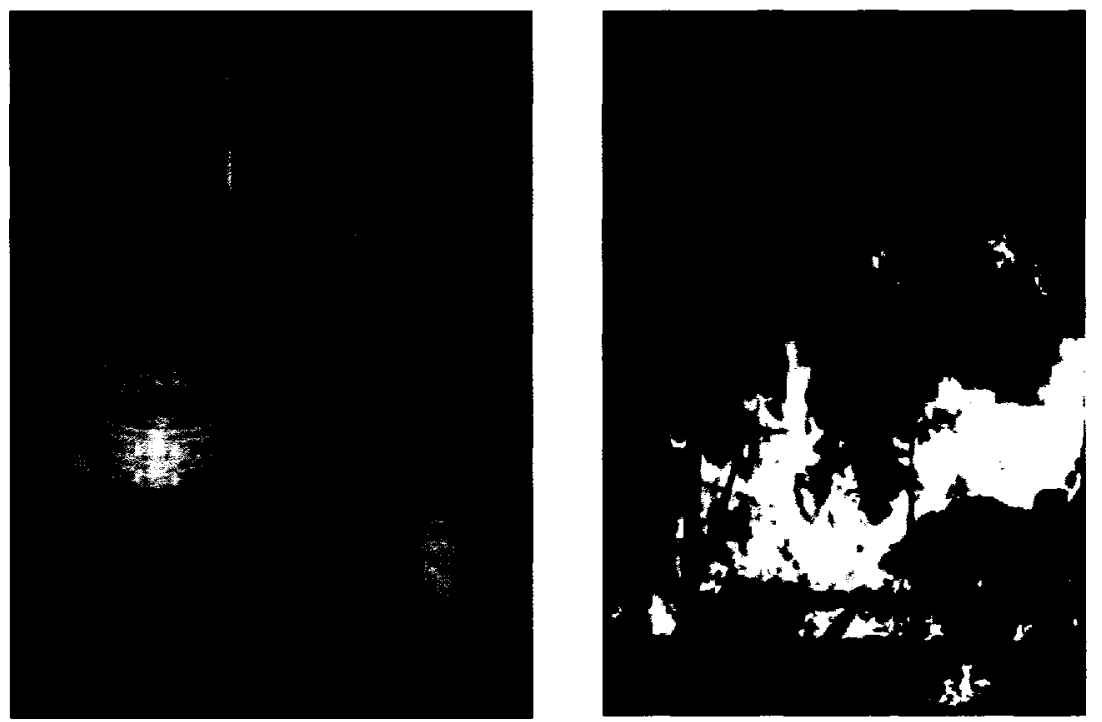

Figure 113. Photographs depicting test SA-I progress
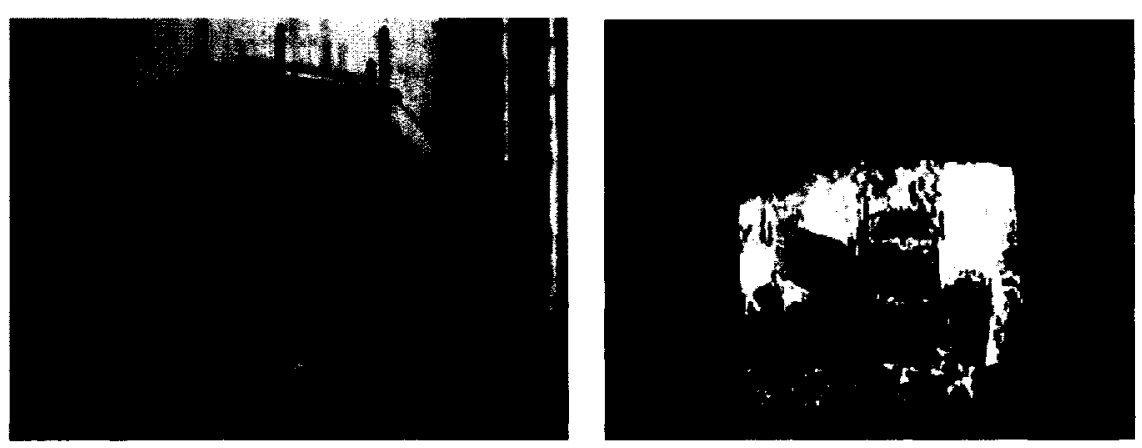

Figure 114. Photographs depicting test SA-II progress 


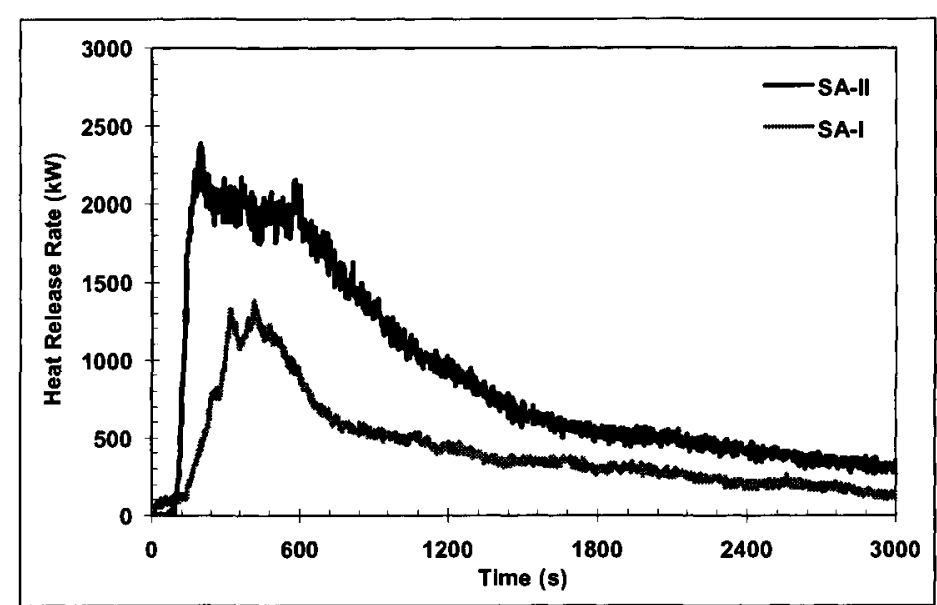

Figure 115. Heat release rate

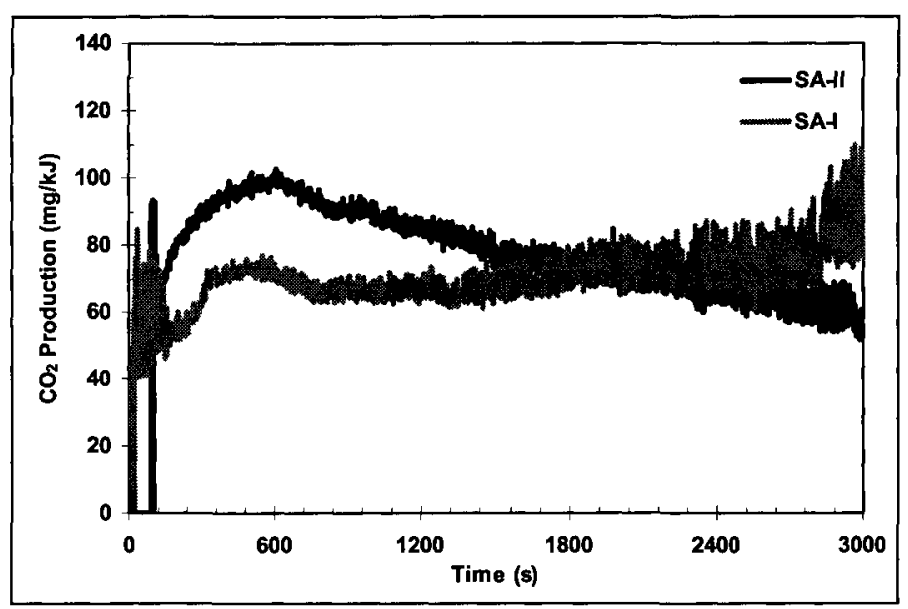

Figure 117. Carbon dioxide production rate

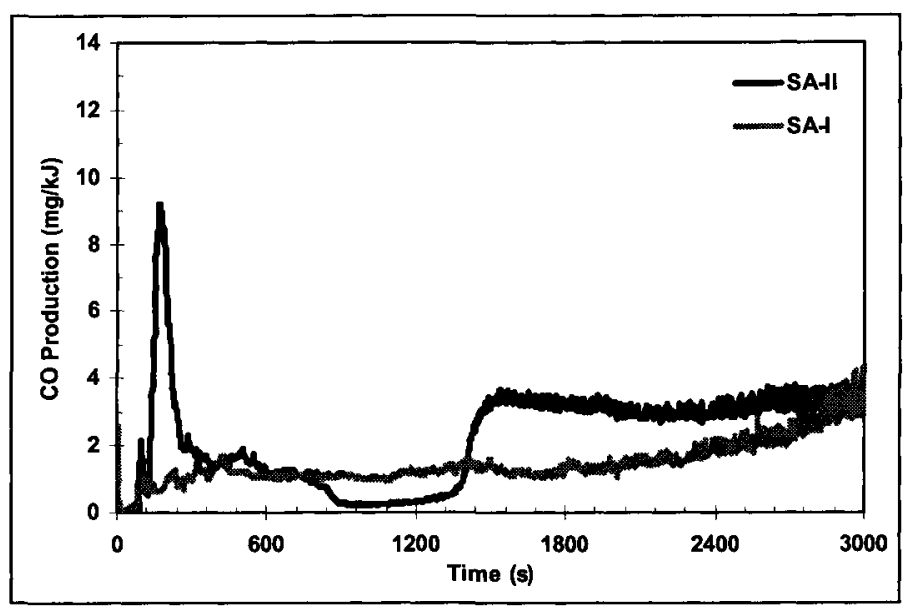

Figure 116. Carbon monoxide production rate 


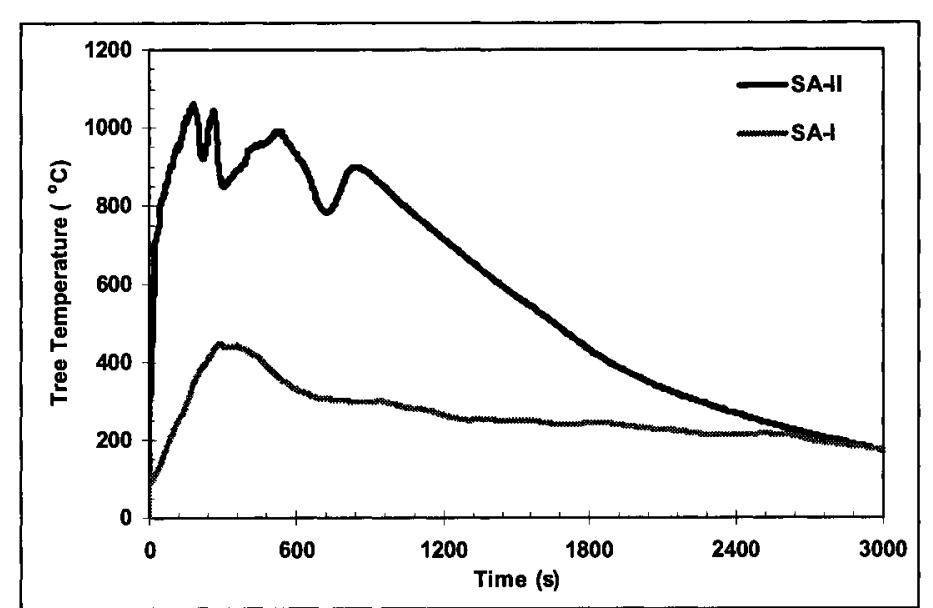

Figure 118. Temperature $2.1 \mathrm{~m}$ from floor

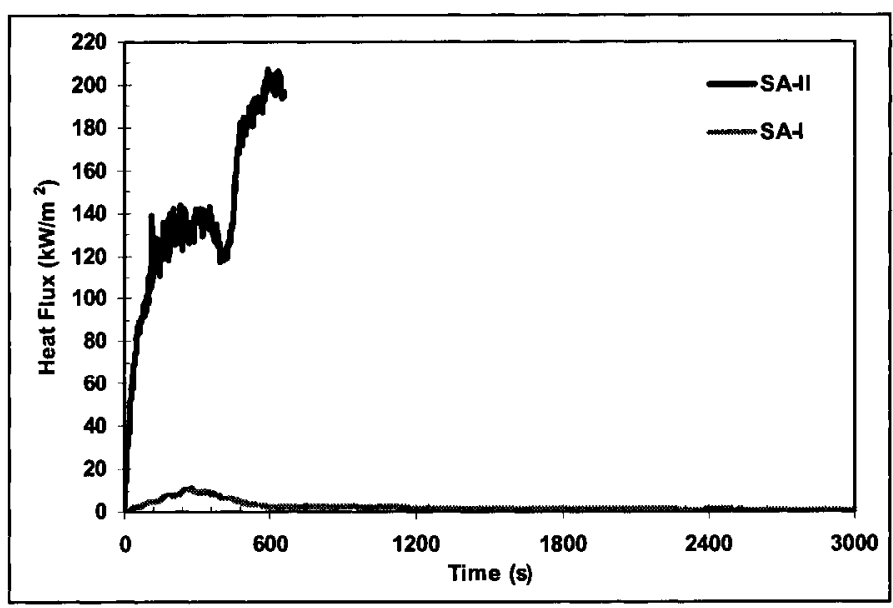

Figure 120. Heat flux

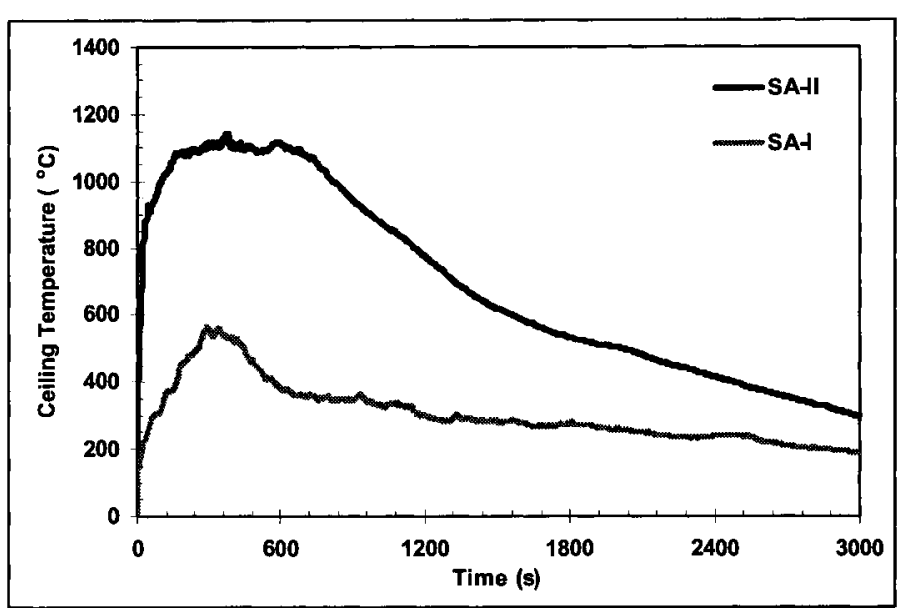

Figure 119. Temperature at the ceiling level

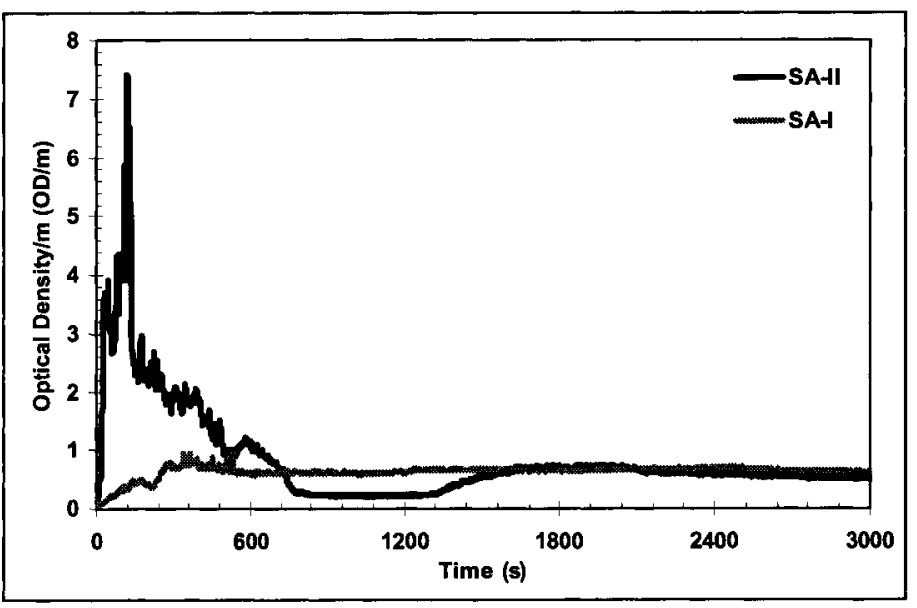

Figure 121. Optical density 


\subsubsection{Clothing Stores Tests, Tests CLC-I and CLC-II}

The fuel load density used in clothing store tests was $661 \mathrm{MJ} / \mathrm{m}^{2}$. For test CLC-I, $1 \mathrm{~m}^{2}$ (total fire load of $661 \mathrm{MJ}$ ) of combustibles was tested and selected to represent Phase I experiments of clothing stores. CLC-II had a $2 \mathrm{~m}^{2}$ area with a total fire load of $1322 \mathrm{MJ}$. The packages were arranged in a fashion usually seen in clothing stores. The test setup was of a steel hanger full of hung clothes to simulate rack display usually found in these stores, and a small wooden box full of textiles on the floor. The combustibles used were textiles, wood, paper bags and wrapping papers, rubber, and leather. Details of the combustibles used in the tests are shown in Table 16. The photographs in Figure 122 and Figure 123 depict the tests setup and the developed stage of the fire.

The HRR profile of CLC-I reached 1.53 MW at 4:30 minutes, while the HRR in CLC-II reached 2.66 MW at 2:40 minutes, Figure 124. While the fuel loads in CLC-I and CLC-II packages were 661 and $1322 \mathrm{MJ}$, respectively, the total measured HR was 632 and $1610 \mathrm{MJ}$, respectively. This increase in the measured values could be attributed to the uncertainty about the textiles composition and heat contents (cotton vs wool, polyethylene, and nylon), and the fact that there were no remaining unburned materials. In CLC-I, the mass loss was recorded. Based on the initial weight and the remaining unburned weight, the weighted average of the heat content per kilogram (MJ/kg) was measured. It was found that the experimental weighted average was close to the theoretical weighted average, 20.0 and $18.65 \mathrm{MJ} / \mathrm{kg}$, respectively.

Production rate profiles of $\mathrm{CO}$ and $\mathrm{CO}_{2}(\mathrm{mg} / \mathrm{kJ})$ are shown in Figure 125 and Figure 126. $\mathrm{CO}$ and $\mathrm{CO}_{2}$ production rates have average values of 1.2 and $73(\mathrm{mg} / \mathrm{kJ})$ in CLC-I, and 1.31 and 
$63(\mathrm{mg} / \mathrm{kJ})$ in CLC-II. These average values are similar and help to identify the toxic gases produced from a clothing store fuel package. Gas temperatures measured at the corner of the room and at the ceiling level are depicted in Figure 127 and Figure 128. In CLC-I and CLC-II tests, at a level of $2.1 \mathrm{~m}$ at the corner of the room, the gas temperatures were 470 and $1010^{\circ} \mathrm{C}$, respectively, showing an increase in room temperature with the use of 2 packages in CLC-II versus 1 package in CLC-I. The same finding was noted in the heat flux value, with maximum recorded values of 11 and $107 \mathrm{~kW} / \mathrm{m}^{2}$, respectively, Figure 129 . Values of optical density followed the above trend with a maximum of 1.07 and $2.7 \mathrm{OD} / \mathrm{m}$, Figure 130. 

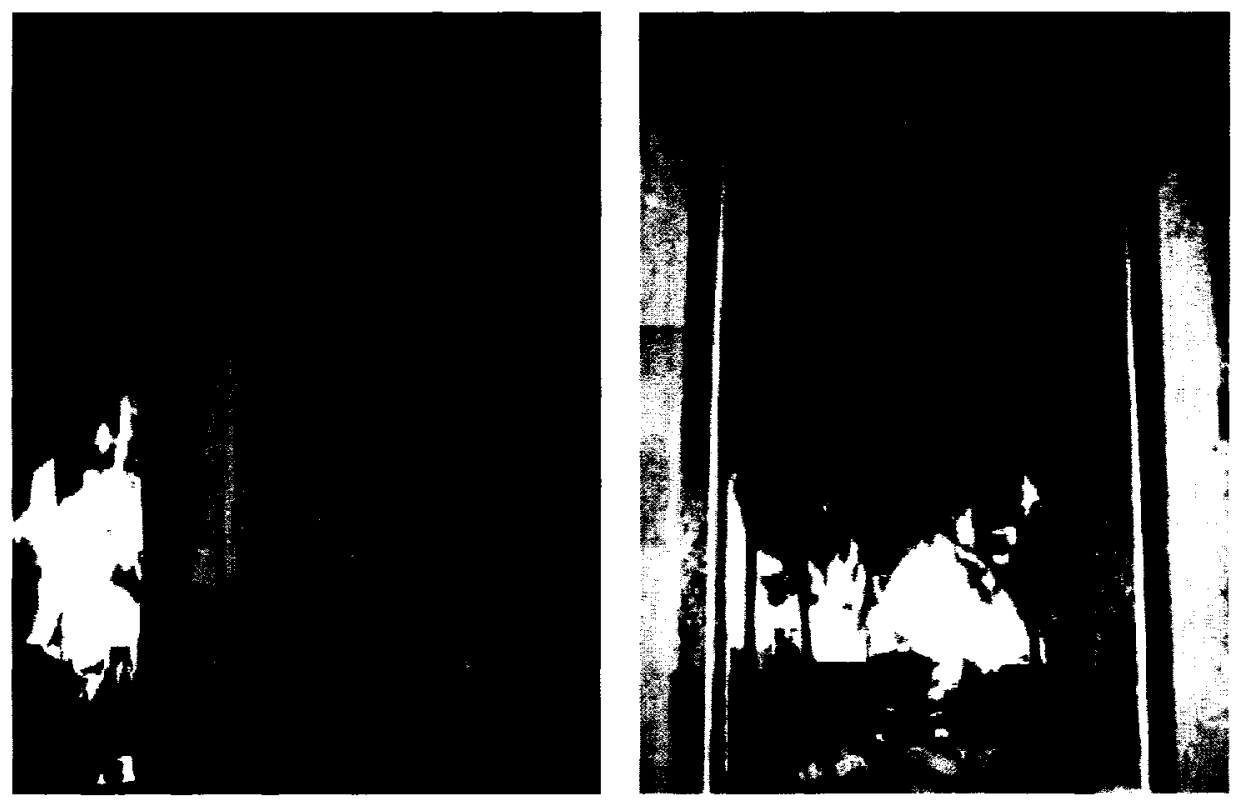

Figure 122. Photographs depicting the test in progress, Test CLC-I
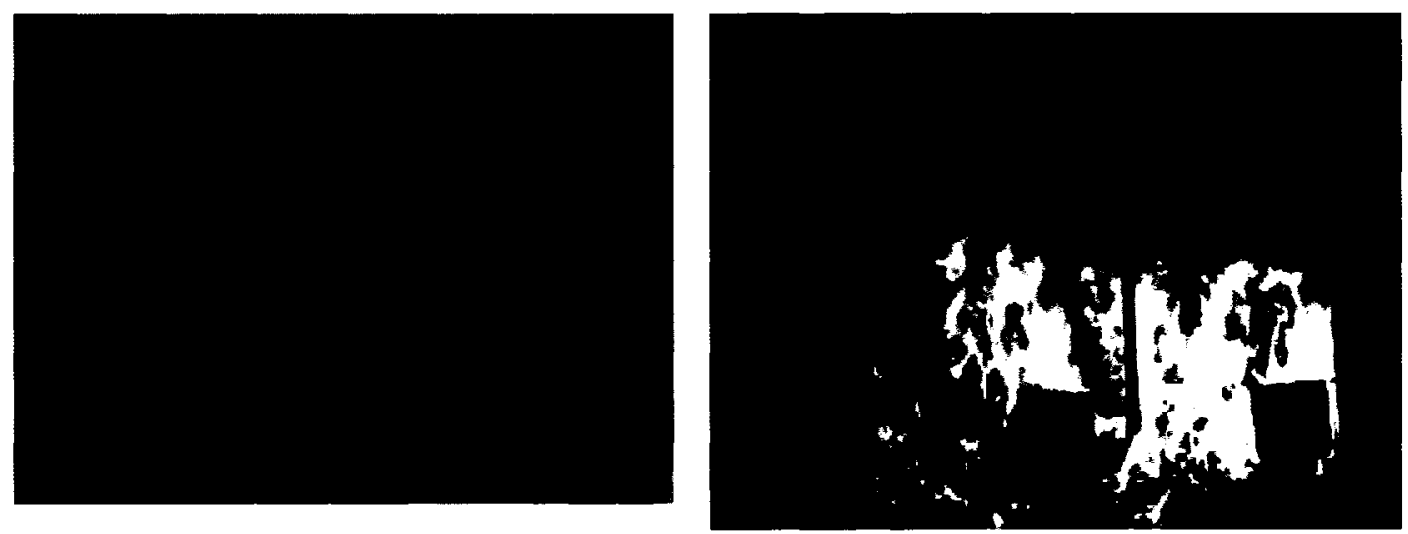

Figure 123. Photographs depicting the test in progress, Test CLC-II 


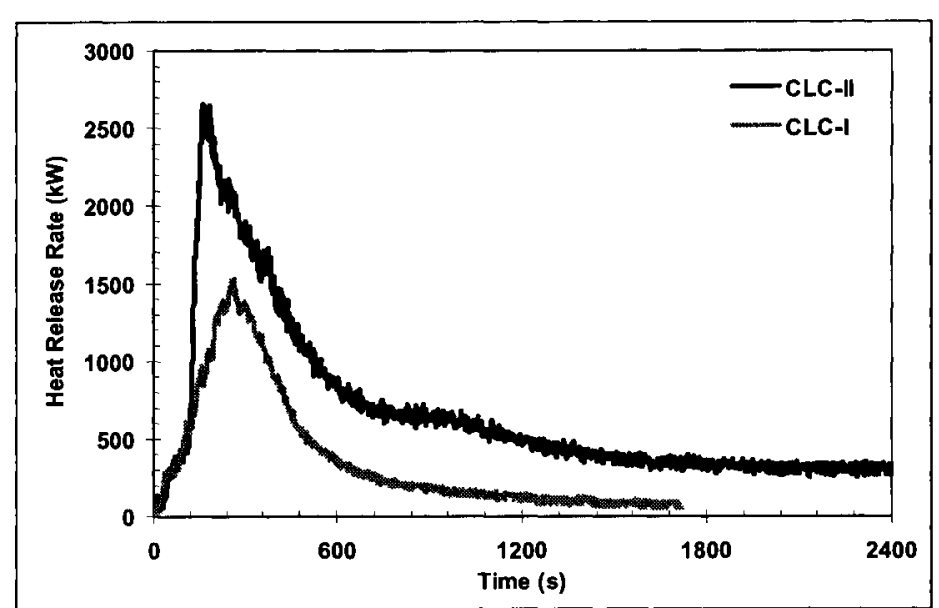

Figure 124. Heat release rate

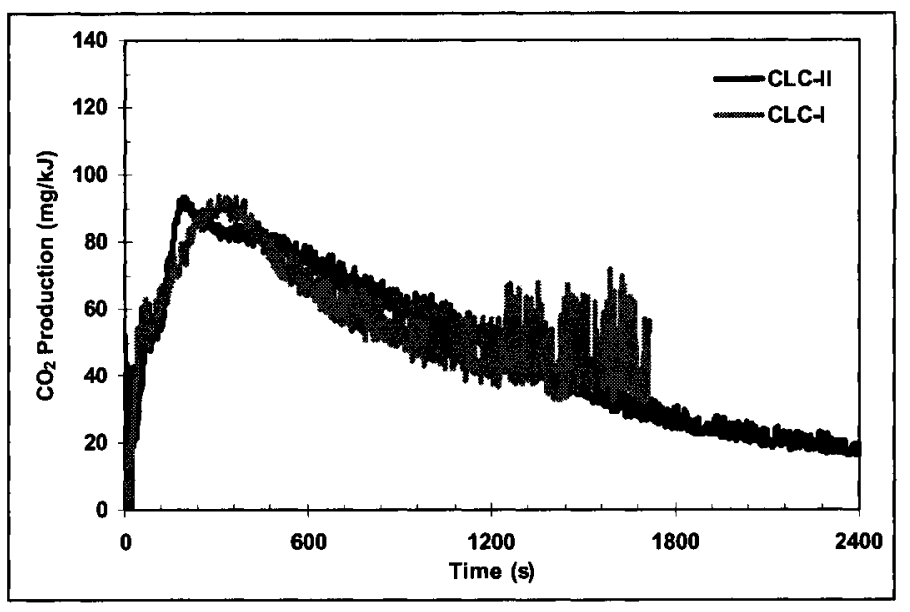

Figure 126. Carbon dioxide production rates

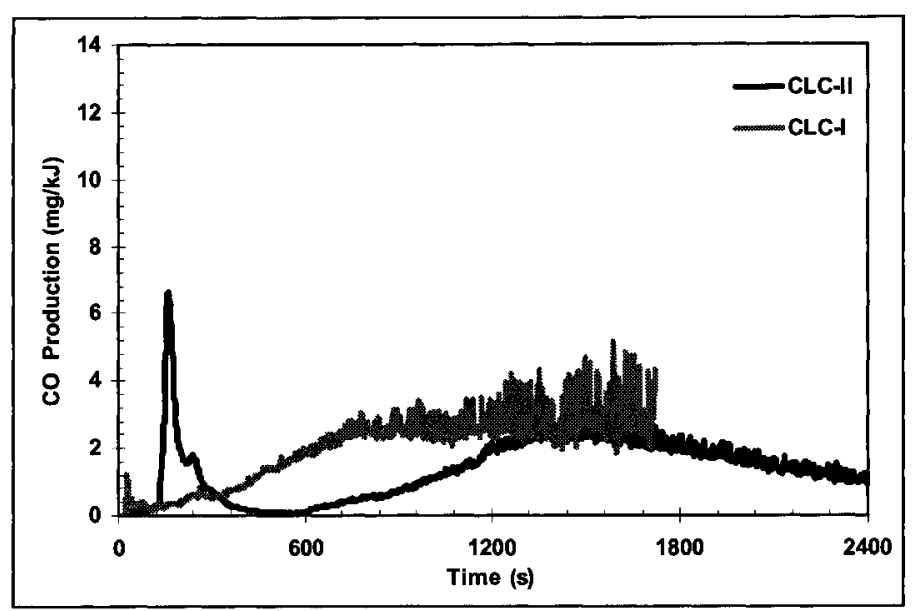

Figure 125. Carbon monoxide production rates 


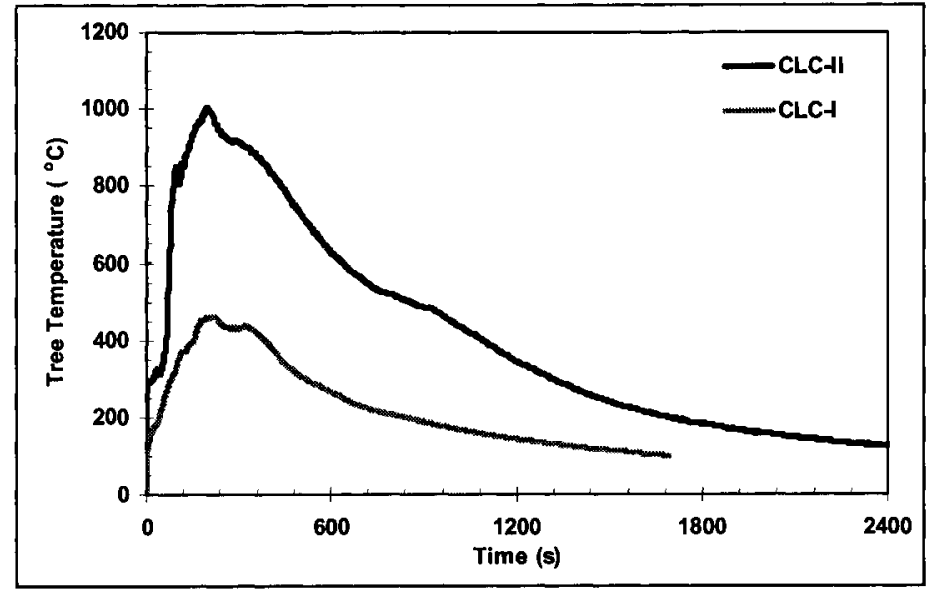

Figure 127. Temperature $2.1 \mathrm{~m}$ from floor

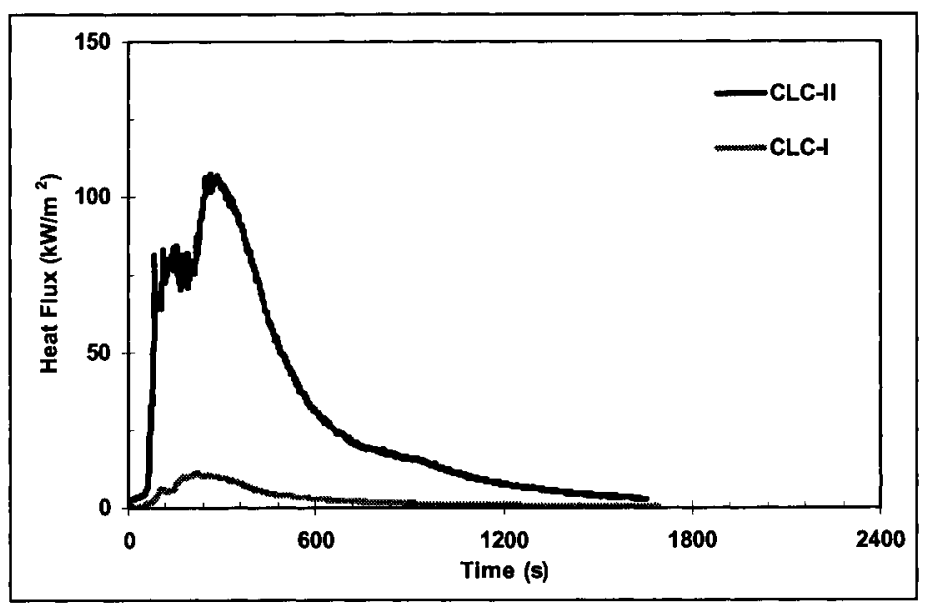

Figure 129. Heat flux

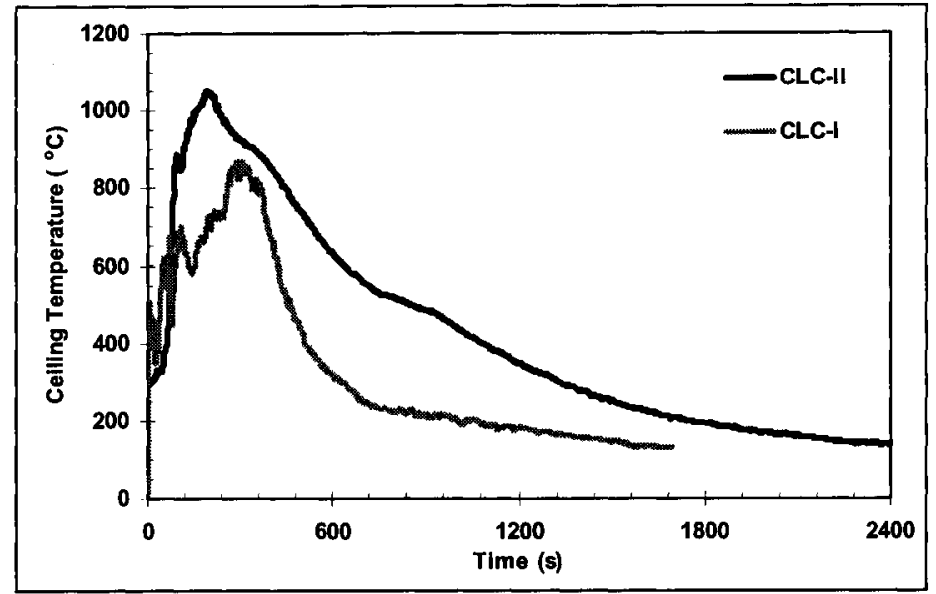

Figure 128. Temperature at the ceiling level

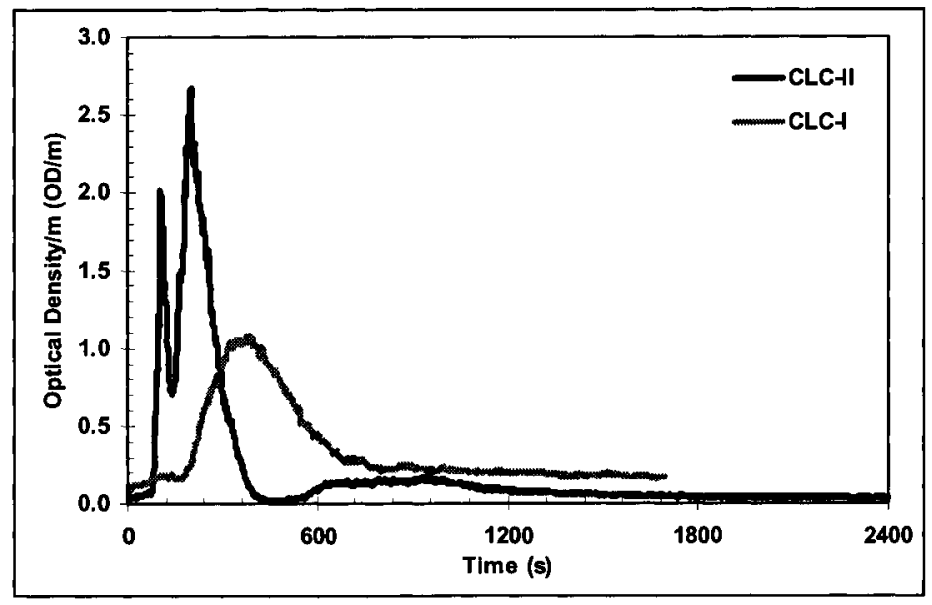

Figure 130. Optical density 


\subsubsection{Toy Store Tests, TOY-I and TOY-II}

The toy store fuel package represents the 95 th percentile of the fire load density of the surveyed stores, with a fire load density equal to $1,223 \mathrm{MJ} / \mathrm{m}^{2}$. For test TOY-I fuel package, $1 \mathrm{~m}^{2}$ of combustibles was tested, while $2 \mathrm{~m}^{2}$ were tested in TOY-II, with total fire loads of 1223 and $2446 \mathrm{MJ}$, respectively. In these tests, toys were displayed in a fashion typically seen in toy stores. Hard and soft (stuffed) toys were placed on a wooden display cabinet. The arrangement of toys was chosen to represent a severe scenario for these stores involving a substantial amount of plastics placed on shelves. The combustibles used were different types of plastic toys, stuffed animals, electronic games, wood, and paper bags, placed in wooden display cabinet. Bennetts et al..$^{35}$ used a similar fuel package arrangement for a toy store test; however, his experiments were conducted in a large burn hall, and HRR was not measured.

Details of the combustibles used in the tests are shown in Table 16. The photographs in Figure 131 and Figure 132 depict the tests setup and the developing stage of the fire. The development of the fire in both tests was quite interesting, because at about 4 minutes all combustibles became involved in the fire. Fire spread from the first item to the other combustibles so fast that it looked like liquid pool flame spread. This was due to the melting of the plastic materials. The HRR profile of TOY-I reached $1.1 \mathrm{MW}$ at $4: 30$ minutes, and maintained a value of about $1 \mathrm{MW}$ for about 5 minutes, while the HRR in TOY-II reached 2.6 MW at 4:30 minutes and maintained a value between 2.6 and $2 \mathrm{MW}$ for about 6 minutes, Figure 133. While the theoretical fuel loads in TOY-I and TOY-II packages were 1223 and $2446 \mathrm{MJ}$, respectively, the total measured HR was 1066 and $2125 \mathrm{MJ}$, respectively. This could be attributed to the remaining unburned materials and 
the uncertainty about the exact composition of both hard and soft (stuffed) toys. In TOYI test, the mass loss was recorded. Based on the initial weight and the remaining unburned weight, the weighted average of the heat content per kilogram $(\mathrm{MJ} / \mathrm{kg})$ was measured. The experimental weighted average was close to the theoretical weighted average, 19.2 and $20.25 \mathrm{MJ} / \mathrm{kg}$, respectively.

Production rates of $\mathrm{CO}$ and $\mathrm{CO}_{2}$ in the duct are shown in Figure 134 and Figure 135. $\mathrm{CO}$ and $\mathrm{CO}_{2}$ production rates have average values of 1.66 and $62(\mathrm{mg} / \mathrm{kJ})$ in TOY-I, and 1.9 and $82(\mathrm{mg} / \mathrm{kJ})$ in TOY-II. These values are similar and help to identify the toxic gases produced from a toy store fuel package.

Gas temperatures measured at the corner of the room and at the ceiling level are depicted in Figure 136 and Figure 137. In TOY-I and TOY-II tests, at a level of $2.1 \mathrm{~m}$ at the corner of the room, the gas temperatures were 510 and $1070^{\circ} \mathrm{C}$, respectively, showing an increase in room temperature with the use of 2 packages in TOY-II versus 1 package in TOY-I. The same finding was found in the heat flux value, with maximum-recorded heat fluxes of 18 and $194 \mathrm{~kW} / \mathrm{m}^{2}$, respectively, Figure 138 . Values of optical density followed the above trend with a maximum of 1.35 and $6.8 \mathrm{OD} / \mathrm{m}$, Figure 139. 

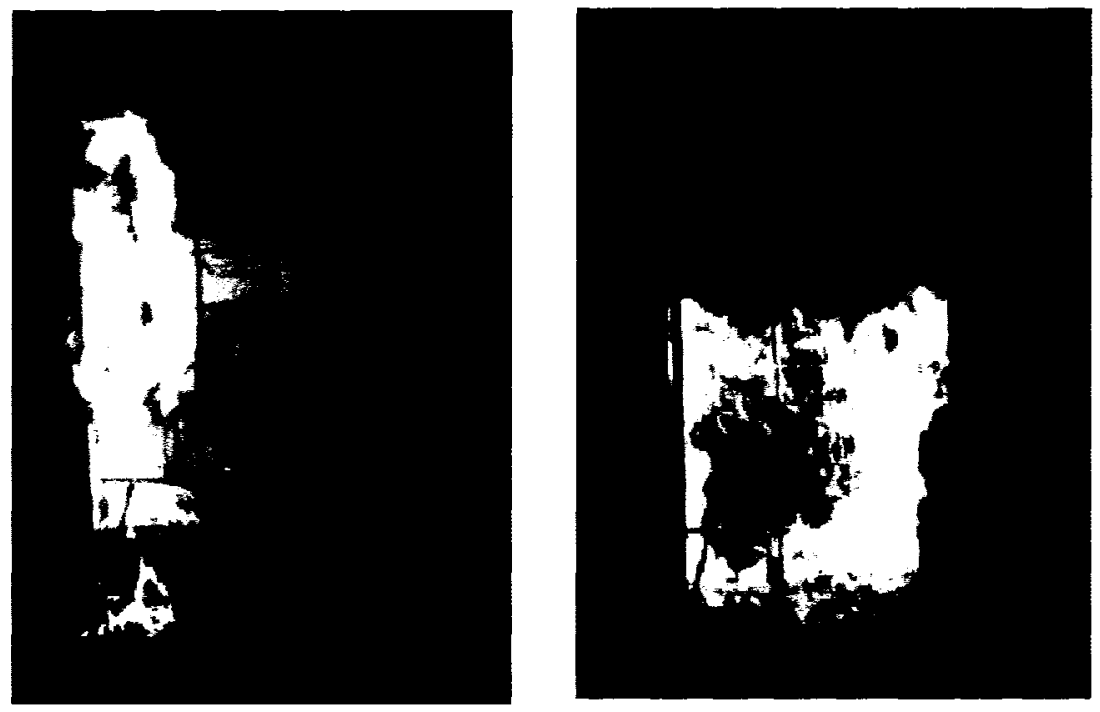

Figure 131. Photographs depicting test TOY-I progress
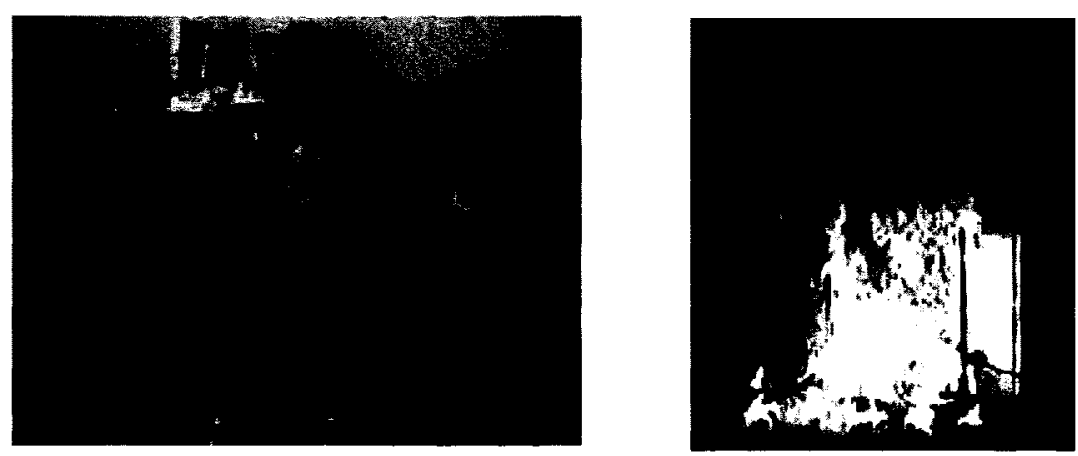

Figure 132. Photographs depicting test TOY-II progress 


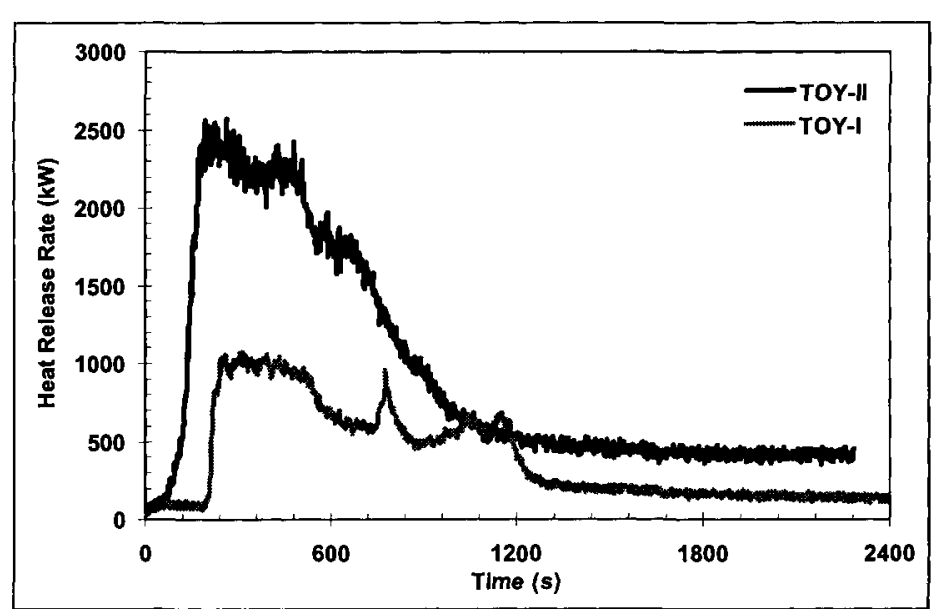

Figure 133. Heat release rate

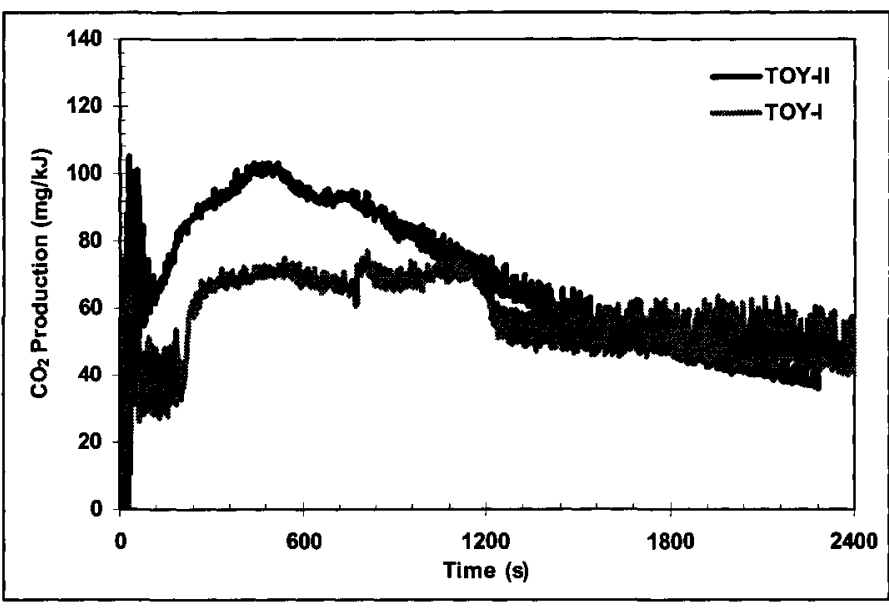

Figure 135. Carbon dioxide production rates

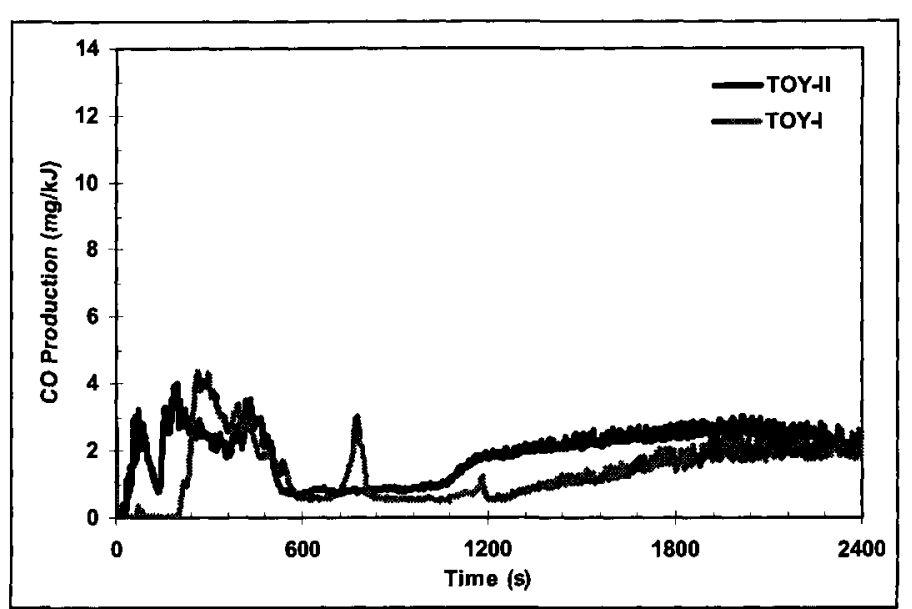

Figure 134. Carbon monoxide production rates 


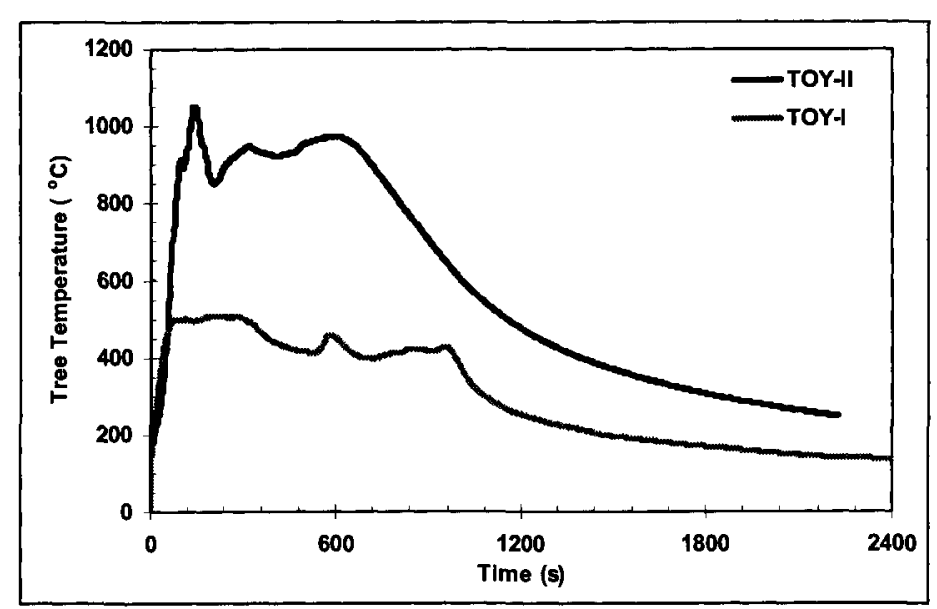

Figure 136. Temperature $2.1 \mathrm{~m}$ from floor

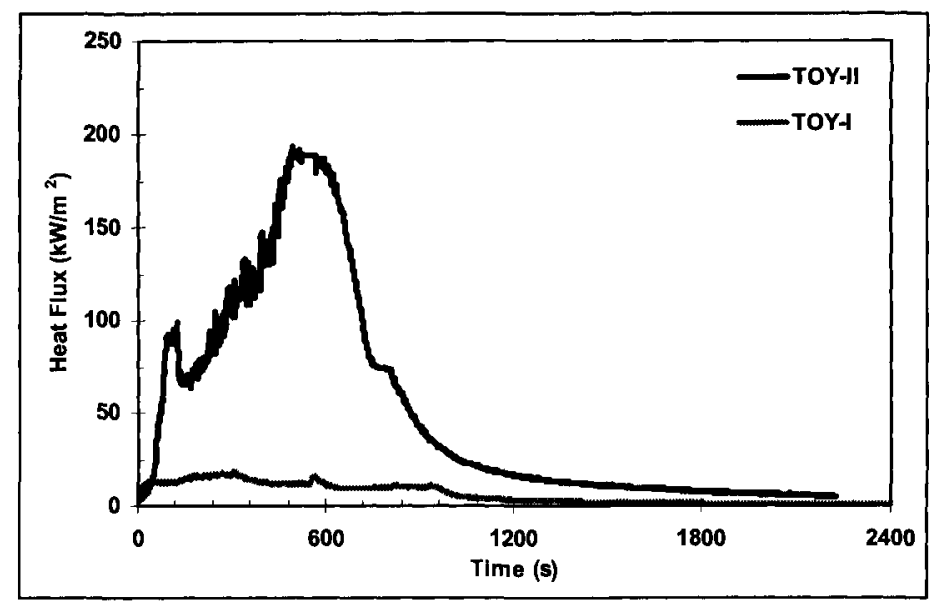

Figure 138. Heat flux

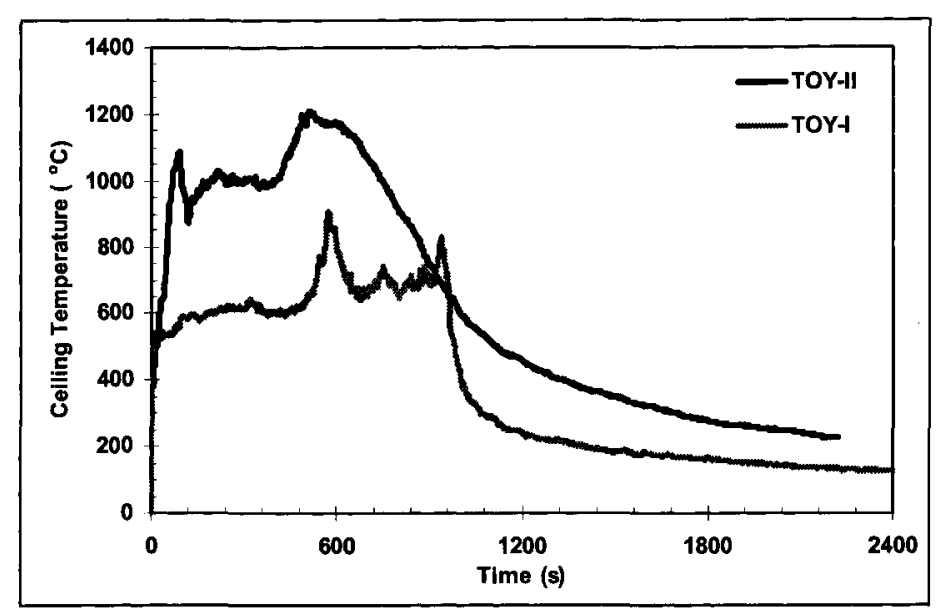

Figure 137. Temperature at the ceiling level

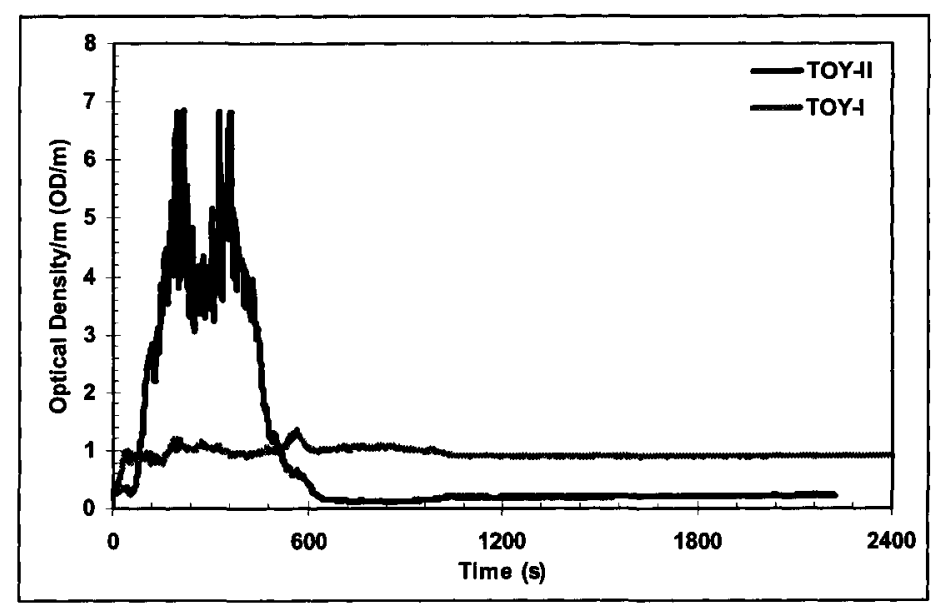

Figure 139. Optical density 


\subsubsection{Shoe Stores and Shoe Storage Areas, SHO-I and SHO-II}

The shoe storage fuel package of $4,900 \mathrm{MJ} / \mathrm{m}^{2}$ was the maximum for all surveyed shoe storage areas and shoe stores, and is the highest of all surveyed storage areas. The decision was made to use the maximum values from the surveyed shoe store storage areas and shoe stores because the two areas are usually attached and partitions are not fire rated.

Test SHO-I was tested in the ISO room and had to be extinguished early during the test because the gas temperature approached the limit for the safe operation of the facility. SHO-II was identical to SHO-I but tested in the post-flashover facility. This facility was able to accommodate the gas temperature and the combustion products. Both SHO-I and SHO-II had a $1 \mathrm{~m}^{2}$ fuel package representing combustibles found in a shoe storage area. The combustibles used were different types of leather and rubber shoes and bags, wooden shelves, textiles, and paper shoeboxes. The fuel package involved substantially noncellulosic materials (leather and rubber with a mass of $119.6 \mathrm{~kg}$ ), stored in a shelving unit.

Details of the combustibles used in the test are shown in Table 16. The photographs in Figure 140 and Figure 141 depict the tests setup and the developed stage of the fire. In SHO-I, at 2 minutes, all combustibles were burning as fire spread from item to item very fast, and HRR quickly reached $1.88 \mathrm{MW}$ at 3:40 minutes after ignition, the highest and fastest among all Phase I experiments. At 4:00 minutes, the in-house fire brigade started suppressing the fire because the temperature in the duct went beyond the safety limit. Figure 142 depicts HRR. The HRR in SHO-II reached $2.55 \mathrm{MW}$ at 4:00 minutes and stayed at a value between 2.55 and $2.25 \mathrm{MW}$ for about 10 minutes. 
While the theoretical fuel loads, in SHO-II packages was $4900 \mathrm{MJ}$, the total measured HR was 3990 MJ. Only $81 \%$ of the fuel load was consumed during the fire. The difference between the experimental and theoretical heat release can be attributed to the remaining unburned materials and the uncertainty about the exact composition of different types of leather and rubber shoes.

Production rates of $\mathrm{CO}$ and $\mathrm{CO}_{2}(\mathrm{mg} / \mathrm{kJ})$ are shown in Figure 143 and Figure 144. CO and $\mathrm{CO}_{2}$ yields have average values of 2.02 and $78(\mathrm{mg} / \mathrm{kJ})$ in SHO-II; however, values from the incomplete test SHO-I, were not calculated. Even though it is not possible to verify the SHO-II values with SHO-I values, these values are comparable to the overall trend of other similar tests (example, SA-II and TOY-II). So, these values can be used to identify the toxic gases produced from a shoe store fuel package. Gas temperatures measured at the corner of the room and at the ceiling level are depicted in Figure 145 and Figure 146. In SHO-I and SHO-II tests, at a level of $2.1 \mathrm{~m}$ at the corner of the room, the hot layer temperature were $600^{\circ} \mathrm{C}$ (at $2: 35$ minutes), and $1210^{\circ} \mathrm{C}$ (at $12: 00$ minutes), respectively. The maximum heat flux in SHO-II reached $181 \mathrm{~kW} / \mathrm{m}^{2}$ and maintained this level for about 8 minutes, it then dropped to zero, probably due to a falling object that covered the heat flux meter. After about 16 minutes, the heat flux was $85 \mathrm{~kW} / \mathrm{m}^{2}$, and then slowly decreased, see Figure 147. The maximum optical density was $5.2 \mathrm{OD} / \mathrm{m}$, however, it was between 2 and $3 \mathrm{OD} / \mathrm{m}$ during the first 12 minutes of the test, Figure 148 . Bennetts et $a l .{ }^{35}$ had also tested a similar fuel package arrangement for shoe storage areas as a high hazard area within commercial premises, and reported the substantial amount of smoke produced from testing a shoe store fuel package compared to other packages. 
However, his experiments were conducted in a large burn hall and HRR was not measured.
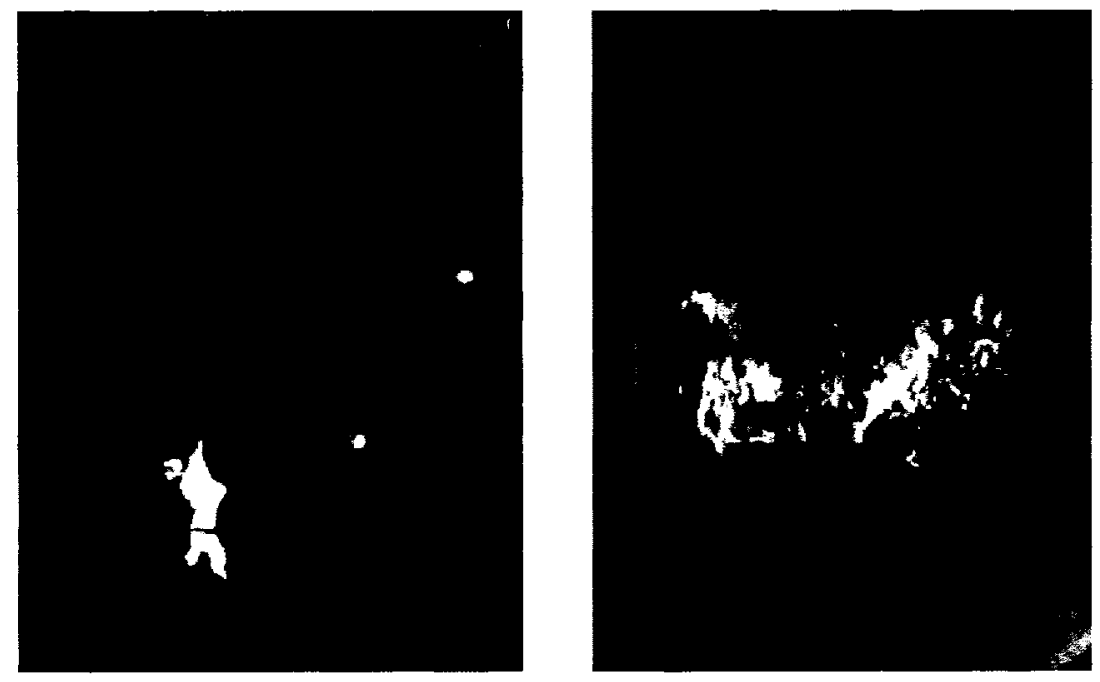

Figure 140. Photographs depicting test SHO-I progress
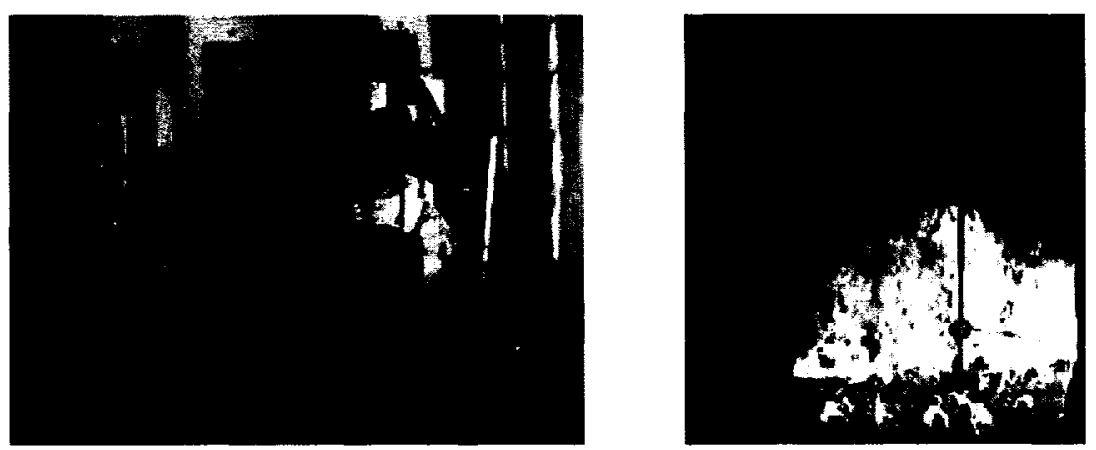

Figure 141. Photographs depicting test SHO-II progress 


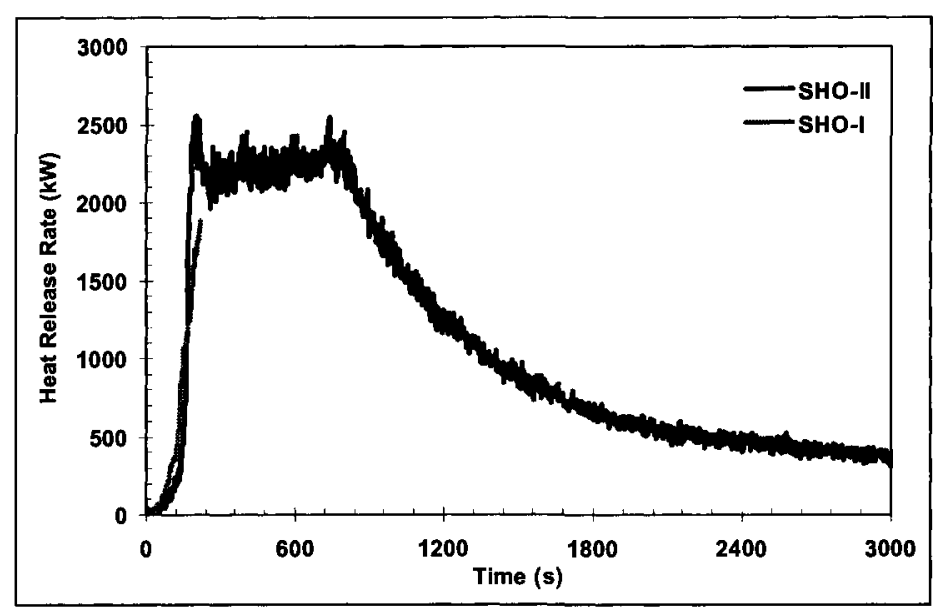

Figure 142. Heat release rate

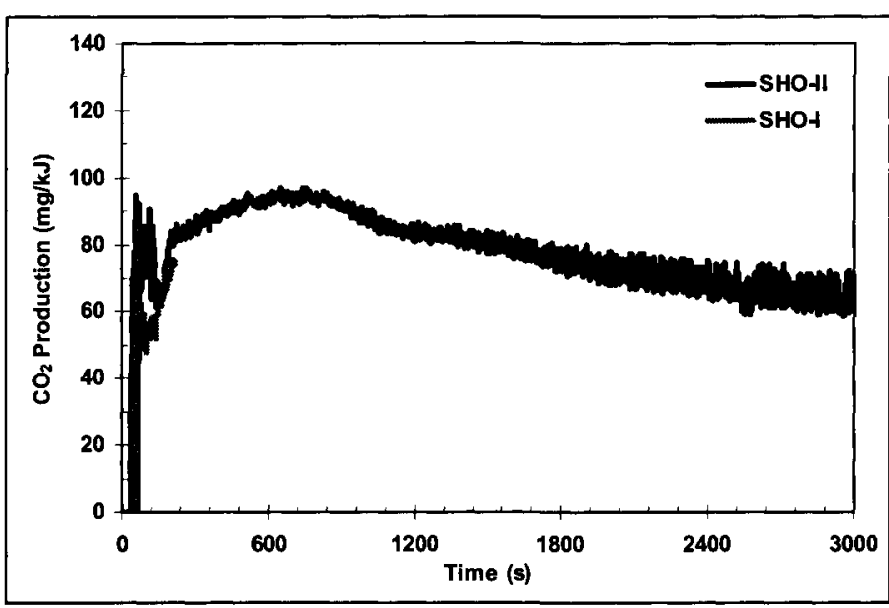

Figure 144. Carbon dioxide production rates

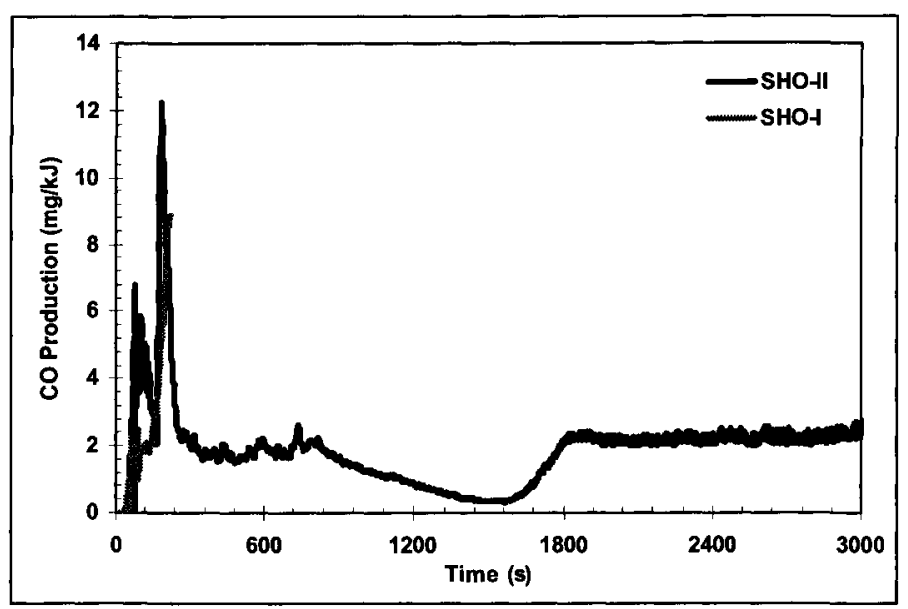

Figure 143. Carbon monoxide production rates 


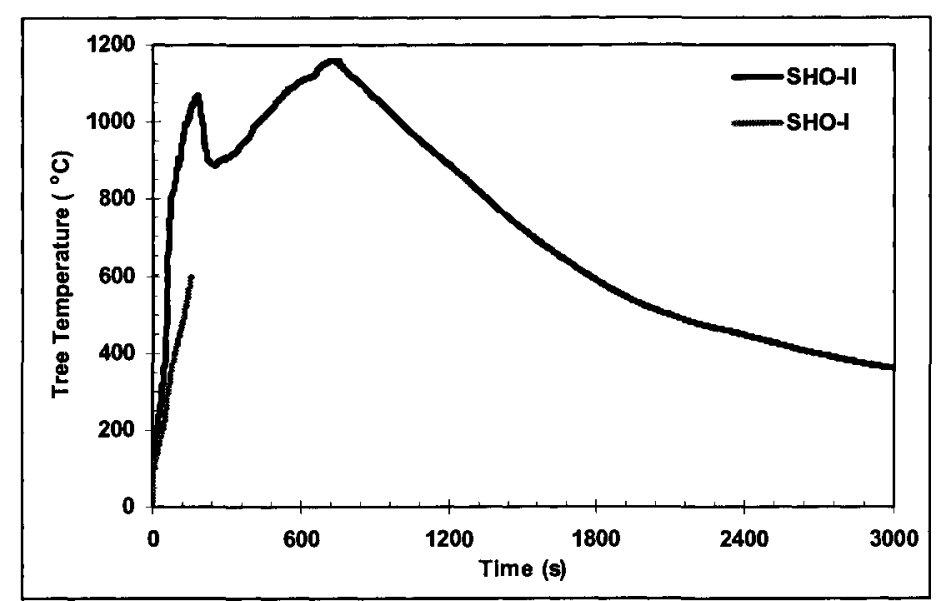

Figure 145. Temperature $2.1 \mathrm{~m}$ from floor

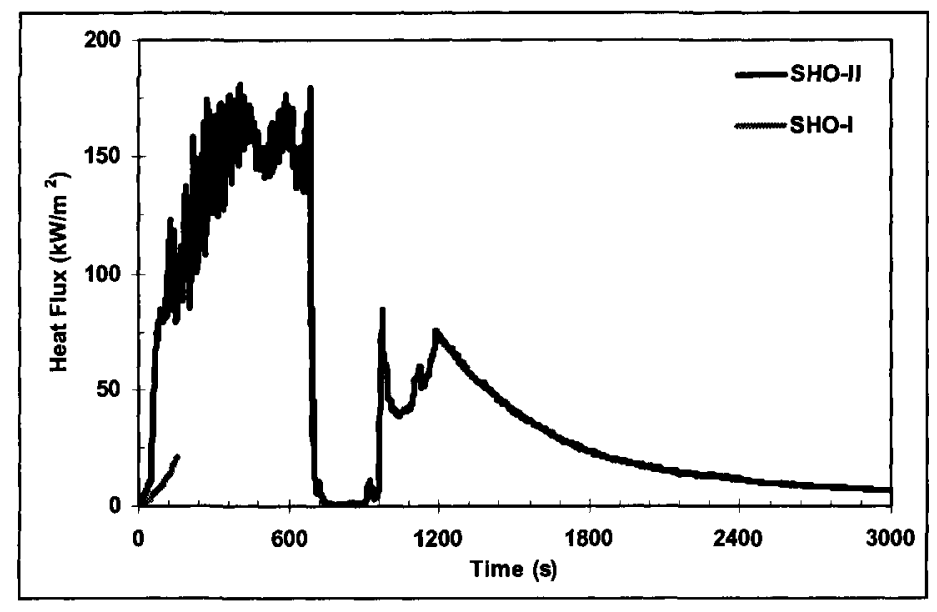

Figure 147. Heat flux

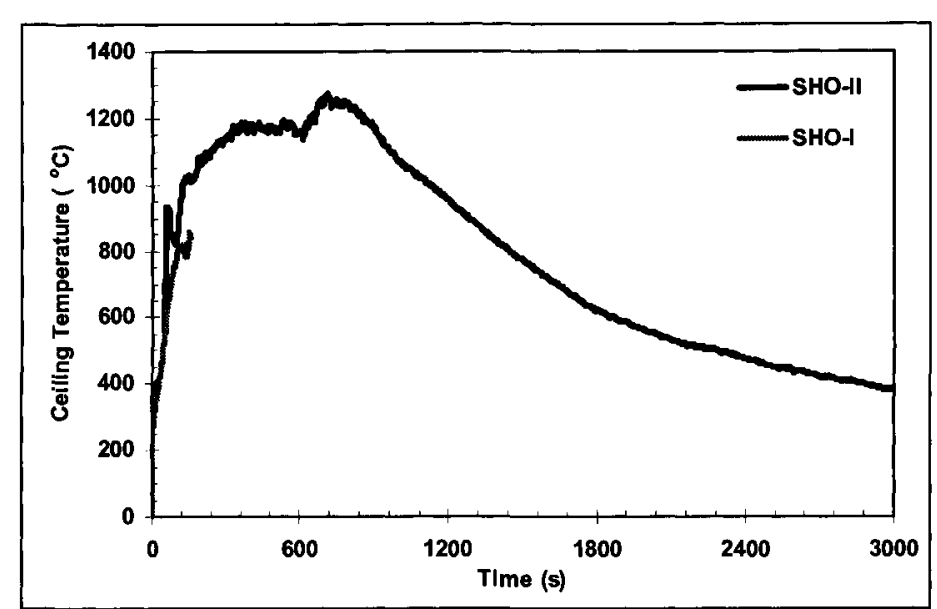

Figure 146. Temperature at the ceiling level

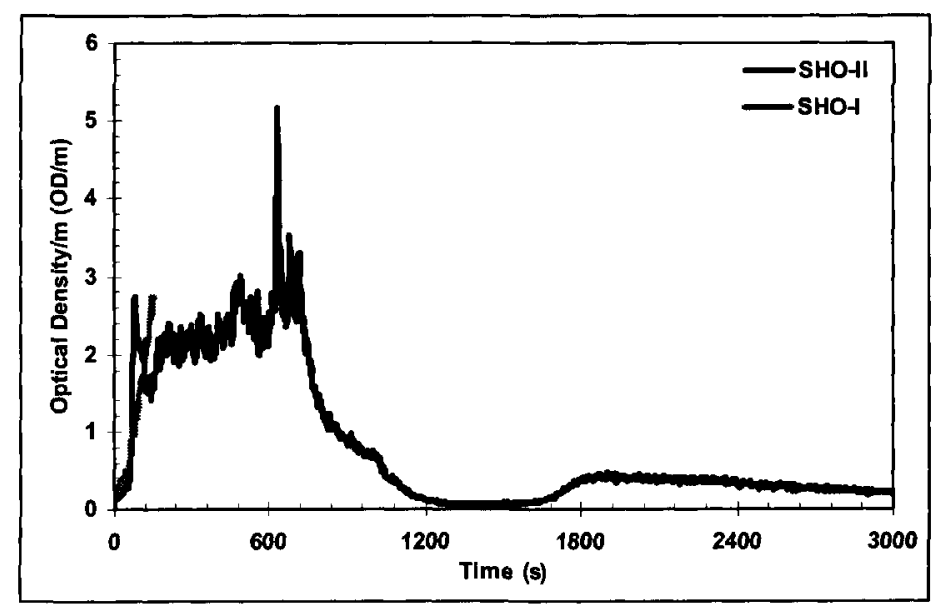

Figure 148. Optical density 


\subsubsection{Bookstores and Storage Area of Bookstores, Test BK-I and BK-II}

The fire load of fuel package was $5,305 \mathrm{MJ} / \mathrm{m}^{2}$ for bookstores and storage area of bookstores, and represented the maximum fire load density of the surveyed bookstore storage areas $4,900 \mathrm{MJ} / \mathrm{m}^{2}$. In test BK-I, a $1 \mathrm{~m}^{2}$ fuel package was used while a $2 \mathrm{~m}^{2}$ fuel package was used in test BK-II. The package was arranged in the fashion typically seen in bookstores, and consisted of different sizes of hardcover and paperback books, magazines, and newspapers that were arranged on wooden shelves. In test BK-I, three single-sided book-display cabinets were arranged to form a $\mathrm{U}$-shape, representing an end of a corridor in a bookstore. In test BK-II, the fuel package consisted of two side-by-side U-shape arrangements. Details of the combustibles used in the tests are shown in Table 16. The photographs in Figure 149 and Figure 150 depict the tests setup and the developing stage of the fire.

The development of the fire in the BK-I test was very slow, as it took about 14 minutes for the fire to reach the growth phase and to spread to all combustibles. However, in test BK-II, the fire spread to all combustibles in 2 minutes. Figure 151 depicts the heat release rate (HRR) that shows a slow increase in HRR for BK-I to only $0.25 \mathrm{MW}$ during the first 14 minute and then reached $1.1 \mathrm{MW}$ at 17:20 minutes after ignition. The HRR subsequently fluctuated around 1.1 MW before increasing to $1.2 \mathrm{MW}$ at 34 minutes. At 34 minutes, the inhouse fire brigade started suppressing the fire because the temperature in the duct went beyond the safety limit. The test BK-II HRR profile was similar to the other Phase II experiments. The HRR profile of BK-II reached 2.4 MW in about 4:40 minutes and maintained a HRR between 2.4 and $1.5 \mathrm{MW}$ for about 22 minutes. While the theoretical fuel loads in the BK-II packages was $10610 \mathrm{MJ}$, the total measured HR in 
BK-II was $4154 \mathrm{MJ}$. This can be attributed to (1) the incomplete combustion that occurred (only $40 \%$ of the fuel load was consumed during the 48 -minute fire test); (2) the test was going to affect the integrity of the facility and had to be extinguished at 48 minutes; and (3) the amount of unburned material that was left after the test. This bookstore test could have easily burnt for 6-8 hours.

Production rates of $\mathrm{CO}$ and $\mathrm{CO}_{2}(\mathrm{mg} / \mathrm{kJ})$ are shown in Figure 152 and Figure 153. $\mathrm{CO}$ and $\mathrm{CO}_{2}$ production rates had average values of 1.44 and $99(\mathrm{mg} / \mathrm{kJ})$ in BK-II. These values are comparable to another test with mostly cellulosic combustible packages (CLW-I). So these values can be used to identify the toxic gases produced from a bookstore fuel package.

Gas temperatures measured at the corner of the room and at the ceiling level are depicted in Figure 154 and Figure 155. In BK-I and BK-II tests, at a level of $2.1 \mathrm{~m}$ at the corner of the room, the gas temperatures were 580 and $1120^{\circ} \mathrm{C}$, respectively, showing an increase in room temperature with the use of 2 fuel packages in BK-II versus 1 fuel package in BK-I. The same trend was observed in the heat flux value with maximum heat fluxes of 18 and $77 \mathrm{~kW} / \mathrm{m}^{2}$, respectively, Figure 156 . The heat flux measurements for the Phase II test stopped at 8:00 minutes when a falling object covered the heat flux meter. Values of optical density reached a maximum of 13.6 and $1.5 \mathrm{OD} / \mathrm{m}$ for BK-I and BK-II, respectively, Figure 157. 

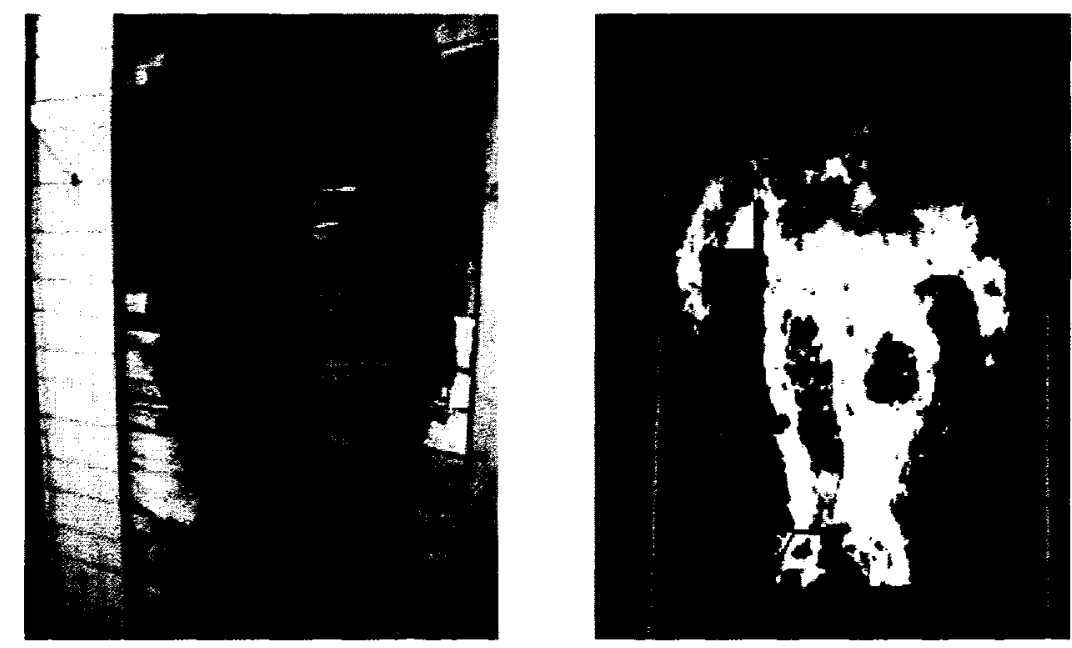

Figure 149. Photographs depicting test BK-I progress
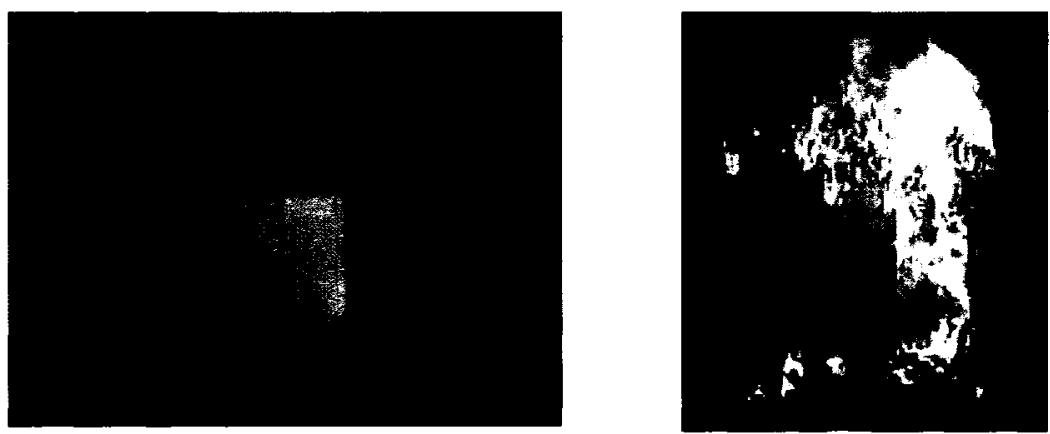

Figure 150. Photographs depicting test BK-II progress 


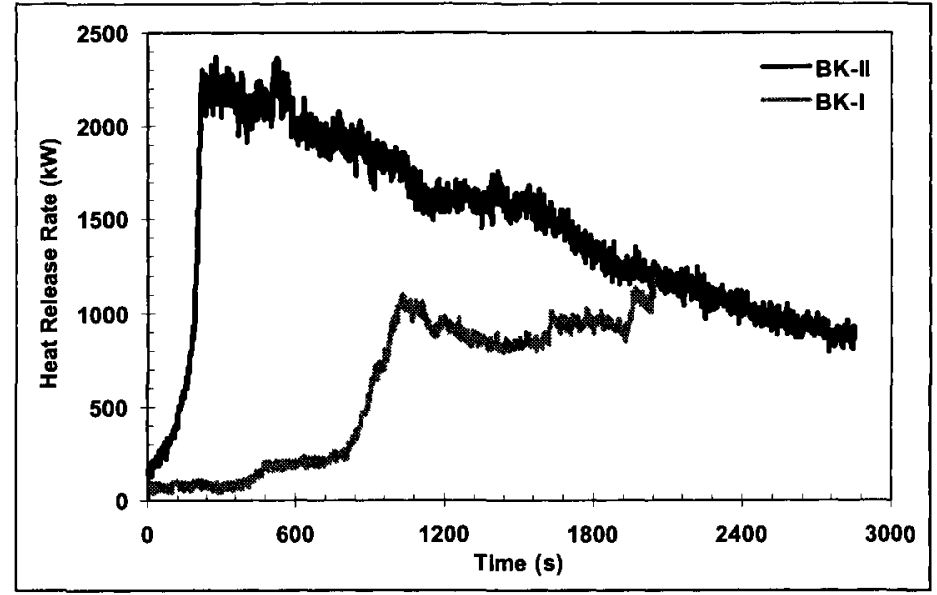

Figure 151. Heat release rate

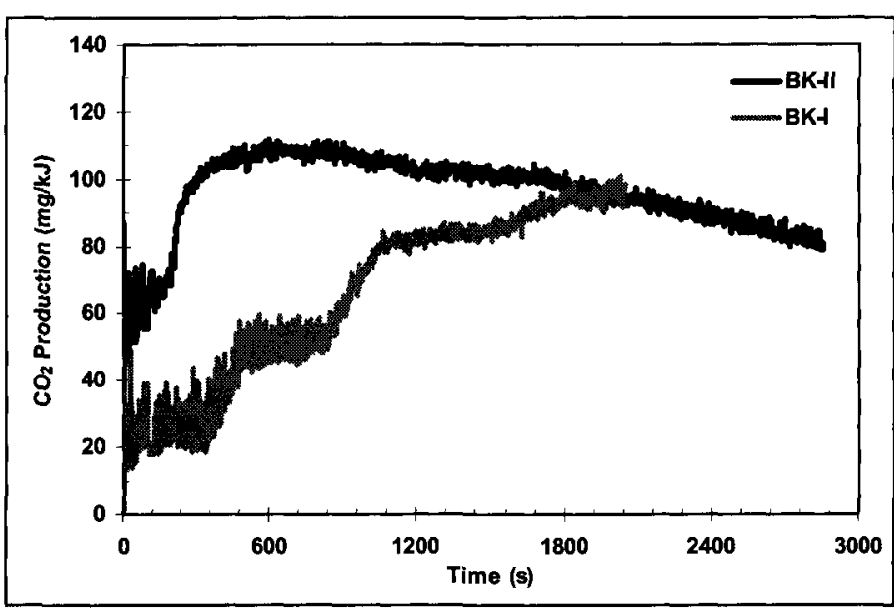

Figure 153. Carbon dioxide production rates

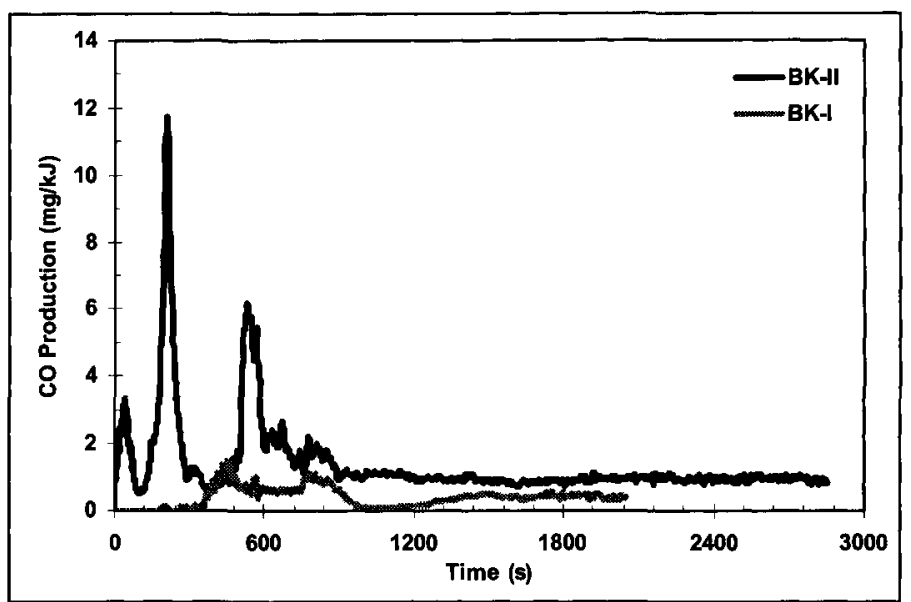

Figure 152. Carbon monoxide production rates 


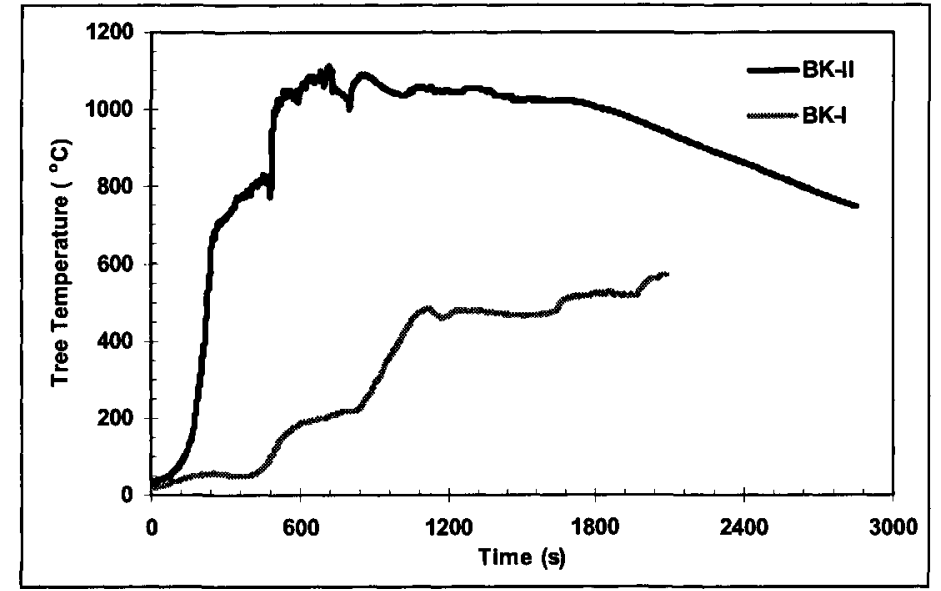

Figure 154. Temperature $2.1 \mathrm{~m}$ from floor

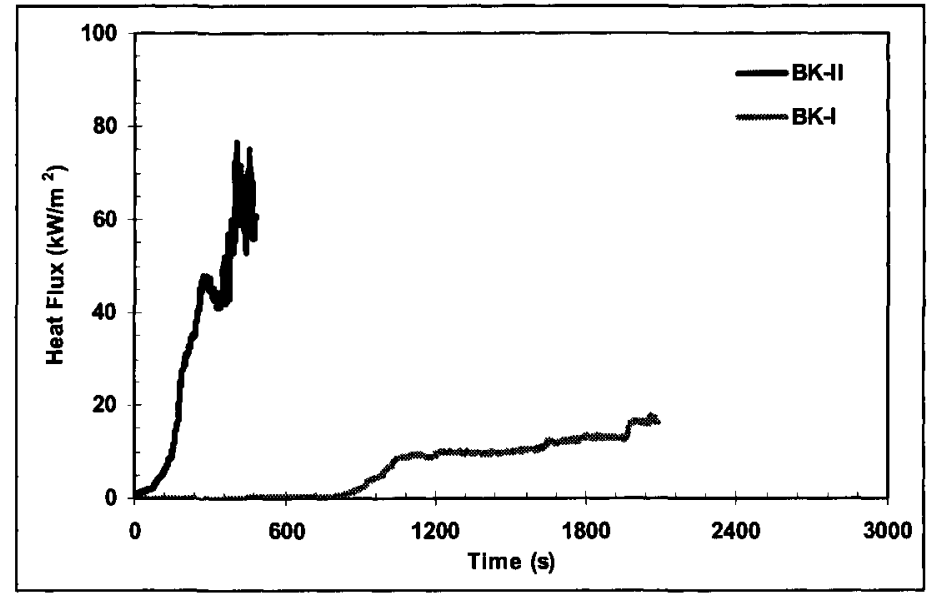

Figure 156. Heat flux

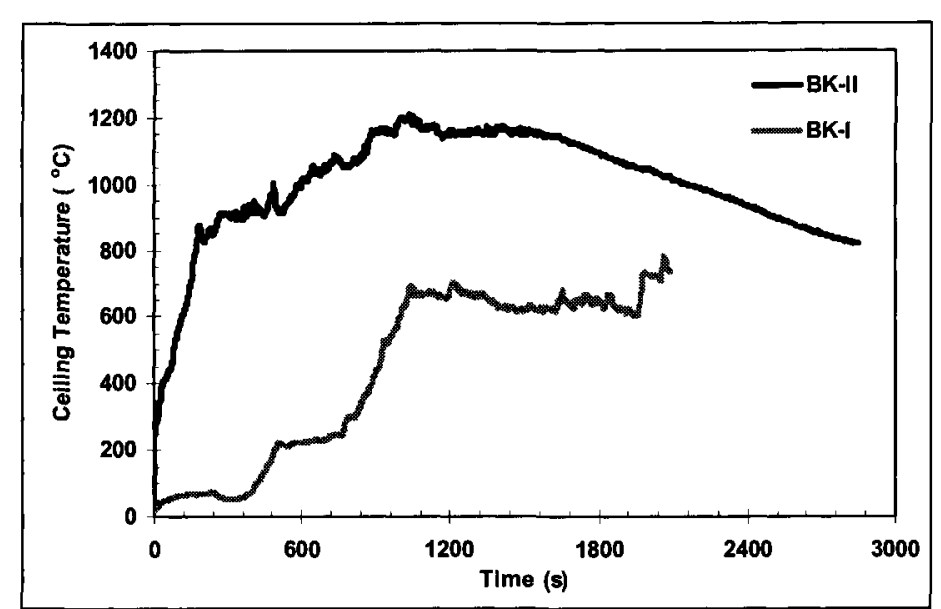

Figure 155. Temperature at the ceiling level

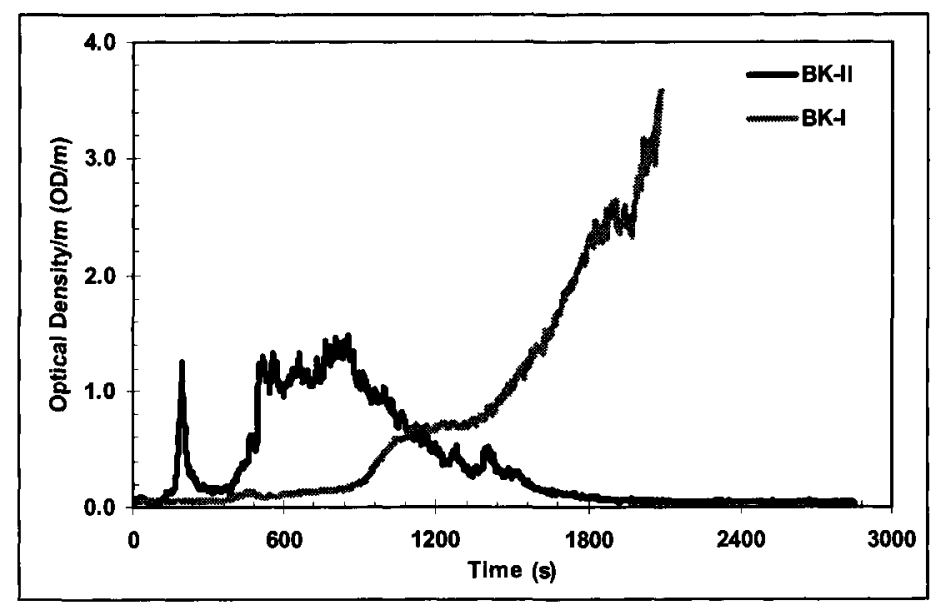

Figure 157. Optical density 


\subsubsection{Fast Food Outlets, Test FF-I and FF-II}

These tests represented a fire in a fast food outlet cooking area. With a fire load density equal to $881 \mathrm{MJ} / \mathrm{m}^{2}$, this fuel package represented the 95 th percentile of the fire load density of the surveyed fast food outlets. This fire load density was also representative of restaurants, both in the seating areas $\left(582 \mathrm{MJ} / \mathrm{m}^{2}\right)$, and in the kitchens $\left(553 \mathrm{MJ} / \mathrm{m}^{2}\right)$.

In FF-I and FF-II tests, the fuel packages were $1 \mathrm{~m}^{2}$ and $2 \mathrm{~m}^{2}$, respectively. The fuel package represented combustibles typically found in a fast food outlet cooking areas. The setup included only a wooden cabinet filled with cooking oil, paper napkins, and polystyrene cups and plates. The whole fuel package was installed inside a steel pan to keep the leaking cooking oil within the test area. Details of the combustibles used in the test are shown in Table 16. Also, the photographs in Figure 158 and Figure 159 depict the tests setups and the developing stage of the fire.

Figure 160 depicts the HRR of tests FF-I and FF-II. The HRR of test FF-I reached $1.56 \mathrm{MW}$ at $4: 30$ minutes after ignition, and decreased to $100 \mathrm{~kW}$ at 20 minutes. The HRR for FF-II HRR increased to $2.7 \mathrm{MW}$ at 6:00 minutes after ignition, dropped to $300 \mathrm{~kW}$ at 20 minutes. While the theoretical fuel loads in FF-I and FF-II packages were 881 and $1762 \mathrm{MJ}$, the total measured HR was 830 and $1660 \mathrm{MJ}$, respectively. It is worth noting that the two fuel packages tested in FF-II test produced exactly twice the heat released from the single fuel package tested in FF-I test.

Production rates of $\mathrm{CO}$ and $\mathrm{CO}_{2}$ in the duct are shown in Figure 161 and Figure 162. $\mathrm{CO}$ and $\mathrm{CO}_{2}$ production rates have average values of 1.10 and $63(\mathrm{mg} / \mathrm{kJ})$ in $\mathrm{FF}-\mathrm{I}$, and 1.29 
and $68(\mathrm{mg} / \mathrm{kJ})$ in FF-II. These values are similar and help to identify the toxic gases produced from a fast food outlet fuel package.

Gas temperatures measured at the corner of the room and at the ceiling level are depicted in Figure 163 and Figure 164. In FF-I and FF-II tests, at a level of $2.1 \mathrm{~m}$ at the corner of the room, the gas temperatures were 460 and $1100^{\circ} \mathrm{C}$, respectively, showing an increase in room temperature with the use of two fuel packages in FF-II versus one fuel package in FF-I. There was a similar increase in the heat flux, with peak values of 14 and $150 \mathrm{~kW} / \mathrm{m}^{2}$, respectively, see Figure 165 . The optical density reached a maximum of $2 \mathrm{OD} / \mathrm{m}$ for test FF-I and $7.4 \mathrm{OD} / \mathrm{m}$ for test FF-II, see Figure 166.
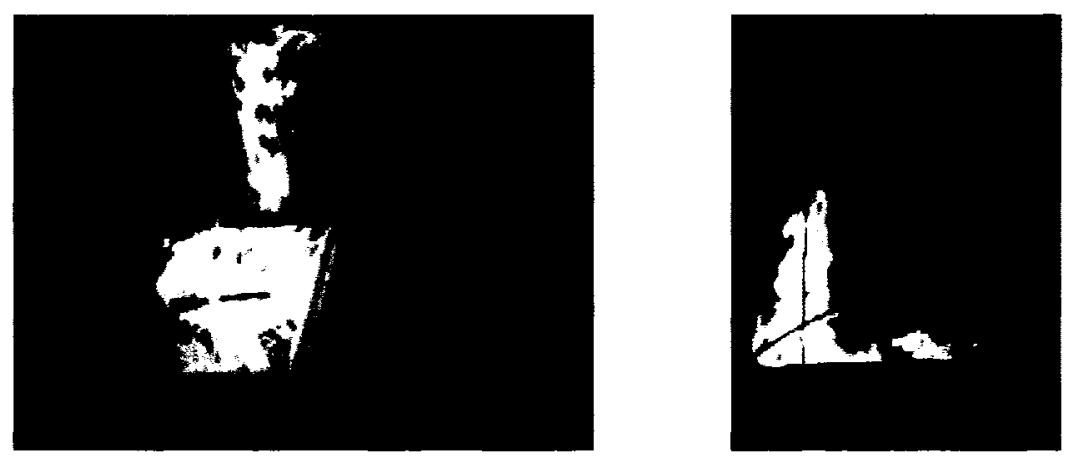

Figure 158. Photographs depicting test FF-I progress
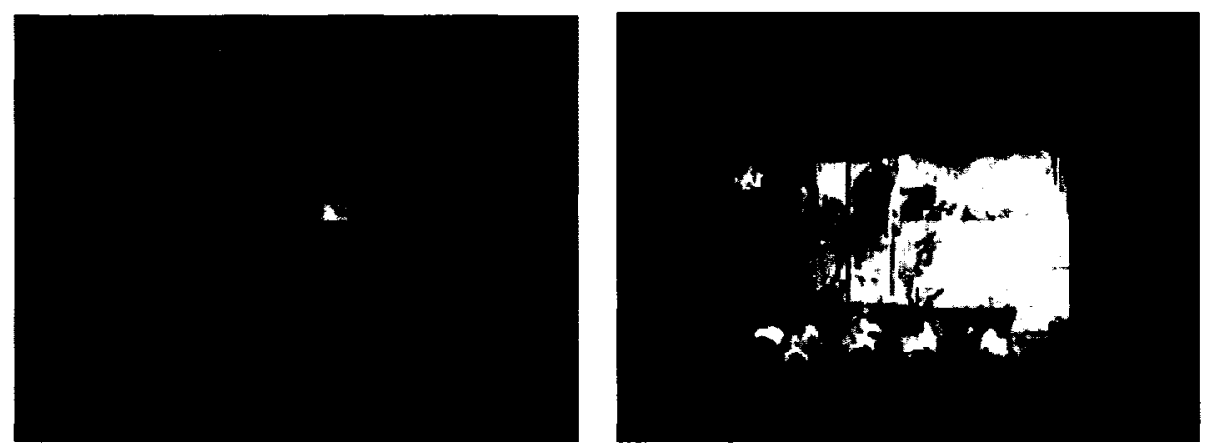

Figure 159. Photographs depicting test FF-II progress 


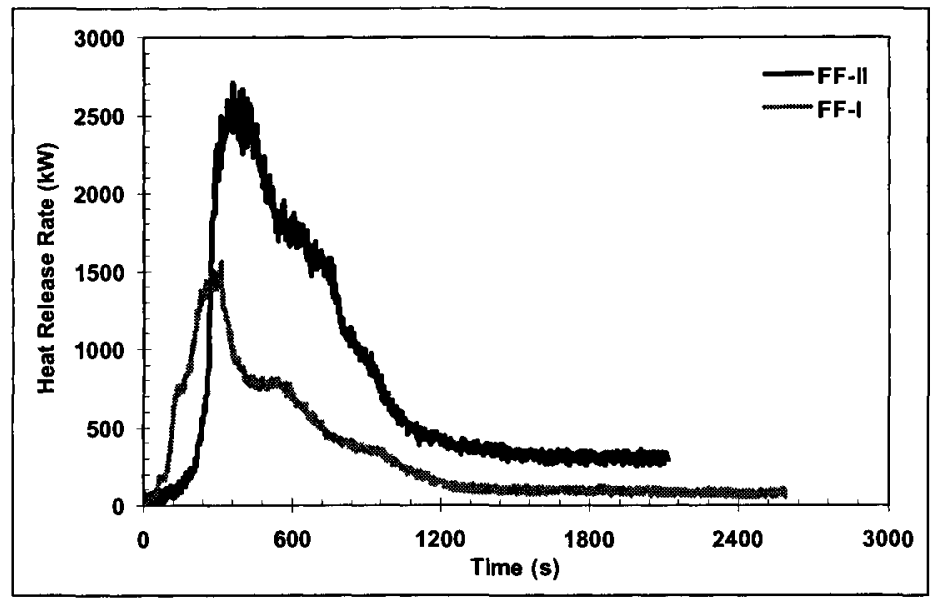

Figure 160. Heat release rate

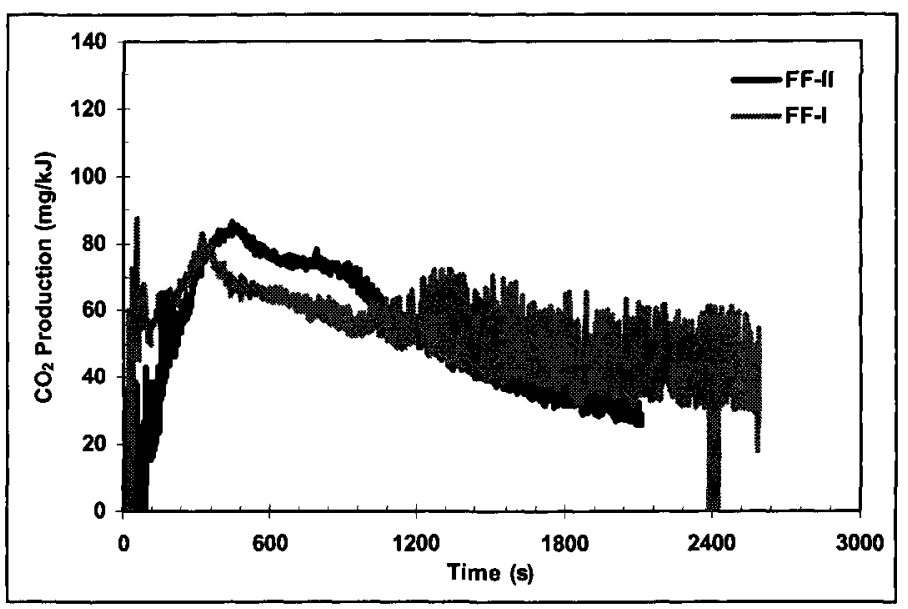

Figure 162. Carbon dioxide production rates

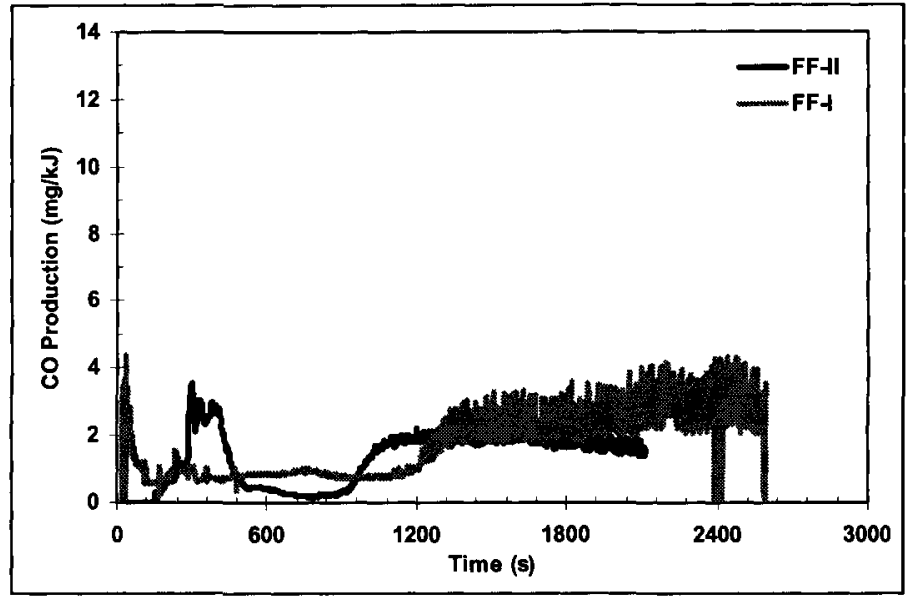

Figure 161. Carbon monoxide production rates 


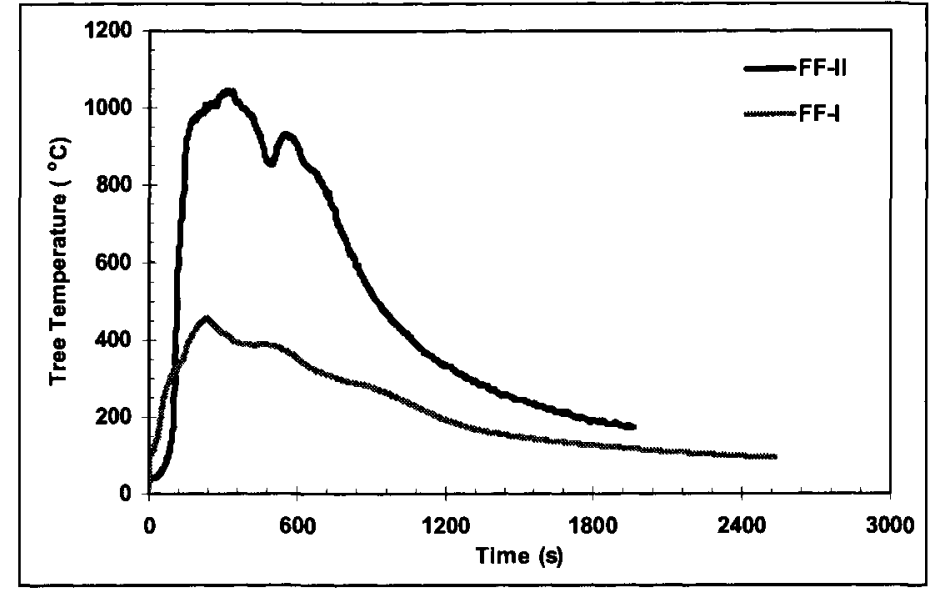

Figure 163. Temperature $2.1 \mathrm{~m}$ from floor

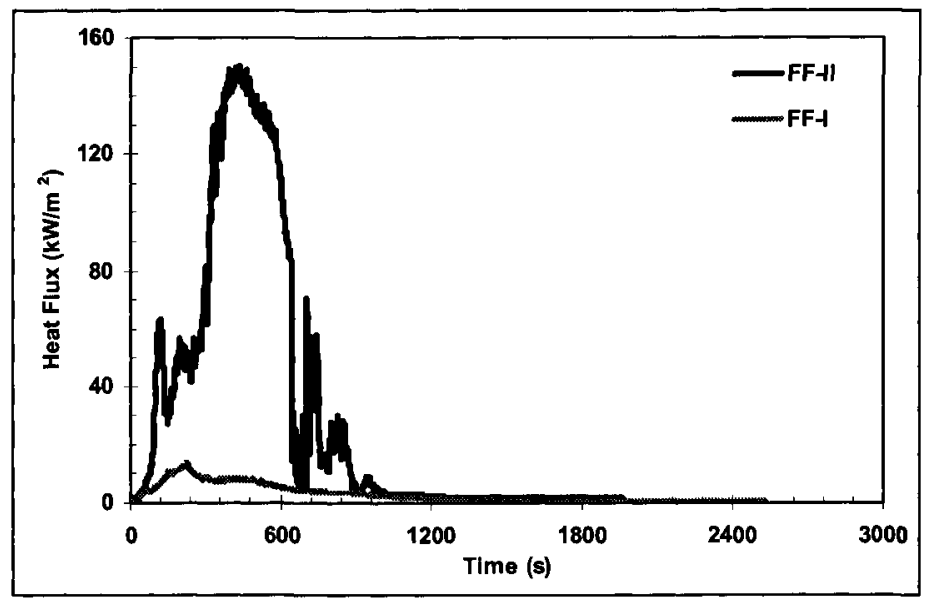

Figure 165. Heat flux

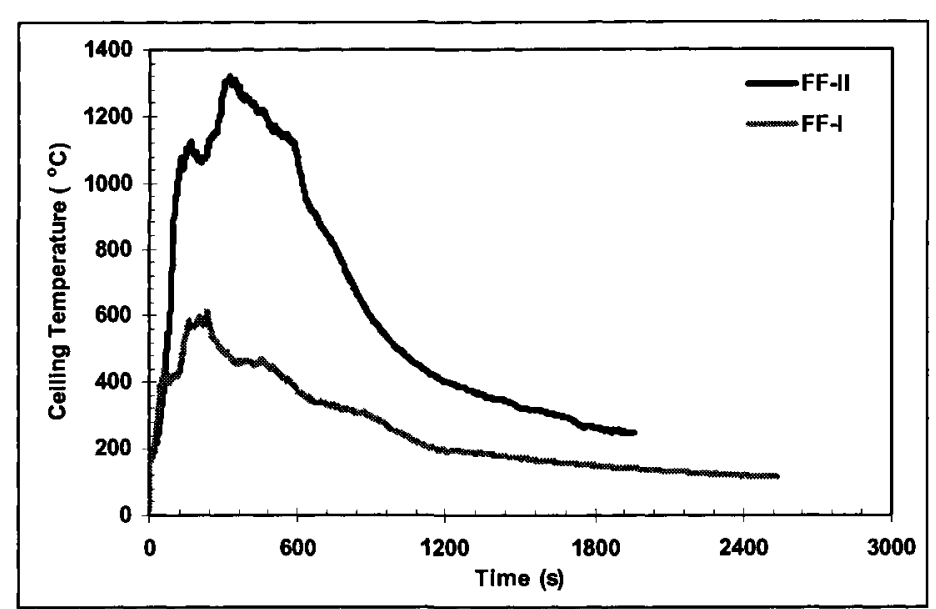

Figure 164. Temperature at the ceiling level

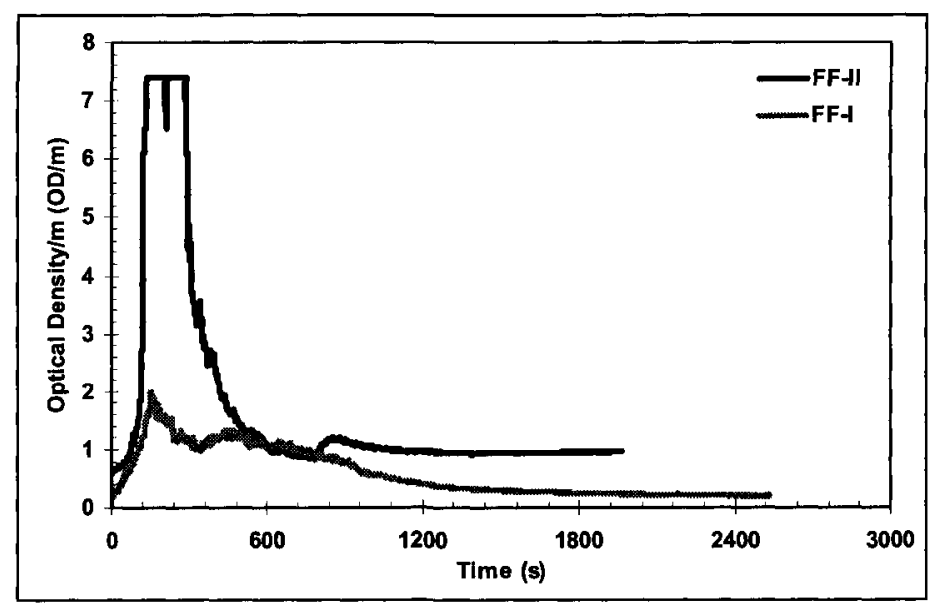

Figure 166. Optical density 


\subsection{Summary}

This section presented the experimental results of the Phase I and II experiments of fire tests performed to identify fire characteristics of fuel packages for commercial premises. The design of the fuel packages was based on results of the survey analysis conducted to characterize fire loads and combustibles in these premises. The Phase I experiments were conducted in a test room compatible with ISO $9705^{3}$, while the Phase II experiments were conducted in a post-flashover test facility. Both facilities were equipped with instrumentation to monitor and record the fire parameters.

The fuel packages in the Phase I medium-scale tests were arranged to represent the fire load density and type of combustibles covering $1.0 \mathrm{~m}^{2}$ in commercial premises, while Phase II experiments, except test SHO-II, represented a $2 \mathrm{~m}^{2}$ fuel package. The combinations of combustibles used were carefully selected to represent as closely as possible the types of combustibles and their arrangements in the actual stores. Based on the sample size of each of the surveyed group of commercial premises, the fuel packages represented the maximum, the 95 th or the 90 th percentile values of the fire load density. All packages were ignited using a $75-\mathrm{kW}$ propane T-burner running for 4 minutes, to simulate an ignition source from a large wastepaper basket.

The temperatures resulting from a fire have a negative effect on structures (wood, concrete, steel), and reduce and/or destroy the integrity, insulation, and stability of different structural elements (walls, floors, and ceilings). In most tests, the recorded upper layer temperatures were about $1200^{\circ} \mathrm{C}$. 
Production rates of carbon monoxide and carbon dioxide affect tenability, fire systems response to a fire, and challenge the smoke management systems in buildings. The calculated average production rates of $\mathrm{CO}$ and $\mathrm{CO}_{2}(\mathrm{mg} / \mathrm{kJ})$ are shown in Table 18 and Table 22. Production rates of $\mathrm{CO}$ can be summarized as: (1) computer stores 2.9 to $3.17 \mathrm{mg} / \mathrm{kJ}$; (2) storage areas 1.55 to $2.09 \mathrm{mg} / \mathrm{kJ}$; (3) clothing stores 0.72 to $2.93 \mathrm{mg} / \mathrm{kJ}$; (4) toy stores 1.66 to $1.90 \mathrm{mg} / \mathrm{kJ}$; (5) shoe stores $2.02 \mathrm{mg} / \mathrm{kJ}$; (6) bookstores $1.44 \mathrm{mg} / \mathrm{kJ}$; and (7) fast food outlets 1.10 to $1.29 \mathrm{mg} / \mathrm{kJ}$. Based on $\mathrm{CO}_{2}$ production rates: (1) computer stores 52 to $58 \mathrm{mg} / \mathrm{kJ}$; (2) storage areas 71 to $84 \mathrm{mg} / \mathrm{kJ}$; (3) clothing stores 40 to $101 \mathrm{mg} / \mathrm{kJ}$; (4) toy stores 62 to $82 \mathrm{mg} / \mathrm{kJ}$; (5) shoe stores $78 \mathrm{mg} / \mathrm{kJ}$; (6) bookstores $99 \mathrm{mg} / \mathrm{kJ}$; and (7) fast food outlets 63 to $68 \mathrm{mg} / \mathrm{kJ}$.

In Phase I experiments, the fuel packages had a fuel load ranging from 661 to $5305 \mathrm{MJ}$ (based on survey results). A comparison between the experimentally measured heat released and the theoretical total heat release indicated that the experimental value range from 67 to $116 \%$ of the theoretical value. The experimentally measured weighted average of the heat content ranged from 70 to $110 \%$ of theoretical value. In Phase II experiments, the fuel packages had a fuel load ranging from 1,322 to $10,610 \mathrm{MJ}$ (based on Phase I analysis). The experimentally measured heat released ranged from 60 to $130 \%$ of the theoretical value. The peak HRR in Phase I experiments ranged from 0.7 to $1.9 \mathrm{MW}$ and usually occurred during the first 1:30 to 7:00 minutes. In Phase II, however, the peak HRR range was relatively small ranging from 2.4 to $2.7 \mathrm{MW}$. In all Phase II experiments, the peak HRR occurred during the first 2:40 to 6:00 minutes. The growth rates of the tests in Phase I and Phase II were compared to the standard t-squared fires 
and the observed growth ranged from slow to fast in Phase I, and slow/medium to fast in Phase II.

In all Phase I experiments, the room was capable of withstanding the fire effects. However, the exhaust system was capable of handling the temperatures produced in only seven of the nine tests. Two of the nine tests conducted in Phase I had to be terminated early because the gas temperatures inside the duct exceeded the safety limits for the facility. 


\section{MODELLING}

\subsection{Introduction}

The computational fluid dynamics (CFD) code, Fire Dynamics Simulator (FDS) of the National Institute of Standards and Technology (USA) ${ }^{2,55}$ was used to model the fuel packages and the fire tests conducted in both Phase I and Phase II experiments. FDS consists of hydrodynamic models, combustion models, and radiation transport models. The hydrodynamic models solve numerically a form of the Navier-Stokes equations appropriate for low speed, thermally-driven flow with an emphasis on smoke and heat transport from fires. In the model, turbulence is treated by means of the Smagorinsky form of Large Eddy Simulation (LES), which is the default mode in the model. It is also possible to perform a Direct Numerical Simulation (DNS) if the underlying numerical grid is fine enough. For most applications, FDS uses a mixture fraction combustion model, which assumes that combustion is mixing-controlled, and that the reaction of fuel and oxygen is infinitely fast. The mass fractions of all of the major reactants and products can be derived from the mixture fraction by means of "state relations". There are empirical expressions arrived at by a combination of simplified analysis and measurement. Radiation heat transfer is included in the model via the solution of the radiation transport equation for a non-scattering grey gas. The equation is solved using the Finite Volume Method (FVM) ${ }^{2}$.

The objective of this modelling work was to use FDS to simulate the fire characteristics determined in the experimental work of Phase I and II. To achieve this, the goal was to create a virtual fuel package in the input file for FDS with material properties and ideal stoichiometric coefficients for the fuel, such that the prediction of FDS would simulate 
the fire characteristics of the medium and large-scale experiments. Once this was achieved, this virtual fuel package could be used with FDS to simulate fires in compartments with different sizes.

The strategy followed in the FDS modelling exercise was as follows:

1. Use experimental results of the Phase I experiments to develop a virtual fuel package for FDS such that the FDS prediction would match the experimental data.

2. Use FDS to simulate the Phase II experiments using the virtual package developed in Step 1. Compare predictions with eperiments. Make minor adjustments to the virtual fuel package and redo Phase I, if necessary.

3. Use FDS to simulate a fire in a real commercial store using the virtual fuel package developed in Step 2.

The objective of this modelling work was to use FDS to simulate the fire characteristics observed in the experimental work of Phases I and II. To achieve this, the goal was to create a virtual fuel package in the input file for FDS with material properties and ideal stoichiometric coefficients for the fuel, such that the prediction of FDS would simulate the fire characteristics of the medium and large-scale experiments. Once this was achieved, this virtual fuel package could be used with FDS to simulate fires in compartments of different sizes.

FDS approximates the governing equations on a rectilinear grid and the geometry is prescribed as rectangular obstructions that are forced to conform to the underlying grid. 
All solid surfaces are assigned thermal boundary conditions, plus information about the burning behaviour of the material. Usually, material properties are stored in a database and invoked by name. To optimize output accuracy and simulation time, it was extremely important to determine an appropriate grid size for use in simulating the experiments. As per the FDS technical guide, FDS is second-order accurate in space and time, meaning that halving the grid cell size will decrease the discretization error in the governing equations by a factor of 4 . Because of the non-linearity of the equations, the decrease in discretization error does not necessarily translate into a comparable decrease in the error of a given FDS output quantity. With each halving of the grid cell size, the time required for the simulation increases by a factor of $2^{4}=16$ (a factor of two for each spatial coordinate, plus time). In the end, a compromise is struck between model accuracy and computer capacity.

The basis of large eddy simulation is that accuracy increases, as the numerical mesh is refined. For fire applications, grid sensitivity studies, explained afterwards, have shown that the accuracy of the model is a function of the characteristic fire diameter $D^{*}$ divided by the grid cell size. It is not enough to describe the resolution of the calculation solely in terms of the grid cell size, but rather the grid cell size relative to the heat release rate. For non-fire applications, there are no simple means to evaluate "good resolution". As a rule of thumb, FDS predictions for simulations with limited resolution are more reliable in the far-field because the substantial numerical diffusion mimics the unresolved subgrid scale mixing, McGrattan ${ }^{55}$. This is hard to quantify other than through comparisons with experiment. In a sensitivity study by $\mathrm{McGrattan}^{55}$, it has been concluded that the code works best with a cell size of a given value, and often this cell is not the smallest 
one tested. The same can be said for phenomena closer to the fire. However, grid resolution is more critical for near-field phenomena because numerical diffusion near the fire for simulations with coarse grids does not have the same fortuitous effect as it does on far-field results. In general, a coarse grid will decrease temperatures and velocities by smearing the values over the large grid cells. This can affect the radiative flux, convection to surrounding solids, and ultimately flame spread and fire growth.

The optimum grid size is best described by the resolution of the fire plume, which is a dimensionless parameter $\left(R^{*}\right)$. A value of 1 or less would represent a fine grid for most natural fires (McGrattan and Forney ${ }^{2}$; Reid et al. ${ }^{56}$; Bounagui et $a l .{ }^{57}$; and Ma and Quintiere $^{58}$ ). In all Phase II experiments, the maximum peak HRR ranged from 2375 to $2700 \mathrm{~kW}$, with fuel packages area of $1 \times 2$ meters, the effective diameter was $2.828 \mathrm{~m}$, and the values of $R^{*}$ ranged from 0.53 to 0.56 . In Phase $\mathrm{II}$, the burn room had dimensions of $3.6-\mathrm{m}$ length by $2.7-\mathrm{m}$ width by $2.4-\mathrm{m}$ high. The burn room is connected to a corridor $1.4-\mathrm{m}$ width by $11.0-\mathrm{m}$ long by $2.6-\mathrm{m}$ high. The grid size for the room was $0.10 \times 0.10 \times 0.10 \mathrm{~m}$ and $0.233 \times 0.22 \times 0.216 \mathrm{~m}$ for the corridor. The grid size was smaller inside the room to capture the higher variable parameters expected to occur in the room. 
$R^{*}=\frac{\max (\delta x, \delta y, \delta z)}{D^{*}}$

Equation 16

Where, $D^{*}=$ Characteristic fire diameter $(\mathrm{m})=\left(\frac{\dot{Q}}{\rho_{\infty} c_{p} T_{\infty} \sqrt{g D} D^{2}}\right)^{2 / 5} D$

$D=$ effective diameter $(\mathrm{m}), \dot{Q}=$ maximum heat release rate $(\mathrm{kW}), \rho_{\infty}=$ air density at ambient temperature $\left(\mathrm{kg} / \mathrm{m}^{3}\right), \quad c_{p}=$ specific heat of gas $(\mathrm{kJ} / \mathrm{kg} . \mathrm{K}), T_{\infty}=$ ambient temperature $(\mathrm{K}), g=$ acceleration of gravity $\left(\mathrm{m} / \mathrm{s}^{2}\right)$.

In the experimental work, the fuel packages had a combination of different materials (wood, plastics, textiles, etc.), and in each package, the contribution of each of these materials to the total mass was also different. Every material burned differently and produced different fire characteristics because of the fact that each material has a number of unique properties such as: (1) heat of vaporization $(\mathrm{kJ} / \mathrm{kg})$; (2) heat content $(\mathrm{MJ} / \mathrm{kg})$; (3) burning rate $\left(\mathrm{kg} / \mathrm{m}^{2} / \mathrm{s}\right)$ (4) density $\left(\mathrm{kg} / \mathrm{m}^{3}\right)$; (5) ignition temperature $\left({ }^{\circ} \mathrm{C}\right)$; and (6) chemical composition.

The stoichiometric or complete combustion is the ideal combustion process in which a fuel is burned completely. In complete combustion, all the carbon (C) is converted to $\mathrm{CO}_{2}$, all hydrogen $(\mathrm{H})$ to $\mathrm{H}_{2} \mathrm{O}$ and all sulphur $(\mathrm{S})$ to sulphur dioxide $\left(\mathrm{SO}_{2}\right)$. If there are unburned components in the exhaust gas such as $\mathrm{C}, \mathrm{H}_{2}, \mathrm{CO}$ the combustion process is incomplete.

To deal with the variances in material properties, mass contribution, and the uncertainty about the occurrence of complete or incomplete combustion, a 'virtual' fuel package that has material properties, which is not necessarily identical to the 'actual' fuel package, 
was used in the modelling. Based on the design fire characteristics identified from the literature review and the results obtained from the experiments, the objective of the simulations was to develop a simple fuel package that produces the same HRR, hot layer temperature, and total $\mathrm{CO}$ and $\mathrm{CO}_{2}$ produced in the experiments.

\subsubsection{Factors affecting the FDS output results}

Detailed descriptions of different input parameters for the FDS input file are explained in Appendix C. The details include: (1) the computational domain; (2) grid size; (3) room geometry; (4) boundary conditions; (5) simulation time; (6) ignition source; (7) fuel package geometry; (8) thermal properties; (9) material properties in the solid and gas phases; (10) combustion properties; (11) thermocouple locations; (12) limitations; and (13) definitions of the terms, symbols, and units used.

Almost all input parameters explained above affect the output results of a simulation; however, from the sensitivity analysis and intensive trials, it was determined that some of the fuel properties in the solid phase have a large effect on the results. Hence, they should be carefully selected to produce a HRR profile that is similar to the experiments. The following section describes these parameters and their effect on the results. The examples considered are based on the boundary conditions, geometry, and properties of the fuel packages tested in the ISO room explained in Appendix C and Appendix D.

\subsubsection{Material Density}

Material density $\left(\mathrm{kg} / \mathrm{m}^{3}\right)$ affects all fire phases; usually the denser the material the harder it is to burn. It was found that a $25 \%$ decrease in the density of polymethylmethacrylate (PMMA) would cause a faster growth rate and earlier peak HRR by about $1: 30$ to $2: 30$ 
minutes than the normal PMMA density. It would also produce a minor decrease in the peak HRR value (about $2 \%$ ) and force the HRR profile to decay faster than normal PMMA, Figure 167. This could be attributed to the decrease in mass caused by the decrease in density.

\subsubsection{Heat of Vaporization}

The heat of vaporization $(\mathrm{HoV})(\mathrm{kJ} / \mathrm{kg})$ is the amount of energy required to vaporize a solid or liquid fuel once it has reached its ignition temperature (McGrattan and Forney $\left.{ }^{2}\right)$. It affects the burning rate of the fuel, which is dependent on the heat feedback from the fire to the fuel surface. The lower the HoV for a combustible substance, the faster it can vaporize and burn. It was found that a $25 \%$ decrease in the HoV of PMMA would cause a faster growth rate but make no changes to the time to peak HRR, Figure 168. It would also produce about a $10 \%$ increase in the peak HRR value and a very minor change in the decay phase.

\subsubsection{Heat of Combustion}

Heat of combustion $(\mathrm{kJ} / \mathrm{kg})$ is the amount of energy released, in the event of fire, per unit mass of a substance. It affects the burning rate of the fuel and the total heat released. The lower the HC value of a substance, the lower the total heat release. It was found that a $25 \%$ decrease in the HC of PMMA would cause a decrease in the growth rate but produce no changes to the time to peak HRR, Figure 169 . It would also produce about a $30 \%$ decrease in the peak HRR value and a minor change in the decay phase. 


\subsubsection{Ignition Temperature}

The ignition temperature $\left({ }^{\circ} \mathrm{C}\right)$ is the minimum temperature to which the surface of a material must be heated before it will spontaneously burn independently of the source of heat. As a result, it affects the onset of ignition. The lower the ignition temperature for a material, the earlier it will burn. It was found that a $25 \%$ decrease in the ignition temperature of PMMA would cause faster growth rate and faster peak HRR by about 1:00 minute, Figure 170, and produced about a 7\% increase in the peak HRR value. It also produced an increase in the developed phase period and a faster decay rate. 


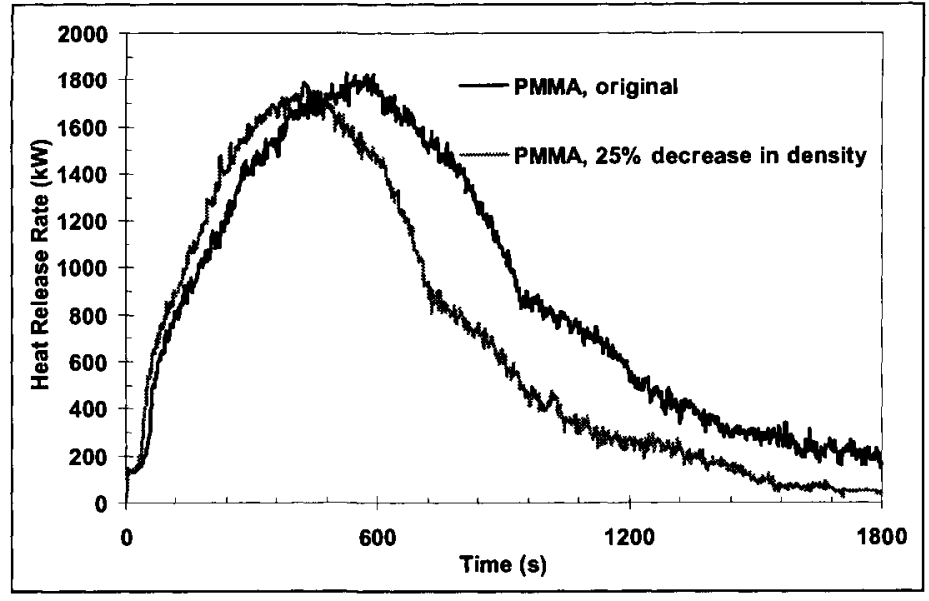

Figure 167. Effect of material density on HRR

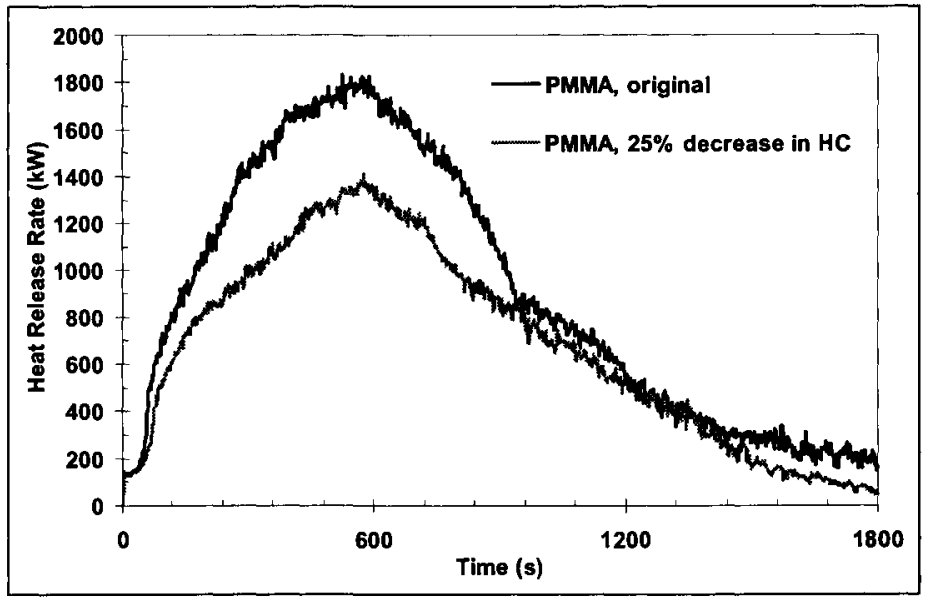

Figure 169. Effect of heat content on HRR

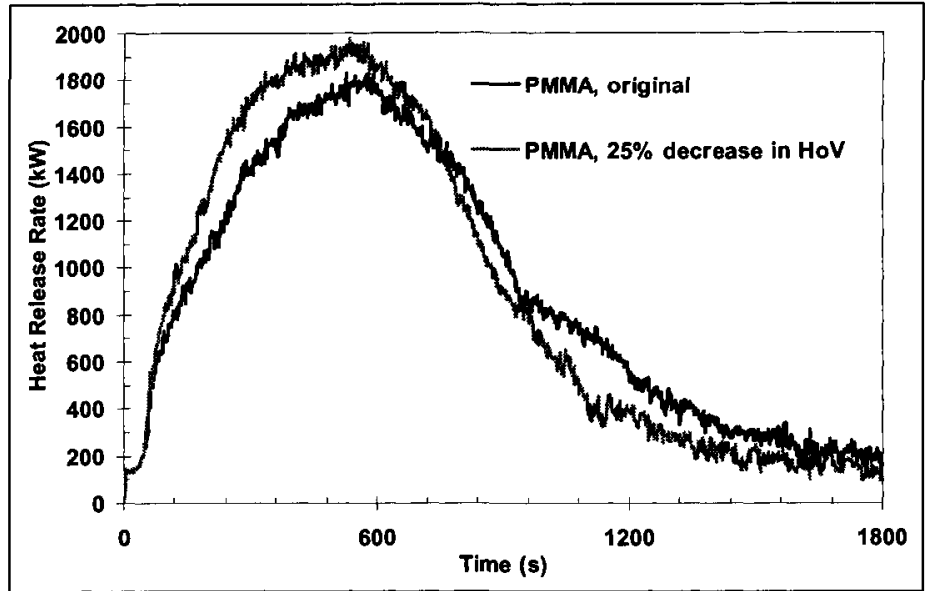

Figure 168. Effect of heat of vaporization on HRR

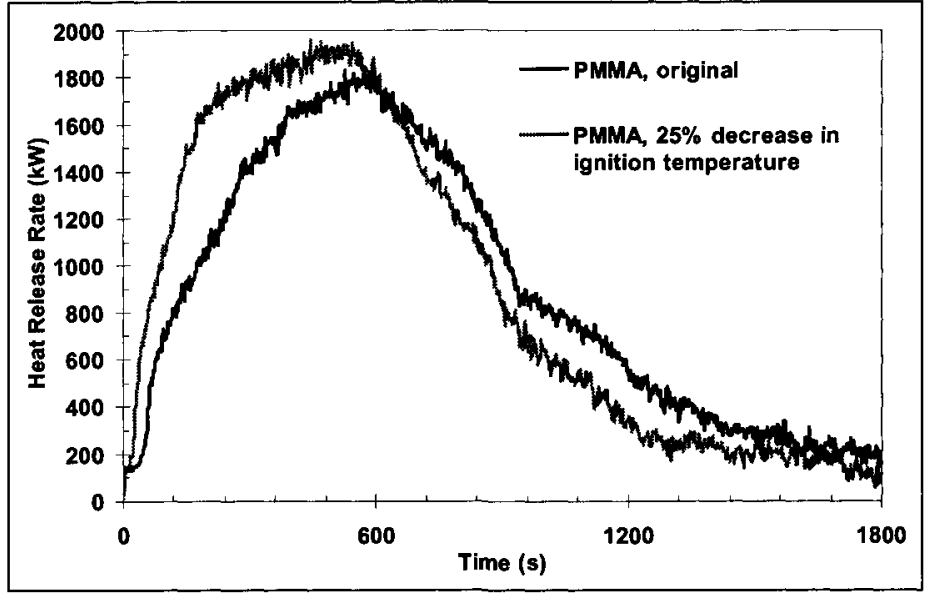

Figure 170. Effect of ignition temperature on HRR 


\subsection{Modelling Results and Comparisons with Experiments}

\subsubsection{Introduction}

The simulation output included the HRR, hot layer temperature, and total production rates of CO and $\mathrm{CO}_{2}$ until $1800 \mathrm{~s}$. Based on the experimental results, it was assumed that most of the fire events would occur during the first $1800 \mathrm{~s}$ of the fire.

In Phase I, some differences were found when comparing the simulated HRR with the experimental results; however, it was found that for most Phase II simulations, the HRR profile, hot layer temperature, and smoke production rates compared favourably with the experimental results.

Figure 171 and Figure 172 show the geometry of the burn rooms and corridor, as well as the fuel packages. Detailed input files for all simulations are listed in Appendix D. 


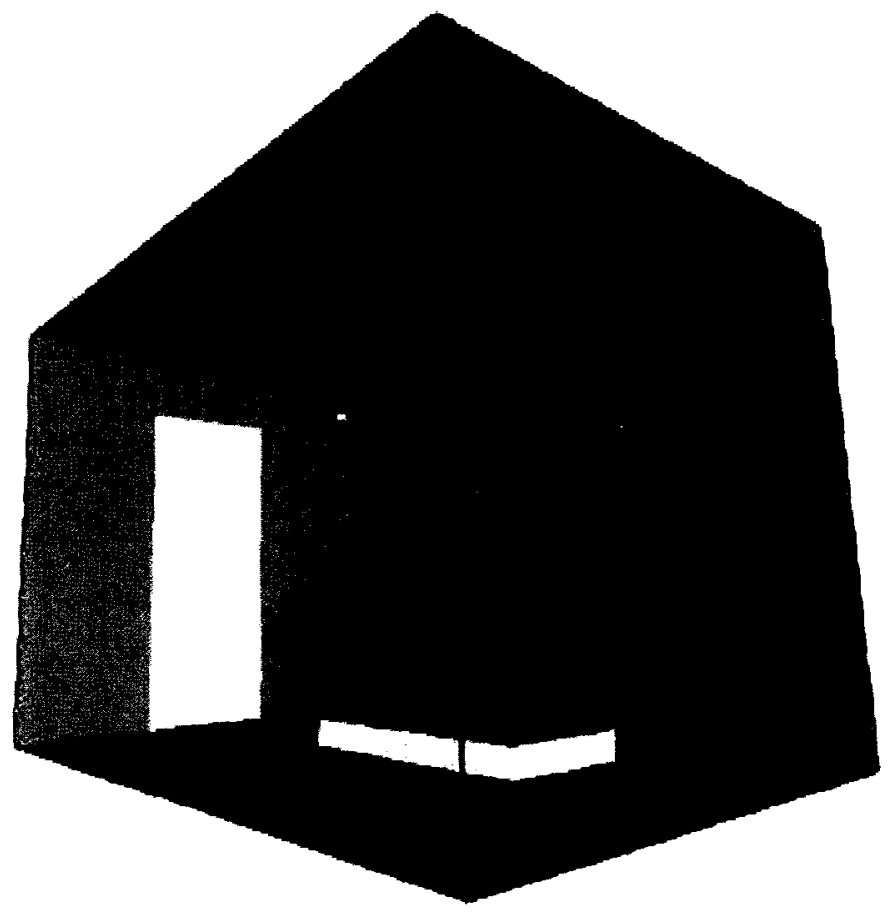

Figure 171. Geometry of the burn room and the fuel package, Phase I experiments.

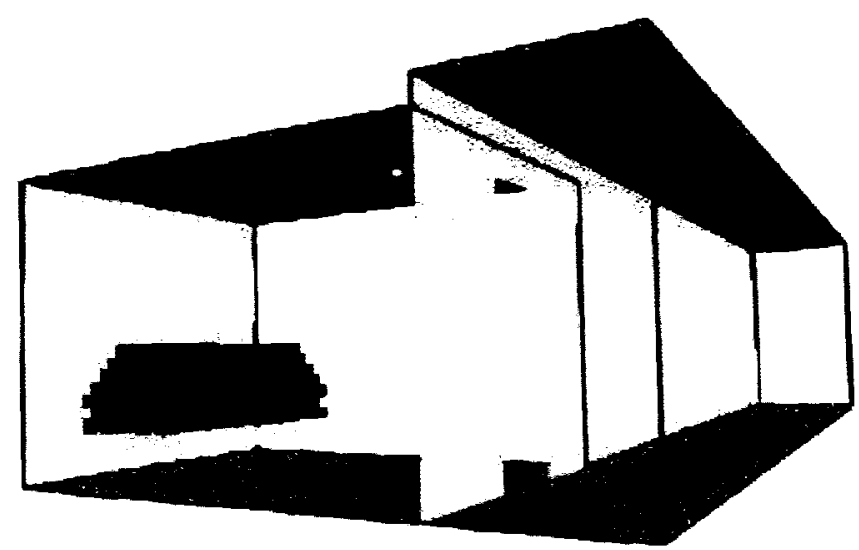

Figure 172. Geometry of the burn room, corridor, and the fuel packages, Phase II experiments 


\subsubsection{Results and Discussions}

This section presents a comparison between the simulation predictions of FDS and the experimental data of Phase I and II experiments.

\subsubsection{Virtual Fuel Packages}

The virtual fuel packages used to simulate real packages had a trapezoidal shape and consisted of a number of rectangular sticks; each stick had a length of $1.0 \mathrm{~m}$ and cross section $0.1 \times 0.1 \mathrm{~m}$. To simulate the HRR profile and the amount of combustibles used in every test, the geometry and number of sticks were chosen based on trial and error process. The fuel packages for a computer store, storage area, clothing store, toy store, and fast food outlet had 15 rectangular sticks that were placed in the trapezoidal shape. The fuel package for the bookstore had 24 sticks, and 33 sticks for the shoe store, Figure 171. Trapezoidal geometry and the number of rectangular sticks were chosen to obtain a HRR profile similar to the experimental results. In order to simulate the $\mathrm{HRR}$, temperature of the hot layer, and the total $\mathrm{CO}$ and $\mathrm{CO}_{2}$ production rates, the material properties of the sticks in the solid and gas phases were varied for each fuel package with PMMA as the base material.

In the solid phase, the following properties in the FDS input file had to be modified, and detailed descriptions of the parameters used in the FDS input file are explained in Appendix C.

Properties in the solid phase: (1) heat of vaporization (HEAT_OF_VAPORIZATION); (2) heat of combustion (HEAT_OF_COMBUSTION); (3) maximum burning rate (BURNING_RATE_MAX); (4) material thickness (DELTA); (5) density (DENSITY); and (6) ignition temperature (TMPIGN). Properties in the gas phase: (1) carbon dioxide ideal stoichiometric coefficient for the reaction of 
a hydrocarbon fuel ( $\mathrm{NU} \_\mathrm{CO} 2$ ); and (2) fraction of fuel mass converted into smoke particulate from the fire (SOOT_YIELD).

Based on the geometry, number of sticks, and the material properties in both gas and solid phases, the virtual fuel packages when used in FDS were able, to a great extent, to simulate the burning characteristics of the real fuel packages tested in Phase I and Phase II experiments. The definition of the parameters used in the FDS input data file is explained in Appendix C. Based on the sensitivity analysis and intensive trials, the numerical value of each of these parameters (e.g., heat of vaporization, heat of combustion, and soot yield) was selected so that they produced a similar $\mathrm{HRR}$ and total $\mathrm{CO}$ and $\mathrm{CO}_{2}$ measured in the experiments.

Details of the material properties in the solid and gas phases for each of the fuel packages are shown in Table 25 to Table 31. 
Table 25. Material properties of the computer store virtual package

\begin{tabular}{lll}
\hline \multicolumn{2}{c}{ Material properties in the solid phase } & Material properties in the gas phase \\
\hline \&SURF ID & 'CMP' & \&REAC ID='CMP_GAS' \\
FYI='Computer store Package, Carleton Uni.' & FYI='Modified Propane, C_3 H_8' \\
HEAT_OF_VAPORIZATION & $=1134$. & MW_FUEL $=44$ \\
HEAT_OF_COMBUSTION & $=20097$. & NU_O2 $=5$. \\
BURNING_RATE_MAX & $=0.028$ & NU_CO2 $=0.505$ \\
DELTA & $=0.012$ & NU_H2O=4. \\
KS & $=0.19$ & SOOT_YIELD $=0.035 /$ \\
CEP & $=1.42$ & \\
DENSITY & $=536$. & \\
BACKING & $=1$ INSULATED' \\
TMPIGN & $=380 . /$ & \\
\end{tabular}

Table 26. Material properties of the storage area virtual package

\begin{tabular}{|c|c|}
\hline Material properties in the solid phase & Material properties in the gas phase \\
\hline$\& S U R F=' S A-I I '$ & $\& R E A C \quad I D=' S A$ GAS' \\
\hline $\begin{array}{l}\text { FYI }=\text { 'Storage area package, Carleton Uni.' } \\
\text { HEAT OF VAPORIZATION }=1620 .\end{array}$ & $\begin{array}{l}\text { FYI ='Modified Propane, } \mathrm{C}_{-} 3 \mathrm{H} \mathrm{H}_{-}{ }^{\prime} \\
\text { MW FUEL }=44\end{array}$ \\
\hline HEAT_OF_COMBUSTION $=18270$. & $\mathrm{NU}^{-} \mathrm{O} 2=5$ \\
\hline BURNING RATE MAX & $\mathrm{NU}^{-} \mathrm{CO} 2=0.577$ \\
\hline$=0.02$ & $\mathrm{NU}_{-}^{-} \mathrm{H} 2 \mathrm{O}=4$. \\
\hline$=0.19$ & SOŌT_YIELD $=0.022 /$ \\
\hline$=1.42$ & \\
\hline DENSITY & \\
\hline$=$ 'INSULATED' & \\
\hline$=285.1$ & \\
\hline
\end{tabular}

Table 27. Material properties of the clothing store virtual package

\begin{tabular}{|c|c|}
\hline Material properties in the solid phase & Material properties in the gas phase \\
\hline \&SURF ID $=$ 'CLC-II' & \&REAC ID $=$ 'CLC_GAS' \\
\hline FYI='Clothing store Package, Carleton Uni.' & FYI='Modified Propane, C_3 H_8' \\
\hline HEAT_OF_VAPORIZATION $=1134$ & MW_FUEL $=44$ \\
\hline HEAT_OF_COMBUSTION $=18270$. & NU_O2 $=5$. \\
\hline BURNĪNG_RATE_MAX & $\mathrm{NU}_{-}^{-} \mathrm{CO} 2=0.469$ \\
\hline DELTA -- & $\mathrm{NU}^{-} \mathrm{H} 2 \mathrm{O}=4$. \\
\hline$=0.19$ & SOOTT_YIELD $=0.011 /$ \\
\hline$=1.42$ & \\
\hline DENSITY & \\
\hline$=$ 'INSULATED' & \\
\hline$=380.1$ & \\
\hline
\end{tabular}


Table 28. Material properties of the toy store virtual package

\begin{tabular}{|c|c|}
\hline Material properties in the solid phase & Material properties in the gas phase \\
\hline$\&$ SURF ID $=$ 'TOY-II' & \&REAC ID='TOY_GAS' \\
\hline FYI $=$ 'Toy store Package, Carleton Uni.' & FYI ='Modified Propane, C 3H 8' \\
\hline HEAT_OF_VAPORIZATION $=1620$. & MW FUEL $=44$ \\
\hline $\mathrm{HEAT}^{-} \mathrm{OF}^{-}$COMBUSTION $=18270$. & $\mathrm{NU}^{-} \mathrm{O} 2=5$ \\
\hline BURNĪNG_RATE_MAX & $\mathrm{NU}^{-} \mathrm{CO} 2=0.481$ \\
\hline DELTA - - & $\mathrm{NU}^{-} \mathrm{H} 2 \mathrm{O}=4$. \\
\hline$=0.19$ & SOOTT_YIELD $=0.0161 /$ \\
\hline$=1.42$ & \\
\hline DENSITY & \\
\hline$=$ 'INSULATED' & \\
\hline$=285 . /$ & \\
\hline
\end{tabular}

Table 29. Material properties of the shoe store virtual package

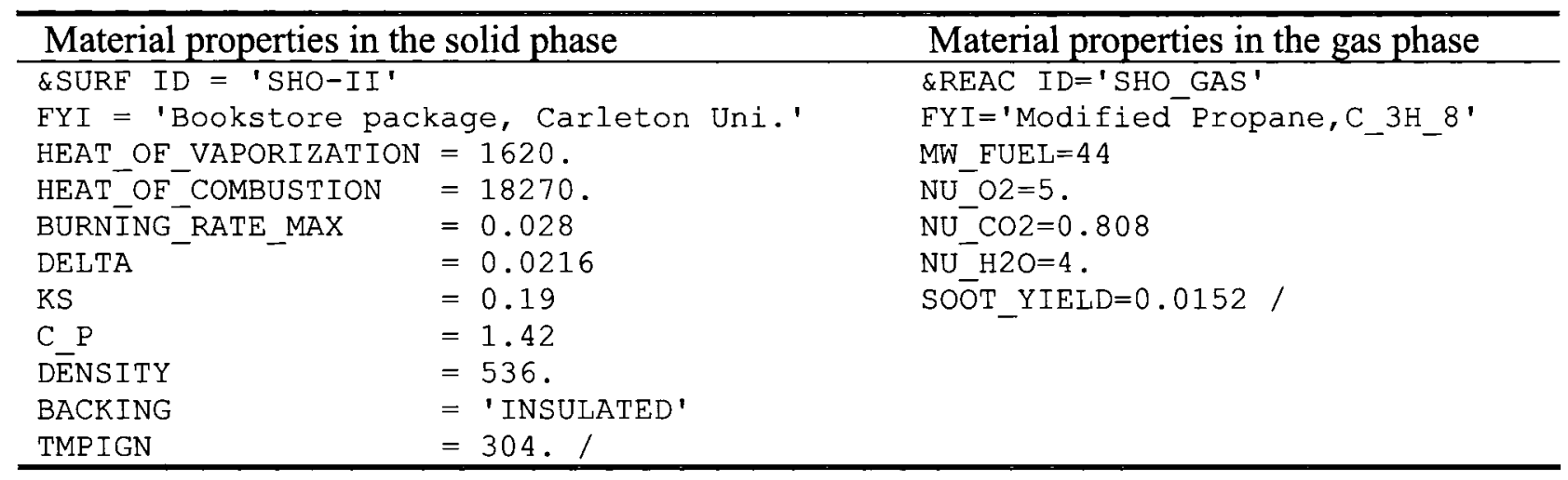

Table 30. Material properties of the bookstore virtual package

\begin{tabular}{|c|c|}
\hline Material properties in the solid phase & Material properties in the gas phase \\
\hline \&SURF ID $=$ 'BK-II' & $\& R E A C \quad I D=' B K$ GAS' \\
\hline FYI = 'Bookstore Package, Carleton Uni.' & FYI='Modifie $\bar{d}$ Propane, C $3 \mathrm{H}$ \\
\hline HEAT OF VAPORIZATION $=1620$ & MW FUEL $=44$ \\
\hline HEAT_OF_COMBUSTION $=18270$. & $\mathrm{NU}^{-} \mathrm{O} 2=5$ \\
\hline BURNĪNG ${ }^{-}$RATE MAX & $\mathrm{NU}^{-} \mathrm{CO} 2=0.808$ \\
\hline$=0.0216$ & NU_H $20=4$. \\
\hline$=0.19$ & SOŌT YIELD $=0.0152 /$ \\
\hline$=1.42$ & \\
\hline DENNSITY & \\
\hline$=$ 'INSULATED' & \\
\hline$=304$ & \\
\hline
\end{tabular}


Table 31. Material properties of the fast food outlet virtual package

\begin{tabular}{|c|c|}
\hline Material properties in the solid phase & Material properties in the gas phase \\
\hline \&SURF ID $=' F F-I I '$ & \&REAC ID='FF_GAS' \\
\hline FYI = 'Fast food outlet Package, Carleton & FYI='Modified Propane, C_3H_8' \\
\hline 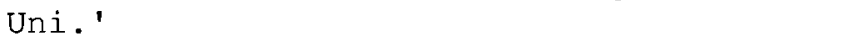 & MW_FUEL $=44$ \\
\hline HEAT_OF_VAPORIZATION $=1620$. & $\mathrm{NU}-\mathrm{O} 2=5$. \\
\hline HEAT_OF_COMBUSTION $=22000$. & $\mathrm{NU}_{-}^{-} \mathrm{CO} 2=0.304$ \\
\hline BURNING_RATE_MAX & $\mathrm{NU}_{-}^{-} \mathrm{H} 2 \mathrm{O}=4$. \\
\hline DELTA -- & SOOT_YIELD $=0.007$ \\
\hline$=0.19$ & \\
\hline$=1.42$ & \\
\hline DĒNSITY & \\
\hline$=$ 'INSULATED' & \\
\hline$=383 . /$ & \\
\hline
\end{tabular}




\subsubsection{Heat Release Rate}

Figure 173 to Figure 179 show the comparison between the experimental HRR profiles from the Phase I and II experiments and the FDS predicted profiles. In these figures; Phase I experiments are denoted using the symbol 'I' (e.g., CMP-I), and the corresponding modelling case is denoted as (FDS-I), while for Phase II, the experiments are denoted using the symbol 'II' (e.g., CMP-II), and the corresponding modelling case is denoted as (FDS-II).

The figures show that, in general, the model compares well with the experimental results for both phases, especially for Phase II. The model was able to predict the peak HRR, time to reach the peak, and decay characteristics.

Figure 177 for the shoe store and Figure 178 for the bookstore show only the comparisons of the Phase II experiments. Test SHO-I and BK-I are not shown in the figures as both tests were extinguished early because the gas temperature inside the duct exceeded the safety limits for the facility. 


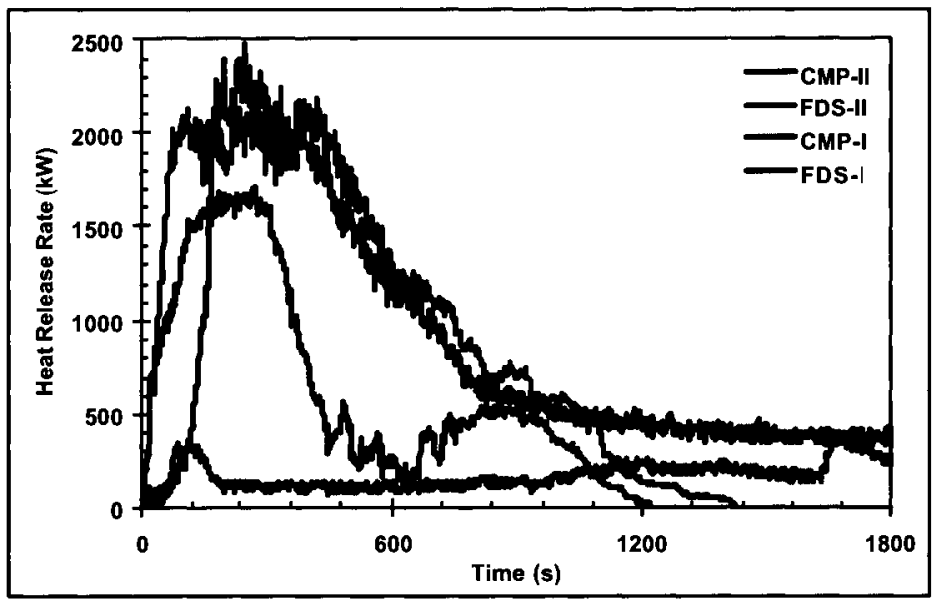

Figure 173. Computer store-HRR (FDS vs experiments)

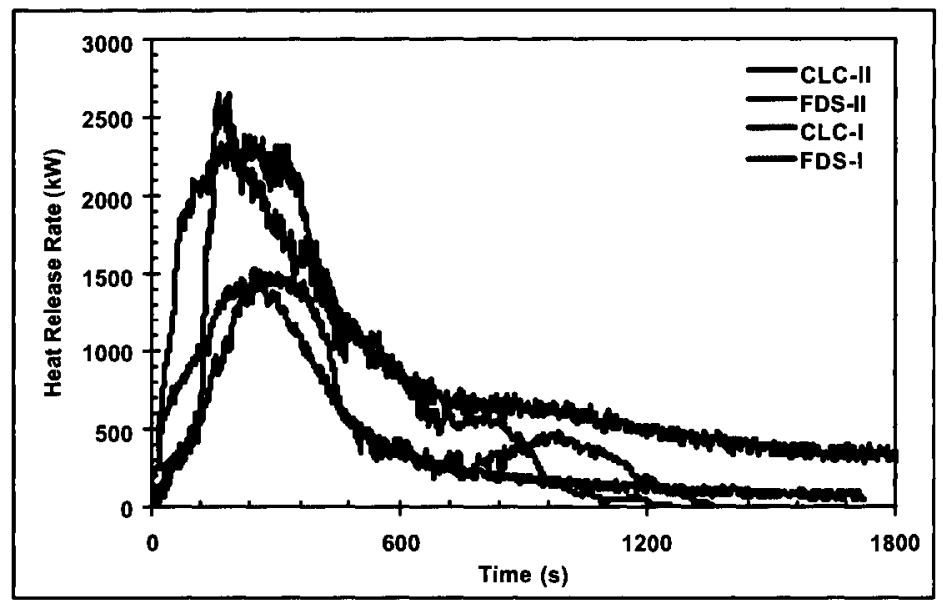

Figure 175. Clothing store-HRR (FDS vs experiments)

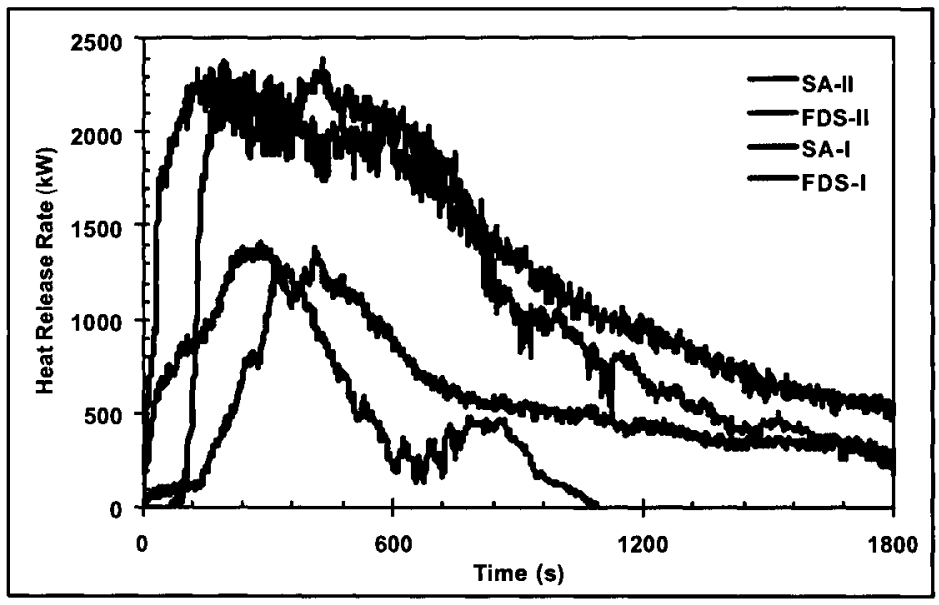

Figure 174. Storage areas-HRR (FDS vs experiments)

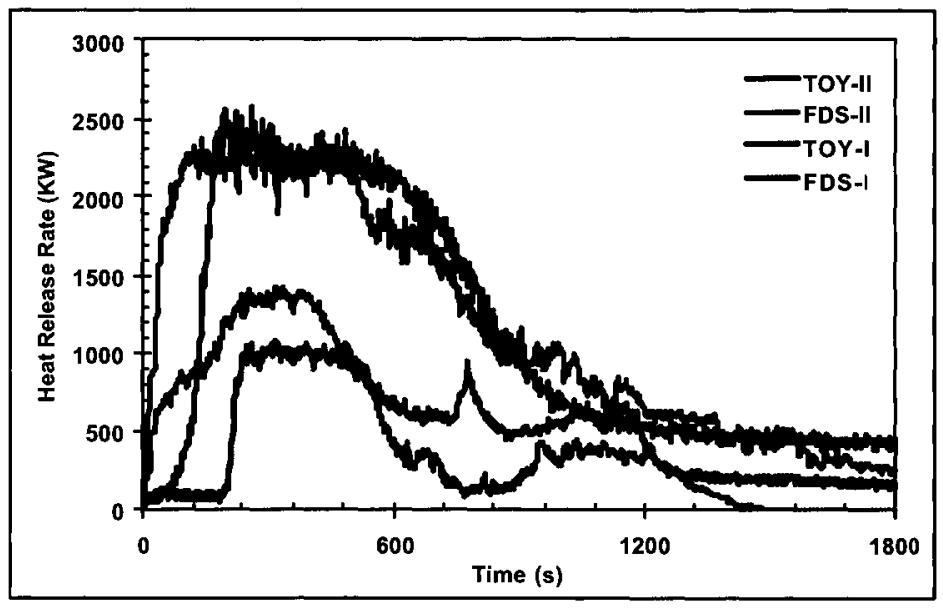

Figure 176. Toy store-HRR (FDS vs experiments) 


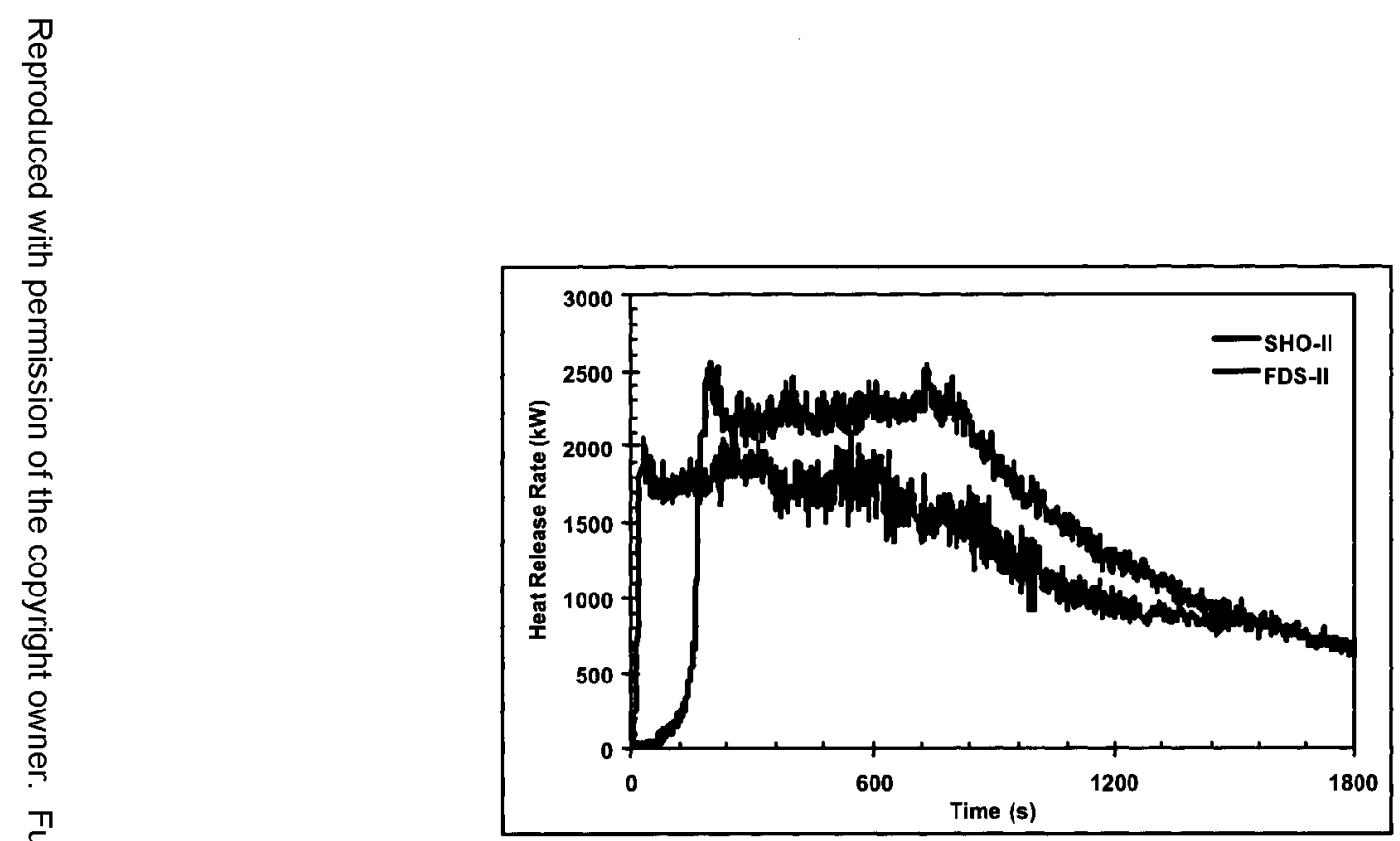

Figure 177. Shoe store-HRR (FDS vs experiments)

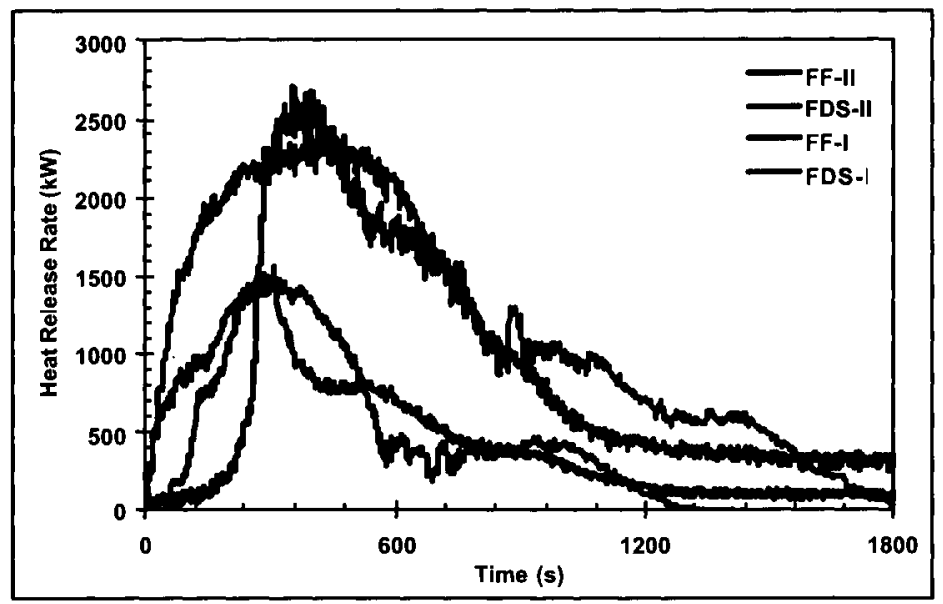

Figure 179. Fast food outlet-HRR (FDS vs experiments)

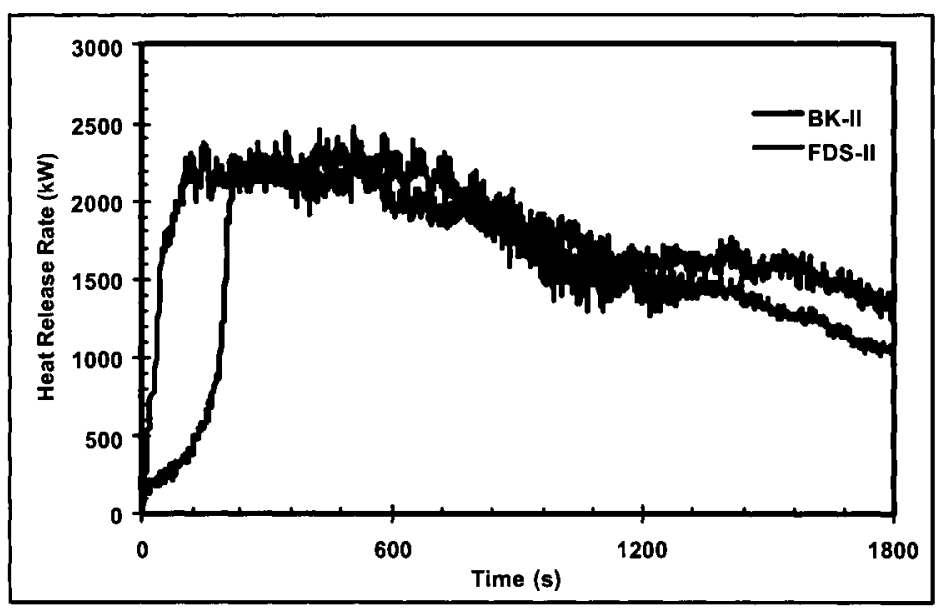

Figure 178. Bookstore-HRR (FDS vs experiments) 


\subsubsection{Hot Layer Temperature and $\mathrm{CO}$ and $\mathrm{CO}_{2}$ production}

Figure 180 to Figure 186 show the comparisons between the measured temperatures from Phase I and Phase II experiments, and FDS temperature predictions. The peak values of temperatures are listed in Table 32. The results indicate that the measured temperatures inside the burn room compare well with those predicted by FDS, however, the temperatures in the corridor predicted by FDS (Phase II) were much lower than the experimental values. This would suggest that FDS was not able to predict the combustion of combustible vapours in the corridor.

As shown in Table 32, the total $\mathrm{CO}$ and $\mathrm{CO}_{2}$ released in the Phase II experiments compare well with those predicted by FDS. 


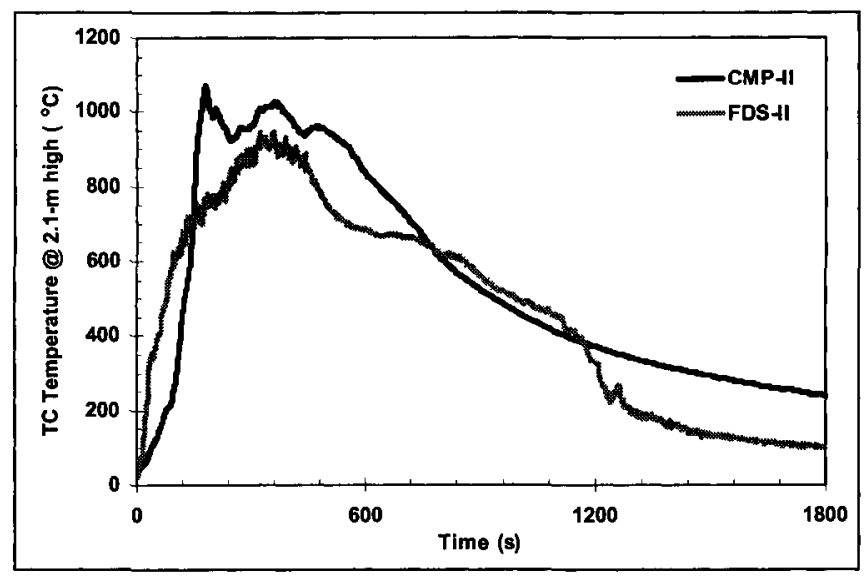

Figure 180. Computer store-Temperature (FDS vs experimental)

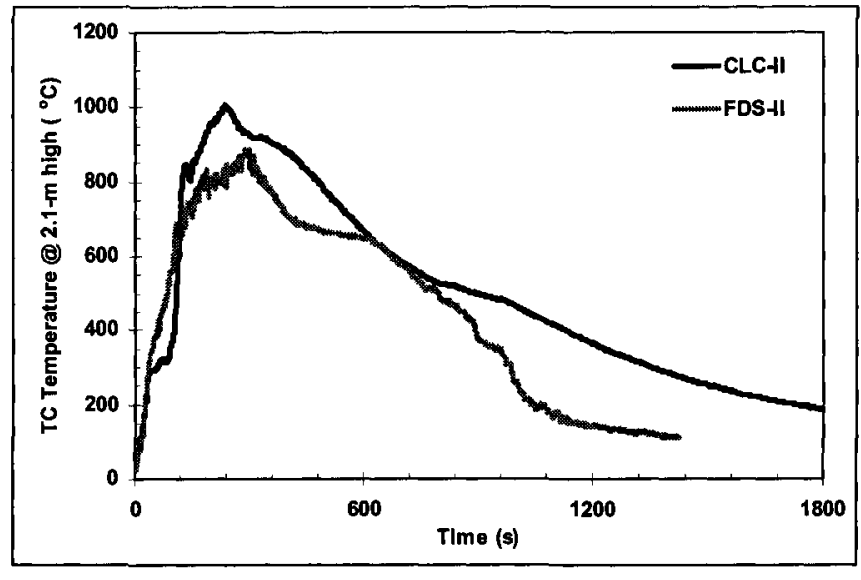

Figure 182. Clothing store-Temperature (FDS vs experimental)

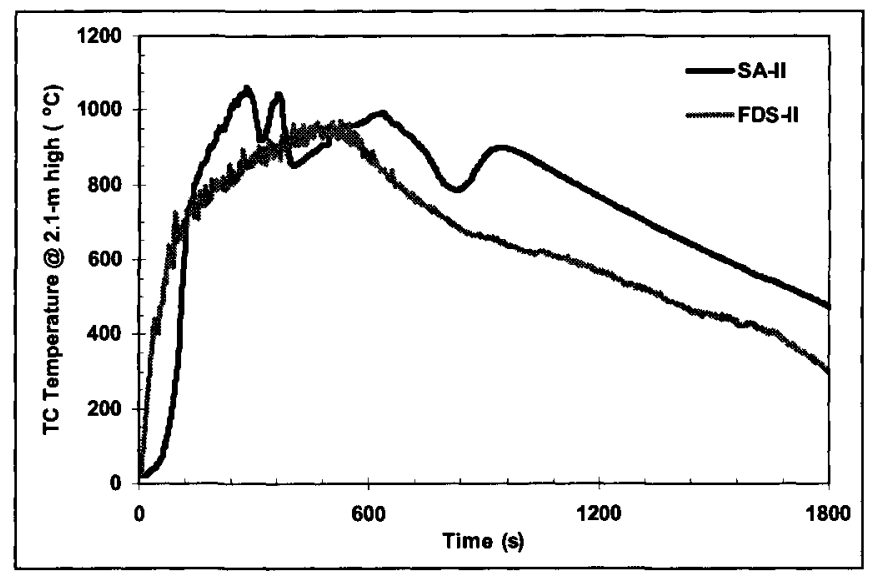

Figure 181. Storage areas-Temperature (FDS vs experimental)

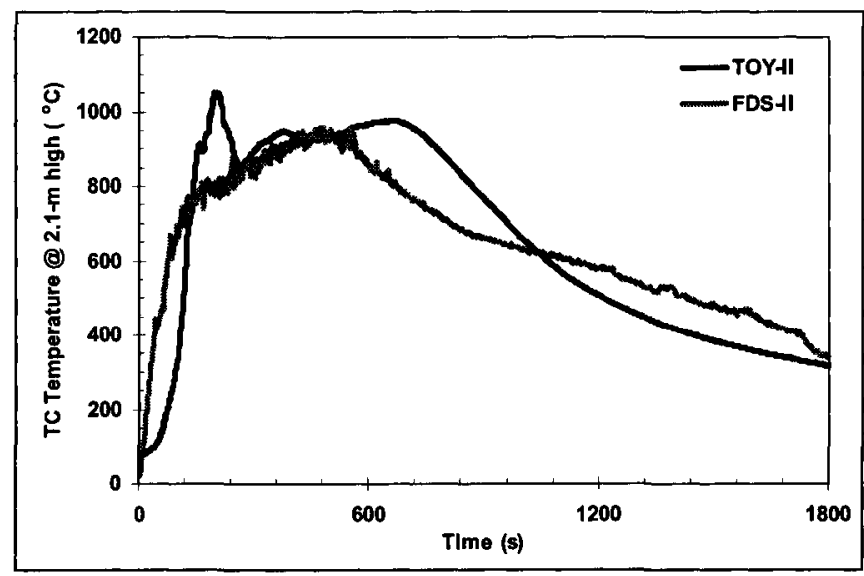

Figure 183. Toy store-Temperature (FDS vs experimental) 


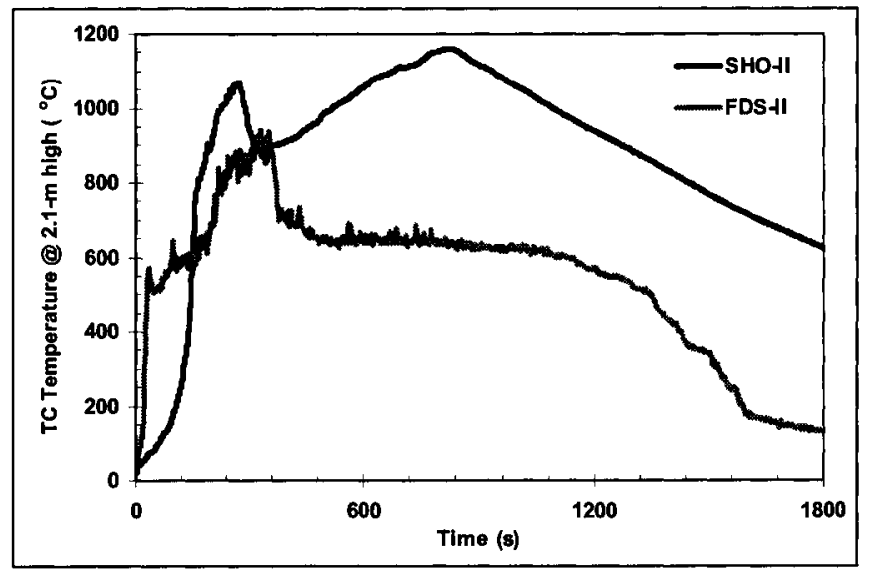

Figure 184. Shoe store-Temperature (FDS vs experimental)

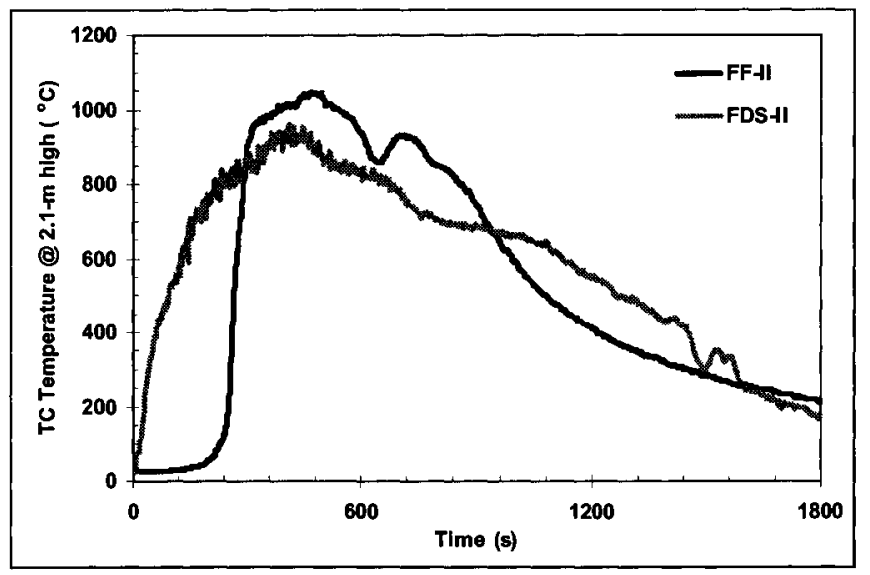

Figure 186. Fast food outlet-Temperature (FDS vs experimental)

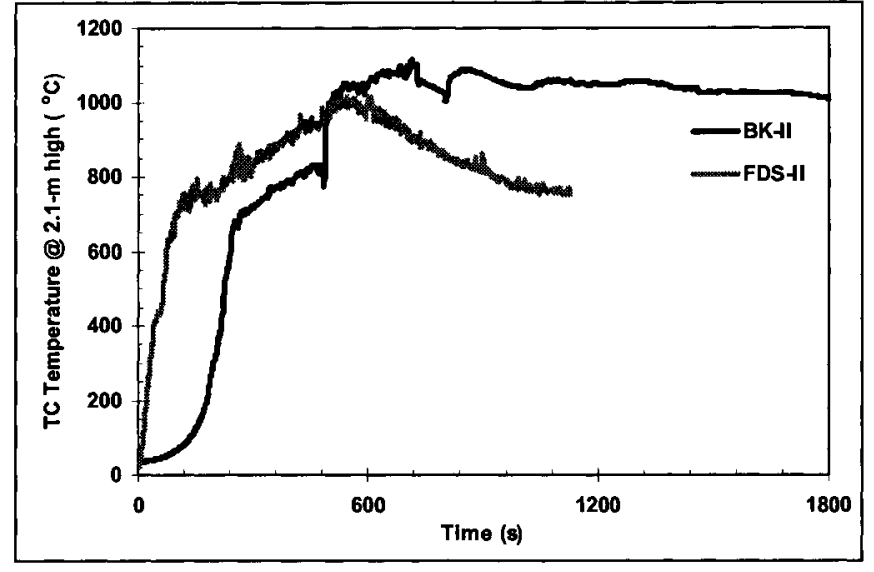

Figure 185. Bookstore-Temperature (FDS vs experimental) 
Table 32. HRR, gas data, and temperatures for FDS and experimental results

\begin{tabular}{|c|c|c|c|c|c|c|c|c|c|}
\hline \multirow[b]{2}{*}{ Test } & \multirow[b]{2}{*}{ Test ID } & \multicolumn{2}{|c|}{$\begin{array}{c}\text { Heat release } \\
\text { data }\end{array}$} & \multicolumn{2}{|c|}{ Gas data } & \multicolumn{4}{|c|}{ Temperature $\left({ }^{\circ} \mathrm{C}\right)$} \\
\hline & & 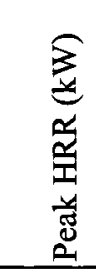 & $\stackrel{\Xi}{E}$ & $\begin{array}{l}80 \\
\stackrel{80}{y} \\
0 \\
0 \\
0 \\
0 \\
0\end{array}$ & 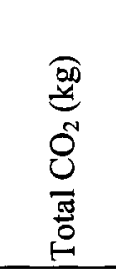 & 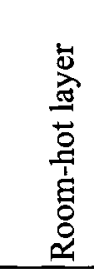 & 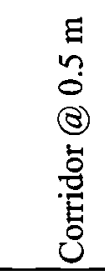 & $\begin{array}{l}\Xi \\
n \\
n \\
\text { (e) } \\
\ddot{0} \\
\stackrel{0}{0} \\
\dot{0}\end{array}$ & 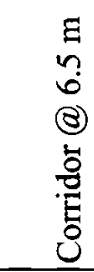 \\
\hline \multirow[t]{4}{*}{ Computer store } & CMP-I & $\begin{array}{l}340 \\
410\end{array}$ & $\begin{array}{l}1: 30 \\
28: 00\end{array}$ & 1.71 & 31.3 & 180 & -- & -- & -- \\
\hline & FDS-I & 1710 & $4: 30$ & -- & -- & 550 & -- & -- & -- \\
\hline & CMP-II & 2475 & $4: 10$ & 6.09 & 109.30 & 1070 & 1035 & 960 & 860 \\
\hline & FDS-II & 2245 & $4: 45$ & 6.45 & 112.30 & 946 & 597 & 407 & 355 \\
\hline \multirow[t]{4}{*}{ Storage area } & SA-I & 1385 & $7: 00$ & 2.13 & 97.3 & 450 & -- & -- & -- \\
\hline & FDS-I & 1420 & $4: 45$ & -- & -- & 540 & -- & -- & -- \\
\hline & SA-II & 2385 & $3: 30$ & 5.74 & 230.30 & 1080 & 1080 & 985 & 860 \\
\hline & FDS-II & 2401 & $2: 45$ & 6.12 & 239.41 & 971 & 671 & 452 & 390 \\
\hline \multirow[t]{4}{*}{ Clothing store } & CLC-I & 1530 & $4: 30$ & 0.76 & 46.1 & 470 & -- & -- & -- \\
\hline & FDS-I & 1535 & $4: 15$ & -- & -- & 600 & -- & -- & -- \\
\hline & CLC-II & 2660 & $2: 40$ & 2.11 & 101.80 & 1010 & 950 & 825 & 750 \\
\hline & FDS-II & 2395 & $3: 30$ & 1.91 & 107.18 & 888 & 527 & 387 & 340 \\
\hline \multirow[t]{4}{*}{ Toy store } & TOY-I & 1080 & $4: 30$ & 1.77 & 66.40 & 510 & -- & -- & -- \\
\hline & FDS-I & 820 & $5: 00$ & -- & -- & 540 & -- & -- & -- \\
\hline & TOY-II & 2570 & $4: 30$ & 4.04 & 174.70 & 1070 & 940 & 1010 & 970 \\
\hline & FDS-II & 2420 & $4: 15$ & 4.45 & 180.79 & 960 & 680 & 465 & 400 \\
\hline \multirow[t]{4}{*}{ Shoe store } & SHO-I & 1880 & $3: 40$ & - & -- & 600 & -- & -- & -- \\
\hline & FDS-I & -- & -- & -- & -- & -- & -- & -- & -- \\
\hline & SHO-II & 2555 & $3: 20$ & 8.05 & 311.20 & 1210 & 1370 & 1030 & 1225 \\
\hline & FDS-II & 2090 & $4: 00$ & 8.49 & 315.61 & 939 & 659 & 566 & 475 \\
\hline \multirow[t]{4}{*}{ Bookstore } & BK-I & $\begin{array}{l}1090 \\
1180\end{array}$ & $\begin{array}{l}17: 20 \\
34: 00\end{array}$ & - & -- & 580 & -- & -- & -- \\
\hline & FDS-I & 1625 & $8: 00$ & -- & -- & 700 & -- & -- & -- \\
\hline & BK-II & 2375 & $4: 40$ & 6.01 & 409.40 & 1120 & 1040 & 1020 & 900 \\
\hline & FDS-II & 2475 & $2: 50$ & 6.40 & 415.80 & 1012 & 785 & 668 & 568 \\
\hline \multirow[t]{4}{*}{ Fast food outlet } & FF-I & 1560 & $4: 30$ & 0.91 & 52.20 & 460 & -- & -- & -- \\
\hline & FDS-I & 1485 & $3: 00$ & -- & -- & 550 & -- & -- & -- \\
\hline & FF-II & 2700 & $6: 00$ & 2.14 & 113.50 & 1100 & 1360 & 1370 & 1040 \\
\hline & FDS-II & 2390 & $6: 15$ & 2.06 & 108.55 & 962 & 666 & 476 & 412 \\
\hline
\end{tabular}




\subsubsection{Simulating Real-Size Stores}

To investigate the burning characteristics of a real-size store, the FDS input data file that was used in simulating Phase I and II experiments was then used to simulate a real-size fire in a toy store (FDS-III). Fundamental equations were used to verify the simulation results due to the lack of reported data on burning characteristics of real size stores.

The simulated toy store was a corner store with floor area of $10 \times 10 \mathrm{~m}$ and $2.6-\mathrm{m}$ high, with two openings of $6 \times 2.6 \mathrm{~m}$ each. Combustibles with $0.5 \mathrm{~m}$ high were blocking the openings and causing the effective height to be $2.1 \mathrm{~m}$ high. The effective opening of $6 \times 2.1 \mathrm{~m}$ were kept open for the whole simulation. In the FDS input data file, the bounding surfaces were of normal weight concrete, and every one square meter of floor space was filled with a toy store fuel package (total of 100 fuel packages), Figure 187. The hot layer temperature for the simulation $\left(800\right.$ to $\left.1200^{\circ} \mathrm{C}\right)$, Figure 188 , compared well with the average gas temperature $\left(700\right.$ to $\left.1200^{\circ} \mathrm{C}\right)$ in an enclosure during the fullydeveloped fire as reported by Karlsson and Quintiere ${ }^{59}$. At the fully-developed stage, the simulated store resulted in a peak HRR of $50 \mathrm{MW}$. Karlsson and Quintiere ${ }^{59}$ used Equation 17 to calculate the absolute peak HRR (MW) based on the ventilation factor $A_{\circ} \sqrt{H_{\circ}}$. Using the equation to calculate the estimated the peak HRR, based on the configurations stated above, results in a peak HRR of $55.4 \mathrm{MW}$ that colleraates well with the value resulted from the simulation.

$H R R=1.518 A_{\circ} \sqrt{H_{0}}$ Equation 17

Where, $A_{0}=$ weighted average of all openings $\left(\mathrm{m}^{2}\right), H_{0}=$ weighted average of all openings height (m). 


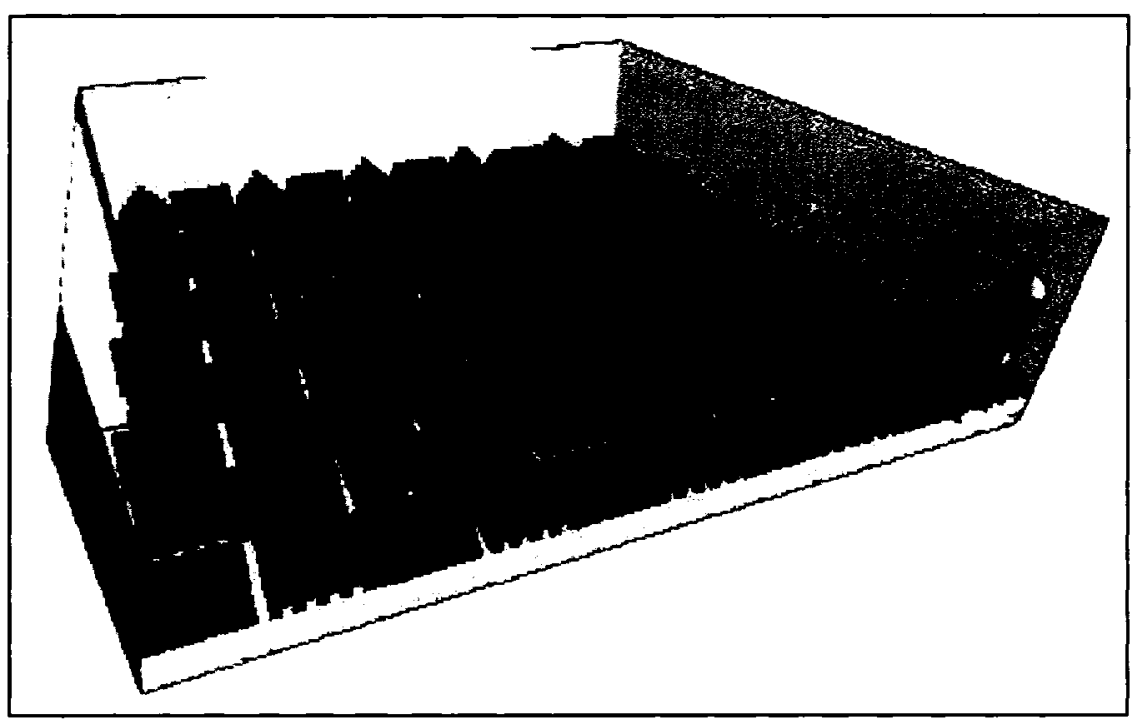

Figure $18710 \times 10 \mathrm{~m}$ toy store simulation, TOY-III

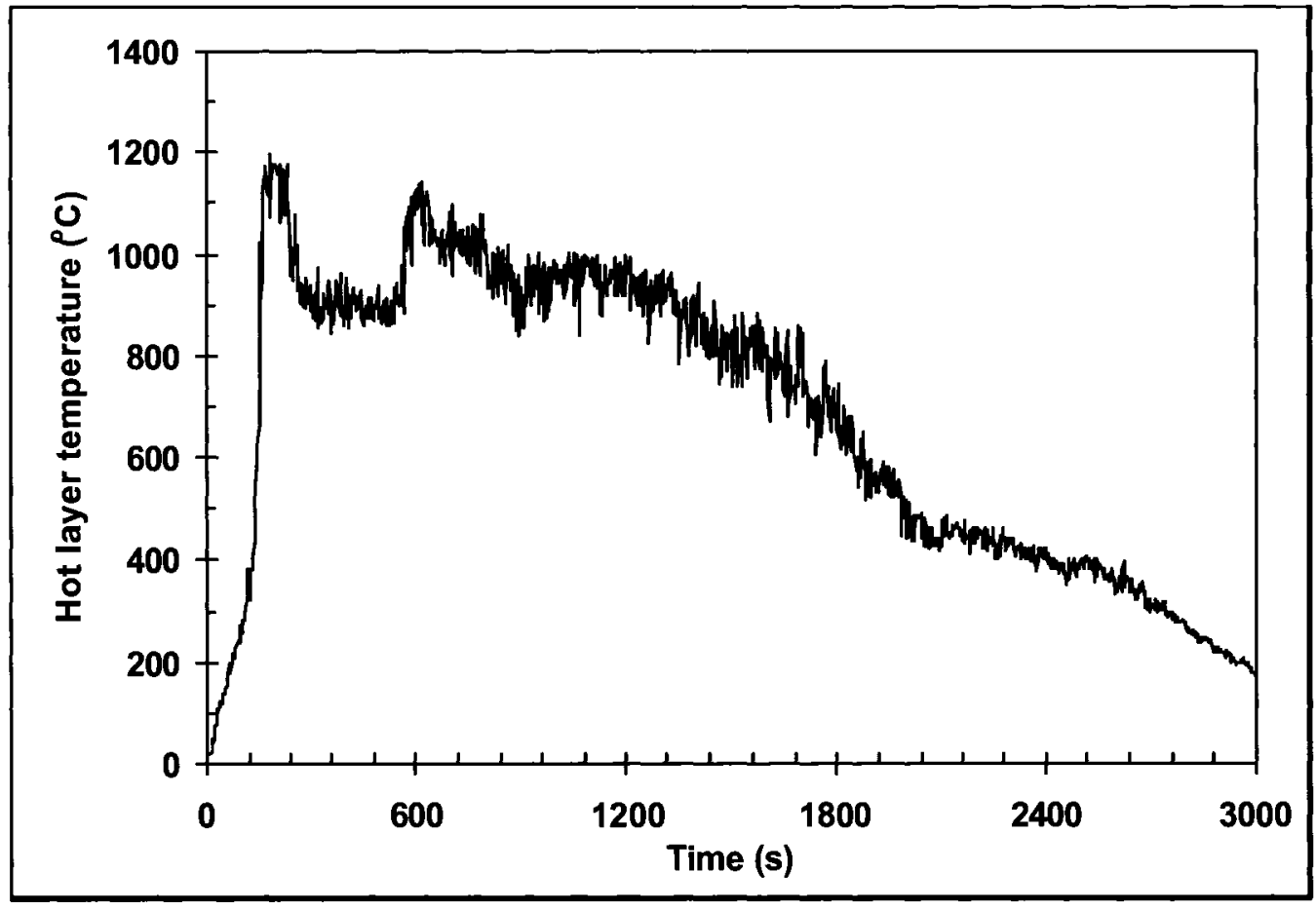

Figure 188. Hot layer temperature, simulation of real-size toy store 


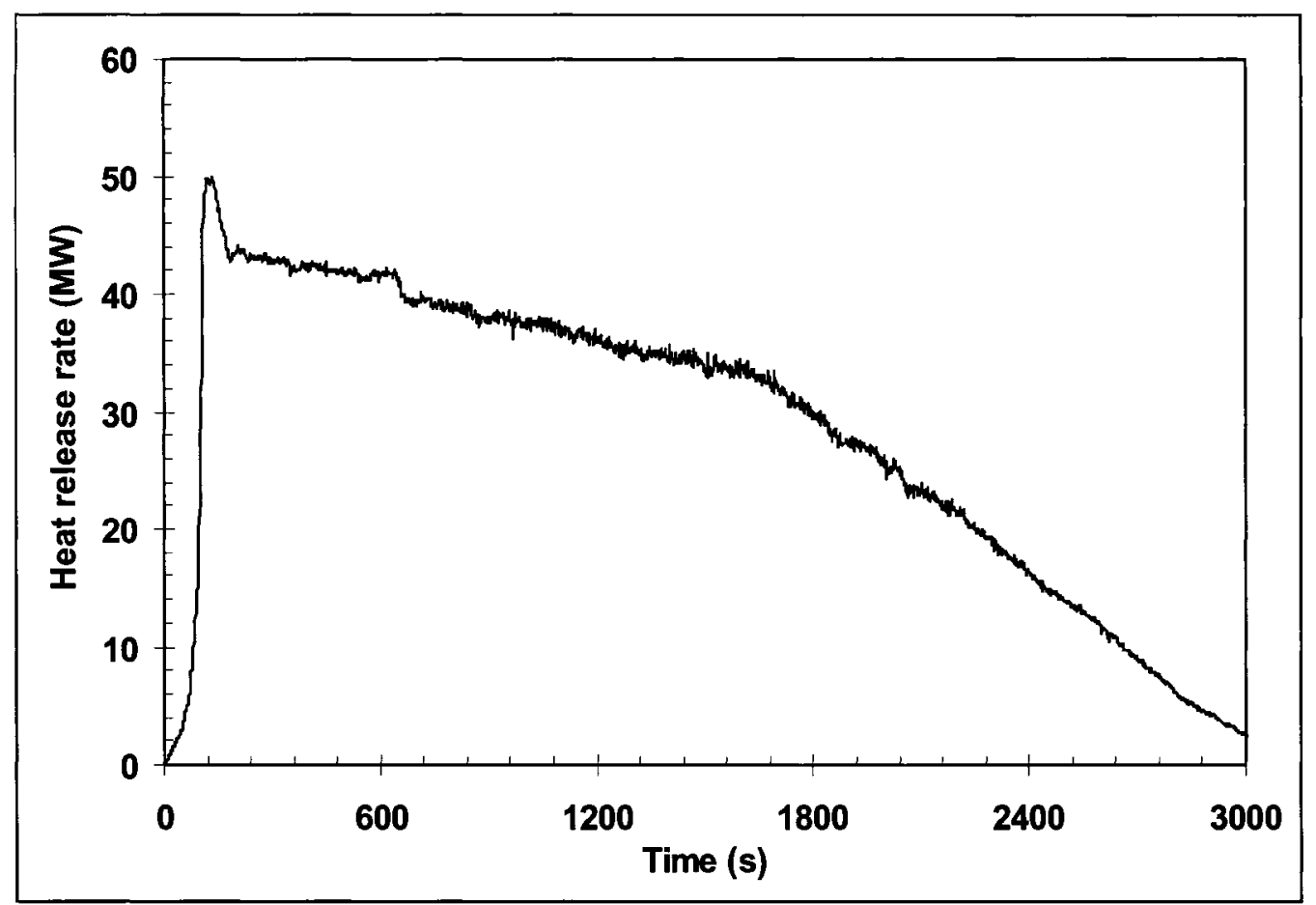

Figure 189 . Heat release rate, simulation of $10 \times 10 \mathrm{~m}$ toy store 


\subsubsection{Summary of Modelling Results}

The main parameters used to characterize design fires are the values of HRR, $\mathrm{CO}$ and $\mathrm{CO}_{2}$ production rates. Conducting experiments to measure these parameters is important. Nonetheless, full-scale fire experiments are expensive. To minimize the number of experiments, computer simulations are necessary. Although models might not always give accurate predictions, the results of validated models can be used with confidence in the design of fire protection systems.

In most simulations conducted in Phase II of this research, the model was able to simulate the overall HRR trend (peak HRR and time to peak HRR, developed and decay phases). For most simulations, the difference between the predicted peak HRR from modelling and the experimental peak HRR was less than $16 \%(88 \%$ to $104 \%)$ giving confidence in the model for use in predicting more complicated cases.

The production rates of carbon monoxide and carbon dioxide affect tenability. In all Phase II simulations, the model was quite capable of predicting the total $\mathrm{CO}$ and $\mathrm{CO}_{2}$ released during the fire experiments.

High gas temperatures resulting from fires have a negative effect on structures (wood, concrete, or steel), and reduce and/or destroy the integrity, insulation, and stability of different structural elements (walls, floors, and ceilings). The model was able to predict the hot layer temperature inside the burn room and, to some extent, in the corridor. 


\section{SUMMARY AND DEFINING DESIGN FIRES}

\subsection{Introduction}

The approach used in this research for defining appropriate design fires for commercial premises included the following tasks:

Building survey. Conduct a survey of commercial premises to collect data on (1) fire load density; (2) types of combustibles (plastics, wood, etc.); (3) arrangement of combustibles inside the stores; (4) compartment size and geometry; and (5) characteristics of ventilation openings.

Statistical analysis. Perform a statistical analysis of available data to determine the frequency of fires, ignition sources, and locations relevant for these premises.

Fuel package design and Phase I testing. Use survey data and statistical information to design fuel packages for these premises, to be tested in a medium-scale fire tests (Phase I). The objective of these tests was to determine the fire characteristics for the selected fuel packages, such as heat release rate, production rates of toxic gases, and hot layer temperature.

Modelling of Phase I. Based on information on fuel packages, develop input data files for the computational model FDS to simulate the characteristics of the fuel packages used in Phase I tests. Perform simulations and compare model predictions with experimental data. Modify fuel package characteristics used in the model to obtain results that compare favourably with the experimental data. 
Phase II testing. Perform selected large-scale tests to determine the burning characteristics of selected fuel packages in post-flashover fires

Modelling of Phase II. Using a modified version of the fuel package input data file determined from Phase I modelling, perform simulations using FDS to verify that the model can predict Phase II test results. This demonstrated the capability of FDS to simulate these fuel packages in different compartments, and the possibility of using it to simulate larger scale fires.

Design fire selection. Based on the results from all the above, define appropriate design fire characteristics to represent potential fires in commercial buildings. Design fires for each store reflects the experimental and modelling results from this research.

\subsection{Summary and Conclusions}

The main conclusions of this work are as follows:

The survey results demonstrated that there is a great variation among the fire load densities of different stores in commercial buildings. The highest fire load densities were found in bookstores, followed by shoe stores, storage areas, toy stores, fast food outlets, computer showrooms, and clothing stores. In most stores, the 95th percentile and the mean fire load density showed a tendency to decrease with an increase of floor area, which was consistent with those of earlier surveys.

Type of combustibles is an important characteristic of the fuel package representing a design fire. The survey was used to identify 9 fuel packages that represent the fire loads in commercial premises. The fuel packages represent the combustibles that exist in 
commercial premises in terms of: (1) the fire load per square meter for different kinds of stores; and (2) the combination of materials that might exist in these fuel packages (wood, plastics, textiles, etc.).

The key fire parameters that define a design fire include the heat release rate and gaseous products of combustion. Tests indicated that there was a vast difference in the combustion characteristics of the selected fuel packages.

Growth rates vary from: 'slow to medium' for a bookstore and a fast food outlet, 'medium to fast' for a computer showroom, clothing store, and shoe store, 'fast' for a storage area, and toy store. In most tests, the peak HRR occurred between 3.5 and 8 minutes after ignition.

When the amount of carbon monoxide and carbon dioxide produced from the experiments were released in the virtual average size room identified from the survey, all experiments produced visibility levels that would render the space untenable. Comparisons between FDS predictions and experimental data indicated that FDS was able to predict the HRR profile (excluding the growth rate), temperature profile in the burn room, and the total production of $\mathrm{CO}$, and $\mathrm{CO}_{2}$. Validated fire hazard models using medium- and large-scale tests provides a numerical tool, which can be used to predict the fire characteristics in actual full-size commercial premises. 


\subsection{Contribution}

The outcome of this research can be summarized as follows: (1) the collected data of the fire loads and contribution of different combustibles in commercial premises; (2) recommendation of 7-fuel packages and their burning characteristics to be used by fire protection designers; and (3) production of 7-fuel packages to be in FDS to simulate fires in commercial premises.

\subsection{Recommendations for Future Research}

While working on this research, especially in the last year, the author recognised that some research areas have to be extensively studied. These research areas are directly related to the work conducted in this research, such as (1) conducting surveys; (2) carrying out experimental research; (3) effective use of computer models; and (4) teaching 'how to carry on experimental research' in research centres and universities.

Conducting extended surveys: Even though a wide survey was conducted and the usefulness of the results has been demonstrated within this document, it is recommended that a general fire load survey be conducted, to include more stores in order to refine the results from the survey, and to include other types of stores usually found in shopping centres. The change in life style, and consequently the type of materials displayed in stores will change within time. Also, different countries and/or cultures have different life styles. It is recommended surveys be conducted periodically, for example, every 10 years to accommodate changes and stay up to date. Also surveys should be conducted in different countries. The extended survey can result in better refining the fuel packages summarized in this document and include further fuel packages. 
Conducting large fire tests: the research within this document was limited to experiments with a maximum of two square meters of combustibles. Fires in full-size commercial premises are difficult and costly to run in a real fire scenario. However, without conducting full-size experiments, results from numerical modelling are uncertain. Further validation of hazard assessment models is required. It is suggested that different research centres worldwide could collaborate, with one another, and with universities and shareholders to share the benefit from the results and the cost of conducting the full-size experiments.

Improve the simulation methods: It is rather simple to simulate fires when the heat release rate is well defined and is an 'input parameter' in the model input data file. However, it was a tedious task to simulate experimental results when the heat released from the fire is based on the ignition source and the ignition temperature, the heat of vaporization and the burning rate of the material. In addition, the surface area of combustibles is an important factor in the burning rate. To simulate the surface areas of thin combustibles, for example, an empty wooden shelf, one has to refine the grid to be a maximum $20 \mathrm{~mm}$ in the vertical and horizontal direction of that shelf. Refining the grid to this limit while simulating large compartments requires long labour hours and needs high computer capabilities. It is recommended that computer models be revised to better handle the calculation with fine grids. Until this happens, modellers are encouraged to use simplified fuel packages, such as the one used in this document, to better simulate fine objects in large computational domains.

As many stakeholders as possible, should be involved when defining design fires. These include the designers, the regulators, the authorities having jurisdiction, and the owners. 203 
The acceptance of the recommended design fires by the stakeholders will bring consistency in the engineering design of fire protection systems in commercial buildings.

In universities that offer fire safety or fire protection graduate programs, courses are usually taught in the areas of theoretical fire dynamics, fire-structures interaction, and modelling. On average, $50 \%$ of graduate students, especially at a doctoral level, will conduct experiments; it is then recommended that a course be offered that teaches the concepts of 'Conducting Experimental Fire Research'. 


\section{References}

1. SFPE. 2000. Engineering Guide to Performance-based Fire Protection, Analysis and Design of Buildings. Society of Fire Protection Engineers and National Fire Protection Association.

2. McGrattan, K. and G. Forney. 2005. Fire Dynamics Simulator (Version 4) User's Guide. 2005. U.S. Government Printing Office. Washington DC USA 20402 202512-1800. NIST Special Publication 1019.

3. ISO 9705. 1993. Fire tests-full-scale room test for surface products. International Organization for Standardisation, Genève, Switzerland.

4. Drysdale, D. 1998. An Introduction to Fire Dynamics. $2^{\text {nd }}$ edition. Chichester, U.K: John Wiley \& Sons.

5. ISO/TR 13387-2. 1998. Fire safety engineering- Part 2: Design fire scenarios and design fires. Technical report.

6. Chow, W.K., Zou, G., Dong, H., and Gaw, Y. 2003. Necessity of carrying out fullscale burning tests for post-flashover retail shop fires. International Journal on Engineering Performance-based Fire codes Vol. 5, No. 1, pp. 20-27.

7. Australian Building Codes Board. 2001. Fire Safety Engineering Guidelines. Australian Building Codes Board, Canberra.

8. NFPA 1. 2003. Uniform Fire Code, National Fire Protection Association.

9. Thomas, I., and Bennetts, I. 2004. The Development of Design Fires for Buildings. Fire Safety Engineering: Issues and Solutions, Sydney, Australia.

10. ASTM E119-05. 2005. Standard Test Methods for Fire Tests of Building Construction and Materials. ASTM International. Philadelphia, USA.

11. Underwriters' Laboratories of Canada. 1989. Standard Methods of Fire Endurance Tests of Building Construction and Materials. CAN/ULC-S101, Scarborough, Canada.

12. ISO 834-1. 1999. Fire-resistance Tests - Elements of Building Construction - Part 1: General Requirements. International Organisation for Standardization.

13. Heskestad, G. 1982. Engineering Relations for Fire Plumes. SFPE TR 82-8.

14. Evans, D.D. 1995. Ceiling jet flows. SFPE Handbook of Fire Protection Engineering. 2nd Edition. Section 2. Chapter 4, National Fire Protection Assoc., Quincy, MA, DiNenno, P. J.; Beyler, C. L.; Custer, R. L. P.; Walton, W. D., Editor(s), pp. 2/32-39.

15. Yung, D., Wade, C., and Fleischmann, C. 2004. Development of Design Fires for Buildings. Fire Safety Engineering: Issues and Solutions, Sydney, Australia.

16. Kumar, S., and Rao, C. V. S. K. 1997. Fire loads in office buildings. Journal of Structural Engineering, Vol. 123, No. 3 (March), pp. 365-368.

17. Buchanan, A.H. 2001. Fire Engineering Design Guide, 2001 edition. Center of Advanced Engineering, University of Canterbury, New Zealand.

18. Petterson, O. 1976. Fire Engineering Design of Steel Structures, Publication 50. Swedish Institute of Steel Construction, Stockholm, Sweden, pp 33-41. 
19. Yii, Y. W. 2000. Effect of Surface Area and Thickness on Fire Loads. Fire Engineering Research Report, 2000/13, ISSN 1173-5996. School of Engineering, University of Canterbury, Christchurch, New Zealand.

20. Thomas, P. H. 1986. Design Guide: Structure Fire Safety CIB W14 workshop report. Fire Safety Journal, Vol. 10, No. 2, pp. 77-137.

21. Narayanan, P. 1994. Fire Severities for Structural Fire Engineering Design. Study Report No. 67, Building Technology Ltd., BRANZ, Porirua, New Zealand.

22. Barnett, C. R. 1984. Pilot Fire Load Survey carried out for the New Zealand Fire Protection Association. MacDonald Barnett Partners, Auckland.

23. Bush, B., Anno, G., McCoy, R., Gaj, R., and Small, R. D. 1991. Fuel Loads in U.S. Cities. Fire Technology. Vol. 27, No. 1, pp 5-32.

24. Kumar, S., and Rao, C. V. S. K. 1995. Fire Load in Residential Buildings. Building and Environment, Vol. 30, No. 2, pp. 299-305.

25. Chow, W.K. 1995. Zone Model Simulation of Fires in Chinese Restaurants in Hong Kong. Journal of Fire Sciences, Vol. 13, No. 3, pp 235-253.

26. Bennetts, I. D., Poh, K. W., Poon, S. L., Thomas, I. R., Lee, A. C., Beever, P. F., Ramsay, G. C., and Timms, G. R. 2001. Fire Safety in Shopping Centres. Fire Code Reform Research Program, Project 6. Final Project Report and Supplement, Final Submission, June 2001.

27. Bennetts, I. D., Poh, K. W., Thomas, I. R., Lee, C, and Beever, F. 1996. Case Studies of Fires in Retail Buildings. FCRC Project 6, BHPR/SM/R/056, Broken Hill Proprietary Company, Ltd, Victoria, Australia.

28. Kawagoe, K., and Sekine, T. 1964. Estimation of Fire Temperature-time Curve in Rooms. B.R.I. Occasional report No. 17. Building Research Institute, Ministry of Construction, Tokyo.

29. Kawagoe, K. 1958. Fire Behaviour in Rooms. Report No. 27. Building Research Institute, Tokyo.

30. Thomas, P. H. 1961. Research on Fire Using Models. Institute of Fire Engineers Quart.

31. Buchanan, A. H. 1998. Modelling Post-Flashover Fires with FASTLite. Journal of Fire Protection Engineering, Vol. 9, No. 3, pp 1-11.

32. Buchanan, A. H. 1999. Structural Design for Fire. University of Canterbury, New Zealand.

33. Stroup, D.W., DeLauter, L., Lee, J., and Roadarmel, G. 2001. Fire Tests of Men's Suits on Racks. U.S. Department of Commerce, National Institute Of Standards And Technology, Gaithersburg, report of test FR 4013.

34. Janssens, M. L. 1991. Measuring Rate of Heat Release by Oxygen Consumption. Fire Technology, Vol. 27, pp. 234-249.

35. Bennett, I.D., Culton, M., Dickerson, M.L., Lewins, R., Poh, K.W., Peon, S.L., Ralph, R., Lee; C., Beever, F. Cooper, J., Haggar, P.I., Moore, I.P., Ramsay, G.C., Timms, G.R. 1997. Simulated Shopping Centre Fire Tests. FCRC Project 6, BHPR/SM/R/G/062, Broken Hill Proprietary Company, Ltd, VIC, Australia.

36. Law, M., and Arnault, P. 1972. Fire Loads, Natural Fires and Standard Fires. Technical Committee No. 8, Fire and Blast, State of Art Report No. 1, pp 475-490. 
37. Thornton, W. 1917. The Relation of Oxygen to the Heat of Combustion of Organic Compounds. Philosophical Magazine and J. of Science.

38. Huggett, C. 1980. Estimation of the Rate of Heat Release by means of Oxygen Consumption. Journal of Fire and Flammability. pp. 61-65.

39. Kumar, S., and Rao, C.V.S.K. 1995. Fire load in residential buildings. Building and Environment, Vol. 30, No. 2, pp. 299-305.

40. Microsoft Corporation. 2000. Microsoft Office Online. Retrieved Feb. 26, 2006 from World Wide Web: http://office.microsoft.com/enca/assistance/HP052092111033.aspx.

41. Borghers, E. and Wessa, P. 2006. Statistics - Econometrics - Forecasting. Office for Research Development and Education. Retrieved February 26, 2006 from World Wide Web: http://www.xycoon.com/method_8.htm.

42. Weisstein, E.W. 2006. Kolmogorov-Smirnov Test. Retrieved January 24, 2006 from World Wide Web:http://mathworld.wolfram.com/Kolmogorov-SmirnovTest.html.

43. EasyFit. 2005. MathWave Technologies. Distribution fitting program. Retrieved Oct 28, 2005 from World Wide Web: http://www.mathwave.com.

44. Venables, W. N. and Smith, D. M. 2005. An Introduction to R. ISBN 3-900051-12-7, Version 2.2.0.

45. Venables, W. N. and Ripley, B. D. 2002. Modern Applied Statistics with S. $4^{\text {th }}$ edition. Springer, 2002. ISBN 0-387-95457-0.

46. Hadjisophocleous, G., and Zalok, E. 2003. A Survey of Fire Loads in Commercial Premises, 4th International Seminar on Fire and Explosion Hazards, Northern Ireland.

47. Hadjisophocleous, G., and Zalok, E. 2004. Development of Design Fires for Commercial Buildings. Fire Safety Engineering: Issues and Solutions FSE 2004, Sydney, Australia.

48. Hadjisophocleous, G., and Zalok, E. 2004 Fire Loads And Design Fires For Commercial Buildings. Interflam 2004, Scotland, UK.

49. International Council for Research and Innovation in Building and Construction CIB. 1983. A conceptual approach towards a probability based design guide on structural fire safety. CIB W14 Workshop Report.

50. Tewarson, A. 2002. Generation of Heat and Chemical Compounds in Fire. The SFPE Handbook of Fire Protection Engineering. Quincy, MA: National Fire Protection Association.

51. Lougheed, G.D.; McCartney, C.; Kanabus-Kaminska, M. 2004a. Initial investigations on plenum cable fires. ASHRAE Transactions, Vol. 108, pt. 1, 2002, pp. 712-723

52. Lougheed, G.D., McCartney, C. and Kanabus-Kaminska, M. 2004b, Cable Fires in Plenums: Full-Scale Fire Tests. ASHRAE Transactions, 110, pt. 1, pp. 652-665.

53. Klote, J.H. and Milke, J.A. 2002. Principles of Smoke Management, American Society of Heating. Refrigerating and Air-Conditioning Engineers.

54. Purser, D. 2002. Toxicity Assessment of Combustion Products. The SFPE Handbook of Fire Protection Engineering. Quincy, MA: National Fire Protection Association. 
55. McGrattan, K. 2004. Fire Dynamics Simulator (Version 4) Technical Reference Guide. U.S. Government Printing Office. Washington DC USA 20402 202-5121800. NIST Special Publication 1018.

56. Reid, R., Prausnitz, J., and Sherwood, T. 1973. The Properties of Gases and Liquids. McGraw-Hill, $3^{\text {rd }}$ edition, New York, p. 193.

57. Bounagui, A., Benichou, N., McCartney, C., and Kashef, A. 2003. Optimizing the Grid Size used in CFD Simulations to evaluate Fire Safety in Houses. In 3rd NRC Symposium on Computational Fluid Dynamics, High Performance Computing and Virtual Reality, Ottawa, Ontario, Canada, December 2003. National Research Council, Canada.

58. Ma, T.G., and Quintiere, J.G. 2003. Numerical simulation of axi-symmetric fire plumes: accuracy and limitations. Fire Safety Journal 38, pp. 467-492.

59. Karlsson, B. and Quintiere, J.G. 2000. Enclosure Fire Dynamics. CRC Press, Boca Raton, FL.

60. Babrauskas, V. 1995. The SFPE Handbook of Fire Protection Engineering. Society of Fire Protection Engineers, $2^{\text {nd }}$ edition.

61. Lawson, R. J., Walton, D.W., and Twilley, W. H. 1984. Fire performance of as measured in the NBS calorimeter. Part I. U.S. Department Of Commerce, National Bureau of Standards, National Engineering Laboratory, Center for Fire Research, Washington, DC 20234. 


\begin{tabular}{|c|c|c|c|c|c|c|c|}
\hline MATERIAL & 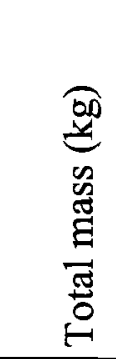 & 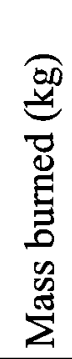 & 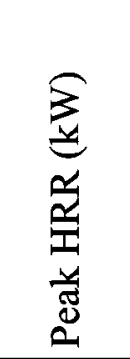 & 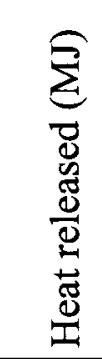 & 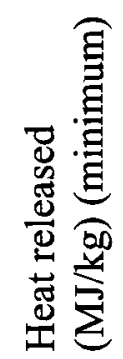 & 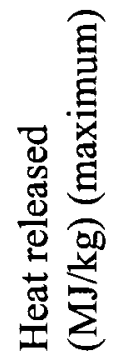 & 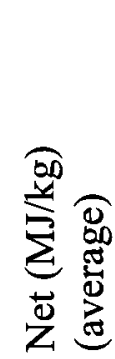 \\
\hline \multicolumn{8}{|l|}{ SOLIDS } \\
\hline Anthracite $^{20}$ & & & & & 31.0 & 36.0 & 33.5 \\
\hline Asphalt ${ }^{20}$ & & & & & 40.0 & 42.0 & 41.0 \\
\hline Bitumen $^{20}$ & & & & & 41.0 & 43.0 & 42.0 \\
\hline Bread $^{19}$ & & & & & & & 10.0 \\
\hline Cellulose $^{20}$ & & & & & 15.0 & 18.0 & 16.5 \\
\hline Charcoal $^{20}$ & & & & & 34.0 & 35.0 & 34.5 \\
\hline Christmas tree (dry $)^{60}$ & 7.0 & & 650.0 & 41.0 & & & \\
\hline Christmas tree (dry) ${ }^{60}$ & 7.4 & & 500.0 & 30.0 & & & \\
\hline Christmas tree (green) ${ }^{60}$ & 6.5 & & 69.0 & 11.0 & & & \\
\hline Textiles $^{20}$ & & & & & 17.0 & 21.0 & 19.0 \\
\hline Coal, Coke ${ }^{20}$ & & & & & 28.0 & 34.0 & 31.0 \\
\hline Cork $^{20}$ & & & & & 26.0 & 31.0 & 28.5 \\
\hline Cotton $^{20}$ & & & & & 16.0 & 20.0 & 18.0 \\
\hline Flour $^{19}$ & & & & & & & 15.0 \\
\hline Foam rubber ${ }^{20}$ & & & & & 34.0 & 40.0 & 37.0 \\
\hline Grain $^{20}$ & & & & & 16.0 & 18.0 & 17.0 \\
\hline Grease $^{20}$ & & & & & 40.0 & 42.0 & 41.0 \\
\hline Kitchen refuse ${ }^{20}$ & & & & & 8.0 & 21.0 & 14.5 \\
\hline Leather $^{20}$ & & & & & 18.0 & 20.0 & 19.0 \\
\hline Linoleum $^{20}$ & & & & & 19.0 & 21.0 & 20.0 \\
\hline Meat $^{19}$ & & & & & & & 10.0 \\
\hline Paper, Cardboard ${ }^{20}$ & & & & & 13.0 & 21.0 & 17.0 \\
\hline Paraffin wax ${ }^{20}$ & & & & & 46.0 & 47.0 & 46.5 \\
\hline Particle board (chipboar & oard) ${ }^{20}$ & & & & 17.0 & 18.0 & 17.5 \\
\hline Plastics, $\mathrm{ABS}^{20}$ & & & & & 34.0 & 40.0 & 37.0 \\
\hline Plastics, Acrylic ${ }^{20}$ & & & & & 27.0 & 29.0 & 28.0 \\
\hline Plastics, Celluloid $^{20}$ & & & & & 17.0 & 20.0 & 18.5 \\
\hline Plastics, Epoxy ${ }^{20}$ & & & & & 33.0 & 34.0 & 33.5 \\
\hline Plastics, Melamine resin & & & & & & & 19.0 \\
\hline Plastics, Petroleum ${ }^{20}$ & & & & & 40.0 & 42.0 & 41.0 \\
\hline Plastics, Phenolformalde & & & & & 27.0 & 30.0 & 28.5 \\
\hline Plastics, Polycarbonate ${ }^{20}$ & & & & & 28.0 & 30.0 & 29.0 \\
\hline
\end{tabular}




\begin{tabular}{|c|c|c|c|c|c|c|c|}
\hline MATERIAL & 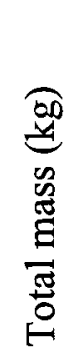 & 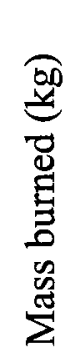 & 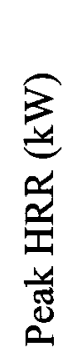 & 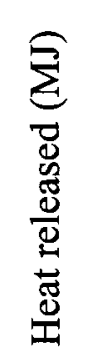 & 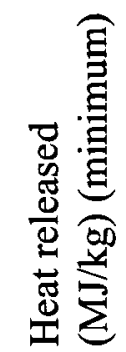 & 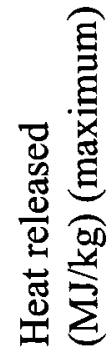 & 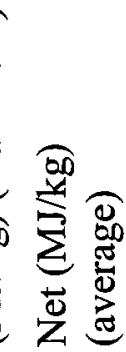 \\
\hline Plastics, Polyethylene ${ }^{20}$ & & & & & 43.0 & 44.0 & 43.5 \\
\hline Plastics, Polyisocyanurate foam ${ }^{20}$ & & & & & 22.0 & 26.0 & 24.0 \\
\hline Plastics, Polypropylene $\mathrm{e}^{20}$ & & & & & 42.0 & 43.0 & 42.5 \\
\hline Plastics, Polyster ${ }^{20}$ & & & & & 30.0 & 31.0 & 30.5 \\
\hline Plastics, Polyster, fibre reinforced ${ }^{20}$ & & & & & 20.0 & 22.0 & 21.0 \\
\hline Plastics, Polystyrene ${ }^{20}$ & & & & & 39.0 & 40.0 & 39.5 \\
\hline Plastics, Polytetrafluorethylene ${ }^{20}$ & & & & & & & 5.0 \\
\hline Plastics, Polyurethane ${ }^{20}$ & & & & & 22.0 & 24.0 & 23.0 \\
\hline Plastics, Polyurethane foam ${ }^{20}$ & & & & & 23.0 & 28.0 & 25.5 \\
\hline Plastics, Polyvinylchloride ${ }^{20}$ & & & & & 16.0 & 17.0 & 16.5 \\
\hline Plastics, Ureaformaldehyde ${ }^{20}$ & & & & & 14.0 & 15.0 & 14.5 \\
\hline Plastics, Ureaformaldehyde foam ${ }^{20}$ & & & & & 12.0 & 15.0 & 13.5 \\
\hline Rice $^{19}$ & & & & & & & 15.0 \\
\hline Rubber isoprene ${ }^{20}$ & & & & & 44.0 & 45.0 & 44.5 \\
\hline Rubber tire $^{20}$ & & & & & 31.0 & 33.0 & 32.0 \\
\hline Silk $^{20}$ & & & & & 17.0 & 21.0 & 19.0 \\
\hline Straw $^{20}$ & & & & & 15.0 & 16.0 & 15.5 \\
\hline Sugar $^{19}$ & & & & & & & 15.0 \\
\hline Wood $^{4}$ & & & & & 18.0 & 19.5 & 18.75 \\
\hline Wood $^{20}$ & & & & & 17.0 & 20.0 & 18.5 \\
\hline Wool $^{20}$ & & & & & 21.0 & 26.0 & 23.5 \\
\hline \multicolumn{8}{|l|}{ LIQUIDS } \\
\hline$\overline{\text { Alcohol, drink }}^{19}$ & & & & & & & 38.0 \\
\hline Benzene $^{20}$ & & & & & & & 40.1 \\
\hline Benzyl Alcohol ${ }^{20}$ & & & & & & & 32.9 \\
\hline Ethyl Alcohol ${ }^{20}$ & & & & & & & 26.9 \\
\hline Gasoline $^{20}$ & & & & & 43.0 & 45.0 & 44.0 \\
\hline Isopropyl Alcohol $^{20}$ & & & & & & & 31.4 \\
\hline Methanol $^{20}$ & & & & & 19.0 & 21.0 & 20.0 \\
\hline Oil, Diesel oil ${ }^{20}$ & & & & & 40.0 & 43.0 & 41.5 \\
\hline Oil, Linseed oil ${ }^{20}$ & & & & & 38.0 & 41.0 & 39.5 \\
\hline Oil, Cooking ${ }^{19}$ & & & & & & & 42.0 \\
\hline Oil, Paraffin oil ${ }^{20}$ & & & & & 40.0 & 43.0 & 41.5 \\
\hline Spirits $^{20}$ & & & & & 26.0 & 29.0 & 27.5 \\
\hline $\operatorname{Tar}^{20}$ & & & & & 37.0 & 39.0 & 38.0 \\
\hline \multicolumn{8}{|l|}{ GASES } \\
\hline Acetylene $^{20}$ & & & & & & & 48.2 \\
\hline Butane $^{20}$ & & & & & & & 45.7 \\
\hline
\end{tabular}




\begin{tabular}{|c|c|c|c|c|c|c|c|}
\hline MATERIAL & 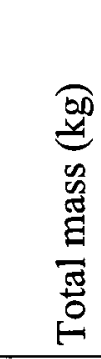 & 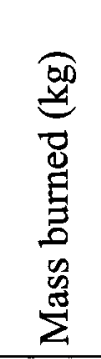 & 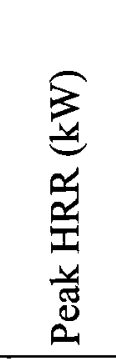 & 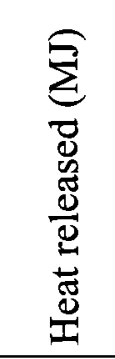 & 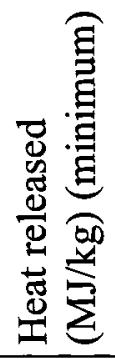 & 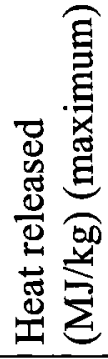 & 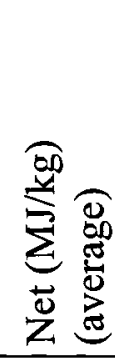 \\
\hline Carbon monoxide $^{20}$ & & & & & & & 10.1 \\
\hline Hydrogen ${ }^{20}$ & & & & & & & 119.7 \\
\hline Propane $^{20}$ & & & & & & & 45.8 \\
\hline Methane $^{20}$ & & & & & & & 50.0 \\
\hline Ethanol $^{20}$ & & & & & & & 26.8 \\
\hline \multicolumn{8}{|l|}{ OBJECTS } \\
\hline Sofa ${ }^{61}$ & & & & & & & 18.9 \\
\hline TV set, 24 inches $^{60}$ & 32.7 & 10.2 & 230.0 & 146.0 & & & 14.0 \\
\hline TV set ${ }^{60}$ & 27.2 & 5.8 & 120.0 & & & & \\
\hline TV set, 36 inches ${ }^{60}$ & 39.8 & 10.2 & 290.0 & 150.0 & & & 15.0 \\
\hline
\end{tabular}




\section{Appendix B}

\section{ASSUMPTIONS MADE IN CALCULATING FIRE LOADS}

1. Carpets assumed to be textiles with density $1 \mathrm{~kg} / \mathrm{m}^{2}$

2. Vinyl identified as Linoleum with density $1 \mathrm{~kg} / \mathrm{m}^{2}$

3. MDF considered to be wood

4. Cardboard, magazines, and paper have the same heat of combustion $(17 \mathrm{MJ} / \mathrm{kg})$

5. Sofa- average weight of $25 \mathrm{~kg}$ and average heat released of $18.9 \mathrm{MJ} / \mathrm{kg}$

6. Cosmetic sprayers, lotions, shampoos, and detergents calorific values are set to zero

7. Fridge contains $10 \mathrm{~kg}$ of plastics

8. Hairdryer contains $1.5 \mathrm{~kg}$ of plastics

9. Microwave contains $1.0 \mathrm{~kg}$ of plastics

10. Washing machine contains $5.0 \mathrm{~kg}$ of plastics

11. Chair (wood) contains $4 \mathrm{~kg}$ of wood

12. Chair (office) contains $7 \mathrm{~kg}$ of wood

13. Chair (long) contains $10 \mathrm{~kg}$ of wood

14. Cigarette boxes contains $0.3 \mathrm{~kg}$ of cellulose

15. Potato chips bags, $43 \mathrm{~g}$, Calories $=150 \mathrm{cal} / 28 \mathrm{~g}$

16. Copy machine contains $10 \mathrm{~kg}$ of plastics

17. Coffee maker contains $1 \mathrm{~kg}$ of plastics

18. Computer contains $3 \mathrm{~kg}$ of plastics

19. Printer or fax contains $3 \mathrm{~kg}$ of plastics

20. Alcohol - $15 \%$ by vol. as average for beer, wines, and spirits

21. Computer ink toner contains $3 \mathrm{~kg}$ of plastics

22. Tanning machine contains $20 \mathrm{~kg}$ of plastics

23. Fan contains $1 \mathrm{~kg}$ of plastics

24. Vacuum cleaner contains $3 \mathrm{~kg}$ of plastics

25. Perfume contains $30 \%$ alcohol by volume

Typically, polyethylene plastics were used when calculating fire loads in this research. 


\section{Appendix C}

\section{FDS INPUT DATA CHARACTERISTICS}

The FDS input file consists of many command lines to characterize the fire compartment and the combustibles. FDS has good capabilities for simulating simple pool fires, as well as complex situations such as intervention of sprinkler and vents, etc. The characteristics of the problem are described in FDS $^{2}$ using different 'namelists'. Details of these characteristics (namelist) that were used in this research are explained below, as well as the rationale behind certain choices and their values.

\section{Naming the Job: The HEAD Namelist Group}

The namelist group HEAD contains two parameters (1) CHID is a character string of 30 characters or less used to tag output files with a given character string; and (2) TITLE is a character string of 60 characters or less that describes the problem. Example of a job that simulated the storage area test of Phase II, would read:

\&HEAD CHID='SA-II', TITLE='Storage area, Phase II' /

\section{The Numerical Grid: Computational Domain (PDIM) and Grid Size (GRID)}

All FDS calculations must be performed within a domain that is made up of rectangular meshes, each with its own rectilinear grid. All obstructions, vents, etc. are forced to conform with the numerical grid(s). To establish the computational domain grid, first the overall physical dimensions of the rectangular grid is specified via the PDIM namelist group. Second, the number of grid cells spanning each coordinate direction is specified 
via the GRID namelist group. The origin of the domain is the point (XBARO, YBARO, ZBAR0), and the opposite corner of the domain is at the point (XBAR, YBAR, ZBAR) in units of meters. The domain is subdivided uniformly to form a grid of IBAR by JBAR by KBAR cells specified by the GRID namelist group. The following example defines the physical computational domain of a burn room of dimensions $3.6 \mathrm{~m}$ length by $2.7 \mathrm{~m}$ width by $2.4 \mathrm{~m}$ high, which is connected to a corridor $1.4 \mathrm{~m}$ width by $11.0 \mathrm{~m}$ long by $2.6 \mathrm{~m}$ high. The grid size for the room is $0.10 \times 0.10 \mathrm{x}$ $0.10 \mathrm{~m}$ and $0.233 \times 0.220 \times 0.216 \mathrm{~m}$ for the corridor. The grid size was smaller inside the room to capture the higher variable parameters expected to occur in the room.

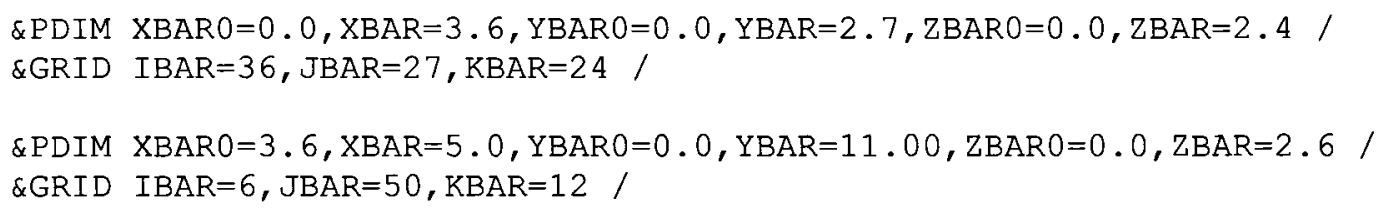

\section{Creating Voids and Designating Vents Surfaces: The VENT\&HOLE Group}

Used to create a door in an existing obstruction or carve a hole in the obstruction. For example, to open a door of $0.9 \times 2.2 \mathrm{~m}$ in the burn room leading to the corridor, add line of the form:

\&HOLE XB=3.59,3.61,1.0,1.9,0.0,2.2/

The extra centimetre ( 3.59 and 3.61) added to the $x$ coordinates of the hole (3.6) make it clear that the hole is to punch through the entire obstruction.

The VENT group is used to prescribe planes adjacent to obstructions or external walls. The vents are chosen in a similar manner to the obstructions, with the sextuplet $\mathrm{XB}$ denoting a plane abutting a solid surface. In this example, it is used to open a door from 
the corridor to the outside $(1.4 \times 2.6 \mathrm{~m})$. A HOLE cannot be used on a VENT or a mesh boundary.

\&VENT XB=3.6,5.0,11.0,11.0,0.0,2.6,SURE_ID="OPEN" /

\section{The MISC Namelist Group}

MISC is the namelist group of miscellaneous input parameters. Only one MISC line should be entered in the data file. The most important parameter in this category is the one that determines whether a Large Eddy Simulation (LES) calculation is to be performed, or whether a Direct Numerical Simulation (DNS) is to be performed. By default, an LES calculation is performed. In the following example, the parameter REACTION= 'SA_GAS' means that the combustion stoichiometry is for a particular gas produced from a storage area test, this was used to establish that the burning characteristics of the gas phase have properties close, but not identical to some of the well defined gases. This was done to be able to produce the amount of $\mathrm{CO}$ and $\mathrm{CO}_{2}$ produced from the test. SURF_DEFAULT='GYPSUM BOARD' establishes that all bounding surfaces are to be made of GYPSUM BOARD, unless otherwise indicated. In Phase II experiments, all walls were lined with a ceramic fibre material, and a modified GYPSUM BOARD was used. In Phase I experiments, the room surfaces were constructed of concrete, and the SURF_DEFAULT='CONCRETE' was used. NFRAMES parameter is the default number of output dumps per calculation for HRR, thermocouple, and smoke products data (e.g., 900 frames). TMPA parameter defines the ambient temperature in degrees Celsius (e.g., $20^{\circ} \mathrm{C}$ ), and the TMPO parameter defines the temperature outside the computational domain, in degrees Celsius (e.g., $20^{\circ} \mathrm{C}$ ). In this modeling work, it was 
assumed that shopping centres are air-conditioned and will maintain a temperature of $20^{\circ} \mathrm{C}$ all year long.

\&MISC REACTION='SA_GAS', SURF_DEFAULT= ' INERT ', NFRAMES=900, TMPA $=20 .$, $\mathrm{TMPO}=20$. /

\section{Setting Time Limits: The TIME Namelist Group}

TIME is the name of a group of parameters defining the time duration of the simulation and the initial time step used to advance the solution of the discretized equations. Usually, only the duration of the simulation is required on this line, via the parameter TWFIN (Time When FINished). In the example below the required simulation time is $1800 \mathrm{~s}$.

\&TIME TWEIN=1800. /

\section{Static Data Dumps: The PL3D Namelist Group}

PL3D is the namelist group that defines how often and what quantities are to be output into files of Plot3D format. At most one PL3D line should be listed in the input file. For the example below, five quantities are written out to a file at one instant in time every $\operatorname{DTSAM}(\mathrm{s})$; these quantities are the temperature $\left({ }^{\circ} \mathrm{C}\right)$, heat release rate per unit volume $\left(\mathrm{kW} / \mathrm{m}^{3}\right), \mathrm{O}_{2}, \mathrm{CO}_{2}$, and $\mathrm{CO}$ concentrations $(\mathrm{mol} / \mathrm{mol})$.

\&PL3D DTSAM=2 .0, QUANTITIES=' TEMPERATURE' , 'HRRPUV' , ' oxygen' , ' carbon dioxide', 'carbon monoxide' / 


\section{Point Measurements: The THCP Namelist Group}

THCP is the name of a group of parameters that can be used to record values of various quantities at a point as a function of time, much like a thermocouple or other point measurement. Each THCP line consists of the coordinates of the point at which the measurement is to be recorded, XYZ, and a quantity to record, QUANTITY. For example, the following line is used to record the THERMOCOUPLE temperature of a thermocouple placed inside the burn room at the following location $(X Y Z=3.3,0.3,2.1)$, and labeled $L A B E L=$ 'Room $T C$ @2. $1 \mathrm{~m}^{\prime}$. The temperature at the thermocouple will then be recorded in an output file every $\mathrm{DTSAM}=2.0$ (s) as described in the \&PL3D namelist group.

\&THCP XYZ=3.3,0.3,2.1, QUANTITY= 'THERMOCOUPLE' , LABEL=' ROOM TC @ $2.1 \mathrm{~m}$ ' /

\section{Creating Obstructions: The OBST Namelist Group}

OBST is the namelist group listing information about obstructions. Each OBST line contains the coordinates of a rectangular solid within the flow domain. This solid is defined by two points $(\mathrm{X} 1, \mathrm{Y} 1, \mathrm{Z} 1)$ and $(\mathrm{X} 2, \mathrm{Y} 2, \mathrm{Z} 2)$ that are entered on the OBST line in terms of the sextuplet $\mathrm{XB}=\mathrm{X} 1, \mathrm{X} 2, \mathrm{Y} 1, \mathrm{Y} 2, \mathrm{Z} 1, \mathrm{Z} 2$. In this example, the obstruction has different boundary conditions for its top, sides and bottom, and thus SURF_IDS is used as an array of three character strings specifying the boundary condition IDs. The following OBST line, means that there is an obstacle that has the coordinates $(0.20,1.20,1.60,2.10,0.20,0.30)$ and its upper surface is a BURNER where all other surfaces area of INERT. A colour WHITE is given to the obstacle. 
$\mathrm{XB}=0.20,1.20,1.60,2.10,0.20,0.30, \mathrm{SURF}$ IDS= 'BURNER' , 'INERT' , 'INERT' , COLOR='WHITE' /

The burner size, position, and its surface IDs details are explained above, to completely identify the heat release rate per unit area of the burner $\left(\mathrm{kW} / \mathrm{m}^{2}\right)$ the parameter HRRPUA $=400$ was added to the SURF ID='BURNER' . In the example below the character string RAMP_Q $=$ 'HRRvalue' was used to ramp the heat release rate value HRRvalue from zero at $0 \mathrm{~s}$, to full $400\left(\mathrm{~kW} / \mathrm{m}^{2}\right)$ at $1 \mathrm{~s}$, and continue at the same value up till $360 \mathrm{~s}$, then shut down the fire at $361 \mathrm{~s}$.

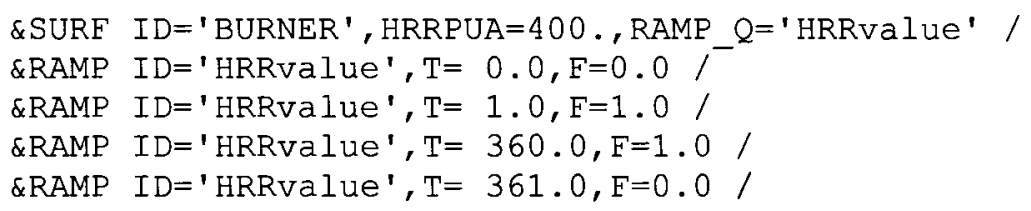

In the input file the combustible materials were expressed as number of rectangular sticks that are placed in a trapezoidal geometry, this geometry was of a great help to simulate the one peak HRR profile that resulted in most Phase I and Phase II experiments. Every crib has a dimension of $0.1 \times 0.1 \times 1.0 \mathrm{~m}$. The total number of rectangular sticks, the number of rectangular sticks per row, and the number of rows vary according to the simulated test. Also, the material properties varied according the simulated test. In the example below, 6 rectangular sticks are arranged in a trapezoidal setting, the first row has 3 rectangular sticks, the second has 2 rectangular sticks and the third has $1 \mathrm{crib}$. The SURF_ID=' SA ' is of a storage area, and assigned the colour green. 
\&OBST XB=0.50,0.60,0.40,1.40,0.70,0.80,SURF_ID='SA', COLOR='GREEN' /

\&OBST XB $=0.70,0.80,0.40,1.40,0.70,0.80$, SURF_ID $^{\prime}$ 'SA', COLOR='GREEN' $/$

\&OBST XB=0.60,0.70,0.40,1.40,0.80,0.90, SURF_ID='SA' , COLOR='GREEN' /

\section{Prescribing Boundary Conditions: The SURF Namelist Group}

SURF is the namelist group that defines boundary conditions for all solid surfaces or openings within or bounding the flow domain. While, the physical coordinates of obstructions are listed in the OBST namelist group, boundary conditions for the obstructions are prescribed by referencing the appropriate SURF line(s). In FDS, a fire is basically modeled as the ejection of pyrolyzed fuel from a solid surface that burns when mixed with oxygen. To model a fire, either a heat release rate per unit area or a heat of vaporization at the fuel surface is specified. In all Phase I and Phase II experiments, the fires were generated based on heat of vaporization and flame spread, and not the direct identification of the HRR per unit area. The stoichiometry of the reaction is set by the parameter REACTION on the MISC line. In the SURF line different material properties are listed, such as (1) heat of vaporization (HEAT _OF_VAPORIZATION) (kJ/kg); (2) heat of combustion (HEAT_OF_COMBUSTION) (kJ/kg); (3) maximum burning rate (BURNING_RATE_MAX) $\left(\mathrm{kJ} / \mathrm{m}^{2} / \mathrm{s}\right)$; (4) material thickness DELTA (m); (5) thermal conductivity KS (W/m.K); (6) specific heat C_P $(\mathrm{kJ} / \mathrm{kg} / \mathrm{K})$; (7) DENSITY $\left(\mathrm{kg} / \mathrm{m}^{3}\right)$; (8) insulation condition BACKING; and (9) ignition temperature $\left({ }^{\circ} \mathrm{C}\right)$. These parameters were used to simulate the HRR from experiments. Below is an example of a surface line for one of the materials used in conducting the modeling. 


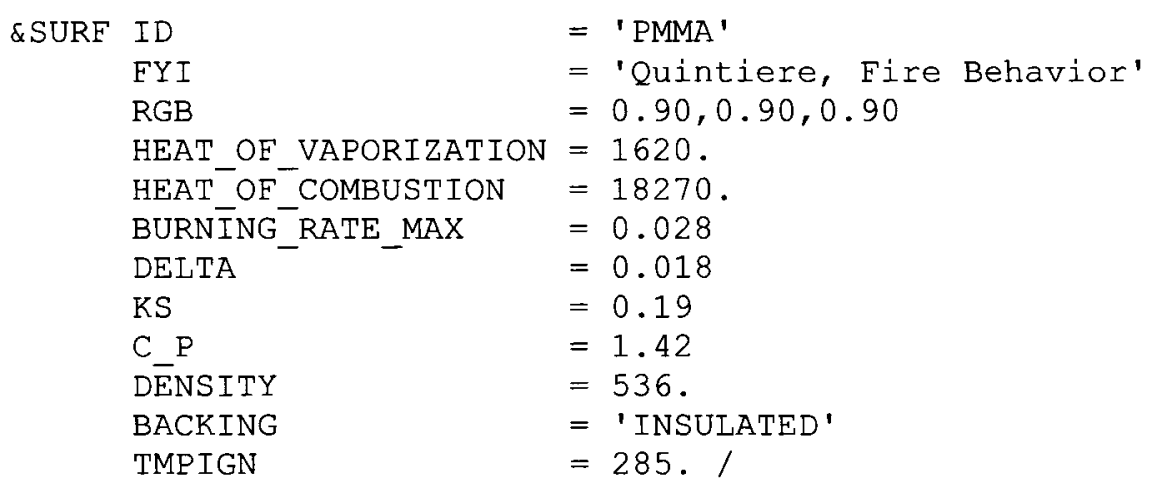

10. Combustion Parameters: The REAC Namelist Group

In all Phase I and II experiments, fires were simulated by prescribing the heat of vaporization, where the burning rate of the fuel depends on the net heat feedback to the surface, and the mixture fraction combustion model was used. The REAC line was used for various parameters associated with the gas phase reaction of fuel and oxygen. It was assumed that a single hydrocarbon fuel was being burned,

$\mathrm{C}_{X} \mathrm{H}_{\mathrm{Y}} \mathrm{O}_{\mathrm{Z}}+v_{\mathrm{O}_{2}} \mathrm{O}_{2} \rightarrow v_{\mathrm{CO}_{2}} \mathrm{CO}_{2}+v_{\mathrm{H}_{2} \mathrm{O}} \mathrm{H}_{2} \mathrm{O}+v_{\mathrm{CO}} \mathrm{CO}+v_{\text {Soot }}$ Soot $\quad$ Equation 18

The above equation specifies the ideal stoichiometric coefficients for the fuel, $\mathrm{O}_{2}, \mathrm{CO}_{2}$, and $\mathrm{H}_{2} \mathrm{O}$, and yields for $\mathrm{CO}$ and soot. Most often, one selects a reaction from the FDS DATABASE via the REACTION parameter on the MISC line. However in this modeling work, no specific hydrocarbon was used, the stoichiometric coefficients were another key variables in order to yield the required amount of smoke $\left(\mathrm{CO}, \mathrm{CO}_{2}\right)$. The following parameters may be prescribed on the REAC line.

$\mathrm{NU} \_\mathrm{O} 2, \mathrm{NU} \_\mathrm{H} 2 \mathrm{O}, \mathrm{NU} \_\mathrm{CO} 2$ are the ideal stoichiometric coefficients for the reaction of a hydrocarbon fuel. MW_FUEL is the molecular weight of the fuel $(\mathrm{g} / \mathrm{mol})$. SOOT 
YIELD is the fraction of fuel mass converted into smoke particulate from the fire. Below is an example of a hydrocarbon fuel modified to simulate the smoke produced from experiments.

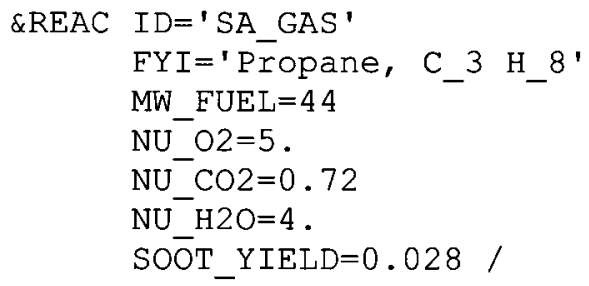




\section{Appendix D}

\section{FDS INPUT DATA FILES}

\section{Computer Store, CMP-I Input File}

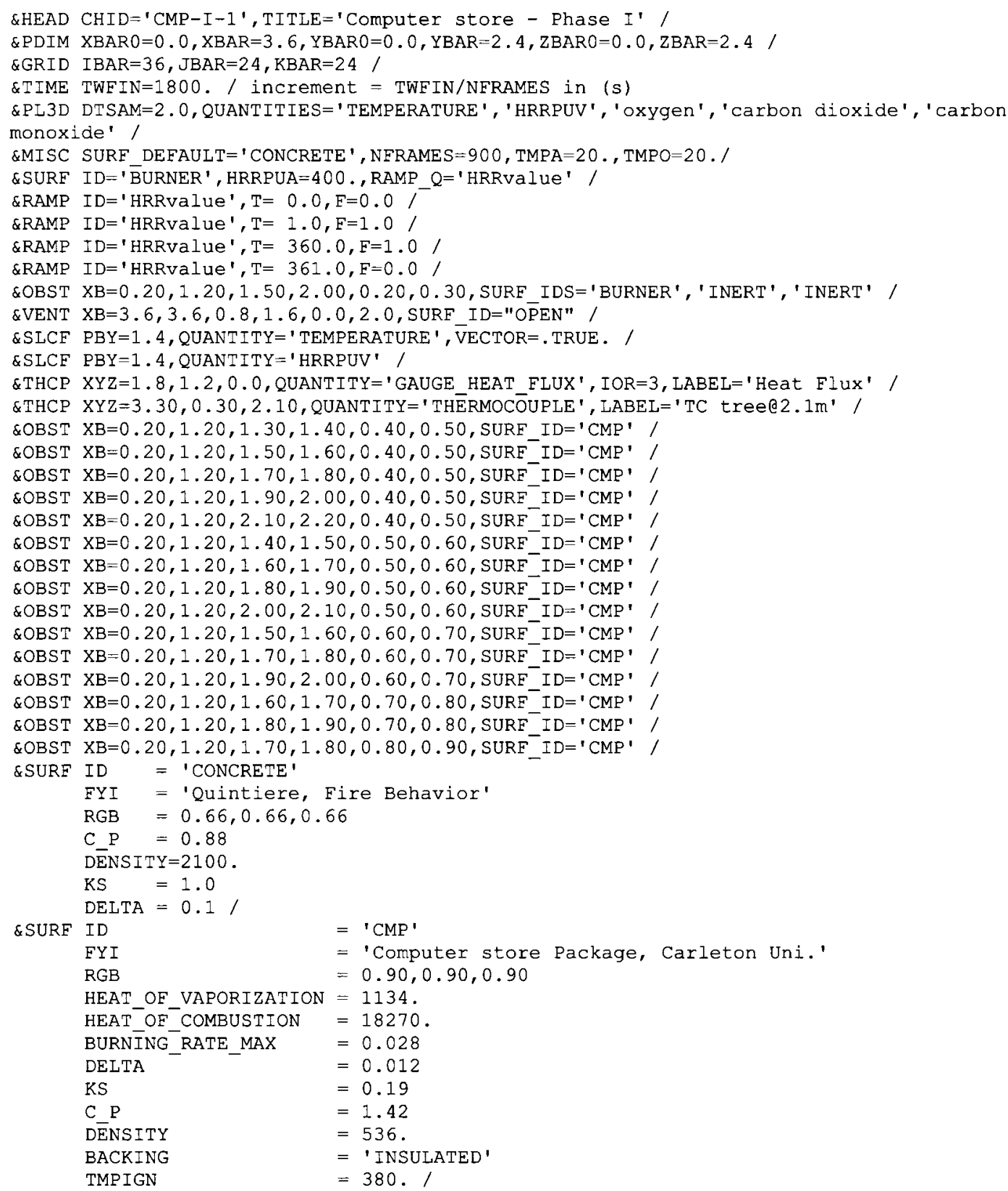




\section{Computer Store, CMP-II Input File}

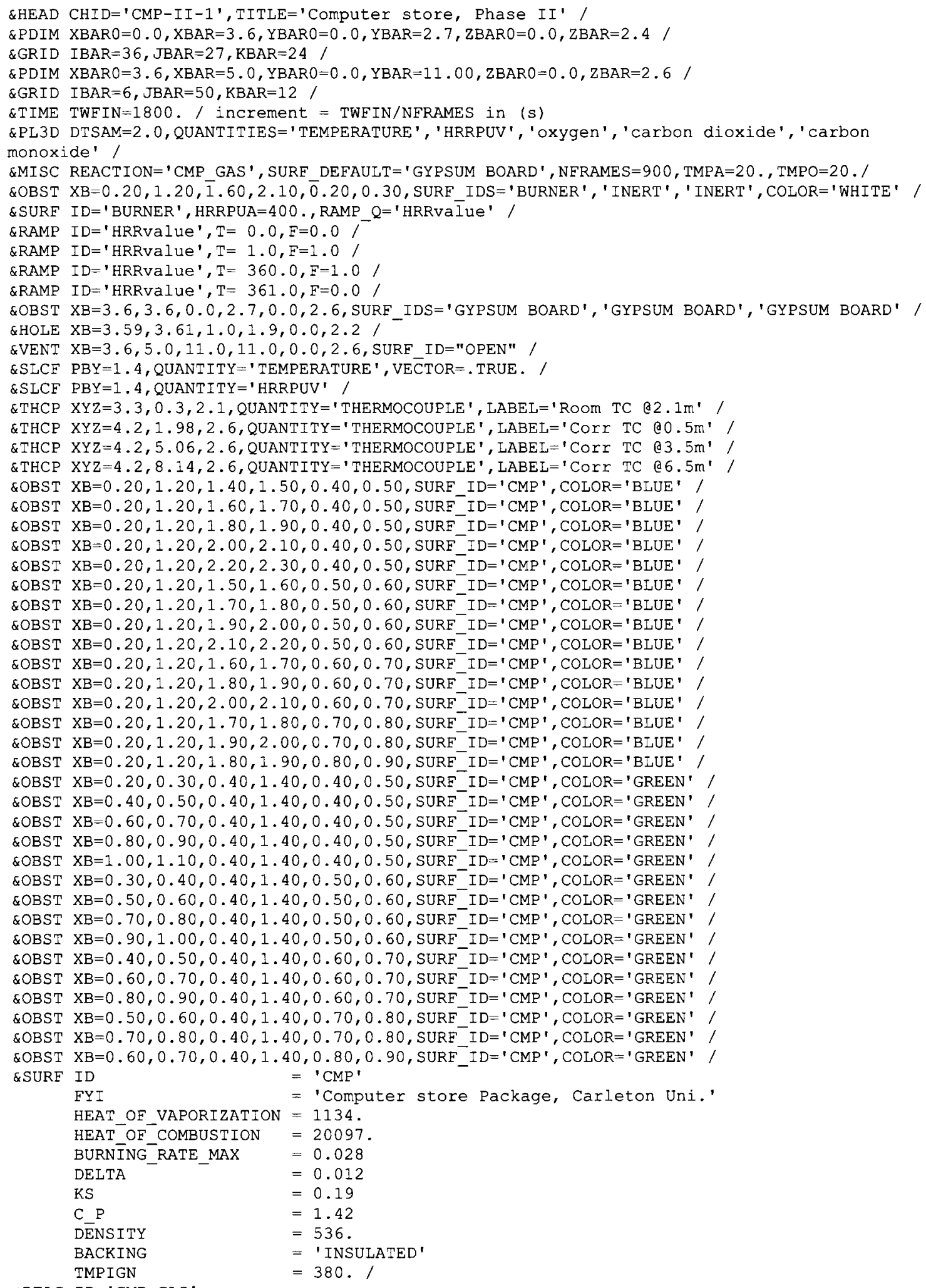

\&REAC ID='CMP_GAS' 


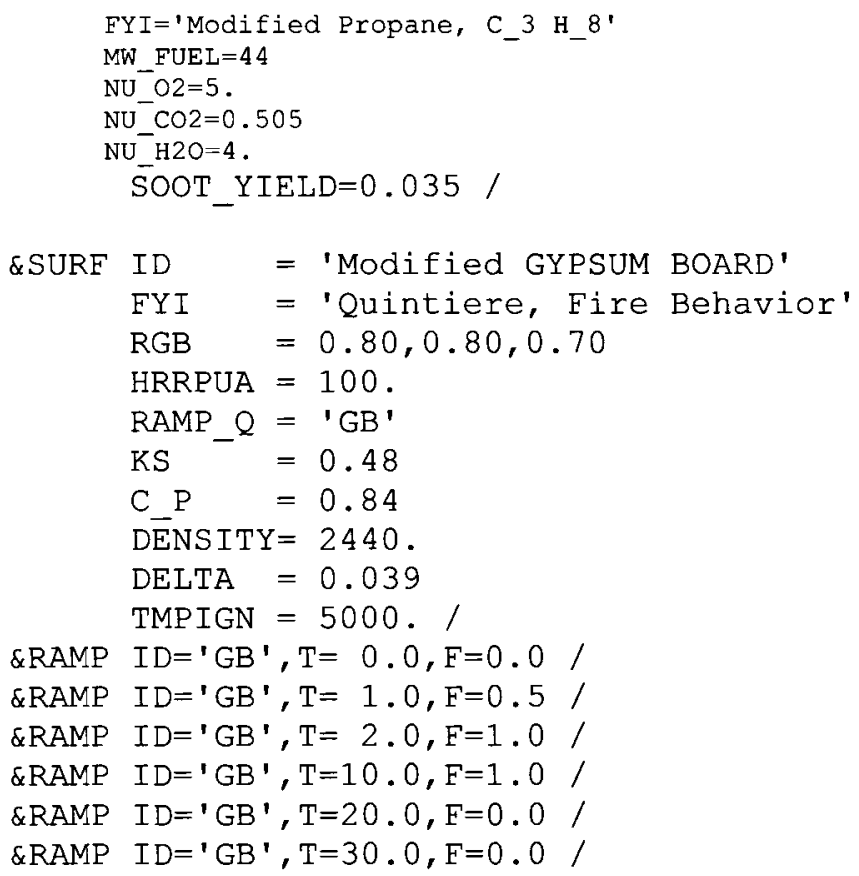


Storage Area, SA-I Input File

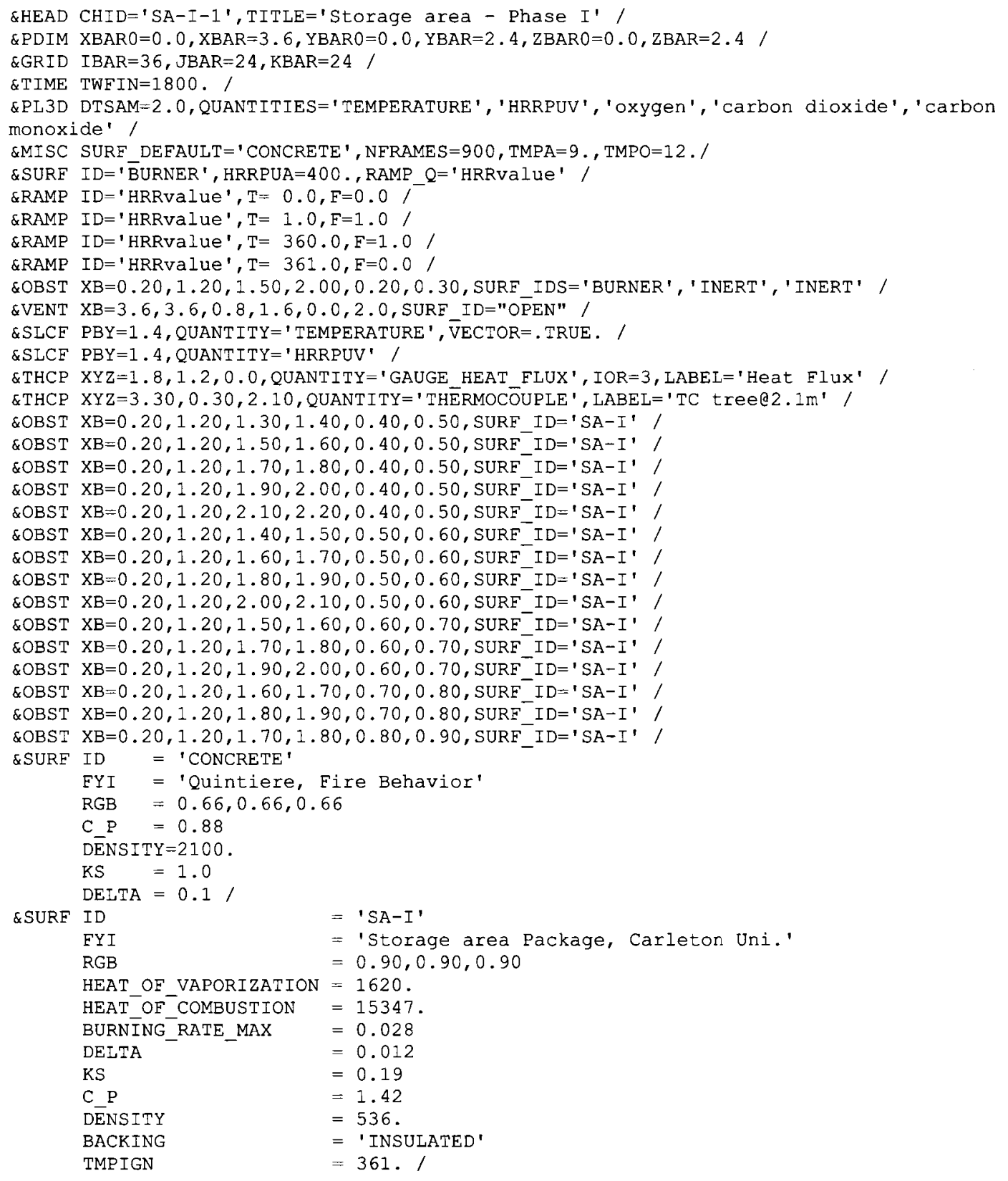


Storage Area, SA-II Input File

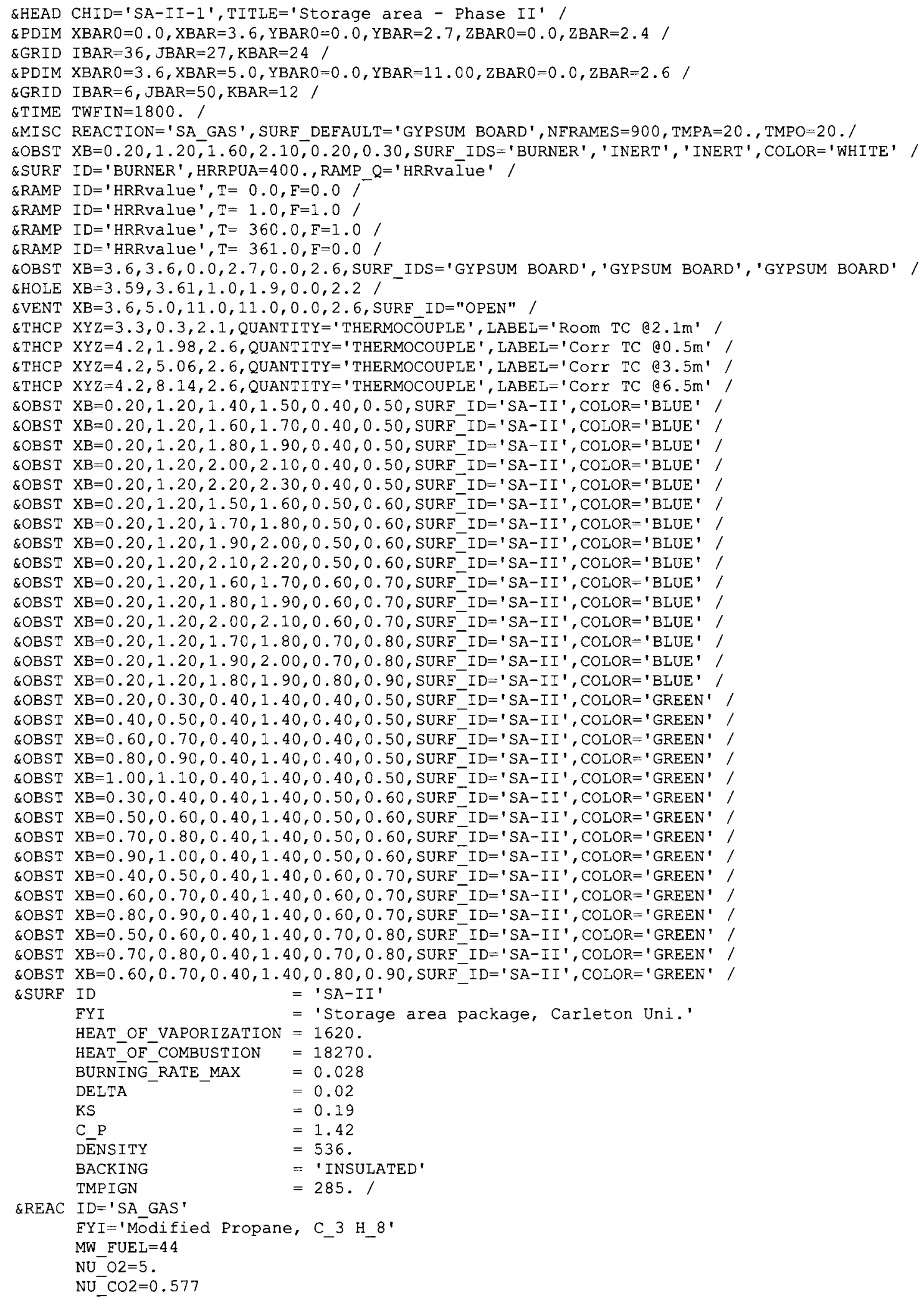


$\mathrm{NU} \mathrm{H} 2 \mathrm{O}=4$.

SOOT_YIELD $=0.022$ /

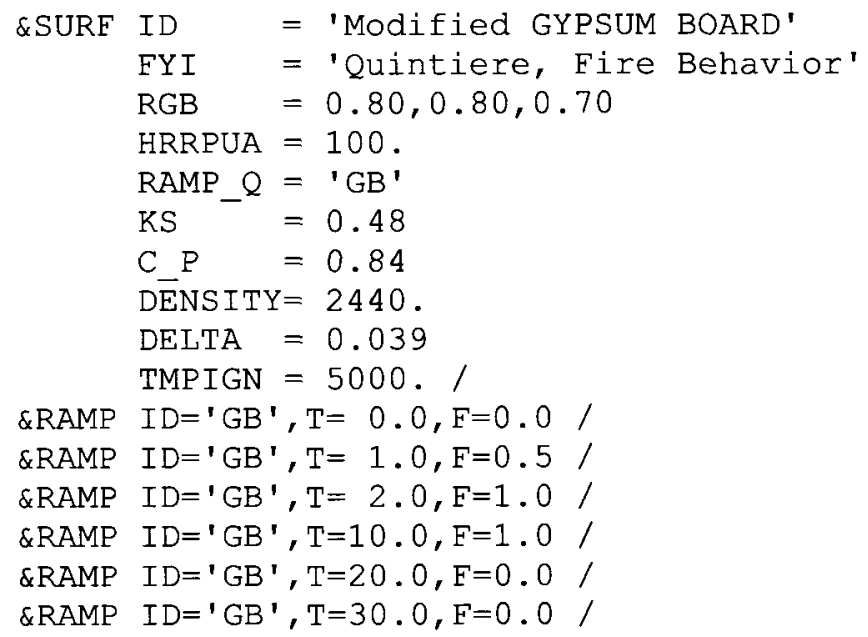




\section{Clothing Store, CLC-I Input File}

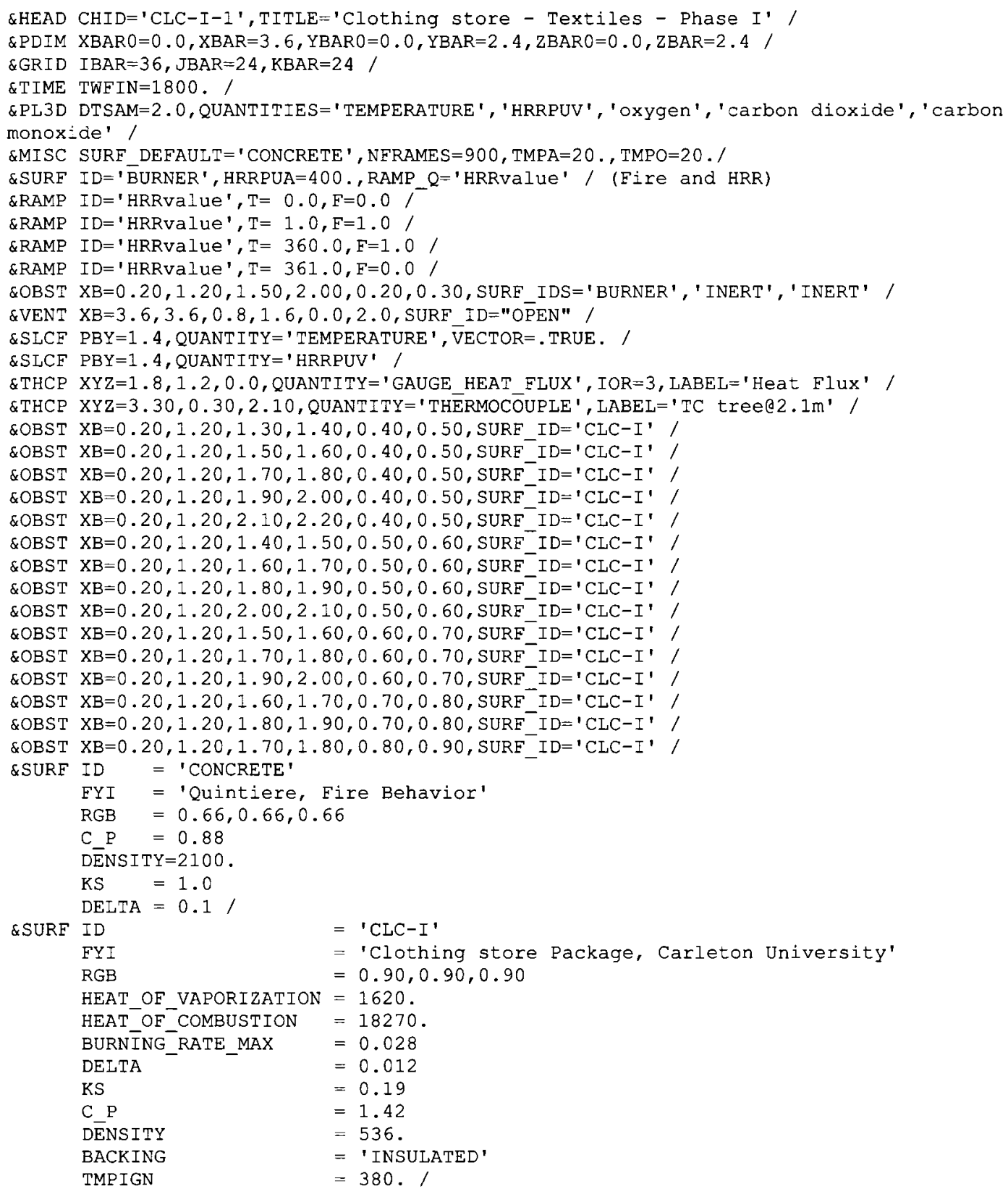




\section{Clothing Stores, CLC-II Input File}

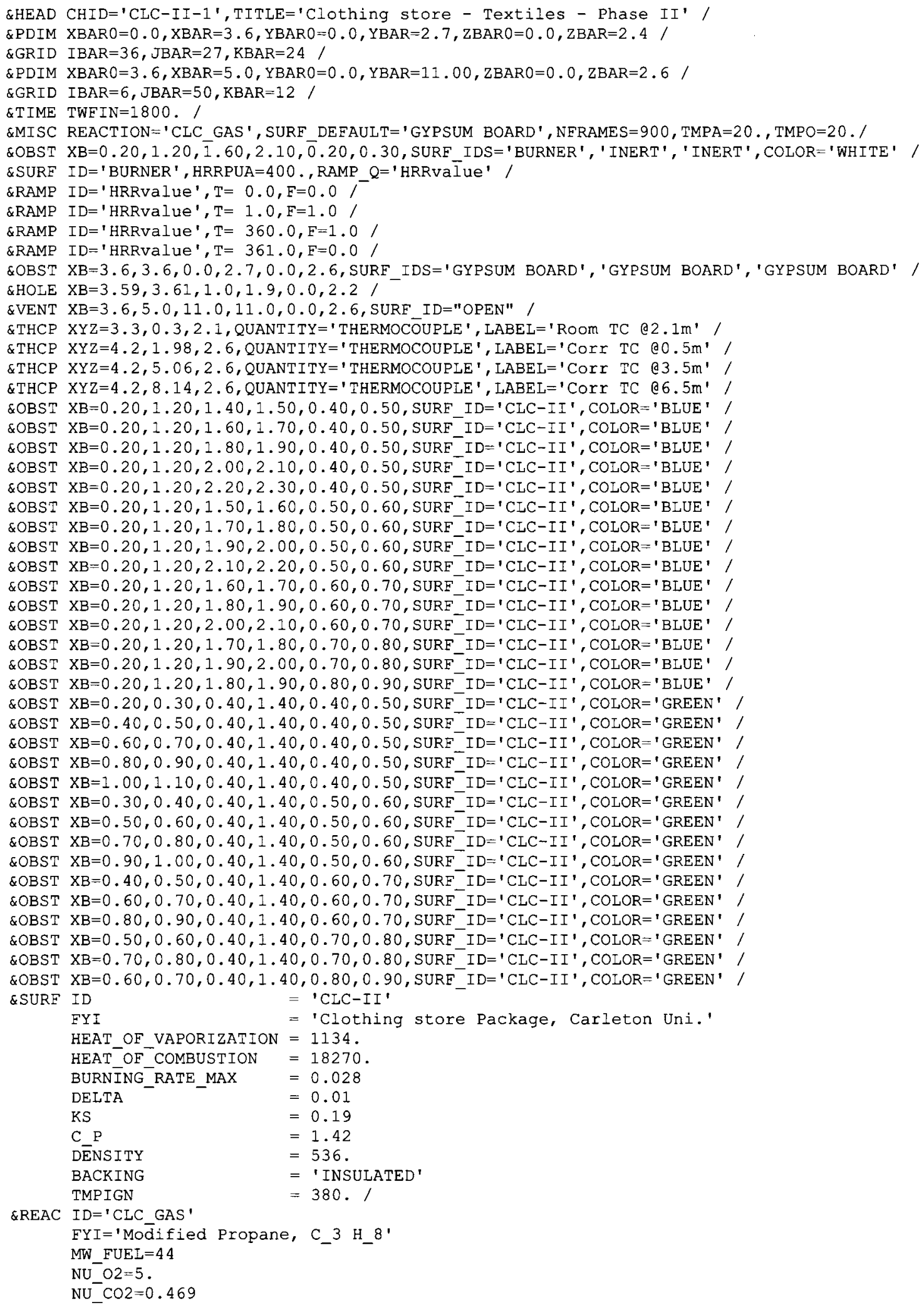


$\mathrm{NU} \mathrm{H} 2 \mathrm{O}=4$.

SOOT_YIELD $=0.011 /$

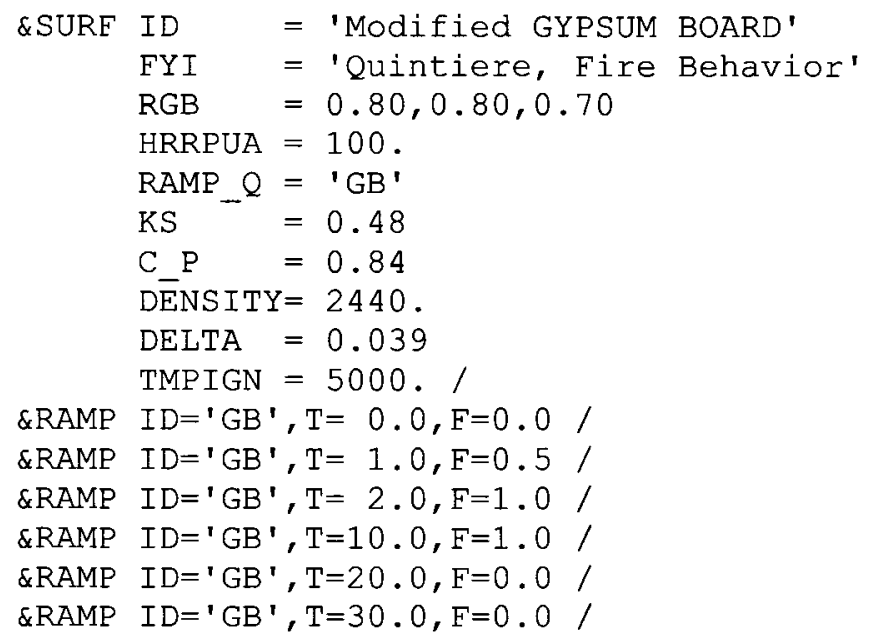




\section{Toy Store, TOY-I Input File}

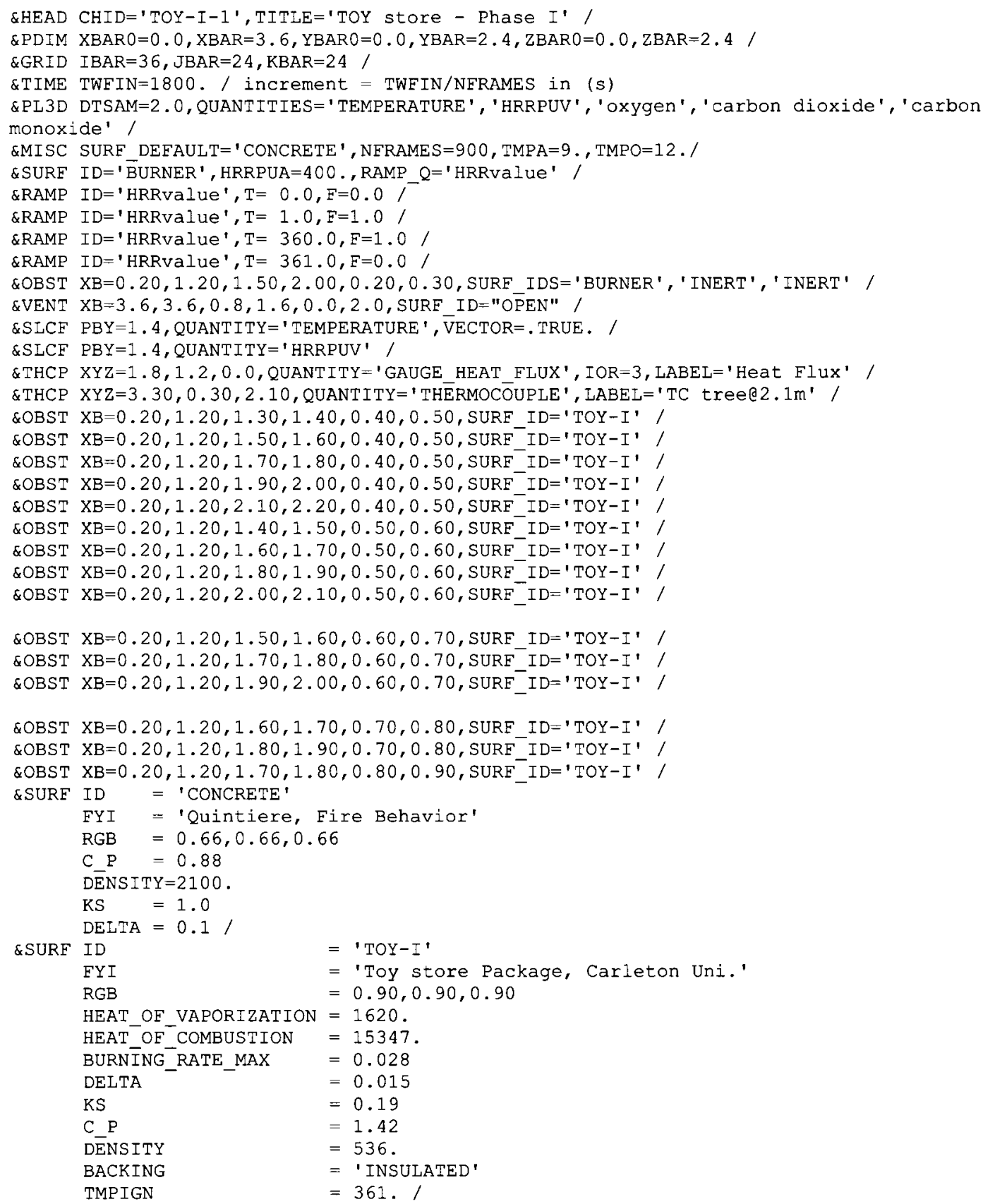




\section{Toy Store, TOY-II Input File}

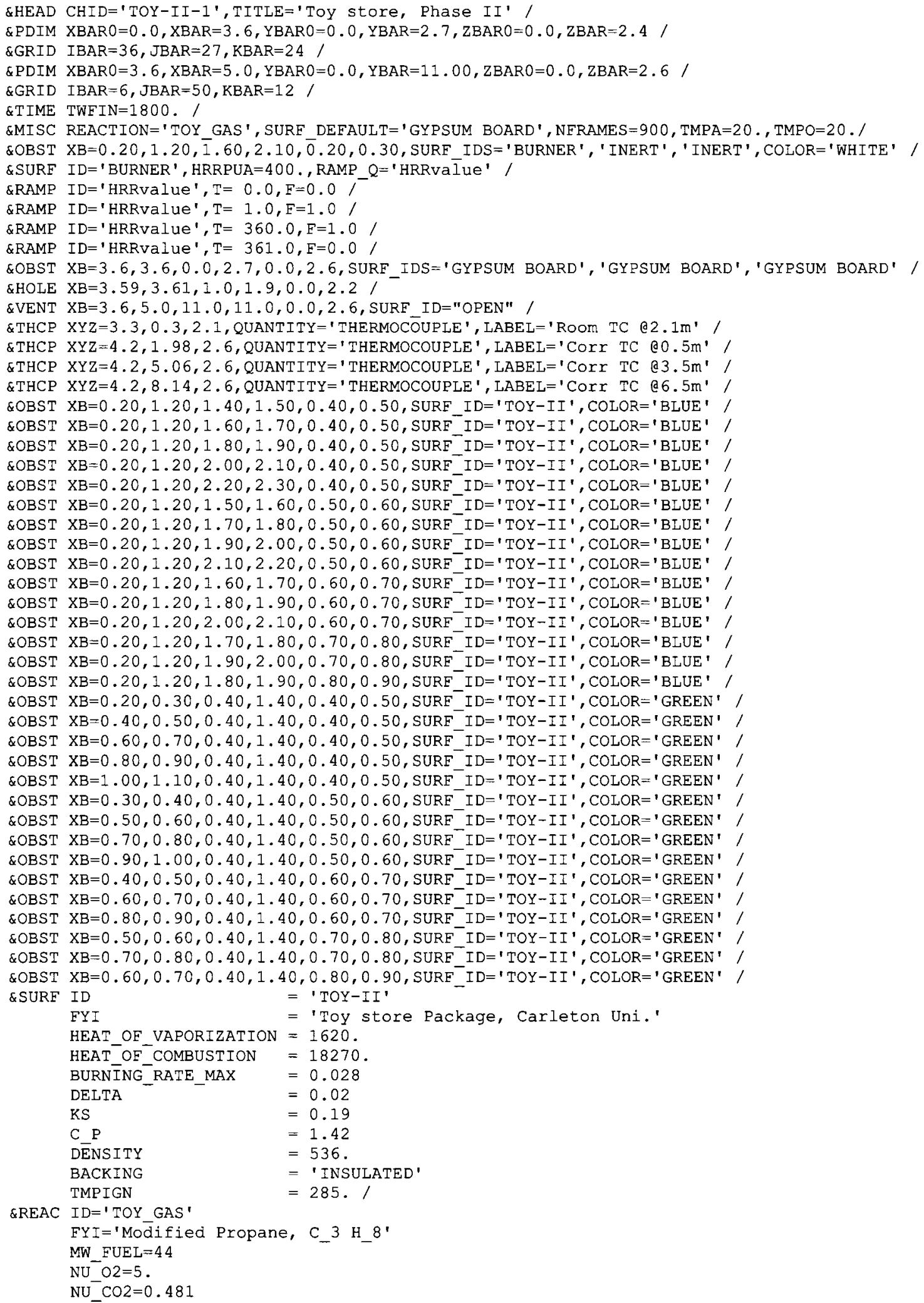


$\mathrm{NU} \mathrm{H} 2 \mathrm{O}=4$.

SOOT_YIELD $=0.0161 /$

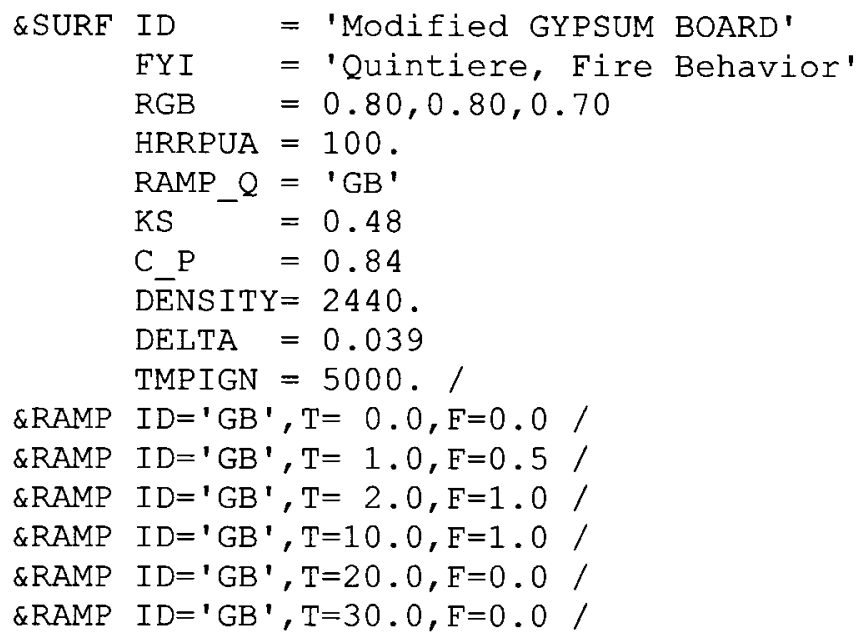




\section{Shoe Store and Storage Area, SHO-II Input File}

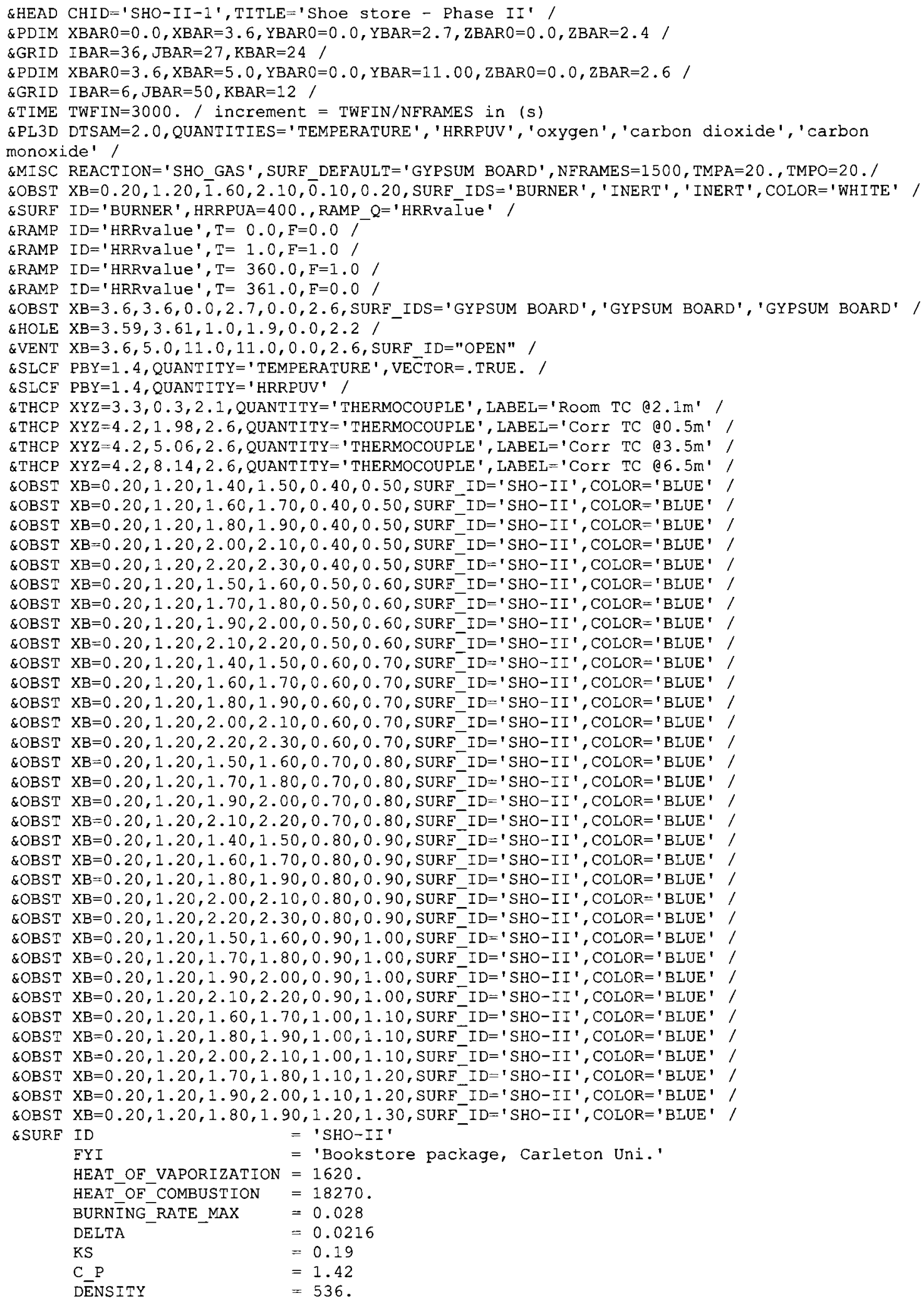




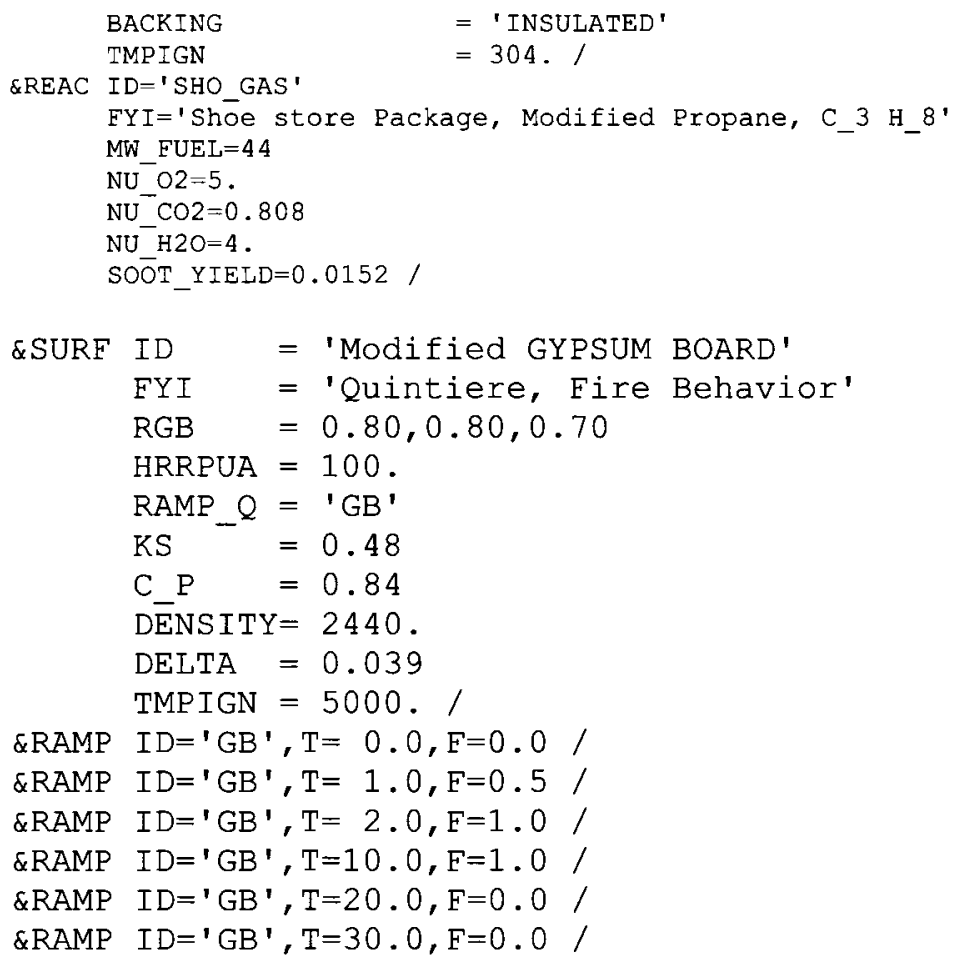




\section{Bookstore and Storage Area of Bookstore, BK-I Input File}

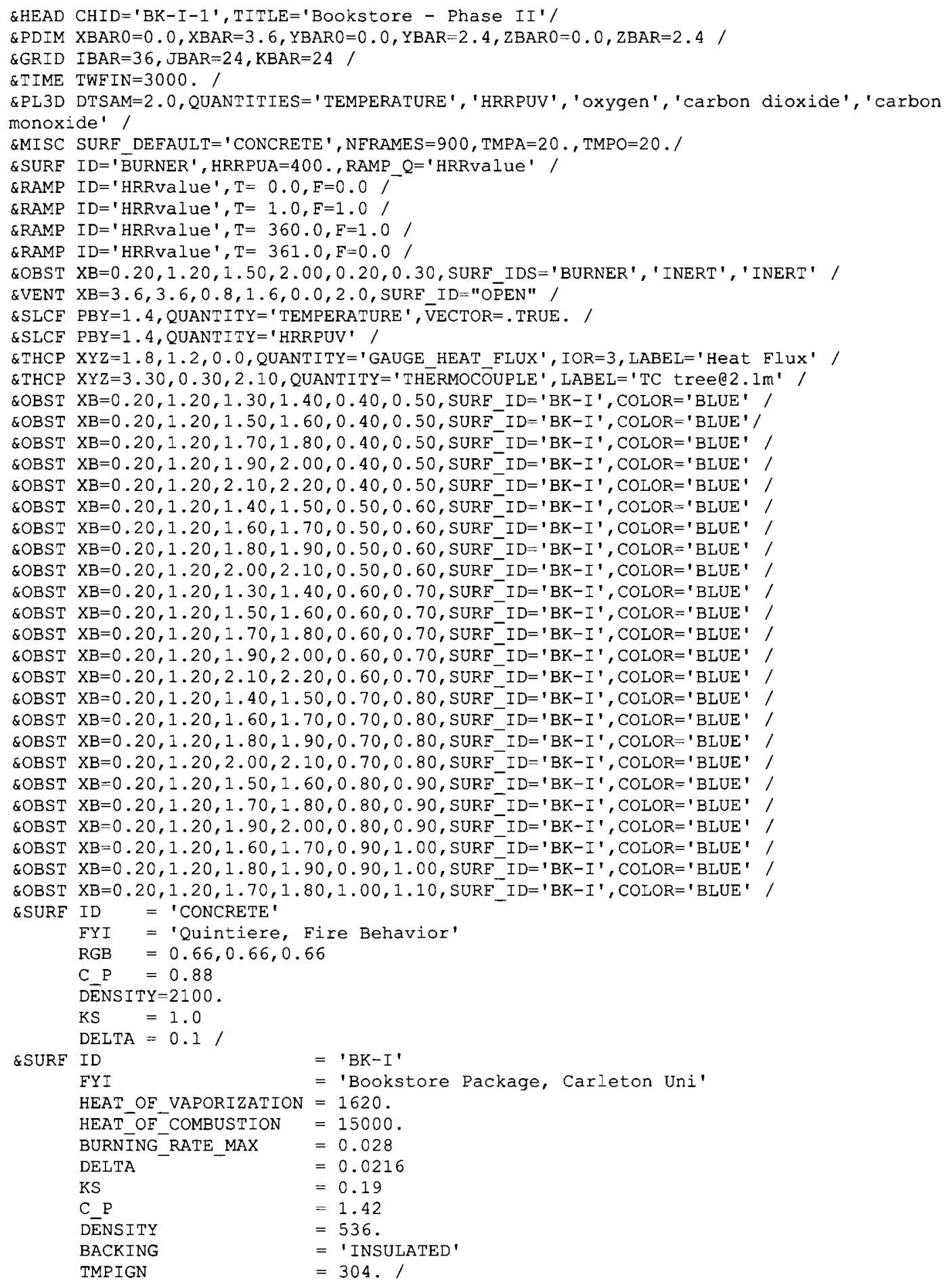




\section{Bookstore and Storage Area of Bookstores, BK-II Input File}

\&HEAD CHID='BK-II-1', TITLE='Bookstore - Phase II' /

$\& \mathrm{PDIM} \mathrm{XBARO}=0.0, \mathrm{XBAR}=3.6, \mathrm{YBARO}=0.0, \mathrm{YBAR}=2.7, \mathrm{ZBAR0}=0.0, \mathrm{ZBAR}=2.4 /$

\&GRID IBAR $=36, \mathrm{JBAR}=27, \mathrm{KBAR}=24$,

$\& \mathrm{PDIM} X \mathrm{XBARO}=3.6, \mathrm{XBAR}=5.0, \mathrm{YBARO}=0.0, \mathrm{YBAR}=11.00, \mathrm{ZBAR} 0=0.0, \mathrm{ZBAR}=2.6 /$

\&GRID IBAR $=6, \mathrm{JBAR}=50, \mathrm{KBAR}=12$ /

\&TIME TWFIN $=1800$. $/$

\&MISC REACTION='BK GAS', SURF DEFAULT='GYPSUM BOARD', NERAMES=900, TMPA=20. TMPO=20.7

\&OBST XB=0.20,1.20,1.60,2,10,0.20,0.30, SURF IDS='BURNER', 'INERT', 'INERT', COLOR='WHITE' /

\&SURF ID='BURNER', HRRPUA $=400$, RAMP $Q=$ 'HRRvalue' /

\&RAMP ID='HRRValue', $T=0.0, F=0.0 /$

\&RAMP ID='HRRvalue', $\mathrm{T}=1.0, \mathrm{~F}=1.0 \%$

\&RAMP ID='HRRvalue', $T=360.0, F=1.0 /$

\&RAMP ID $=$ 'HRRvalue' $, T=361.0, F=0.0 /$

\&OBST XB=3.6,3.6,0.0,2.7,0.0,2.6, SURF IDS='GYPSUM BOARD', 'GYPSUM BOARD', 'GYPSUM BOARD' /

\&HOLE XB=3.59,3.61,1.0,1.9,0.0,2.2/

\&VENT XB=3.6,5.0,11.0,11.0,0.0,2.6, SURF ID="OPEN"

\&THCP XYZ=3.3, 0.3,2.1, QUANTITY=' THERMOCOUPLE', LABEL='ROOM TC @ 2.1m' /

\&THCP XYZ=4.2,1.98,2.6, QUANTITY='THERMOCOUPLE', LABEL=' COr TC @0.5m'/

$\& \mathrm{THCP} X Y Z=4.2,5.06,2.6$, QUANTITY='THERMOCOUPLE', LABEL=' COrI TC @ 3.5m'/

\&THCP $X Y Z=4.2,8.14,2.6$, QUANTITY= 'THERMOCOUPLE' , LABEL= 'COrY TC $06.5 \mathrm{~m}$ '

\&OBST XB=0.20,1.20,1.40,1.50,0.40,0.50, SURF ID='BK-II', COLOR='BLUE' /

$\&$ OBST XB=0.20,1.20,1.60,1.70,0.40,0.50, SURF ID='BK-II', COLOR='BLUE'/

$\&$ OBST XB=0.20,1.20,1.80,1.90,0.40,0.50, SURE_ID='BK-II', COLOR='BLUE'/

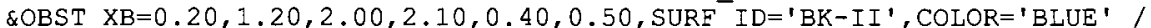

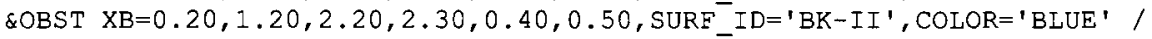

\&OBST $X B=0.20,1.20,1.50,1.60,0.50,0.60, S U R F^{-I D}=$ 'BK-II', COLOR='BLUE',

\&OBST XB=0.20,1.20,1.70,1.80,0.50,0.60, SURF ID='BK-II', COLOR='BLUE'/

$\&$ OBST XB=0.20,1.20,1.90,2.00,0.50,0.60, SURF_ID='BK-II', COLOR='BLUE'/

\&OBST $X B=0.20,1.20,2.10,2.20,0.50,0.60, S U R F{ }^{-} I D=' B K-I I ', C O L O R=' B L U E ' /$

¿OBST XB=0.20,1.20,1.40,1.50,0.60,0.70, SURF_ID='BK-II', COLOR='BLUE'

\&OBST $\mathrm{XB}=0.20,1.20,1.60,1.70,0.60,0.70$, SURF ID='BK-II', COLOR='BLUE',

\&OBST XB=0.20,1.20,1.80,1.90,0.60,0.70, SURF_ID='BK-II', COLOR='BLUE' /

\&OBST $X B=0.20,1.20,2.00,2.10,0.60,0.70$, SURF_ID='BK-II', COLOR='BLUE',

\&OBST XB=0.20,1.20,2.20,2.30,0.60,0.70, SURF ID= 'BK-II', COLOR='BLUE' /

$\S$ OBST XB=0.20,1.20,1.50,1.60,0.70,0.80, SURF_ID='BK-II', COLOR='BLUE' /

\&OBST $\mathrm{XB}=0.20,1.20,1.70,1.80,0.70,0.80, \mathrm{SURF}$ ID='BK-II', COLOR='BLUE',

\&OBST XB=0.20,1.20,1.90,2.00,0.70,0.80, SURF_ID='BK-II', COLOR='BLUE'/ \&OBST $X B=0.20,1.20,2.10,2.20,0.70,0.80, \mathrm{SURF}^{\mathrm{I}} \mathrm{ID}=$ 'BK-II', COLOR='BLUE', \&OBST XB=0.20,1.20,1.60,1.70,0.80,0.90, SURF ID='BK-II', COLOR='BLUE' / \&OBST XB=0.20,1.20,1.80,1.90,0.80,0.90, SURF_ID='BK-II', COLOR='BLUE' / \&OBST XB=0.20,1.20,2.00,2.10,0.80,0.90, SURF'ID='BK-II', COLOR='BLUE'। \&OBST XB=0.20,1.20,1.70,1.80,0.90,1.00,SURF_ID='BK-II', COLOR='BLUE' / \&OBST $X B=0.20,1.20,1.90,2.00,0.90,1.00$, SURF'ID='BK-II', COLOR='BLUE', \&OBST XB=0.20,1.20,1.80,1.90,1.00,1.10, SURF'ID='BK-II', COLOR='BIUE' / \&OBST $X B=0.20,0.30,0.40,1.40,0.40,0.50$, SURF_ID='BK-II', COLOR='GREEN' / \&OBST $X B=0.40,0.50,0.40,1.40,0.40,0.50$, SURF' ID='BK-II', COLOR='GREEN', \&OBST $X B=0.60,0.70,0.40,1.40,0.40,0.50, \mathrm{SURF}^{\prime} \mathrm{ID}={ }^{\prime} \mathrm{BK}-\mathrm{II}$ ' , COLOR='GREEN' / ¿OBST $X B=0.80,0.90,0.40,1.40,0.40,0.50$, SURE $^{-} I D=' B K-I I '$ ' COLOR='GREEN', $\varangle$ OBST $X B=1.00,1.10,0.40,1.40,0.40,0.50, \mathrm{SURF}$ ID $=$ 'BK-II', COLOR='GREEN' / \&OBST XB=0.30,0.40,0.40,1.40,0.50,0.60,SURF_ID='BK-II', COLOR='GREEN' / \&OBST $X B=0.50,0.60,0.40,1.40,0.50,0.60$, SURF ID='BK-II' , COLOR= 'GREEN' / \&OBST XB=0.70,0.80,0.40,1.40,0.50,0.60, SURE_ID='BK-II', COLOR= 'GREEN' / ¿OBST XB=0.90,1.00,0.40,1.40,0.50,0.60, SURF ID='BK-II', COLOR='GREEN' / \&OBST $X B=0.20,0.30,0.40,1.40,0.60,0.70, \mathrm{SURE}^{-} \mathrm{ID}=$ 'BK-II' , COLOR= 'GREEN' / \&OBST $X B=0.40,0.50,0.40,1.40,0.60,0.70, \mathrm{SURF}{ }^{-} I D={ }^{\prime} \mathrm{BK}-I I^{\prime}$, COLOR $=$ 'GREEN' / \&OBST XB=0.60,0.70,0.40,1.40,0.60,0.70, SURF ID='BK-II' , COLOR= 'GREEN' / \&OBST $X B=0.80,0.90,0.40,1.40,0.60,0.70$, SURF_ID='BK-II', COLOR='GREEN' / \&OBST $X B=1.00,1.10,0.40,1.40,0.60,0.70$, SURF ID='BK-II' , COLOR= 'GREEN' / \&OBST $X B=0.30,0.40,0.40,1.40,0.70,0.80$, SURF ID='BK-II' , COLOR='GREEN' / \&OBST $X B=0.50,0.60,0.40,1.40,0.70,0.80, S U R E$ ID $=$ 'BK-II', COLOR='GREEN' / \&OBST $X B=0.70,0.80,0.40,1.40,0.70,0.80$, SURF $^{-} \mathrm{ID}=$ ' $\mathrm{BK}-\mathrm{II}$ ' , COLOR= 'GREEN' / \&OBST $X B=0.90,1.00,0.40,1.40,0.70,0.80, S U R F=I D=' B K-I I '$, COLOR='GREEN' / \&OBST XB=0.40,0.50,0.40,1.40,0.80,0.90, SURF ID='BK-II', COLOR='GREEN', \&OBST XB=0.60,0.70,0.40,1.40,0.80,0.90, SURF_ID='BK-II', COLOR='GREEN' / \&OBST $\mathrm{XB}=0.80,0.90,0.40,1.40,0.80,0.90, \mathrm{SURF}$ ID='BK-II', COLOR='GREEN', \&OBST XB=0.50,0.60,0.40,1.40,0.90,1.00, SURF ID='BK-II', COLOR='GREEN' / 


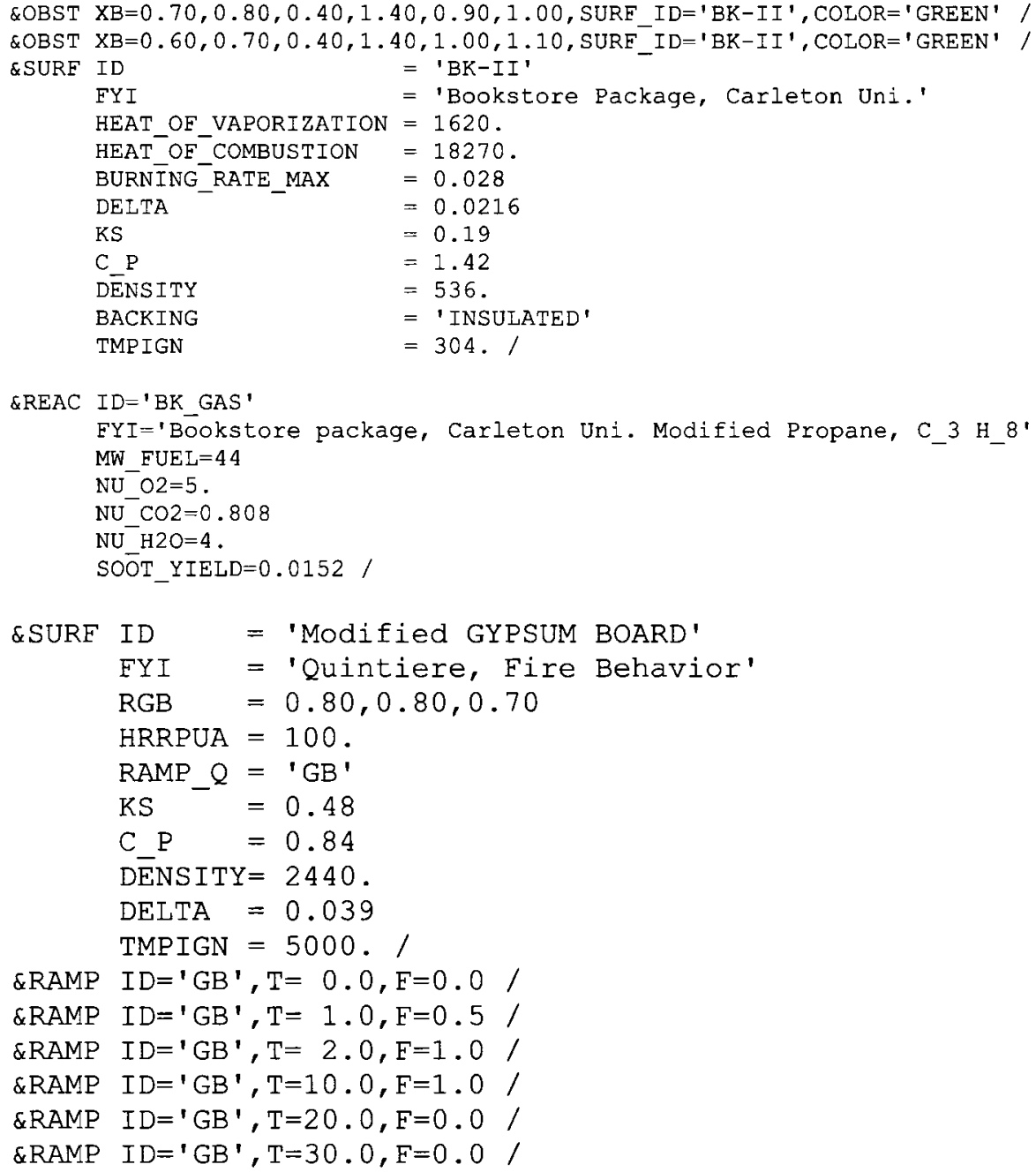




\section{Fast Food Outlet, FF-I Input File}

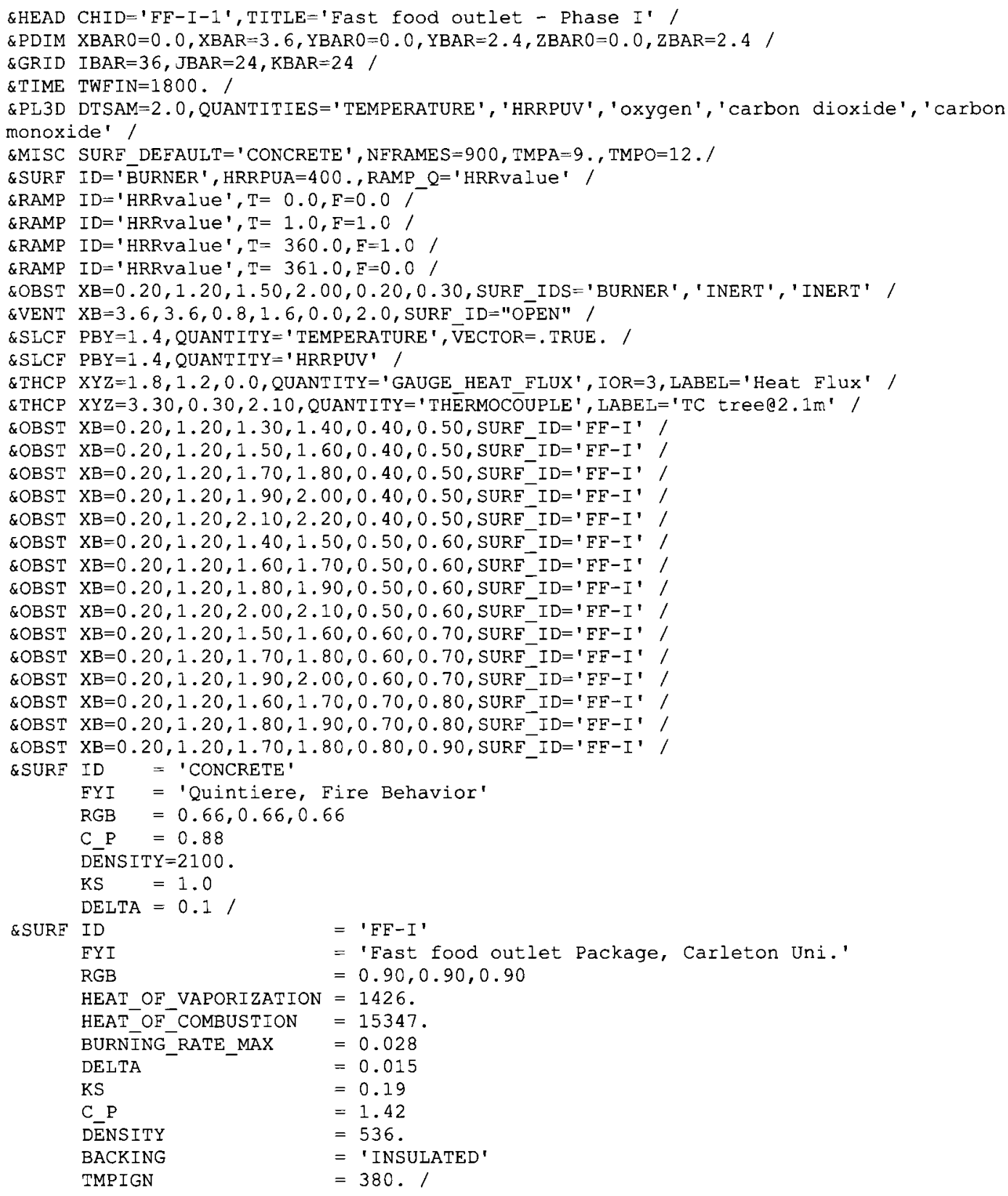




\section{Fast Food Outlet, FF-II Input File}

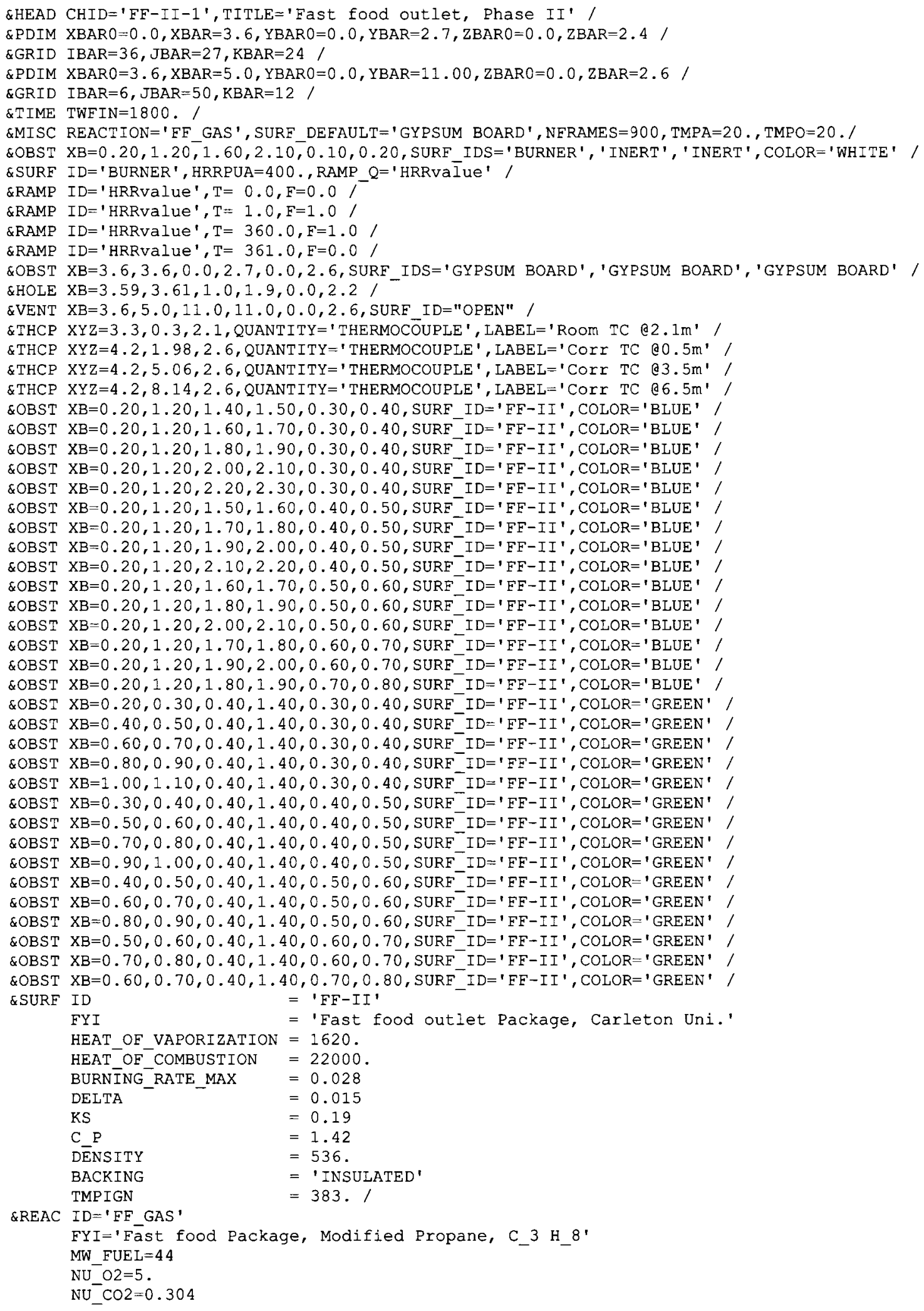


$\mathrm{NU} \mathrm{H} 2 \mathrm{O}=4$

SOOT_YIELD $=0.007 /$

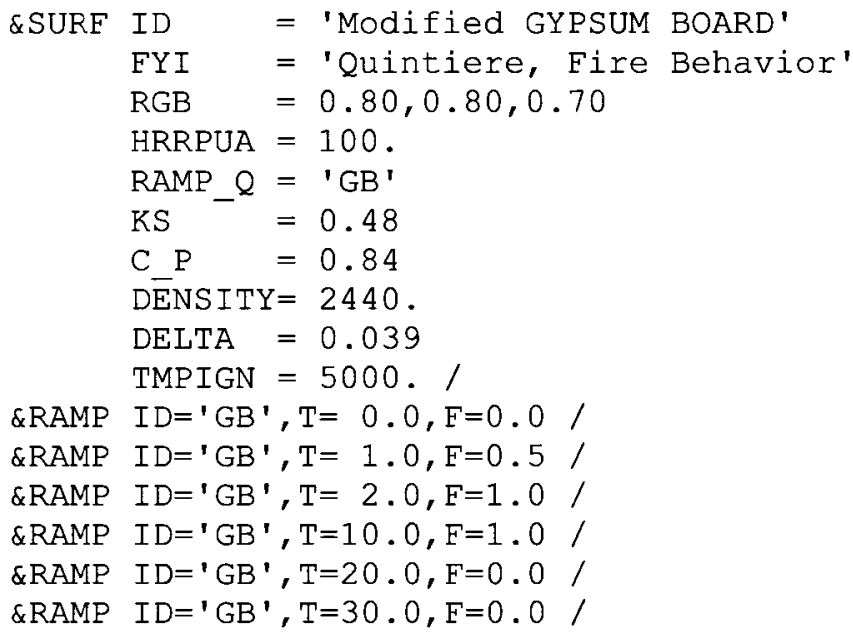

